\title{
The Balanced Counseling Strategy Plus: A Toolkit for Family Planning Service Providers Working in High HIV/STI Prevalence Settings (Spanish translation)
}

Population Council

Follow this and additional works at: https://knowledgecommons.popcouncil.org/departments_sbsr-rh

Part of the International Public Health Commons, Obstetrics and Gynecology Commons, Public Health and Community Nursing Commons, and the Women's Health Commons How does access to this work benefit you? Let us know!

\section{Recommended Citation}

Population Council. 2015. "The Balanced Counseling Strategy Plus: A Toolkit for Family Planning Service Providers Working in High HIV/STI Prevalence Settings (Spanish translation)." Washington, DC: Population Council. 
Estrategia de Consejería Balanceada Plus Un paquete de herramientas para proveedores de servicios de planificación familiar que trabajan en entornos con alta prevalencia de ITS/VIH

\section{GUÍA DEL USUARIO}

Tercera edición, 2015 
(C) 2008, 2011, 2015 The Population Council, Inc.

El Population Council aborda problemas críticos relacionados con la salud y el desarrollo, que van desde frenar la propagación del VIH hasta mejorar la salud reproductiva y garantizar que los jóvenes tengan una vida plena y productiva. A través de investigaciones en biomedicina, ciencias sociales y salud pública en 50 países, trabajamos con nuestros socios para entregar soluciones que se traducen en políticas y programas más efectivos, y en tecnologías que mejoren vidas alrededor del mundo. Establecido en 1952, y con sede central en Nueva York, Project Council es una organización no gubernamental sin fines de lucro regida por un consejo administrativo internacional.

Cualquier parte de esta publicación puede fotocopiarse sin autorización del editor, siempre que las copias se distribuyan de forma gratuita y se proporcione la cita completa de la fuente. El Population Council agradecería recibir copia de todo material en el cual se incluya este texto.

Cita sugerida: Population Council. 2015. Guía del usuario de la Estrategia de Consejería Balanceada Plus, tercera edición, parte de la Estrategia de Consejería Balanceada Plus: Un paquete de herramientas para proveedores de servicios de planificación familiar que trabajan en entornos con alta prevalencia de ITS / VIH, tercera edición, Washington, DC.

El proyecto Knowledge for Health II (K4Health [Conocimiento para la salud]) (AID-OAA-A-13-00068) adaptó este contenido con el permiso de Population Council y con el apoyo de los ciudadanos estadounidenses a través de la Agencia de los Estados Unidos para el Desarrollo Internacional (USAID, por sus siglas en inglés). El contenido de este material adaptado es responsabilidad exclusiva de la fuente original, y no refleja los puntos de vista de la USAID ni del Gobierno de los Estados Unidos. El material original se encuentra aquí: http://www.popcouncil.org/research/the-balanced-counseling-strategy-plus-a-toolkit-for-familyplanning-service.

Nota: Esta publicación es parte de un paquete de publicaciones titulado Estrategia de Consejería Balanceada Plus: Un paquete de herramientas para proveedores de servicios de planificación familiar que trabajan en entornos con alta prevalencia de ITS/VIH. El paquete de herramientas de la Estrategia de Consejería Balanceada Plus consta de lo siguiente:

- Algoritmo

- Tarjetas de consejería

- Folletos de métodos

- Guía del usuario

- Guía del instructor

- Rueda con los criterios médicos de elegibilidad para el uso de anticonceptivos de la OMS

Si alguna de las partes no está incluida con el material, comuníquese con el Population Council enviando un correo electrónico a publications@popcouncil.org. 


\section{Prefacio de la tercera edición}

El paquete de herramientas de la Estrategia de Consejería Balanceada Plus (ECB+) se desarrolló y probó en Kenia (del 2005 al 2007) y en Sudáfrica (del 2004 al 2006) debido a que ambos países tienen altas tasas de infecciones de transmisión sexual (ITS), incluido el virus de la inmunodeficiencia humana $(\mathrm{VIH})$, y sus tasas de prevalencia de anticonceptivos son relativamente altas para la región. En la ECB+, se proporciona la información y los materiales que los proveedores de los centros de atención de salud necesitan para brindar consejería de planificación familiar completa y de calidad a clientes que viven en áreas con altas tasas ITS y VIH. La ECB+ se adaptó de la Estrategia de Consejería Balanceada (León 1999; León et al. 2003a, b, c; León, Vernon, Martin, and Bruce 2008). La primera edición de los paquetes de herramientas de la Estrategia de Consejería Balanceada y de la Estrategia de Consejería Balanceada Plus son producto del programa FRONTERAS del Population Council, con apoyo de la Agencia de los Estados Unidos para el Desarrollo Internacional (USAID), acuerdo cooperativo HRN-A-00-98-00012-00.

La segunda edición se actualizó según los Criterios médicos de elegibilidad (CME) de 2010 de la OMS y según recomendaciones de autores y socios, quienes experimentaron, evaluaron y legitimaron la implementación de la herramienta en entornos y escenarios alrededor del mundo mediante el programa Integra Initiative, el cual contó con el apoyo de la Fundación Bill y Melinda Gates. Esta edición incluyó tarjetas de consejería adicionales sobre detección de cáncer de cuello uterino, y salud infantil y de posparto.

En la tercera edición de la ECB+, se incluye contenido actualizado de acuerdo con los últimos Criterios médicos de elegibilidad de la OMS (2015). Incorpora la evidencia más actualizada sobre indicaciones clínicas para proporcionar métodos de planificación familiar, e incluye nuevos métodos (diafragma y anillo vaginal de progesterona Caya ${ }^{\circledR} /$ SILCS) y seis nuevas tarjetas de consejería sobre consejería para adolescentes, servicios para hombres, atención posaborto, apoyo y seguridad para mujeres, información y concienciación sobre el cáncer de mama, y prevención y tratamiento del virus del Zika. Las tarjetas actualizadas incluyen instrucciones para guiar a los proveedores en la consejería adicional y los servicios que puedan necesitar los clientes de la planificación familiar. El desarrollo de esta tercera edición del paquete de herramientas de la ECB+ recibió la financiación de Evidence Project, mientras que el acuerdo cooperativo AID-OAA-A-13-00087 de USAID y la Fundación Bill y Melinda Gates apoyaron el programa Integra Initiative en el Population Council. 


\section{包 Agradecimientos}

El desarrollo de la Estrategia de Consejería Balanceada Plus (ECB+) no hubiese sido posible sin el invalorable apoyo de los proveedores de servicio que pusieron a prueba el paquete de herramientas y de los directores de programas que autorizaron y supervisaron la aplicación de este paquete. Los autores desean agradecer al Departamento de Salud de Sudáfrica, a la División de Salud Reproductiva y al Programa Nacional de Control del SIDA y las ETS del Ministerio de Salud de Kenia. También agradecemos a los instructores de la Unidad de Salud Reproductiva e Investigación sobre el VIH (RHRU, Reproductive Health and HIV Research Unit) de la Universidad de Witwatersrand por su contribución al estudio en Sudáfrica.

Population Council apoyó el desarrollo y la producción de la tercera edición de la Estrategia de Consejería Balanceada Plus. Los autores agradecen a las siguientes personas por proporcionar su experiencia y sus contribuciones invalorables a esta edición actualizada de la ECB+: Megan Christofield, Heather Clark, Mychelle Farmer, Kamlesh Giri, Joanne Gleason, Mark Hathaway, Anushka Kalyanpur, Maggie Kilbourne-Brook, Karen R. Kirk, Ricky Lu, Ruth Merkatz, Charity Ndigwa, Anne Pfitzer, Saumya RamaRao, Naomi Rijo, Elizabeth Rochette, Jill Schwartz, Leigh Stefanik, John Townsend, Chi-Chi Undie, Katie Unthank, Anneka Van Scoyoc, Charlotte Warren, Ellen Weiss, y Kelsey Wright. 


\section{Índice}

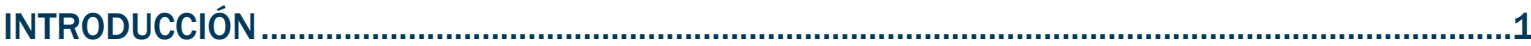

Algoritmo para el uso de la Estrategia de Consejería

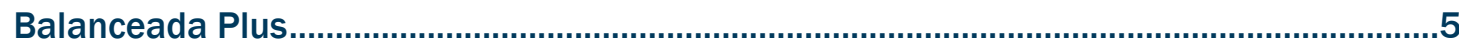

GUÍA PARA ACONSEJAR A LOS CLIENTES CON EL

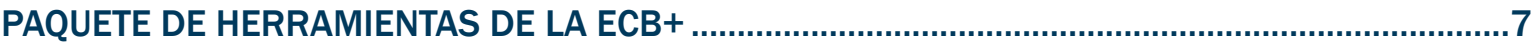

Etapa previa a la elección ..........................................................................................................

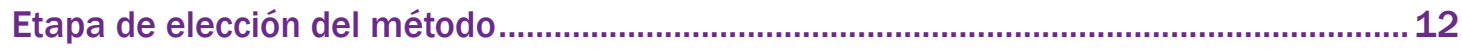

Etapa posterior a la elección ................................................................................................ 15

Etapa de detección sistemática para otros servicios ................................................................ 17

DIRECTRICES PARA ADAPTAR LAS AYUDAS DE

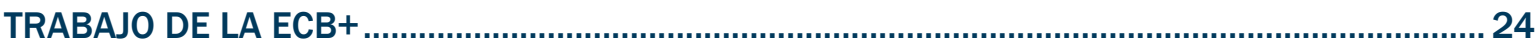

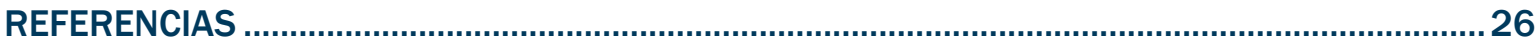




\section{Introducción}

A fines de la década de 1990, el Population Council trabajó en colaboración con los ministerios de salud de distintos países latinoamericanos para desarrollar y probar una estrategia práctica, interactiva y amigable con los clientes, con la cual mejorar la consejería en las consultas sobre planificación familiar en el marco del programa Fronteras de la salud reproductiva (FRONTERAS) patrocinado por la Agencia de los Estados Unidos para el Desarrollo Internacional (USAID). Esta estrategia se llama Estrategia de Consejería Balanceada (ECB) (León 1999; León et al. 2004). En la ECB, se usan ayudas de trabajo clave para aconsejar a los clientes sobre planificación familiar: un algoritmo que sirve como guía para el proveedor a través del proceso de consejería, un conjunto de tarjetas de consejería para métodos anticonceptivos y los folletos correspondientes a cada método. La estrategia, probada y perfeccionada en diversos países, consta de una serie de pasos para determinar el método anticonceptivo que mejor se adapte al/a la cliente, según sus preferencias y necesidades. Esta estrategia mejora la calidad de la consejería del proveedor y permite que el/la cliente tome su propia decisión.

La ECB probó ser efectiva como una herramienta para asistir a los proveedores de planificación familiar a mejorar la calidad de atención (León et al. 2003a, b, c). Este enfoque es práctico, económico y de fácil adaptación a los contextos de cada localidad. Estrategia de Consejería Balanceada: Un paquete de herramientas para proveedores de servicios de planificación familiar se publicó con el fin de proporcionar la información y las herramientas necesarias para que los administradores, los supervisores y los proveedores de servicios de centros de salud implementen la ECB en sus servicios de planificación familiar (León, Vernon, Martin, and Bruce 2008).

\section{¿POR QUÉ ESTRATEGIA DE CONSEJERÍA BALANCEADA PLUS?}

En respuesta a la necesidad de incorporar consejería, exámenes de detección y servicios para las infecciones de transmisión sexual (ITS), incluido el VIH, a las consultas sobre planificación familiar de rutina en entornos caracterizados por una alta prevalencia de estas infecciones, la ECB se revisó para incorporar consejería sobre la prevención de ITS/VIH, evaluación de riesgos, y consejería y pruebas de VIH (HCT, HIV counseling and testing). El resultado fue el paquete de herramientas de la Estrategia de Consejería Balanceada Plus (ECB+), el cual mejora la calidad del servicio de planificación familiar y les permite a los proveedores satisfacer las necesidades de sus clientes relacionadas con las ITS y el VIH en la misma consulta.

La integración de los servicios de salud se define como ofrecer una gama de servicios que puedan satisfacer varias necesidades simultáneamente, por lo general en el mismo centro y a través de un mismo proveedor. Las remisiones o las conexiones a servicios relacionados permiten que el/la cliente reciba una gama de servicios necesarios, incluso si no se reciben simultáneamente (Askew, 2007). En la salud reproductiva, el esfuerzo por la integración o conexión está dado por los clientes que necesitan distintos servicios simultáneamente (por lo que puede reducirse la cantidad de oportunidades perdidas) y por la expectativa de que los servicios se pueden proporcionar de forma más eficiente cuando se integran o conectan que cuando se proporcionan por separado. A pesar de los muchos pedidos para que se le dé mayor importancia a la integración de estos servicios en entornos con alta prevalencia de ITS/VIH, sorprendentemente se le ha prestado muy poca atención al desarrollo y a las pruebas empíricas de las herramientas prácticas que los proveedores usan para reforzar su capacidad de ofrecer servicios integrados.

El programa FRONTERAS desarrolló y probó la ECB+ en Kenia (del 2005 al 2007) y en Sudáfrica (del 2004 al 2006) debido a que ambos países tienen altas tasas de ITS, incluido el VIH, y sus tasas de prevalencia anticonceptiva son relativamente altas para la región. Esta situación brinda oportunidades para comunicarse con una proporción sustancial de la población sexualmente activa (si bien mayormente son mujeres) que busca prevenir los embarazos y que, también, está en riesgo o expuesta a una ITS/VIH. Como en la mayoría de los países, sus programas de ITS/VIH y de planificación familiar se implementan por separado, aunque ambos países buscan activamente formas de integrar ambos servicios. Ambos ministerios de salud deseaban desarrollar herramientas prácticas para mejorar la calidad de los servicios y la cantidad de clientes que recibían servicios integrados.

Los resultados del estudio se describen con mayor detalle en otra parte (consulte Liambila et al. 2008; Mullick et al. 2008), pero ambos estudios demostraron lo siguiente:

- La integración de la consejería sobre prevención de ITS/VIH y la evaluación de riesgos con la oferta de HCT durante las consultas de planificación familiar es posible y aceptable para los clientes y proveedores. 
- La calidad de la atención tanto para la planificación familiar como para la consejería de ITS/ VIH mejoró significativamente con el uso de las herramientas de la ECB+.

- El servicio de HCT mejoró considerablemente. En Kenia, se ofreció el servicio de HCT a más del 40 por ciento de los clientes, y alrededor de la mitad decidió realizarse una prueba, ya sea en el lugar o a través de una remisión. En Sudáfrica, la cantidad de personas a las que se les ofreció una prueba aumentó a un 29 por ciento. Además, se observó un aumento general en el distrito, en el cual se duplicó la cantidad de individuos que se realizaron una prueba.

- El uso de las herramientas de la ECB+ facilitó una mayor evaluación de riesgo para las ITS y el VIH. Asimismo, las decisiones sobre la elección de un método anticonceptivo se realizaron con un mejor entendimiento de su relación con la prevención de infecciones.

- A pesar de la preocupación de que al incorporar estos servicios pueda haber un impacto negativo en el servicio de planificación familiar, la mejora en la calidad de la consejería y la falta de evidencias de una disminución en el uso demostraron que esta preocupación era infundada.

\section{ESTRATEGIA DE CONSEJERÍA BALANCEADA PLUS}

$\mathrm{La} \mathrm{ECB}+$ se divide en cuatro etapas de consejería. Cada etapa cuenta con una secuencia de pasos por seguir. En la $\mathrm{ECB}+$, se asume que el motivo de la visita del/de la cliente es la planificación familiar, pero también ofrece al/a la cliente servicios y consejería adicional en el mismo centro, o a través de una remisión. En la ECB+, se integran mensajes de consejería posparto para garantizar la salud de la madre y del lactante, una oportunidad para analizar un período saludable para el embarazo y el espaciamiento entre embarazos, consejería sobre transmisión y prevención de ITS/ VIH, exámenes de detección de cánceres del sistema reproductivo, prevención de la violencia, atención posaborto, y servicios para hombre y adolescentes. La información en las tarjetas guían a los proveedores para realizar una evaluación de riesgos de ITS/VIH, analizar la protección doble y la salud positiva, y para analizar y ofrecerle al/a la cliente consejería y pruebas de VIH. El proceso de la $\mathrm{ECB}+$ puede resumirse como un algoritmo de toma de decisiones, el cual se describe en las próximas tres páginas. A continuación, encontrará un resumen de las cuatro etapas de consejería:

- Etapa previa a la elección: En esta etapa, el proveedor genera las condiciones que ayudan al/a la cliente a seleccionar un método de planificación familiar. El proveedor saluda al/a la cliente cordialmente. El proveedor hace hincapié en que, durante la consulta, se abordarán otros temas de salud reproductiva según las circunstancias personales del/de la cliente. El proveedor repasa las intenciones de fertilidad de la cliente y aconseja sobre períodos saludables para el embarazo y para el espaciamiento entre embarazos. El embarazo se descarta mediante el uso de una tarjeta de consejería con preguntas de verificación. Si la cliente no está embarazada, el proveedor muestra todas las tarjetas de método y formula las preguntas que se describen en el algoritmo. A medida que la cliente responde cada pregunta, el proveedor separa las tarjetas de los métodos que no son apropiados para ella. Separar estas tarjetas ayuda a evitar que se brinde información sobre métodos que no son relevantes para las necesidades de la cliente.

Si no se puede descartar un embarazo, el proveedor pasa a los pasos 13 al 19 para analizar otros servicios relevantes que la cliente pueda necesitar. Se le da a la cliente un método de respaldo, como preservativos, y se le pide que regrese cuando tenga su menstruación.

- Etapa de elección del método: En esta etapa, el proveedor proporciona información detallada sobre los métodos que no apartó y la efectividad de estos métodos. Esto ayuda a que el/la cliente seleccione un método acorde a sus necesidades reproductivas. Al seguir los pasos en el algoritmo de la $\mathrm{ECB}+$, el proveedor reduce del número de tarjetas de consejería hasta que se elige un método.

- Etapa posterior a la elección: En esta etapa, el proveedor usa el folleto del método que el/ la cliente eligió para proporcionarle información completa. Si el/la cliente tiene afecciones por las cuales no se recomienda el método o no está satisfecho con la elección, el proveedor vuelve a la etapa de elección del método para ayudar al/a la cliente a elegir otro método. El proveedor también alienta al/a la cliente a involucrar a su pareja en las decisiones sobre métodos anticonceptivos, ya sea a través de una charla o una visita a la clínica.

- Etapa de detección sistemática para otros servicios: En esta etapa, el proveedor usa la información obtenida en las etapas anteriores y formula preguntas específicas para determinar los servicios de salud adicionales y la consejería que el/la cliente de planificación familiar pueda necesitar. El proveedor puede usar las tarjetas de consejería restantes para realizar lo siguiente: repasar información importante para una madre en etapa de posparto o para un lactante; remitir al/a la cliente a servicios de controles de salud infantil; ofrecer exámenes de detección de cáncer de cuello uterino; ofrecer servicios de consejería para hombres y adolescentes; hablar 
sobre apoyo y seguridad para la mujer; ofrecer atención posaborto, según sea necesario; hablar sobre la transmisión y prevención de ITS/VIH y zika; ${ }^{1}$ realizar una evaluación de riesgos; hablar sobre protección doble y salud positiva, y ofrecerle al/a la cliente consejería y pruebas de VIH. El proveedor le ofrece una prueba de VIH al/a la cliente, según los protocolos nacionales, y lo/a alienta a divulgar su estado de ITS/VIH a su(s) pareja(s), lo cual incluye hacer saber al/a la cliente los riesgos y beneficios de la divulgación. Una vez que se completa la sesión de consejería, el proveedor le da al/a la cliente instrucciones de seguimiento sobre el método anticonceptivo elegido, el folleto del método y un folleto sobre preservativos. El proveedor y el/la cliente también acuerdan una fecha para una visita de seguimiento.

\section{¿QUÉ INCLUYE ESTE PAQUETE DE HERRAMIENTAS?}

Las ayudas de trabajo y las guías de la ECB+ están diseñadas para programas de salud reproductiva centrados en reforzar la calidad de la consejería de planificación familiar, y en responder a las necesidades de servicios y consejería adicionales de los clientes. Para complementar las herramientas ya existentes de los proveedores y facilitar la prestación de servicios de planificación familiar integrales, la segunda edición incorporó ayudas de trabajo adicionales y la Rueda con los criterios médicos de elegibilidad para el uso de anticonceptivos de la Organización Mundial de la Salud, además de agregar orientación adicional sobre otros servicios integrados. A continuación, encontrará una lista de los componentes del paquete de herramientas:

1. Guía del usuario de la ECB+ sobre cómo implementar la ECB+. Explica cómo usar las ayudas de trabajo; puede distribuirse durante la capacitación de la ECB + o usarse para autoaprendizaje con las ayudas de trabajo de la ECB+.

2. Ayudas de trabajo de la ECB+, incluidas las siguientes:

- El Algoritmo de la ECB+ que resume los 19 pasos recomendados para implementar la ECB+ durante la consulta de planificación familiar. Estos pasos se organizan según cuatro etapas de consulta: evaluación de necesidades previas a la elección, elección del método, acciones posteriores a la elección y detección sistemática para otros servicios. Durante cada etapa de consulta, se guía al proveedor sobre cómo usar las ayudas de trabajo de la $\mathrm{ECB}+$ paso a paso. De acuerdo con la respuesta del/de la cliente sobre los puntos analizados, el algoritmo indica qué acciones realizar. Se puede encontrar el algoritmo de la $\mathrm{ECB}+$ en las páginas 6 y 8 , y también por separado en otras ayudas de trabajo en el paquete de herramientas.

- Tarjetas de consejería que el proveedor usa durante la sesión de consejería. Hay 34 tarjetas de consejería. La primera tarjeta presenta seis preguntas que el proveedor de servicios formula para descartar un embarazo de la cliente (adoptadas de aquellas desarrolladas por Stanback et al. 1999). Hay 18 tarjetas específicas de métodos que presentan información sobre cada método de planificación familiar. Cada tarjeta de método tiene en el frente una ilustración del método anticonceptivo. En el reverso se presenta una lista de las características clave del método y se describe su uso, indicaciones, factores de riesgo y nivel de efectividad. Estas tarjetas se usan para descartar aquellos métodos que no son apropiados para las intenciones reproductivas del/de la cliente, y para acotar la elección y llegar a una decisión final. En las quince (15) tarjetas de consejería se proporciona información adicional sobre la consejería y los servicios que puede necesitar un cliente de planificación familiar. Las tarjetas son las siguientes: Períodos saludables para el embarazo y el espaciamiento entre embarazos; Promoción de un período posparto saludable para la madre; Atención posaborto; Promoción de la salud del recién nacido y del lactante; Prevención y transmisión de ITS/VIH; Prevención y transmisión del virus del Zika; Evaluación de riesgo de ITS/VIH; Prevención, dignidad y salud positiva; Protección doble; Consejería y pruebas de VIH; Pruebas de detección de cáncer de cuello uterino; Consejería para adolescentes; Seguridad y apoyo a la mujer, Servicios para hombres e Información y concienciación sobre l cáncer de mama. Estas tarjetas se usan durante la cuarta etapa de la consulta: detección sistemática para otros servicios.

- Folletos de métodos sobre cada uno de los 18 métodos anticonceptivos. Están diseñados para ayudar al/a la cliente a entender mejor el método elegido. El proveedor le da al/a la cliente un folleto del método seleccionado y un folleto con información sobre preservativos para que se lleve a su casa. Los proveedores deben alentar a los clientes analfabetos, o con un bajo nivel de alfabetización, a que se lleven el folleto a su casa para que su pareja o amigo cercano pueda repasarlo con ellos otra vez.

- La Rueda con los criterios médicos de elegibilidad para el uso de anticonceptivos de la OMS (2015) es una ayuda de trabajo para los proveedores sobre las cuatro

${ }^{1}$ y cualquier otra enfermedad infecciosa de emergencia que pueda transmitirse por vía sexual 
categorías de elegibilidad para el uso de anticonceptivos en relación con las afecciones médicas descritas en el documento Criterios médicos de elegibilidad (CME) para el uso de anticonceptivos, quinta edición publicado por el Departamento de Salud Reproductiva de la Organización Mundial de la Salud. Esta herramienta guía a los proveedores a través de las afecciones médicas y los medicamentos que pueden tener contraindicaciones con el uso de algún método anticonceptivo en particular. La OMS probó la ayuda de trabajo en tres países y encontró que resultó ser muy útil para los proveedores que la usaron.

3. Guía del Instructor de la ECB+ que los supervisores y otros pueden usar para capacitar a los proveedores en el uso de la ECB + . La guía incluye ejercicios y actividades para aumentar la comprensión y el uso apropiado del paquete de herramientas ECB+ por parte de los participantes.

Las ayudas de trabajo de la ECB+, la Guía del instructor de la ECB+ y la Guía del usuario de la ECB+ incorporan los últimos estándares internacionales de planificación familiar e ITS/VIH y orientación que siguen las recomendaciones de la Organización Mundial de la Salud (OMS), incluidos los siguientes: Criterios médicos de elegibilidad para el uso de anticonceptivos (OMS, 2015), Planificación familiar: un manual mundial para proveedores (OMS/Departamento de Salud Reproductiva e Investigaciones Conexas y JHU/CCP, actualización del proyecto INFO 2011), Tecnología anticonceptiva (Hatcher et al. 2011), Infecciones de transmisión sexual y otras infecciones del tracto reproductivo: Una guia para la práctica básica (OMS, 2005) y Guias para el tratamiento de las infecciones de transmisión sexual (OMS, 2003).

Estas ayudas de trabajo se pueden adaptar, revisar e imprimir fácilmente para satisfacer las necesidades de cada localidad y en función de los protocolos nacionales o regionales.

\section{¿CÓMO DEBE USARSE ESTE PAQUETE DE HERRAMIENTAS?}

1. Lea esta Guía del usuario de la ECB + por completo para obtener información sobre cómo implementar la Estrategia de Consejería Balanceada Plus.

2. Consulte el algoritmo de la $\mathrm{ECB}+$ para recordar los 19 pasos utilizados para implementar la $\mathrm{ECB}+$. Es útil tener una copia disponible en el escritorio del proveedor o en una pared del área de consulta para que el proveedor pueda consultarla fácilmente.

3. Use las tarjetas de consejería de la ECB + y la Rueda de CME de la OMS para ayudar al/a la cliente a elegir un método que se adapte a sus intenciones reproductivas. Si la cliente es mujer, use la primera tarjeta de consejería para descartar que esté embarazada. Si no lo está, use las tarjetas de método para ayudar al/a la cliente a elegir el método anticonceptivo que mejor se adapte a sus intenciones reproductivas, descartando aquellos métodos que no sean apropiados. Durante la consejería, haga hincapié en la protección doble.

4. Una vez que el/la cliente haya elegido un método anticonceptivo, use el folleto del método de la $\mathrm{ECB}+$ correspondiente para analizar las contraindicaciones. Si no hay ninguna, repase el resto del folleto con el/la cliente para reforzar la información sobre el método elegido y responder preguntas. Esto ayuda a que el/la cliente entienda mejor el método. Entréguele el folleto al/a la cliente. Puede consultarlo en su casa o usarlo para hablar con su pareja.

5. Durante la elección del método anticonceptivo, y después de elegirlo, use las tarjetas de consejería para determinar los servicios de salud adicionales que el/la cliente de planificación familiar pueda necesitar. Estos servicios adicionales incluyen consejería sobre lo siguiente: atención posparto para la madre y el recién nacido; exámenes detección de cáncer de cuello uterino y de cáncer de mama; necesidades del adolescente; seguridad y apoyo a la mujer; atención posaborto; servicios para hombres; prevención y transmisión de ITS / VIH; prevención y transmisión del virus del Zika; realizar una evaluación de riesgos; definir protección doble y hablar sobre VIH y ofrecer consejería y pruebas de detección.

6. Para los instructores, use la Guía del instructor de la ECB+ para que el personal de atención de salud se familiarice con esta perspectiva de consejería y para capacitarlos en un uso efectivo de la ECB+. Los ejercicios en la Guía del instructor de la ECB+ se pueden enseñar todos juntos en un taller, o bien pueden usarse por separado durante las reuniones de personal o en la capacitación en el lugar de trabajo durante visitas de supervisión.

7. Las cuatro ayudas de trabajo de la ECB+, la Guía del usuario de la ECB+ y la Guía del instructor de la $E C B+$ también están disponibles en formato electrónico en la página del Population Council, en http://www.popcouncil.org/research/the-balanced-counselingstrategy-plus-a-toolkit-for-family-planning-service. Adapte estos materiales para el uso en su región o país, según sea necesario. 


\section{Algoritmo para el uso de la Estrategia de Consejería Balanceada Plus}

(1) Establezca y mantenga una relación cordial y cálida.

2 Informe a la cliente (y a su pareja, si se encuentra presente) que durante la consulta tendrá la oportunidad de abordar tanto sus necesidades de salud como sus necesidades de planificación familiar.

(3) Pregúntele a la cliente sobre el tamaño actual de su familia y sobre sus prácticas anticonceptivas actuales. Asesore a la cliente sobre períodos saludables para el embarazo y el espaciamiento entre embarazos usando una tarjeta de consejería.

a) Si la cliente actualmente usa un método de planificación familiar o posponiendo el embarazo, pregúntele si ambos miembros de la pareja están satisfechos con el método y si les interesa continuar con él, o bien si desean cambiar de método.

b) Si la pareja se encuentra presente, use la tarjeta de apoyo y servicios para hombres.

4 Descarte la posibilidad de embarazo usando la tarjeta Lista de verificación para asegurarse de manera razonable de que una mujer no está embarazada.

(5) Muestre todas las tarjetas de métodos. Pregúntele al/a la cliente si desea un método en particular. Formule todas las preguntas que se detallan a continuación. Aparte las tarjetas de método según las respuestas del/de la cliente.

a) ¿Desea tener hijos en un futuro?

Si la respuesta es "Sín, aparte la tarjeta Vasectomía y la tarjeta Ligadura de trompas. Explique por qué. Si la respuesta es "No", conserve todas las tarjetas y continúe.

b) ¿Ha dado a luz en las últimas 48 horas?

Si la respuesta es "Sin", aparte la tarjeta Inyectables combinados y la tarjeta Anticonceptivos orales combinados (Píldora). Explique por qué.

Si la respuesta es "No", continúe con la siguiente pregunta.

c) ¿Está amamantando a un lactante de menos de 6 meses?

Si la respuesta es "Sí,, aparte la tarjeta Inyectables combinados y la tarjeta Anticonceptivos orales combinados (Píldora). Explique por qué.

Si la respuesta es "No" o si ha vuelto a tener la menstruación, aparte la tarjeta Método de la amenorrea de la lactancia (MELA). Explique por qué.

d) ¿Respalda su pareja su decisión sobre planificación familiar?

Si la respuesta es "Sí,, continúe con la siguiente pregunta.

Si la respuesta es "No", aparte las siguientes tarjetas: Preservativo femenino, Preservativo masculino, Método de Días Fijos@, Método de Dos Días@ y Retirada. Explique por qué.

e) ¿Sufre alguna afección médica? ¿Toma medicamentos?

Si la respuesta es "Sí", pregunte qué afecciones padece o qué medicamentos toma. Consulte la Rueda con los criterios médicos de elegibilidad para el uso de anticonceptivos de la OMS o las directrices nacionales actuales y aparte las tarjetas de todos los métodos contraindicados. Explique por qué.

Si la respuesta es "No", conserve todas las tarjetas y continúe.

f) ¿Existen métodos que no desee usar o que no haya tolerado en el pasado?

Si la respuesta es "Sí", aparte las tarjetas de los métodos que el/la cliente no desee.

Si la respuesta es "No", conserve el resto de las tarjetas.

\section{ETAPA DE ELECCIÓN DEL MÉTODO}

(7) Repase brevemente los métodos que no haya apartado e indique su efectividad.

a) Disponga las tarjetas restantes por orden de efectividad (consulte el reverso de cada tarjeta).

b) En orden de efectividad (de mayor a menor), repase brevemente los atributos en cada tarjeta de método.

(8) Pídale al/a la cliente que elija el método que ella o su pareja encuentre más conveniente. a) Si el/la cliente es adolescente, use la tarjeta de consejería para informarle que puede obtener cualquier método.

9) Mediante el folleto específico del método, compruebe que el/la cliente no presente ninguna afección por la cual no se recomiende el método.

a) Repase la sección "Método no recomendado si..." del folleto.

b) Si el método no es recomendable, pídale al/a la cliente que seleccione otro método de las tarjetas restantes. Repita el proceso desde el paso 8. 


\section{ETAPA POSTERIOR A LA ELECCIÓN}

(10) Analice el método elegido con el/la cliente, con el folleto específico del método como herramienta de consejería. Determine el entendimiento del/de la cliente, y refuerce la información clave.

(11) Asegúrese de que el/la cliente haya tomado una decisión definitiva. Dele el método elegido, un método de respaldo o derívelo/a, según el método seleccionado.

12 Aliente al/a la cliente a involucrar a su pareja en las decisiones sobre prácticas anticonceptivas, ya sea mediante una charla o una visita a la clínica.

\section{ETAPA DE DETECCIÓN SISTEMÁTICA PARA OTROS SERVICIOS}

(13) Mediante la información obtenida con anterioridad, determine la necesidad de la cliente de recibir servicios de atención posparto, de control de salud para recién nacidos, lactantes o niños, o de posaborto.

a) Si la cliente informó haber dado a luz recientemente, repase con ella la tarjeta Promoción de un período posparto saludable y la tarjeta Promoción de la salud del recién nacido y del lactante. Proporcione los servicios necesarios o haga una derivación, según corresponda.

b) Para clientes con niños de menos de 5 años, pregunte si los niños han recibido los servicios de control de salud correspondientes. Proporcione los servicios de vacunación o control del crecimiento necesarios o haga una derivación, según corresponda.

c) Si la cliente informó un aborto reciente, repase con ella la tarjeta Atención posaborto. Proporcione los servicios de atención posaborto necesarios o haga una derivación, según corresponda.

14. Pregúntele a la cliente cuándo fue su último examen de detección de cáncer de cuello uterino (IVAA/IVSL o Papanicolaou) o de cáncer de mama.

a) Si su último examen de detección de cáncer de cuello uterino fue hace más de 3 años (o, en caso de ser VIH positivo, en los últimos 6 a 12 meses) o si no sabe, pregúntele si le gustaría hacerse uno ese mismo día. Repase la tarjeta Examen de detección de cáncer de cuello uterino. Proporcione los servicios necesarios o haga una derivación.

b) Si el último examen de detección de cáncer de cuello uterino de la cliente fue hace menos de 3 años, continúe con la siguiente pregunta.

c) Repase con la cliente la tarjeta de consejería Información y concienciación sobre el cáncer de mama.

15. Analice con el/la cliente las tarjetas de consejería Prevención y transmisión de ITS/VIH y Protección doble. Ofrézcale preservativos e instrucciones sobre el uso correcto y constante.

a) En las regiones con virus del Zika activo, analice con el/la cliente las tarjetas de consejería Prevención y transmisión del virus del Zika.

(16) Lleve a cabo una evaluación del riesgo de ITS y VIH usando la tarjeta de consejería. Si se identifican los síntomas, trate al/a la cliente de manera sindrómica.

(17) Pregúntele al/a la cliente si conoce su estado de VIH.

a) Si el/la cliente sabe que tiene VIH,

- repase con el/la cliente la tarjeta de consejería Prevención, dignidad y salud positiva.

- Derive al/a la cliente a un centro de tratamiento y atención de bienestar.

b) Si el/la cliente sabe que es VIH negativo,

- analice un plazo de repetición de la prueba.

c) Si el/la cliente desconoce su estado,

- hable sobre los servicios de consejería y pruebas de VIH (HCT, HIV Counseling and Testing) usando la tarjeta de consejería.

- ofrézcale o hágale una prueba, según los protocolos nacionales.

- Asesore al/a la cliente sobre los resultados de la prueba. Si el/la cliente tiene VIH, repase con el/ella la tarjeta de consejería Prevención, dignidad y salud positiva, y derívelo/a a un centro de tratamiento y atención de bienestar.

d) Aconseje a la cliente usando la tarjeta Seguridad y apoyo a la mujer.

- Si la cliente presenta signos graves que indiquen que puede ser víctima de violencia infligida por la pareja, derívela a servicios especializados.

(18) Proporcione instrucciones de seguimiento, un folleto sobre preservativos y un folleto sobre el método escogido. Fije una fecha para la próxima visita.

(19) Agradézcale por su visita. Complete la sesión de consejería. 


\section{Guía para aconsejar a los clientes con el paquete de herramientas de la ECB+}

\section{Etapa previa a la elección}

En esta etapa, el proveedor genera las condiciones que ayudan al/ a la cliente a seleccionar un método de planificación familiar.

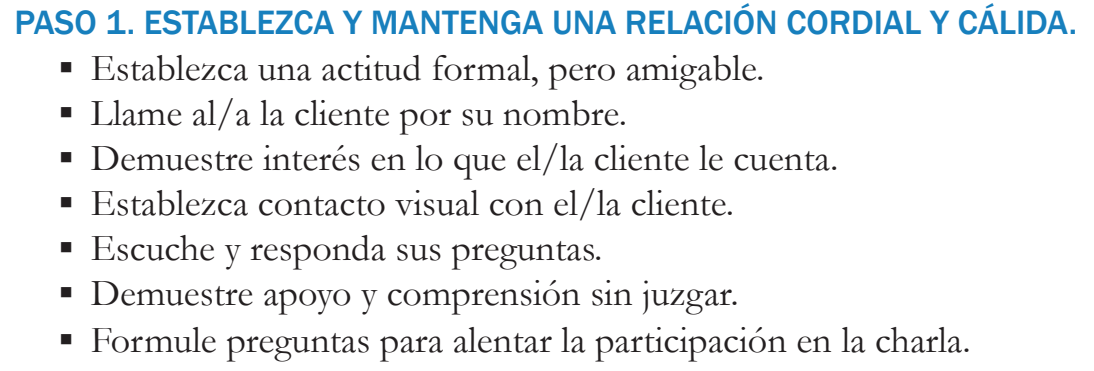

PASO 2. INFORME AL/A LA CLIENTE (Y A SU PAREJA, SI SE ENCUENTRA PRESENTE) QUE DURANTE LA CONSULTA TENDRÁ LA OPORTUNIDAD DE ABORDAR TANTO SUS NECESIDADES DE SALUD COMO SUS NECESIDADES DE PLANIFICACIÓN FAMILIAR.

- Informe al/a la cliente sobre otros servicios disponibles en su centro o mediante derivación.

- Pregunte y tome nota de otros servicios en los cuales el/la cliente pueda estar interesado/a en recibir.

- Pregunte al/a la cliente si desea un método de planificación familiar.

PASO 3. PREGÚNTELE AL/A LA CLIENTE SOBRE EL TAMAÑO ACTUAL DE SU FAMILIA, SOBRE SU DESEO DE TENER MÁS HIJOS Y SOBRE SUS PRÁCTICAS ANTICONCEPTIVAS ACTUALES. ASESORE AL/A LA CLIENTE SOBRE PERÍODOS SALUDABLES PARA EL EMBARAZO Y EL ESPACIAMIENTO ENTRE EMBARAZOS USANDO UNA TARJETA DE CONSEJERÍA.

- Pregúntele al/a la cliente cuántos hijos tiene.

- Pregúntele al/a la cliente cuántos hijos desea tener.

- Pregunte al/a la cliente si actualmente usa algún método anticonceptivo.

- Si la cliente actualmente usa un método anticonceptivo o está posponiendo un embarazo, pregúntele si ambos miembros de la pareja están satisfechos con el método y si les interesa continuar con él, o bien si desean cambiar de método.

- Use la tarjeta de consejería y explíquele al/a la cliente los siguientes puntos:

- Si la pareja de la cliente se encuentra presente, use la tarjeta Apoyo y servicios para hombres.

PASO 4. DESCARTE UN EMBARAZO USANDO LA TARJETA LISTA DE VERIFICACIÓN DE EMBARAZO,

Para las mujeres que desean tener más hijos después de un nacimiento vivo, aconseje lo siguiente:

Para las mujeres que deciden tener un hijo después de un aborto espontáneo o un aborto provocado, aconseje lo siguiente:

Para adolescentes, aconseje lo siguiente:
- Por la salud de la madre y del bebé, espere al menos 2 años (24 meses), pero no más de 5 años antes de tratar de quedar embarazada otra vez.

- El uso de un método de planificación familiar elegido por la mujer permite la planificación de un embarazo saludable.

- Por la salud de la madre y del bebé, espere al menos 6 meses antes de tratar de quedar embarazada otra vez.

- El uso de un método de planificación familiar elegido por la mujer permite la planificación de un embarazo saludable.

- Por la salud de la madre y del bebé espere al menos hasta tener 18 años antes de intentar quedar embarazada.

- Si es sexualmente activa, el uso de un método de planificación familiar de su preferencia permite evitar embarazos no deseados. 


\section{LA CUAL CUENTA CON 6 PREGUNTAS.}

El embarazo es una contraindicación para el uso de la mayoría de los métodos de planificación familiar, excepto los métodos de barrera, como los preservativos. Es importante descartar la posibilidad de que la cliente esté embarazada, lo cual puede hacerse mediante las 6 preguntas que aparecen en la tarjeta Lista de verificación de embarazo.

\section{Lista de verificación para asegurarse de manera razonable de que una mujer no está embarazada:}

- ¿Tuvo un bebé hace menos de 6 meses? Si la respuesta es «Sí», ¿realiza una lactancia completa o casi completa? ¿No ha tenido su menstruación desde el parto?

- ¿Se abstuvo de tener relaciones sexuales sin protección (sin un método de planificación familiar) desde su última menstruación o parto?

- ¿Ha dado a luz en las últimas 4 semanas?

- ¿Su menstruación comenzó en los últimos 7 días (o en los últimos 12 si planea usar un dispositivo intrauterino [DIU])?

- ¿Tuvo un aborto espontáneo o un aborto provocado en los últimos 7 días?

- ¿Usa un método anticonceptivo confiable de forma sistemática y correcta?

Descarte un embarazo usando la tabla a continuación.

\begin{tabular}{|c|c|}
\hline Si la cliente... & Entonces... \\
\hline $\begin{array}{l}\text { Responde "Sín a cualquiera de las pre- } \\
\text { guntas y no tiene señales ni síntomas de } \\
\text { embarazo } \\
\text { *Una vez que la cliente haya respondido } \\
\text { "Sí" a una de las preguntas, no es necesa- } \\
\text { rio que continúe con el resto. }\end{array}$ & $\begin{array}{l}\text { 1.Un embarazo es poco probable. } \\
\text { 2.Dirijase al paso } 5 \text {. }\end{array}$ \\
\hline Responde "No" a todas las preguntas. & $\begin{array}{l}\text { 1. No se puede descartar un embarazo. } \\
\text { 2. De ser posible dele a la cliente una prueba de embarazo o } \\
\text { derívela a una clínica prenatal. } \\
\text { 3. Bríndele un método de respaldo, como preservativos, } \\
\text { para que use hasta que tenga su menstruación. } \\
\text { 4. Bríndele de manera anticipada el método que prefiera } \\
\text { (siempre que sea posible) para que lo use el primer día } \\
\text { de su periodo O BIEN pídale que regrese en ese momento } \\
\text { para recibir su método que eligió. } \\
\text { 5. Diríjase al paso } 13 .\end{array}$ \\
\hline
\end{tabular}

PASO 5. MUESTRE TODAS LAS TARJETAS DE MÉTODO. PREGÚNTELE AL/A LA CLIENTE SI DESEA UN MÉTODO EN PARTICULAR.

1. Muestre todas las tarjetas de métodos sobre un escritorio o mesa y agrúpelas por tipo de método (temporal, conciencia de fertilidad, permanente), según se muestra en la Figura 1 más abajo.

2. Cada tarjeta presenta información sobre un método de planificación familiar diferente.

3. Pregúntele al/a la cliente si tiene en mente un método en particular.

\begin{tabular}{|c|c|}
\hline Si la cliente... & Haga lo siguiente... \\
\hline Responde "No" & Diríjase al paso 6. \\
\hline Responde "Sí" & $\begin{array}{l}\text { 1.Pregúntele qué método desea. } \\
\text { 2.Pregúntele qué sabe acerca del método. } \\
\text { 3.Si la información es correcta, diríjase al paso } 9 .\end{array}$ \\
\hline $\begin{array}{l}\text { Le da información incompleta sobre el } \\
\text { método que eligió } \\
\text { o } \\
\text { no conoce otras alternativas que pueden } \\
\text { ser más convenientes }\end{array}$ & $\begin{array}{l}\text { 1. Corrija la información incorrecta. } \\
\text { 2.Dirijase al paso } 6 \text { para ayudar al/a la cliente a elegir un } \\
\text { método, si es necesario. }\end{array}$ \\
\hline
\end{tabular}



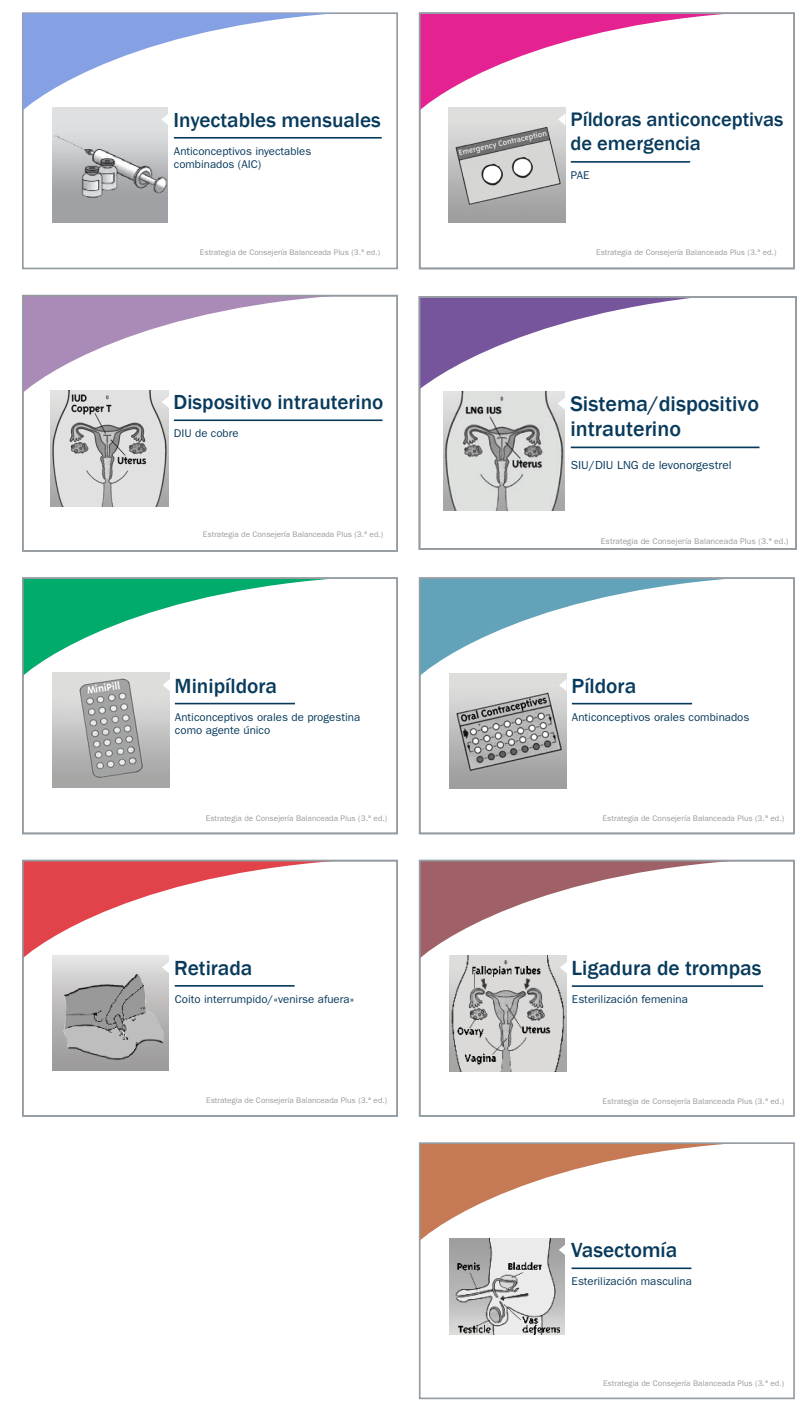
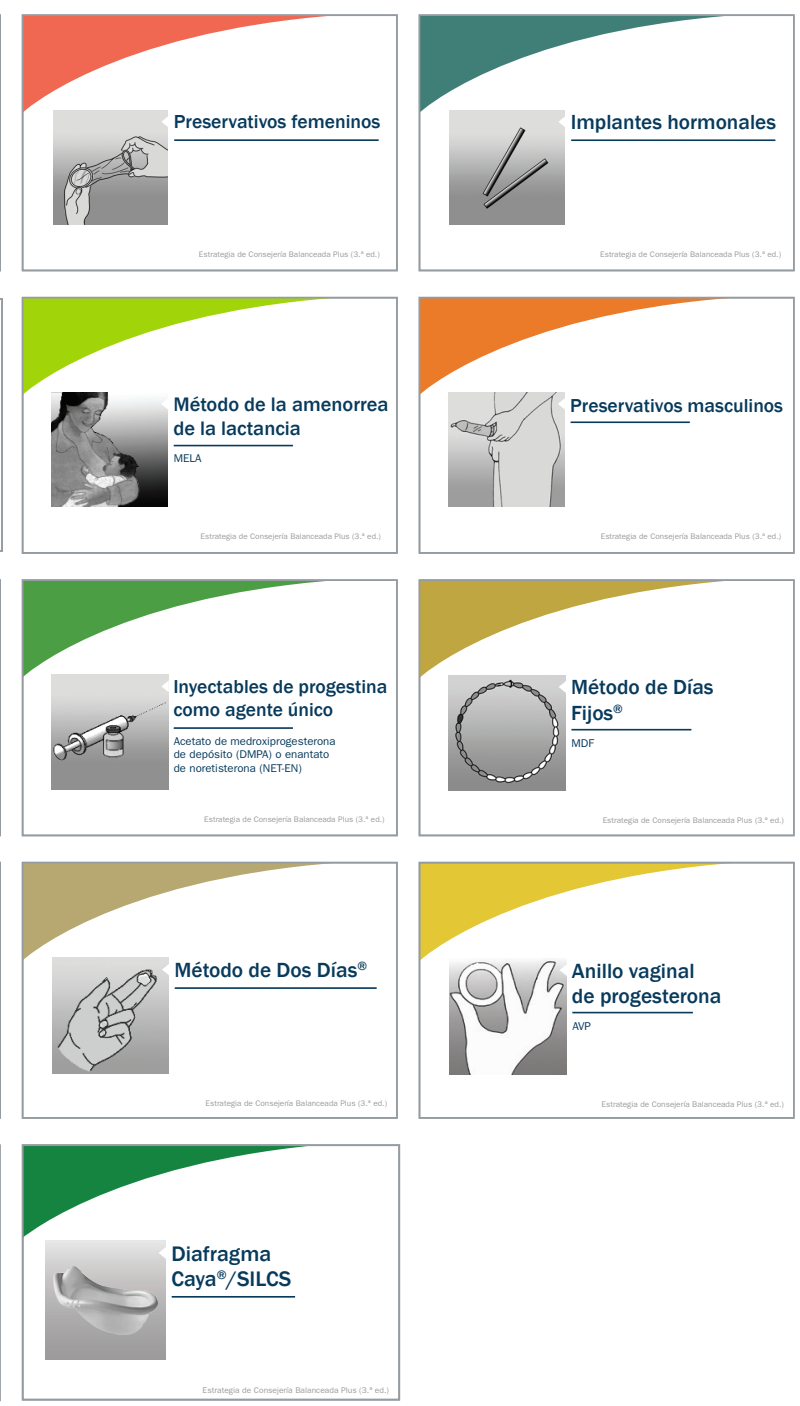

PASO 6. FORMULE TODAS LAS PREGUNTAS QUE SE DETALLAN A CONTINUACIÓN. APARTE LAS TARJETAS DE MÉTODO SEGÚN LAS RESPUESTAS DEL/DE LA CLIENTE.

1. Al mostrar las tarjetas de método, comience el proceso diciéndole al/a la cliente algo como «Ahora analizaremos sus necesidades anticonceptivas. Reduciremos el número de métodos que puedan ser apropiados para usted. Luego, analizaremos las características principales de cada método. Esto nos ayudará a encontrar el método indicado para satisfacer sus necesidades».

2. Formule las 6 preguntas que aparecen a continuación. Según las respuestas del/de la cliente, aparte las tarjetas de método que no se ajustan a sus necesidades.

a. ¿Desea tener hijos en un futuro?

\section{Si la cliente...}

\section{Responde "Sí»}

Responde "No"

\section{Haga lo siguiente...}

1. Aparte las tarjetas Vasectomía y Ligadura de trompas. 2. Explíquele que la esterilización es permanente y no es adecuada para alguien que puede querer otro hijo.

Conserve todas las tarjetas y continúe. 
b. ¿Ha dado a luz en las últimas 48 horas?

\begin{tabular}{|l|l|}
\hline Si la cliente... & Haga lo siguiente... \\
\hline Responde "Sí" & $\begin{array}{l}\text { 1.Aparte las tarjetas Anticonceptivos orales combinados } \\
\text { (Píldora), Inyectable mensual, Implantes y Ligadura de } \\
\text { trompas. } \\
\text { 2.Explique que los métodos hormonales combinados } \\
\text { y la ligadura de trompas no son seguros para el uso } \\
\text { inmediatamente después del parto. }\end{array}$ \\
\hline Responde "No" & Conserve todas las tarjetas y continúe.
\end{tabular}

c. ¿Está amamantando a un lactante de menos de 6 meses?

\begin{tabular}{|l|l|}
\hline Si la cliente... & Haga lo siguiente... \\
\hline Responde "Sí» & $\begin{array}{l}\text { 1. Aparte las tarjetas Anticonceptivos inyectables combina- } \\
\text { dos (AIC) y Anticonceptivos orales combinados (Píldora). } \\
\text { 2. Explique que las hormonas en estos métodos afectan } \\
\text { la lactancia. }\end{array}$ \\
\hline $\begin{array}{l}\text { 1. Aparte las tarjetas Anticonceptivos inyectables } \\
\text { combinados (AIC) y Anticonceptivos orales combinados } \\
\text { Responde "No" }\end{array}$ \\
$\begin{array}{l}\text { (Píldora). } \\
\text { 2. Explique que las hormonas en estos métodos afectan } \\
\text { la lactancia. }\end{array}$ \\
\hline
\end{tabular}

d. ¿Respalda su pareja su decisión sobre planificación familiar?

\begin{tabular}{|c|c|}
\hline Si la cliente... & Haga lo siguiente... \\
\hline Responde "Sí" & Continúe con la pregunta siguiente. \\
\hline Responde "No" & $\begin{array}{l}\text { 1.Aparte las tarjetas Preservativo femenino, Preservativo } \\
\text { masculino, Método de Días Fijos } ₫ \text {, Método de Dos Días } \\
\text { y Retirada. } \\
\text { 2. Explíquele que estos métodos requieren la cooperación } \\
\text { de su pareja. }\end{array}$ \\
\hline
\end{tabular}

3. Invite al/a la cliente a que lleve a su pareja a la sesión de consejería para hablar sobre planificación familiar con un proveedor.

4. Señale que los preservativos masculinos y femeninos son importantes para la protección contra ITS, incluido el VIH.

5. Continúe con la pregunta siguiente.

e. ¿Sufre alguna afección médica? ¿Toma medicamentos?

\begin{tabular}{|l|l|}
\hline Si la cliente... & Haga lo siguiente... \\
\hline Responde "Sī" & $\begin{array}{l}\text { 1.Pregúntele qué afecciones médicas padece o qué } \\
\text { medicamentos toma. } \\
\text { 2. Consulte la Rueda con los criterios médicos de } \\
\text { elegibilidad para el uso de anticonceptivos del la OMS } \\
\text { (incluida) o las directrices nacionales actuales para } \\
\text { identificar los métodos contraindicados. }\end{array}$ \\
$\begin{array}{ll}\text { 3.Aparte todas las tarjetas de los métodos contraindicados. } \\
\text { 4. Explíquele a la cliente por qué aparta aquellas tarjetas, } \\
\text { según la información proporcionada en las directrices. }\end{array}$ \\
\hline Continúe con la pregunta siguiente.
\end{tabular}




\section{NOTA}

La Rueda con los criterios médicos de elegibilidad para el uso de anticonceptivos de la OMS es una herramienta que permite a los proveedores ayudar y guiar a los clientes en el proceso de elección del uso de anticonceptivos y determinar cuáles de ellos están contraindicados por una afección médica que el/la cliente puede tener. La rueda incluye dos discos superpuestos; en el disco exterior, se detallan las afecciones médicas mientras que en el disco interno, se identifica la elegibilidad de los métodos específicos. Al rotar y alinear los discos con una afección específica, el proveedor puede interpretar la viabilidad del método deseado según cuatro categorías de elegibilidad (de la 1 a la 4). La Rueda CME incluye instrucciones adicionales en su reverso.

f. ¿Existen métodos que no desee usar o que no haya tolerado en el pasado?

\begin{tabular}{|c|c|}
\hline Si la cliente... & Haga lo siguiente... \\
\hline Responde "Sí»" & $\begin{array}{l}\text { 1.Pregúntele qué métodos usó y cuál fue su experiencia con } \\
\text { cada uno. } \\
\text { 2.Aparte las tarjetas de los métodos que la cliente } \\
\text { no desee. }\end{array}$ \\
\hline Responde "No" & Conserve el resto de las tarjetas. \\
\hline $\begin{array}{l}\text { El cliente eliminó un método debido a } \\
\text { rumores o información falsa. }\end{array}$ & $\begin{array}{l}\text { 1.Proporciónele la información correcta. } \\
\text { 2. No aparte la tarjeta de ese método. }\end{array}$ \\
\hline
\end{tabular}

6. Si ciertos métodos, como dispositivos intrauterinos (DIU), implantes, ligadura de trompas o vasectomía, no se ofrecen en su centro de salud, igualmente hable con los clientes sobre estos métodos y, si los eligen, derive a los pacientes a otro centro. 


\section{Etapa de elección del método}

\section{PASO 7. REPASE BREVEMENTE LOS MÉTODOS QUE NO SE HAYAN APARTADO E INDIQUE SU EFECTIVIDAD.}

1. Disponga las tarjetas de método restantes que aún no han sido apartadas sobre el escritorio o la mesa por orden de efectividad. Consulte la Figura 2 que se incluye a continuación.

\section{FIGURA 2. TARJETAS DE MÉTODO ORGANIZADAS SEGÚN SU EFECTIVIDAD}

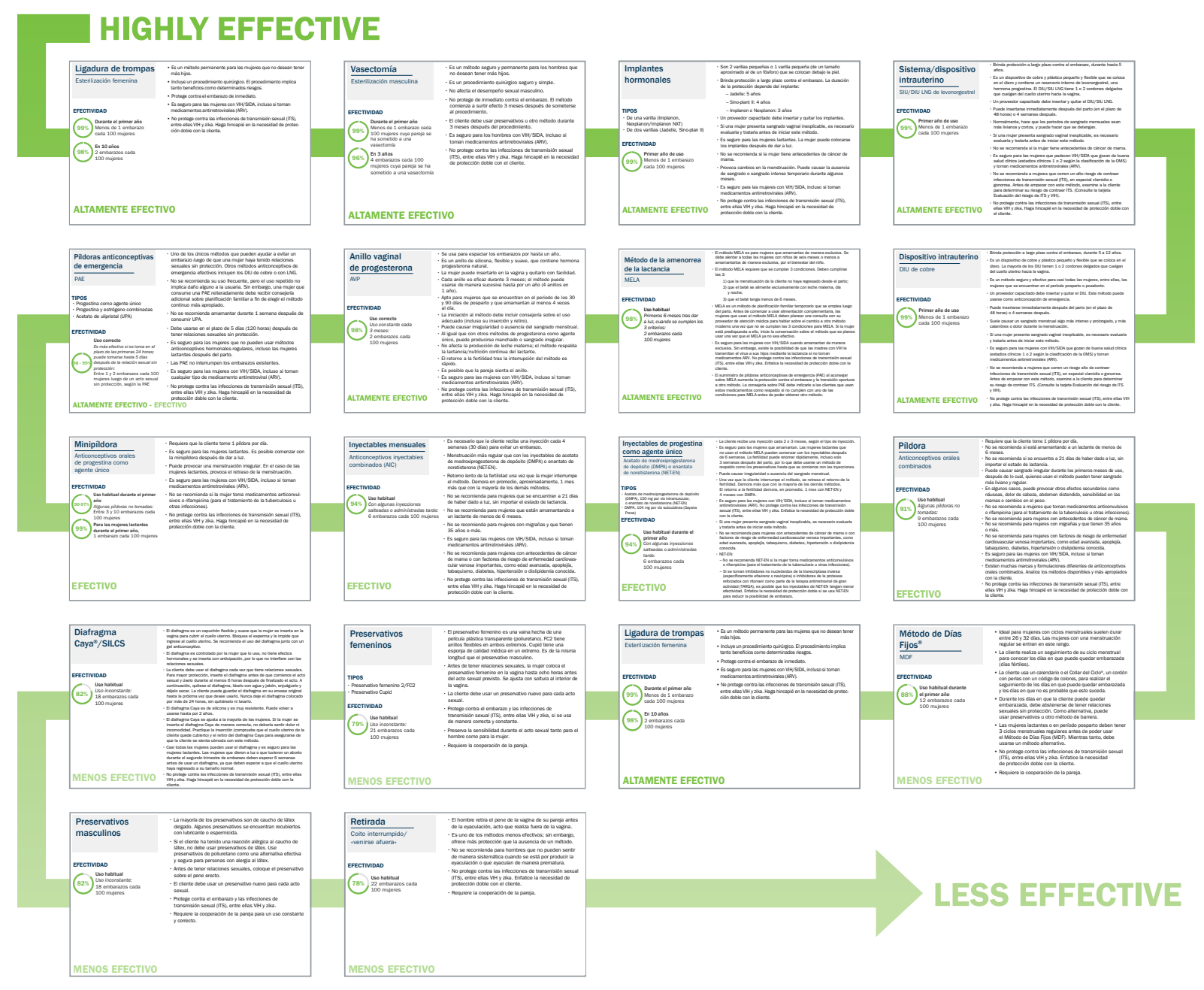

2. Dispóngalas con el menor porcentaje de efectividad primero y los porcentajes más altos al final. (El porcentaje se encuentra en el lado izquierdo del reverso de la tarjeta e indica la efectividad del método; la efectividad del método también se indica con la palabra en color verde que aparece en el extremo inferior izquierdo de la tarjeta: «muy efectivo», «efectivo» o «poco efectivo»).

3. Explique la efectividad de los métodos. La efectividad se mide como el número de embarazos entre 100 mujeres durante el primer año de uso. A mayor porcentaje, más efectivo es el método y menos mujeres quedan embarazadas mientras lo usan. Consulte la Figura 3 como ejemplo. 

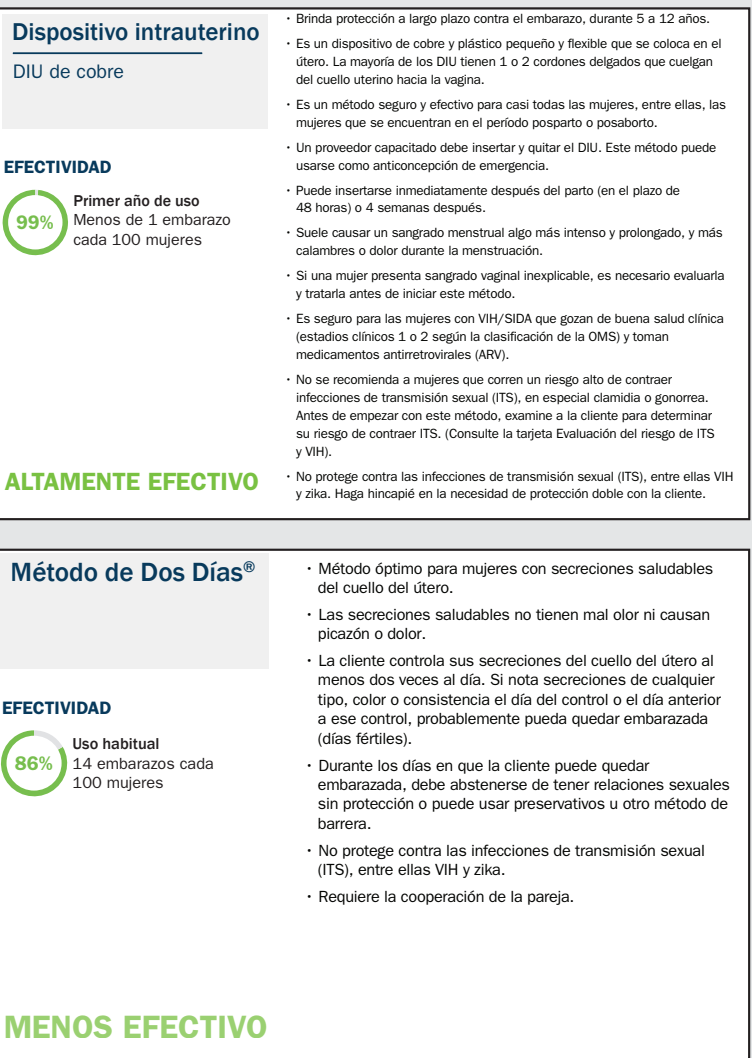

4. Comience con la tarjeta con mayor porcentaje. Lea las características principales de cada método escritas en las tarjetas dispuestas sobre el escritorio o la mesa. También puede pedirle al/a la cliente que lea estos atributos por sí mismo/a.

5. Explique que los preservativos (femeninos y masculinos) son el único método que proporciona protección doble contra embarazos e ITS, incluso el VIH. Haga hincapié en lo siguiente:

- Los preservativos masculinos y femeninos reducen significativamente el riesgo de contraer ITS, incluido el VIH, cuando se usa de forma sistemática y correcta en cada acto sexual.

- Cuando se usa de forma sistemática y correcta en cada acto sexual, el uso de preservativos previene del 80 al 95 por ciento de la transmisión del VIH que hubiera ocurrido sin su uso.

- Los preservativos reducen el riesgo de contraer muchas ITS cuando se usan de forma sistemática y correcta:

- Proporcionan mejor protección contra la propagación de ITS por secreciones, como el VIH, la gonorrea y la clamidia.

- Protegen, asimismo, contra la propagación de ITS por contacto directo, como el herpes y el virus del papiloma humano (VPH).

\section{PASO 8. PÍDALE AL/A LA CLIENTE QUE ELIJA EL MÉTODO QUE ENCUENTRE MÁS CONVENIENTE.}

1. Si el/la cliente es adolescente, use la tarjeta Consejería para adolescentes para informarle que puede obtener cualquier método.

2. Pregúntele al/a la cliente si tiene alguna duda o comentario sobre los métodos analizados. Responda todas las preguntas. Resuelva toda duda antes de continuar.

3. Pídale al/a la cliente que elija el método que encuentre más conveniente.

4. Si el/la cliente le pide que elija el método, explíquele que él/ella es la única persona que conoce sus propias necesidades. Usted puede recomendar un método, pero permita que el/la cliente sea quien tome la decisión final. 
5. Una vez que el/la cliente elige un método, no quite de la mesa las tarjetas de método restantes. Puede que necesite volver a usarlas si el método elegido no es recomendable para él/ella o por si cambia de opinión.

6. Si el/la cliente no prefiere ninguno de los métodos analizados o si no se puede decidir, dele un método de respaldo, como los preservativos, para que use hasta que se decida por un método de su elección. Los preservativos pueden proporcionar doble protección contra el embarazo y las ITS hasta que el/la cliente seleccione otro método o uno adicional. Dirijase al paso 13.

\section{PASO 9. CON EL FOLLETO ESPECÍFICO DEL MÉTODO, COMPRUEBE QUE EL/LA CLIENTE NO PRESENTE NINGUNA AFECCIÓN POR LA CUAL NO SE RECOMIENDE EL MÉTODO.}

1. Seleccione el folleto específico del método de la ECB + correspondiente al método elegido por el/la cliente.

2. Junto con el/la cliente, repase la sección titulada «Método no recomendado si...» del folleto del método. Allí se enumeran las condiciones para las que no se recomienda el método.

\section{Para la píldora:}

Método no recomendado si:

- está amamantando a un lactante de menos de 6 meses;

- si dio a luz hace 21 días o menos (sin importar el estado de lactancia);

- fuma cigarrillos y tiene más de 35 años;

- tiene presión arterial alta, 140/90 o más;

- padece de determinadas enfermedades cardíacas o vasculares graves poco frecuentes (la situación debe analizarse con el proveedor de atención de salud);

- sufre de enfermedad hepática grave;

- presenta coágulos sanguíneos, trombosis venosa profunda o embolia pulmonar, o se encuentra en tratamiento anticoagulante (la situación debe analizarse con el proveedor de atención de salud);

- sufre de lupus;

- sufre de una enfermedad de la vesícula biliar, incluso si se la trata médicamente (la situación debe analizarse con el proveedor de atención de salud);

- tiene cáncer de mama o tuvo antecedentes de esa enfermedad;

- sufre de migraña (dolores de cabeza intensos que no cesan al tomar paracetamol) y tiene 35 años o más;

- presenta aura de migraña (la visualización ocasional de un punto brillante que crece en un ojo);

- toma medicamentos anticonvulsivos o rifampicina (para el tratamiento de la tuberculosis $u$ otras infecciones); $y$

- es VIH positivo y consume inhibidores de la proteasa reforzados con ritonavir como parte de la terapia antirretroviral de gran actividad (TARGA).

3. Haga preguntas exploratorias usando lenguaje simple y claro, a fin de comprobar que el/la cliente no presenta ninguna de las afecciones para las que no se recomienda el método.

4. Según las respuestas del/de la cliente, decida si suministrarle el método o regrese a un paso anterior.

\section{Si la cliente...}

Haga lo siguiente...

Diríjase al paso 10.

1. Explique que es necesario que elija otro método.

2. Vuelva al paso 7.

1. Explique que es necesario que elija otro método.

2. Vuelva al paso 6. 


\section{Etapa posterior a la elección}

\section{PASO 10. ANALICE EL MÉTODO ELEGIDO CON EL/LA CLIENTE, USANDO EL FOLLETO DEL MÉTODO COMO HERRAMIENTA DE CONSEJERÍA. DETERMINE EL ENTENDIMIENTO DEL/DE LA CLIENTE, Y REFUERCE LA INFORMACIÓN CLAVE.}

1. Use el folleto específico del método como herramienta de consejería para repasar toda la información relacionada con el método elegido por el/la cliente. Comience diciendo algo como «Sr./Sra. (nombre), este folleto es para que se lo lleve a casa. Antes de irse, me gustaría que repasáramos la información».

2. Repase con lenguaje simple y claro toda la información relacionada con el método que se incluye en el folleto:

- Información general (es la misma información que en cada tarjeta de método de la ECB+)

- Cómo funciona el método

- Información importante (sobre el método)

- Afecciones para las cuales no se recomienda el método

- Efectos secundarios

- Beneficios para la salud (si corresponde)

- Cómo se usa

- Seguimiento (si corresponde)

- Cuándo regresar al centro de atención de salud

3. Asegúrese de que el/la cliente entienda por completo todos los aspectos del método que eligió. La comprensión es clave para un uso saludable y efectivo del método.

4. Entréguele el folleto al/a la cliente. Aliéntelo a que repase el folleto de nuevo en su casa y cuando necesite recordar algo sobre el método.

5. Confirme la comprensión del/de la cliente al pedirle que responda las siguientes preguntas con sus propias palabras. (El/La cliente puede consultar el folleto).

- ¿Cómo se usa el método que eligió?

- ¿Qué efectos secundarios puede experimentar con el método?

- ¿Puede el método protegerlo contra ITS, incluido el VIH?

- ¿Cuáles son los signos que indican que debe volver al centro de atención de salud?

6. Asegúrele al/a la cliente que no es un problema olvidar algunos detalles. Asegúrese de que el/la cliente pueda encontrar la información en el folleto. (Nota: Si el/la cliente no puede leer o tiene un nivel de alfabetización bajo, pídale que identifique una persona en su hogar que puede leerle la información).

7. Si el/la cliente elige un método que no se encuentra disponible en el sitio, entonces:

a. Igualmente entréguele al/a la cliente el folleto sobre el método elegido.

b. Derive al/a la cliente a un centro o instalación comercial donde pueda obtener el método.

c. Proporciónele un método alternativo y apropiado hasta que pueda obtener el método elegido.

8. Si un/una cliente selecciona un método que no está disponible temporalmente (fuera de stock), entonces:

a. Entréguele al/a la cliente un folleto sobre el método elegido.

b. Derive al/a la cliente a un centro o instalación comercial donde pueda obtener el método.

c. Proporciónele un método de respaldo hasta que pueda obtener el método elegido.

d. Pídale al/a la cliente que vuelva al centro cuando el método esté disponible en su centro de salud. 
PASO 11. ASEGÚRESE DE QUE EL/LA CLIENTE HAYA TOMADO UNA DECISIÓN DEFINITIVA.

DELE EL MÉTODO ELEGIDO, UNA REMISIÓN O UN MÉTODO DE RESPALDO, SEGÚN EL MÉTODO SELECCIONADO.

1. Pregúntele al/a la cliente si conoce su estado de VIH. Asegúrese de que el/la cliente esté satisfecho/a con el método elegido.

\begin{tabular}{|l|l|}
\hline Si la cliente... & Haga lo siguiente... \\
\hline & $\begin{array}{l}\text { 1.Entréguele el método y el folleto. } \\
\text { 2.Si elige DIU, implante, ligadura de trompas } \\
\text { o vasectomía, y no están disponibles en el lugar, } \\
\text { dele una derivación de ser necesario. }\end{array}$ \\
$\begin{array}{ll}\text { 3.Si el/la cliente no puede usar el método elegido } \\
\text { inmediatamente, proporciónele un método de } \\
\text { Está satisfecho/a con el método elegido } \\
\text { respaldo (por ejemplo, preservativos). Entréguele el } \\
\text { folleto de la ECB+ sobre preservativos. }\end{array}$ \\
$\begin{array}{l}\text { 4.Sugiera que se abstenga de tener relaciones sexuales } \\
\text { hasta que obtenga el método elegido. }\end{array}$ \\
\hline No está satisfecho/a con el método elegido y \\
desea considerar otras opciones & $\begin{array}{l}\text { 1.Asegúrele que está bien cambiar de opinión. El/La } \\
\text { cliente tiene derecho a tomar una decisión informada. } \\
\text { 2.Vuelva al paso } 7 .\end{array}$ \\
\hline
\end{tabular}

2. No deje que el/la cliente se vaya con las manos vacías. Si un método no está disponible, asegúrese que el/la cliente tenga un método de respaldo (p. ej., preservativos), una derivación y un folleto de la $\mathrm{ECB}+$ sobre preservativos.

3. Entréguele al/a la cliente el folleto del método.

\section{PASO 12. ALIENTE AL/A LA CLIENTE A INVOLUCRAR A SU PAREJA EN LAS DECISIONES SOBRE PRÁCTICAS ANTICONCEPTIVAS, YA SEA MEDIANTE UNA CHARLA O MEDIANTE UNA VISITA A LA CLÍNICA.}

1. Aliente al/a la cliente a analizar ese método anticonceptivo con su pareja.

2. Mencione que esto puede ayudar de la siguiente manera:

- Su pareja puede recordarle la hora en la que debe tomar el método, si es que toma el método regularmente, y las fechas de seguimiento.

- Puede negociar el uso de preservativos para prevenir ITS, incluido el VIH y el virus del Zika.

- Puede charlar sobre sus planes de tener hijos, sin importar su estado de VIH.

- Puede analizar y ayudar a prevenir la transmisión del VIH de madre a hijo (PTMH) durante el embarazo.

- Su pareja puede ayudarlo/a si necesita servicios de bienestar y de VIH, incluso terapia antirretroviral. 


\section{Etapa de detección sistemática para otros servicios}

Use las catorce (14) tarjetas de consejería para analizar información adicional y brindar la consejería y los servicios adicionales que puede necesitar el/la cliente.

\section{PASO 13. MEDIANTE LA INFORMACIÓN OBTENIDA CON ANTERIORIDAD, DETERMINE LA NECESIDAD DE LA CLIENTE DE RECIBIR SERVICIOS DE ATENCIÓN POSPARTO, DE CONTROL DE SALUD PARA RECIÉN NACIDOS, LACTANTES O NIÑOS, O DE POSABORTO.}

1. Considere la información que le brindó el/la cliente con anterioridad durante la sesión de consejería, incluidas sus respuestas a las preguntas del paso 3 y el paso 4.

2. Si la información no se ha mencionado todavía mediante las preguntas anteriores, hágale las siguientes dos preguntas al/a la cliente:

- ¿Ha dado a luz recientemente?

- ¿'Tiene hijos menores de 5 años?

3. Use esta información para determinar si la cliente necesita información y consejería adicional sobre servicios de atención posparto y de control de salud para recién nacidos, lactantes o niños, o la derivación a estos servicios.

4. Si la cliente informó haber dado a luz recientemente (en las últimas 6 semanas), repase los puntos a continuación que aparecen en la tarjeta de consejería Promoción de un período posparto saludable, y brinde los servicios y la consejería indicados.

- Asegúrese de que la madre tenga ayuda durante los primeros días después del nacimiento; aliente el descanso y el tiempo de sueño.

\begin{tabular}{|c|c|}
\hline Si la cliente... & Haga lo siguiente... \\
\hline Dio a luz recientemente & $\begin{array}{l}\text { 1. Repase con la cliente la tarjeta de consejería Promo- } \\
\text { ción de un período posparto saludable para la madre. } \\
\text { 2. Repase con la cliente la tarjeta de consejería Salud } \\
\text { del recién nacido y del lactante. }\end{array}$ \\
\hline Tiene hijos menores de 5 años & $\begin{array}{l}\text { 1.Pregúntele si los niños han recibido los servicios de } \\
\text { control de salud correspondientes. } \\
\text { 2. Pregúntele si los hijos recibieron todas sus vacunas. } \\
\text { 3. Pregúntele si le controlaron la altura y el peso de los } \\
\text { hijos. } \\
\text { 4.Proporcione servicios de control de salud infantil } \\
\text { o haga una derivación, según corresponda. }\end{array}$ \\
\hline
\end{tabular}

- Recomiende una dieta nutritiva para la madre que incluya mucho líquido y micronutrientes (entre ellos, vitamina A y hierro).

- Analice el sangrado posparto normal y la secreción de loquios. Oriente sobre los signos de peligro materno, como el sangrado o las secreciones vaginales con mal olor.

- Analice la necesidad de que se realicen cuatro visitas de atención posnatal: cuando hayan transcurrido de 24 a 48 horas, 3 a 7 días, 4 a 6 semanas, y de 4 a 6 meses.

- Aconseje sobre el mantenimiento de la higiene personal, incluso del perineo y las mamas.

- Aconseje sobre el regreso a la actividad sexual, que debe darse cuando la madre se sienta lista y, por lo general, cuando se dejen de secretar los loquios. Informe que puede volver a quedar embarazada incluso antes de que vuelva a tener su periodo, si no usa un método anticonceptivo.

- Aconseje sobre la depresión posparto, que puede conllevar lo siguiente: llanto fácil; cansancio, agitación o irritabilidad; falta de motivación; dificultad para dormir y rechazo al bebé.

5. Si la cliente informó haber dado a luz recientemente, repase los puntos a continuación que aparecen en la tarjeta de consejería Promoción de la salud del recién nacido y del lactante, y brinde los servicios y la consejería indicados:

- Hable sobre el lavado cuidadoso de las manos para prevenir infecciones antes de estar en contacto con el bebé y después de cambiarle los pañales.

- Oriente a la madre sobre los signos de peligro de los recién nacidos y sobre cuándo buscar atención inmediata. Los signos de peligro incluyen los siguientes: dificultad en la alimentación o la respiración; temperatura demasiado alta o baja e irritabilidad por largos períodos. 
- Analice la importancia de realizar una buena ventilación de los ambientes y de mantener al bebé tibio.

- Aliente a las madres a amamantar exclusivamente por 6 meses. No es necesario nada más, ni siquiera agua. Incorpore alimentos complementarios a los 6 meses y continúe amamantando.

- Para los lactantes expuestos al VIH:

- Aconseje a la madre para que le dé al lactante medicamentos antirretrovirales (ARV) diariamente mientras amamante y que continúe haciéndolo una semana después de dejar de amamantar (alrededor de un año), y aconséjele que continúe con los ARV según los protocolos nacionales.

- Recomiende que a las 6 semanas se le realice una prueba de detección de VIH al lactante expuesto y que comience a recibir profilaxis con cotrimoxazol (CTX).

- Ponga a la madre y al lactante en contacto con una clínica de VIH.

- Use las directrices nacionales e internacionales para explicar el programa de inmunización, y recomiende suplementos de vitamina A a los 6 meses.

- Analice la necesidad de visitar una clínica de bienestar infantil, y la importancia de recibir atención y controles oportunos durante los primeros cinco años de vida del niño. Los siguientes pueden incluirse en los servicios de controles de salud de niños:

- Vacunación

- Control del crecimiento

- Apoyo de alimentación para lactantes

- Provisión de vitamina A a los 6 meses

- Servicios para niños enfermos (incluida la Atención integrada a las enfermedades prevalentes de la infancia [AIEPI])

6. Si la cliente informó un aborto reciente, repase con ella la tarjeta Atención posaborto. Proporcione los servicios de atención posaborto necesarios o haga una derivación, según corresponda.

7. Si no puede asesorar sobre los servicios, o proporcionarlos, derive al/a la cliente a un centro apropiado en el cual pueda recibir esta información y consejería.

\section{PASO 14. PREGÚNTELE A LA CLIENTE CUÁNDO FUE SU ÚLTIMO EXAMEN DE DETECCIÓN DE CÁNCER} DE CUELLO UTERINO (IVAA/IVSL O PAPANICOLAOU) O DE CÁNCER DE MAMA.

1. Informe brevemente a la cliente sobre el cáncer de cuello uterino. Explique que el cáncer de cuello uterino:

- se produce debido al crecimiento descontrolado y sin tratamiento de células anormales en el cuello uterino;

- se origina por una infección de transmisión sexual, el virus del papiloma humano (VPH);

- tarda entre 10 y 20 años en desarrollarse, por lo que hay un largo período de oportunidad para detectar y tratar los cambios y crecimientos antes de que causen cáncer.

2. Explique a la cliente que el examen de detección de cáncer de cuello uterino:

- ayuda a detectar cualquier cambio y crecimiento precanceroso antes de que se convierta en cáncer;

- es simple, rápido y, por lo general, no provoca dolor.

3. Pregúntele a la cliente cuándo fue su último examen de detección de cáncer de cuello uterino.

4. Repase con la cliente la tarjeta de consejería Información y concienciación sobre el cáncer de mama.

\section{Si la cliente..}

Se realizó el último examen de detección hace más de 3 años

0

No sabe cuándo fue su último examen de detección

Se realizó el último examen de detección hace menos de 3 años
Haga lo siguiente.

Proporcione un examen de detección IVAA/IVSL o un Papanicolaou

o

Cuando el examen esté disponible, derive el examen de detección IVAA/IVSL o el Papanicolaou a un centro apropiado.

Informe a la cliente sobre cuándo realizarse el próximo examen de detección. 

SOBRE EL USO CORRECTO Y SISTEMÁTICO. ${ }^{1}$

1. Explíquele al/a la cliente que si tiene relaciones sexuales sin protección corre el riesgo de contraer una ITS, incluso VIH.

2. Revise los siguientes puntos de la tarjeta de consejería y evalúe el conocimiento del/de la cliente sobre ITS/VIH.

- Una persona puede infectarse con una ITS, incluido el VIH, a través de actividades sexuales inseguras y sin protección.

- Las ITS son frecuentes. El zika es común en algunas zonas.

- Una persona que vive con una ITS (incluido el VIH) puede verse saludable y no tener síntomas ni ser consciente de que está infectada.

- Los síntomas frecuentes de una ITS incluyen secreción vaginal y del pene, irritación en el área genital, ardor al orinar en el caso de los hombres y dolor en la parte abdominal baja en el caso de las mujeres.

- Algunas ITS pueden tratarse. Para evitar una reinfección, se debe tratar a ambos miembros de la pareja.

- El riesgo de infección puede reducirse usando un preservativo, limitando el número de parejas sexuales y retrasando las relaciones sexuales (adolescentes).

- El VIH es una infección de transmisión sexual (ITS). El VIH se transmite mediante el intercambio de fluidos corporales, como semen, sangre y leche materna, y durante el parto.

- Conocer su estado de VIH lo protege a usted, a su pareja y a su familia.

- Aunque el VIH no tiene cura, su identificación y tratamiento tempranos pueden permitir que una persona lleve una vida larga y productiva, y evitar que la pareja se infecte.

- La circuncisión masculina reduce el riesgo de infección heterosexual de VIH en hombres en, aproximadamente, un $60 \%$ y debe ser un elemento de un paquete de prevención de VIH integral.

- La transmisión materna del VIH al niño puede reducirse de manera sustancial al identificar a las mujeres que tienen VIH y proporcionarles tratamiento o medicamentos ARV profilácticos durante el embarazo.

3. Pregunte si el/la cliente tiene alguna duda.

4. Explíquele al/a la cliente que la protección doble previene de forma simultanea las ITS y el embarazo.

5. Use la tarjeta de consejería y revise con el/la cliente las estrategias de protección doble:

- La protección doble es el uso de preservativos de manera sistemática y correcta junto con otro método de planificación familiar. Esto proporciona protección adicional contra embarazos en caso de que el preservativo falle.

- Use preservativos masculinos o femeninos de manera correcta y sistemática en cada acto sexual. Este método protege contra una ITS y evita un embarazo.

- Solo tenga intimidad sexual segura, durante la cual se evite que el semen y los fluidos vaginales entren en contacto con los genitales u otras áreas vulnerables de la pareja, como la boca y el ano.

- Retrase o evite la actividad sexual, especialmente con parejas cuyo estado de ITS/VIH se desconoce.

6. Pregunte si el/la cliente tiene alguna duda.

7. Ofrézcale preservativos. Pregúntele al/a la cliente si sabe cómo usar un preservativo.

8. Demuestre cómo usar un preservativo, de ser necesario. Pídale al/a la cliente que repita la demostración.

9. Bríndele al/a la cliente información sobre dónde puede obtener preservativos. 
1. Pregúntele al/a la cliente si sabe qué factores lo ponen en riesgo de contraer ITS/VIH.

2. Corrija la información errónea, complétela y responda todas las preguntas.

3. Use la tarjeta de consejería y analice con el/la cliente los siguientes factores de la evaluación de riesgo:

- Estado de VIH y estado de VIH de su(s) pareja(s). Si la pareja es positivo, pregunte si toma medicamentos antirretrovirales (ARV).

- Número de parejas sexuales, tanto las actuales como las anteriores.

- Conocimiento sobre las prácticas sexuales y las parejas anteriores de su pareja.

- Conocimiento del estado de circuncisión de la pareja hombre.

- Uso actual y anterior de preservativos (incluida su percepción de la actitud de la pareja) y si es consciente de que los preservativos protegen contra ITS/VIH y evitan los embarazos.

- Tipo de sexo o actividades y conductas sexuales (por ejemplo, monogamia mutua, si la pareja tiene otras parejas sexuales, sexo oral, sexo anal, sexo seco o uso de detergentes o espermicidas).

- Situación en el hogar (por ejemplo, en lo referido a violencia de pareja y apoyo social).

- Uso de los servicios de prevención de la transmisión de madre a hijo (PTMH) durante el embarazo, el parto y la lactancia.

4. Si el/la cliente presenta síntomas de alguna ITS, deben tratarlo/a de manera sindrómica según las directrices nacionales, o bien derivarlo/a para que se realice exámenes de detección, si están disponibles.

5. Ayude al/a la cliente a elaborar un plan para reducir el riesgo. Entre las estrategias pueden incluirse las siguientes:

- Reducción del número de parejas sexuales.

- Uso de preservativos (masculinos o femeninos) de manera correcta y sistemática en cada acto sexual. Los preservativos son el único método que protege contra ITS, incluido el VIH.

- Poner preservativos a disposición de su pareja y fomentar el uso correcto y sistemático.

- Evitar el uso de instrumentos sucios y que puedan cortar la piel, o agujas.

- Detección y tratamiento inmediatos de cualquier ITS o infección de cuello uterino.

- Ejecución de cualquier procedimiento que involucre el tracto genital en un ambiente aséptico.

- Aplicación del método de protección doble.

- Conocimiento del estado de VIH.

PASO 16B. PARA LAS REGIONES CON VIRUS DEL ZIKA ACTIVO O PARA VIAJEROS EN ESAS REGIONES, REALICE UNA EVALUACIÓN DE RIESGO DE ZIKA USANDO LA TARJETA DE CONSEJERÍA.

\begin{tabular}{|c|c|}
\hline Si la cliente... & Haga lo siguiente... \\
\hline $\begin{array}{l}\text { Sabe su estado de VIH y } \\
\text { tiene VIH }\end{array}$ & $\begin{array}{l}\text { 1. Repase con el/la cliente la tarjeta de consejería Prevención, dignidad y sa- } \\
\text { lud positiva. } \\
\text { 2. Pregúntele cuándo fue la última vez que asistió a un centro de salud para } \\
\text { su visita de control. } \\
\text { 3. Derive al/a la cliente a un centro de tratamiento y atención de bienestar, si } \\
\text { es necesario. }\end{array}$ \\
\hline $\begin{array}{l}\text { Sabe su estado de VIH y } \\
\text { es negativo }\end{array}$ & 1. Establezca un plazo para volver a realizar la prueba. \\
\hline Desconoce su estado. & $\begin{array}{l}\text { 1. Hable sobre los servicios de consejería y pruebas de VIH (HCT, HIV Counsel- } \\
\text { ing and Testing) usando la tarjeta de consejería. } \\
\text { 2. Ofrézcale o hágale una prueba, según los protocolos nacionales. } \\
\text { 3. Asesore al/a la cliente sobre los resultados de la prueba. } \\
\text { 4. Si el/la cliente tiene VIH, repase con el/ella la tarjeta de consejería Pre- } \\
\text { vención, dignidad y salud positiva, y derívelo/a a un centro de tratamiento } \\
\text { y atención de bienestar. }\end{array}$ \\
\hline
\end{tabular}




\section{PASO 17. PREGÚNTELE AL/A LA CLIENTE SI CONOCE SU ESTADO DE VIH.}

1. Pregúntele al/a la cliente si conoce su estado de VIH.

2. Pregunte delicadamente si el/la cliente está dispuesto/a a darle a conocer su estado de VIH.

3. Infórmele al/a la cliente que no divulgará su estado sin su consentimiento.

Si el/la cliente conoce su estado de VIH y tiene VIH:

1. Repase los siguientes puntos de la tarjeta de consejería Prevención, dignidad y salud positiva.

- Las personas con VIH siempre deben usar un preservativo de forma correcta y sistemática con sus parejas sexuales.

- Si una mujer con VIH desea quedar embarazada, el riesgo de contagiarle VIH al recién nacido puede reducirse significativamente al tomar medicamentos antirretrovirales (ARV) y mediante un parto seguro. Es importante recibir atención en una clínica de atención prenatal y un centro de tratamiento de VIH.

- Las personas que viven con VIH necesitan chequeos de salud regulares para determinar si necesitan medicamentos ARV, para evaluar el tratamiento con los ARV y para descartar otras infecciones o enfermedades.

- Si un/a cliente toma algún ARV, debe asistir a las visitas de seguimiento en la clínica, según la recomendación del proveedor. Cuando el/la cliente comienza a tomar medicamentos ARV, las visitas pueden ser más frecuentes.

- El/La cliente debe hacer lo mejor posible por respetar el régimen de medicación prescrito y no debe compartir sus medicamentos.

- Las parejas también deben realizarse los exámenes de detección. El/La cliente puede traer a su pareja para recibir consejería y hablar, si es de ayuda.

- Si actualmente toma medicamentos para el tratamiento de la tuberculosis, debe realizar el seguimiento correspondiente con el proveedor.

- La salud positiva se logra al cuidar de uno mismo y al estar alerta a las inquietudes de salud que requieren de atención, entre las que pueden incluirse temas de salud física y mental, así como de apoyo social.

2. Brinde al/a la cliente apoyo y consejería sobre temas relacionados con la divulgación del estado de VIH. Aliente al/a la cliente a divulgar su estado para ayudarle a lo siguiente:

- Obtener apoyo del cónyuge, la familia del/de la cliente y de algún centro de salud.

- Planear mejor y tomar decisiones apropiadas sobre la atención y el apoyo del VIH, y sobre asuntos familiares.

- Obtener acceso temprano a medicamentos y ayuda para mantener al/a la cliente saludable.

- Salvar la vida de una pareja VIH negativo y la de un niño que aún no ha nacido al no infectarlos.

- Negociar mejor el uso de preservativos con la pareja del/de la cliente para evitar que se infecte.

- Evitar la exposición a infecciones repetidas que comprometerán la salud del/de la cliente.

3. Pregúntele cuándo fue la última vez que asistió a un centro de salud para su visita de control. Aliente al/a la cliente a seguir todas las recomendaciones de salud y bienestar.

4. Derive al/a la cliente a un centro de tratamiento y atención de bienestar.

Si el/la cliente conoce su estado de VIH y es negativo:

1. Establezca un plazo para volver a realizar la prueba. Considerar la evaluación de riesgo y las conductas sexuales del/de la cliente para decidir la frecuencia más apropiada para realizar las pruebas de detección de VIH.

2. Consulte los protocolos y directrices nacionales para determinar el período apropiado y las recomendaciones para volver a realizar la prueba de VIH.

3. Durante la vista del/de la cliente, haga hincapié en que la prevención, la detección temprana y el tratamiento rápido de ITS, incluido el VIH, como pilares provechosos para los clientes, sus familias y para la comunidad en general. 


\section{Si el/la cliente desconoce su estado de VIH:}

1. Use la tarjeta Consejería y pruebas de VIH y analice con el/la cliente los siguientes puntos:

- Saber su estado de VIH puede ayudarlo/a a tomar decisiones sobre cómo protegerse a usted mismo/a y a sus parejas sexuales.

- Las pruebas de detección permiten que las personas que viven con VIH reciban tratamiento para que puedan vivir una vida plena. La prueba incluye la extracción de una muestra de sangre pequeña. La prueba es gratuita y se encuentra disponible en clínicas, hospitales y centros de consejería y pruebas de VIH.

- Los resultados de las pruebas se mantienen en estricta confidencialidad.

- Cuando una persona se infecta con VIH, pueden pasar 3 meses o más hasta que la prueba detecte la infección. Esto se denomina «período ventana» y es la razón por la que es tan importante repetir la prueba.

- Un resultado positivo significa que la persona se encuentra infectada con VIH y puede transmitirle el virus a otros.

- Un resultado negativo puede significar que la persona no se encuentra infectada o que se encuentra en el «período ventana». Debe realizarse otra prueba en el plazo de 3 meses. Si la segunda prueba también es negativa, la persona no tiene VIH, pero aún puede infectarse con el virus.

- El VIH es una infección de transmisión sexual (ITS). Es importante pedirle a su(s) pareja(s) sexual(es) que también se haga(n) una prueba.

2. Durante la vista del/de la cliente, haga hincapié en que la prevención, la detección temprana y el tratamiento rápido de ITS, incluido el VIH, como pilares provechosos para los clientes, sus familias y para la comunidad en general.

3. Ofrézcale o hágale una prueba, según los protocolos nacionales. Si la prueba no se encuentra disponible, derive al/a la cliente a servicios de HTC de especialidad.

4. Asesore al/a la cliente sobre los resultados de la prueba de VIH.

- Si el resultado es positivo, repase con el/ella la tarjeta de consejería Prevención, dignidad y salud positiva, y derívelo/a a un centro de tratamiento y atención de bienestar.

Asesore a la cliente usando la tarjeta Seguridad y apoyo a la mujer.

1. Si la cliente presenta signos graves que indiquen que puede ser víctima de violencia infligida por la pareja, derívela a servicios especializados.

\section{PASO 18. PROPORCIONE INSTRUCCIONES DE SEGUIMIENTO, UN FOLLETO SOBRE PRESERVATIVOS} Y UN FOLLETO SOBRE EL MÉTODO ESCOGIDO. FIJE UNA FECHA PARA LA PRÓXIMA VISITA.

1. Resuma los puntos clave analizados en relación con el método anticonceptivo elegido y sobre ITS/VIH y otros servicios. Pregúntele al/a la cliente si tiene alguna duda. Responda todas las preguntas antes de continuar.

En 2007, la OMS y ONUSIDA publicaron una guía de consejería y pruebas de VIH iniciadas por el proveedor (PITC) en los centros de salud para respaldar un mayor acceso a la prevención, el tratamiento y la atención contra el VIH, y mejorar estos aspectos. Para aumentar y mejorar el acceso a la prevención contra el VIH, los servicios de consejería y pruebas de VIH (HCT, HIV counseling and testing) deben expandirse al cuidado prenatal, a las clínicas de tratamiento de ITS y TB y a otros entornos clínicos, así como mediante el compromiso con la mayoría de las poblaciones en riesgo.

2. Bríndele al/a la cliente instrucciones de seguimiento para el método elegido, junto con el folleto de método correspondiente (si el/la cliente aún no tiene uno).

3. Entréguele al/a la cliente el folleto sobre preservativos. Reitere que solo los preservativos proporcionan protección doble contra las ITS, incluido el VIH, y embarazos.

4. Asegúrese de que el/la cliente tenga su método o un método de respaldo y una derivación, según sea necesario. 
5. Reitere la importancia de buscar otros servicios recomendados y brinde al/a la cliente una derivación apropiada.

6. Establezca con el/la cliente una fecha para la próxima visita. El propósito de tal consulta puede ser el siguiente:

- Comprobar cómo el/la cliente usa el método.

- Proporcionar un nuevo suministro del método.

- Proporcionar la información y el apoyo necesarios para que el/la cliente continúe el uso correcto y sistemático del método, o para seleccionar otro método.

- Traer a la pareja para consejería adicional sobre planificación familiar o ITS/VIH.

- Realizarse una prueba de VIH.

7. Alentar al/a la cliente a que vuelva al centro de atención de salud cada vez que tenga una pregunta o deseos de cambiar de método.

8. En la medida de lo posible, anticipe las necesidades futuras del/de la cliente.

\section{RECUERDE}

Un/a cliente tiene el derecho a cambiar sus objetivos en materia de reproducción y a dejar de usar el método de planificación familiar si lo desea o cuando desee tener un hijo.

\section{EJEMPLO}

Explíquele a una cliente que usa la píldora que, de ser más conveniente para ella, puede obtener el suministro en una farmacia local. Recuérdele que es posible que la farmacia tenga paquetes de 21 píldoras, en lugar de los paquetes de 28. En este caso, necesitará seguir las instrucciones de uso que se encuentran en el folleto o prospecto del paquete de píldoras.

PASO 19: AGRADÉZCALE POR SU VISITA. COMPLETE LA SESIÓN DE CONSEJERÍA.

1. Al finalizar la sesión, recuerde ser cálido y cordial. Esta actitud alentará al/a la cliente a sentirse bienvenido a volver. 


\section{Directrices para adaptar las ayudas de trabajo de la ECB+}

Las ayudas de trabajo de la ECB + son genéricas y pueden revisarse según las normas y las necesidades de una región o un país determinados. A continuación, se proporcionan las directrices para adaptar las ayudas de trabajo.

1. Lleve a cabo una revisión técnica de las normas y prácticas de planificación familiar y HCT en su región o país. A continuación, se incluyen algunos ejemplos de los tipos de revisión que le ayudarán a brindar la información apropiada y necesaria para adaptar la ECB + y las ayudas de trabajo de la $\mathrm{ECB}+$ a sus necesidades.

a. Concierte una reunión con representantes del Ministerio de Salud y con otros expertos en planificación familiar y HCT para repasar la ECB + . Determine si necesita adaptarse para incluir las normas y políticas de su país sobre planificación familiar, servicios de salud integrados y HCT.

b. Pídale a los proveedores de servicios con experiencia en consejería sobre planificación familiar y HCT de VIH que revisen el contenido de las ayudas de trabajo de la ECB+.

c. Si las ayudas de trabajo acompañarán la capacitación, trabaje con los instructores para definir las competencias (habilidades) deseadas obtenidas a partir de la capacitación que deben incorporarse a la ayuda de trabajo.

2. Decida si existen problemas regionales o locales que le gustaría incorporar a la estrategia de la ECB+ (p. ej., accesibilidad a ciertos métodos, vulnerabilidad al VIH y a las ITS por matrimonio temprano, mutilación genital femenina o la práctica de sexo seco).

3. De acuerdo con los resultados de la revisión técnica y las normas locales del país, revise los pasos de la $\mathrm{ECB}+$, según sea necesario. Si se revisa la $\mathrm{ECB}+$, asegúrese de obtener información para ajustar el algoritmo, las tarjetas de consejería y los folletos de manera consecuente.

4. Revise las ayudas de trabajo de la ECB+ según la revisión técnica. A continuación, se proporcionan directrices simples para adaptar las ayudas de trabajo:

a. Ajústese al formato existente de las ayudas de trabajo de la ECB + tanto como sea posible. Se han escrito con una metodología muy específica que ha sido probada en el campo y que se ha demostrado que ayuda a los proveedores a actuar de manera efectiva a partir de las instrucciones.

b. Si añade/revisa los pasos del algoritmo, escríbalos usando verbos de acción. Por ejemplo, - Pregúntele a la cliente si ha tenido su menstruación.

- Recuérdele a la cliente que tome la píldora todos los días a la misma hora.

c. Incluya todo subpaso necesario para llevar a cabo el paso. No suponga que el proveedor sabe cómo realizar el paso o la tarea deseada. Comience cada subpaso con una acción.

\section{EJEMPLO}

Paso: Recuérdele a la cliente qué debe hacer si omite una vez la píldora.

Subpasos:

- Tome la píldora en cuanto sea posible

- Continúe tomando las píldoras de la manera habitual (es posible que termine tomando 2 píldoras al mismo tiempo o el mismo día).

d. Si un proveedor de servicios necesita que la toma de una decisión sea parte de un paso, elabore una tabla de decisiones. Una tabla de decisiones tiene dos columnas. La primera columna (la columna «Si») describe cuándo realizar la acción. La segunda columna (la columna «Entonces») se usa para describir la acción que se debe realizar. Al redactar las acciones, use el formato de receta de cocina que se usa en los pasos 1, 2, 3, etc. Comience todos los pasos de acción con verbos de acción. Por ejemplo:

\section{Si la cliente...}

Está amamantando a un lactante de menos de 6 meses

No está amamantando a un lactante

\section{Haga lo siguiente...}

1. Aparte la tarjeta Anticonceptivos orales combinados (Píldora) y explique que las hormonas en las píldoras afectan la lactancia.

2.Analice la opción de la minipíldora.

1. Aparte la tarjeta Método de amenorrea de la lactancia.

2. Explique que el método MELA no es apropiado para mujeres que no amamantan. 
e. Si los pasos y los subpasos son secuenciales, enumérelos. Si el orden de los pasos no es importante, use viñetas en vez de números.

\section{CONSEJO}

Coloque en una caja la información importante que no constituya un paso o un subpaso.

5. Haga una prueba previa (legitime) de las ayudas de trabajo de la ECB+.

a. Pídale a los proveedores de servicios con experiencia en planificación familiar y HCT que usen las ayudas de trabajo revisadas en la consejería de varios clientes de planificación familiar.

b. Observe si siguen las instrucciones que aparecen en las ayudas de trabajo.

c. Tome nota de las acciones no realizadas por el proveedor (que se encuentran en la ayuda de trabajo). Tras la sesión de consejería, pregúntele al proveedor por qué no realizó la acción descrita. Asegúrese de explorar lo siguiente:

- Si entendió el paso/la tarea.

- Si está en desacuerdo con el paso/subpaso y por qué.

- Si las instrucciones son claras o confusas. Si fueron confusas, pregunte de qué manera podrían aclararse.

d. De manera similar, tome nota de las acciones que el trabajador de salud haya añadido a la sesión de consejería y que no se encuentren en las ayudas de trabajo.

e. Pregúntele por qué añadió esos pasos adicionales que no estaban en las ayudas de trabajo. Es posible que el proveedor de servicios haya añadido un paso para lograr claridad. En ese caso, añada el paso a la ayuda de trabajo. La idea es describir el comportamiento deseado por parte del proveedor de servicios para que este pueda usar la $\mathrm{ECB}+$ revisada de manera precisa.

f. Revise las instrucciones a partir de las pruebas previas realizadas con varios proveedores de servicios.

g. Añada o elimine pasos/tareas o pasos/subpasos para permitir que el proveedor lleve a cabo la ECB+ de la manera más efectiva.

6. Pídales a dos o tres proveedores de servicios con menos experiencia que usen las ayudas de trabajo de la $\mathrm{ECB}+$ revisadas y observe si pueden realizar las tareas a partir de las instrucciones que aparecen en las ayudas de trabajo.

7. Revise las ayudas de trabajo en consecuencia. Tome en consideración todo comentario adicional que los proveedores de servicios le hagan en cuanto a cómo mejorar las instrucciones.

8. De ser necesario, haga traducir las ayudas de trabajo revisadas al idioma local. Asegúrese de que otra persona las vuelva a traducir al idioma original para asegurarse de que su significado no se haya modificado durante el proceso de traducción.

9. Incorpore el uso de las ayudas de trabajo a las capacitaciones existentes o desarrolle un curso breve para mostrarle a los proveedores de servicios cómo usarlas.

\section{IMPORTANTE:}

Una ayuda de trabajo siempre debe verse acompañada de capacitación de respaldo. 


\section{Referencias}

Askew, Ian. 2007. «Achieving synergies in prevention through linking sexual and reproductive Health and HIV services» [Logrando sinergias en prevención a través de la combinación de la salud reproductiva y sexual, y los servicios de VIH], en Donta, Balaiah et al. (eds.), Proceedings of the International Conference on Actions to Strengthen Linkages between Sexual and Reproductive Health and HIV/AIDS. Mumbai: Sociedad India para el Estudio de la Reproducción y la Fertilidad y la Organización Mundial de la Salud.

Agencia Central de Estadística (CBS, Central Bureau of Statistics) [Kenia], Ministerio de Salud (MDS) [Kenia] y ORC Macro. 2004. Encuesta Demográfica y de Salud en Kenia 2003. Calverton, Maryland: CBS, MDS y ORC Macro.

Engenderhealth y Planned Parenthood Association de Sudáfrica. 2001. Plan de estudios titulado: Men As Partners: A Program for Supplementing the Training of Life Skills Educators, 2nd Edition. [Hombres como parejas: Un programa para complementar la capacitación de educadores de habilidades para la vida, 2. ${ }^{a}$ edición] Nueva York: Engenderhealth y Planned Parenthood de Sudáfrica. 2002.

Hatcher, R.A. et al. 2011. Contraceptive Technology [Tecnología Anticonceptiva]. Edición 20.a revisada. Nueva York: Ardent Media.

León, Federico R. 1999. «Peru: Providers’ compliance with quality of care norms [Perú: Cumplimiento de los proveedores con las normas de calidad de atención]», Informe final de FRONTERAS. Washington, DC: Population Council.

León, Federico R. et al. 2001. «Length of counseling sessions and the amount of relevant information exchanged: A study in Peruvian clinics [Duración de las sesiones de consejería y cantidad de información relevante proporcionada: Un estudio en clínicas peruanas]», International Family Planning Perspectives 27(1):28-33, 46.

León, Federico R. et al. 2003a. «Effects of IGSS’s job aids-assisted balanced counseling algorithms on quality of care and client outcomes (Guatemala) [Efectos de las ayudas de trabajo de los algoritmos de consejería balanceada en la calidad de atención y en los resultados con los clientes del IGSS] (Guatemala)», Informe final de FRONTERAS. Washington, DC: Population Council.

León, Federico R. et al. 2003b. «Enhancing quality for clients: Balanced Counseling Strategy [Mejorando la calidad para los clientes: Estrategia de Consejería Balanceada]», Documento de Programas n. ${ }^{\circ} 3$. Washington, DC: Population Council.

León, Federico R. et al. 2003c. «Testing balanced counseling to improve provider-client interaction in Guatemala's MOH clinics [Prueba de la consejería balanceada para mejorar la interacción clienteproveedor en las clínicas del MSPAS de Guatemala]», Informe Final de FRONTERAS. Washington, DC: Population Council.

León, Federico R. et al. 2004. «One-year client impacts of quality of care improvements achieved in Peru [Impactos en la calidad de atención a clientes logrados en un año en Perú]», Informe Final de FRONTERAS. Washington, DC: Population Council.

León, Federico, Ricardo Vernon, Antonieta Martin y Linda Bruce. 2008.

Estrategia de Consejería Balanceada: Un paquete de herramientas para proveedores de servicios de planificación familiar. Washington, DC: Population Council. 
Liambila, Wilson et al. 2008. «Feasibility, effectiveness and cost of models of integrating counseling and testing for HIV within family planning services in Kenya [Viabilidad, efectividad y costos de los modelos para la integración de la consejería y pruebas de VIH a los servicios de planificación familiar en Kenia]», Informe Final de FRONTERAS. Washington, DC: Population Council.

Mullick, Saiqa, Mantshi Menziwa, Doctor Khoza, and Edwin Maroga. 2008. «Feasibility, effectiveness and cost of models of integrating counseling and testing for HIV within family planning services in North West Province, South Africa [Viabilidad, efectividad y costos de los modelos para la integración de la consejería y pruebas de VIH a los servicios de planificación familiar en la provincia noroeste, Sudáfrica]», Informe Final de FRONTERAS. Washington, DC: Population Council.

Stanback J. et al. 1999. «Checklist for ruling out pregnancy among family planning clients in primary care [Lista de verificación para descartar el embarazo en las clientes de planificación familiar en atención primaria de salud]», Lancet 354(9178):566.

Organización Mundial de la Salud. 2003. Guías para el tratamiento de las infecciones de transmisión sexual. Ginebra: OMS.

—. 2004. Criterios médicos de elegibilidad para el uso de anticonceptivos. 3. ${ }^{a}$ ed. Ginebra: OMS.

— . 2005. Infecciones de transmisión y otras infecciones del tracto reproductivo: Una guía para la práctica básica. Ginebra: OMS.

—. 2015. Criterios médicos de elegibilidad para el uso de anticonceptivos. 5. a ed. Ginebra: OMS.

— . 2010. WHO Technical Consultation on Postpartum and Postnatal Care [Consulta técnica sobre atención posparto y posnatal de la OMS]. Ginebra: OMS.

— . 2016. Prevención de la transmisión sexual del virus de Zika: Orientaciones provisionales. OMS/ ZIKV/MOC/16. 1 Rev. 3

Organización Mundial de la Salud, Departamento de Salud Reproductiva e Investigación (OMS/ISR) y la Johns Hopkins Bloomberg School of Public Health/Center for Communication Programs (JHU/CCP) Proyecto INFO. 2011. Planificación Familiar: Un manual mundial para proveedores. Baltimore y Ginebra: JHU/CPC y OMS.

Organización Mundial de la Salud y Programa Conjunto de las Naciones Unidas sobre VIH/SIDA (ONUSIDA) Guía sobre los servicios de consejería y pruebas de VIH iniciadas por el proveedor en centros de salud. Ginebra: OMS. 
El Population Council aborda problemas críticos relacionados con la salud y el desarrollo, que van desde frenar la propagación del VIH hasta mejorar la salud reproductiva y garantizar que los jóvenes tengan una vida plena y productiva. A través de investigaciones en biomedicina, ciencias sociales y salud pública en 50 países, trabajamos con nuestros socios para entregar soluciones que se traducen en políticas y programas más efectivos, y en tecnologías que mejoren vidas alrededor del mundo. Establecido en 1952, y con sede central en Nueva York, Project Council es una organización no gubernamental sin fines de lucro regida por un consejo administrativo internacional.

Para obtener información adicional, comuníquese con:

Population Council

4301 Connecticut Ave., NW, Suite 280

Washington, DC 20008 USA

Teléfono: (202) 237-9400

Fax: (202) 237-8410

Correo electrónico: publications@popcouncil.org 
Estrategia de Consejería Balanceada Plus Un paquete de herramientas para proveedores de servicios de planificación familiar que trabajan en entornos con alta prevalencia de ITS/VIH

\section{GUÍA DEL INSTRUCTOR}

Tercera edición, 2015 
(C) 2008, 2011, 2015 The Population Council, Inc.

El Population Council aborda problemas críticos relacionados con la salud y el desarrollo, que van desde frenar la propagación del VIH hasta mejorar la salud reproductiva y garantizar que los jóvenes tengan una vida plena y productiva. A través de investigaciones en biomedicina, ciencias sociales y salud pública en 50 países, trabajamos con nuestros socios para entregar soluciones que se traducen en políticas, programas y tecnologías más efectivos que mejoren vidas alrededor del mundo. Establecido en 1952, y con sede central en Nueva York, Project Council es una organización no gubernamental sin fines de lucro regida por un consejo administrativo internacional.

Cualquier parte de esta publicación puede fotocopiarse sin autorización del editor, siempre que las copias se distribuyan de forma gratuita y se proporcione la cita completa de la fuente. El Population Council agradecería recibir una copia de todo material en el cual se incluya este texto.

Cita sugerida: Population Council. 2015. Guia del instructor de la Estrategia de Consejería Balanceada Plus, tercera edición, parte de la Estrategia de Consejería Balanceada Plus: Un paquete de berramientas para proveedores de servicios de planificación familiar que trabajan en entornos con alta prevalencia de ITS/VIH, tercera edición, Washington, DC.

El proyecto Knowledge for Health II (K4Health [Conocimiento para la salud]) (AID-OAA-A-13-00068) adaptó este contenido con el permiso de Population Council y con el apoyo de los ciudadanos estadounidenses a través de la Agencia de los Estados Unidos para el Desarrollo Internacional (USAID, por sus siglas en inglés). El contenido de este material adaptado es responsabilidad exclusiva de la fuente original, y no refleja los puntos de vista de la USAID ni del Gobierno de los Estados Unidos. El material original se encuentra aquí: http://www.popcouncil.org/research/the-balanced-counseling-strategy-plus-a-toolkit-for-family-planning-service.

Nota: Esta publicación es parte de un paquete de publicaciones titulado Estrategia de Consejería Balanceada Plus: Un paquete de herramientas para proveedores de servicios de planificación familiar que trabajan en entornos con alta prevalencia de ITS/VIH. El paquete de herramientas de la Estrategia de Consejería Balanceada Plus consta de lo siguiente:

- Algoritmo

- Tarjetas de consejería

- Folletos de métodos

- Guía del usuario

- Guía del instructor

- Rueda con los criterios médicos de elegibilidad para el uso de anticonceptivos de la OMS

Si alguna de las partes no está incluida con el material, comuníquese con el Population Council enviando un correo electrónico a publications@popcouncil.org. 


\section{Prefacio de la tercera edición}

El paquete de herramientas de la Estrategia de Consejería Balanceada Plus (ECB+) se desarrolló y probó en Kenia (del 2005 al 2007) y en Sudáfrica (del 2004 al 2006) debido a que ambos países tienen altas tasas de infecciones de transmisión sexual (ITS), incluido el virus de la inmunodeficiencia humana (VIH), y sus tasas de prevalencia de anticonceptivos son relativamente altas para la región. En la ECB+, se proporciona la información y los materiales que los proveedores de los centros de atención de salud necesitan para brindar consejería de planificación familiar completa y de calidad a clientes que viven en áreas con altas tasas de ITS y VIH. La ECB+ se adaptó de la Estrategia de Consejería Balanceada (León 1999; León et al. 2003a, b, c; León, Vernon, Martin y Bruce 2008). La primera edición de los paquetes de herramientas de la Estrategia de Consejería Balanceada y de la Estrategia de Consejería Balanceada Plus son producto del programa FRONTERAS del Population Council, con apoyo de la Agencia de los Estados Unidos para el Desarrollo Internacional (USAID, United States Agency for International Development), acuerdo cooperativo HRN-A-00-98-00012-00.

La segunda edición se actualizó según los Criterios médicos de elegibilidad (CME) de 2010 de la Organización Mundial de la Salud (OMS) y según recomendaciones de autores y socios, quienes experimentaron, evaluaron y legitimaron la implementación de la herramienta en entornos y escenarios alrededor del mundo mediante el programa Integra Initiative, el cual contó con el apoyo de la Fundación Bill y Melinda Gates. Esta edición incluyó tarjetas de consejería adicionales sobre detección de cáncer de cuello uterino y salud infantil y de posparto.

En la tercera edición de la ECB+, se incluye contenido actualizado de acuerdo con los últimos Criterios médicos de elegibilidad de la OMS (2015). Incorpora la evidencia más actualizada sobre indicaciones clínicas para proporcionar métodos de planificación familiar, e incluye nuevos métodos (diafragma y anillo vaginal de progesterona Caya ${ }^{\circledR} /$ SILCS) y seis nuevas tarjetas de consejería sobre consejería para adolescentes, servicios para hombres, atención posaborto, apoyo y seguridad para mujeres, información y concienciación sobre el cáncer de mama, y prevención y tratamiento del virus del Zika. Las tarjetas actualizadas incluyen instrucciones para guiar a los proveedores en la consejería adicional y los servicios que puedan necesitar los clientes de la planificación familiar. El desarrollo de esta tercera edición del paquete de herramientas de la ECB+ recibió la financiación de Evidence Project, mientras que el acuerdo cooperativo AID-OAA-A-13-00087 de USAID y la Fundación Bill y Melinda Gates apoyaron el programa Integra Initiative en el Population Council. 
El desarrollo de la Estrategia de Consejería Balanceada Plus (ECB+) no hubiese sido posible sin el invalorable apoyo de los proveedores de servicios que pusieron a prueba el paquete de herramientas y de los directores de programas que autorizaron y supervisaron la aplicación de este paquete. Los autores desean agradecer al Departamento de Salud de Sudáfrica, a la División de Salud Reproductiva y al Programa Nacional de Control del SIDA y las ETS del Ministerio de Salud de Kenia. También agradecemos a los instructores de la Unidad de Salud Reproductiva e Investigación sobre el VIH (RHRU, Reproductive Health and HIV Research Unit) de la Universidad de Witwatersrand por su contribución al estudio en Sudáfrica.

Population Council apoyó el desarrollo y la producción de la tercera edición de la Estrategia de Consejería Balanceada Plus. Los autores agradecen a las siguientes personas por proporcionar su experiencia y sus contribuciones invalorables a esta edición actualizada de la ECB+: Megan Christofield, Heather Clark, Mychelle Farmer, Kamlesh Giri, Joanne Gleason, Mark Hathaway, Anushka Kalyanpur, Maggie Kilbourne-Brook, Karen R. Kirk, Ricky Lu, Ruth Merkatz, Charity Ndigwa, Anne Pfitzer, Saumya RamaRao, Naomi Rijo, Elizabeth Rochette, Jill Schwartz, Leigh Stefanik, John Townsend, Chi-Chi Undie, Katie Unthank, Anneka Van Scoyoc, Charlotte Warren, Ellen Weiss y Kelsey Wright. 


\section{Índice}

INTRODUCCIÓN

Algoritmo para el uso de la Estrategia de Consejería Balanceada Plus...............................7

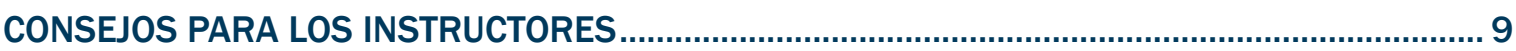

Ejemplo de cronograma: Capacitación de la ECB+ .......................................................... 11

CAPACITACIÓN PARA PROVEEDORES DE PLANIFICACIÓN FAMILIAR SOBRE LA ECB+ ..........12

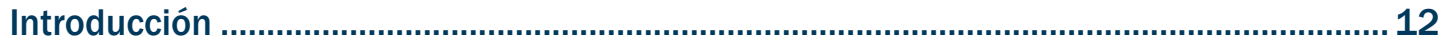

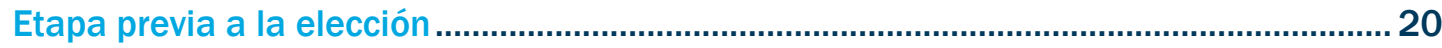

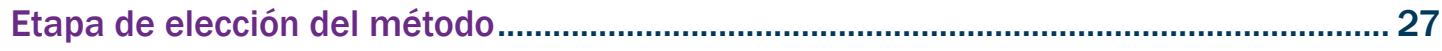

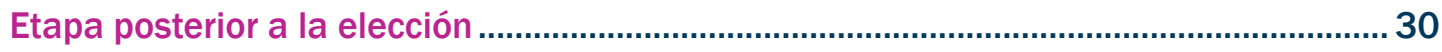

Etapa de detección sistemática para otros servicios ......................................................... 33

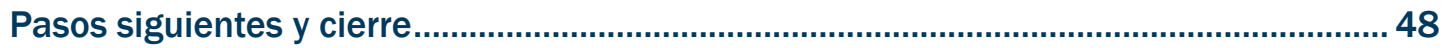

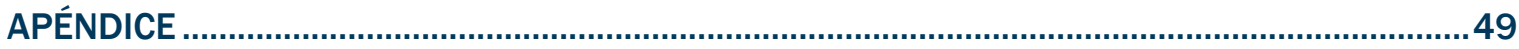

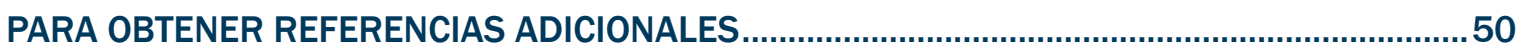

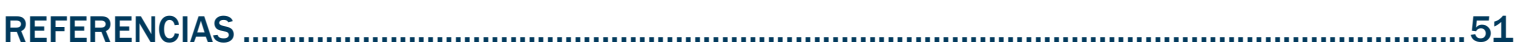


A fines de la década de 1990, el Population Council trabajó en colaboración con los ministerios de salud de distintos países latinoamericanos, para desarrollar y probar una estrategia práctica, interactiva y amigable con los clientes con la cual mejorar la consejería dentro de las consultas sobre planificación familiar en el marco del programa Fronteras de la salud reproductiva (FRONTERAS) patrocinado por la Agencia de los Estados Unidos para el Desarrollo Internacional (USAID). Esta estrategia se llama Estrategia de Consejería Balanceada (ECB) (León 1999; León et al. 2004). En la ECB, se usan ayudas de trabajo clave para aconsejar a los clientes sobre planificación familiar: un algoritmo que sirve como guía para el proveedor a través del proceso de consejería, un conjunto de tarjetas de consejería para métodos anticonceptivos y los folletos correspondientes a cada método. La estrategia, probada y perfeccionada en diversos países, consta de una serie de pasos para determinar el método anticonceptivo que mejor se adapte al/a la cliente, según sus preferencias y necesidades. Esta estrategia mejora la calidad de la consejería del proveedor y permite que el/la cliente tome su propia decisión.

La ECB probó ser efectiva como una herramienta para asistir a los proveedores de planificación familiar a mejorar la calidad de atención (León et al. 2003a, b, c). Este enfoque es práctico, económico y de fácil adaptación a los contextos de cada localidad. Estrategia de Consejería Balanceada: Un paquete de herramientas para proveedores de servicios de planificación familiar se publicó con el fin de proporcionar la información y las herramientas necesarias para que los administradores, los supervisores y los proveedores de servicios de centros de salud implementen la ECB en sus servicios de planificación familiar (León, Vernon, Martin, and Bruce 2008).

\section{¿POR QUÉ USAR LA ESTRATEGIA DE CONSEJERÍA BALANCEADA PLUS?}

En respuesta a la necesidad de incorporar consejería, exámenes de detección y servicios para las infecciones de transmisión sexual (ITS), incluido el VIH, a las consultas sobre planificación familiar de rutina en entornos caracterizados por una alta prevalencia de estas infecciones, la ECB se revisó para incorporar consejería sobre la prevención de ITS/VIH, evaluación de riesgos, y consejería y pruebas de VIH (HCT, HIV counseling and testing). El resultado fue el paquete de herramientas de la Estrategia de Consejería Balanceada Plus (ECB+), el cual mejora la calidad del servicio de planificación familiar y les permite a los proveedores satisfacer las necesidades de sus clientes relacionadas con las ITS y el VIH en la misma consulta.

La integración de los servicios de salud se define como ofrecer una gama de servicios que puedan satisfacer varias necesidades simultáneamente, por lo general en el mismo centro y a través de un mismo proveedor. Las derivaciones o las conexiones a servicios relacionados permiten que el/la cliente reciba una gama de servicios necesarios, incluso si no se reciben simultáneamente (Askew, 2007). En la salud reproductiva, el esfuerzo por la integración o conexión está dado por los clientes que necesitan distintos servicios simultáneamente (por lo que puede reducirse la cantidad de oportunidades perdidas) y por la expectativa de que los servicios se pueden proporcionar de forma más eficiente cuando se integran o conectan que cuando se proporcionan por separado. A pesar de los muchos pedidos para que se le dé mayor importancia a la integración de estos servicios en entornos con alta prevalencia de ITS/VIH, sorprendentemente se le ha prestado muy poca atención al desarrollo y a las pruebas empíricas de las herramientas prácticas que los proveedores usan para reforzar su capacidad de ofrecer servicios integrados.

El programa FRONTERAS desarrolló y probó la ECB+ en Kenia (del 2005 al 2007) y en Sudáfrica (del 2004 al 2006) debido a que ambos países tienen altas tasas de ITS, incluido el VIH, y sus tasas de prevalencia anticonceptiva son relativamente altas para la región. Esta situación brinda oportunidades para comunicarse con una proporción sustancial de la población sexualmente activa (si bien mayormente son mujeres) que busca prevenir los embarazos y que, también, está en riesgo o expuesta a una ITS/ VIH. Como en la mayoría de los países, sus programas de ITS/VIH y de planificación familiar se implementan por separado, aunque ambos países buscan activamente formas de integrar ambos servicios. Ambos ministerios de salud deseaban desarrollar herramientas prácticas para mejorar la calidad de los servicios y la cantidad de clientes que recibían servicios integrados.

Los resultados del estudio se describen con mayor detalle en otra parte (consulte Liambila et al. 2008; Mullick et al. 2008). Ambos estudios demostraron lo siguiente:

- La integración de la consejería sobre prevención de ITS/VIH y la evaluación de riesgos con la oferta de HCT durante las consultas de planificación familiar es posible y aceptable para los clientes y proveedores. 
- La calidad de la atención tanto para la planificación familiar como para la consejería de ITS/ VIH mejoró significativamente con el uso de las herramientas de la ECB+.

- El servicio de HCT mejoró considerablemente. En Kenia, se ofreció el servicio de HCT a más del 40 por ciento de los clientes, y alrededor de la mitad decidió realizarse una prueba, ya sea en el lugar o mediante una derivación. En Sudáfrica, la cantidad de personas a las que se les ofreció una prueba aumentó a un 29 por ciento. Además, se observó un aumento general en el distrito, en el cual se duplicó la cantidad de individuos que se realizaron una prueba.

- El uso de las herramientas de la ECB+ facilitó una mayor evaluación de riesgo para las ITS y el VIH. Asimismo, las decisiones sobre la elección de un método anticonceptivo se realizaron con un mejor entendimiento de su relación con la prevención de infecciones.

- A pesar de la preocupación de que al incorporar estos servicios pueda haber un impacto negativo en el servicio de planificación familiar, la mejora en la calidad de la consejería y la falta de evidencias de una disminución en el uso demostraron que esta preocupación era infundada.

\section{ESTRATEGIA DE CONSEJERÍA BALANCEADA PLUS}

$\mathrm{La} \mathrm{ECB}+$ se divide en cuatro etapas de consejería. Cada etapa cuenta con una secuencia de pasos a seguir. En la $\mathrm{ECB}+$, se asume que el motivo de la visita del/de la cliente es la planificación familiar, pero también ofrece al/a la cliente servicios y consejería adicional en el mismo centro, o mediante una derivación. En la ECB+, se integran mensajes de consejería posparto para garantizar la salud de la madre y del lactante, una oportunidad para analizar un período saludable para el embarazo y el espaciamiento entre embarazos, consejería sobre transmisión y prevención de ITS/VIH, exámenes de detección de cánceres del sistema reproductivo, prevención de la violencia, atención posaborto, y servicios para hombre y adolescentes. La información en las tarjetas guían a los proveedores para realizar una evaluación de riesgos de ITS/VIH, analizar la protección doble y la salud positiva, y para analizar y ofrecerle al/a la cliente consejería y pruebas de VIH. El proceso de la ECB+ puede resumirse como un algoritmo de toma de decisiones, el cual se describe en las próximas tres páginas. A continuación, encontrará un resumen de las cuatro etapas de consejería:

1. Etapa previa a la elección: En esta etapa, el proveedor genera las condiciones que ayudan al/a la cliente a seleccionar un método de planificación familiar. El proveedor saluda al/a la cliente cordialmente. El proveedor hace hincapié en que, durante la consulta, se abordarán otros temas de salud reproductiva según las circunstancias personales del/de la cliente. El proveedor repasa las intenciones de fertilidad del/de la cliente y le aconseja sobre períodos saludables para el embarazo y para el espaciamiento entre embarazos. El embarazo se descarta mediante el uso de una tarjeta de consejería con preguntas de verificación. Si la cliente no está embarazada, el proveedor muestra todas las tarjetas de método y formula las preguntas que se describen en el algoritmo. A medida que la cliente responde cada pregunta, el proveedor separa las tarjetas de los métodos que no son apropiados para ella. Separar estas tarjetas ayuda a evitar que se brinde información sobre métodos que no son relevantes para las necesidades de la cliente.

Si no se puede descartar un embarazo, el proveedor pasa a los pasos 13 al 19 para analizar otros servicios relevantes que la cliente pueda necesitar. Se le da a la cliente un método de respaldo, como preservativos, y se le pide que regrese cuando tenga su menstruación.

2. Etapa de elección del método: En esta etapa, el proveedor proporciona información detallada sobre los métodos que no apartó y su efectividad. Esto ayuda a que el/la cliente seleccione un método acorde a sus necesidades reproductivas. Al seguir los pasos en el algoritmo de la ECB+, el proveedor reduce del número de tarjetas de consejería hasta que se elige un método.

3. Etapa posterior a la elección: En esta etapa, el proveedor usa el folleto del método que el/ la cliente eligió para proporcionarle información completa. Si el/la cliente tiene afecciones por las cuales no se recomienda el método o no está satisfecho/a con la elección, el proveedor vuelve a la etapa de elección del método para ayudar al/a la cliente a elegir otro. El proveedor también alienta al/a la cliente a involucrar a su(s) pareja(s) en las decisiones sobre métodos anticonceptivos, ya sea a través de una charla o una visita a la clínica.

4. Etapa de detección sistemática para otros servicios: En esta etapa, el proveedor usa la información obtenida en las etapas anteriores y formula preguntas específicas para determinar los servicios de salud adicionales y la consejería que el/la cliente de planificación familiar pueda necesitar. El proveedor puede usar las tarjetas de consejería restantes para realizar lo siguiente: repasar información importante para una madre en etapa de posparto o para un lactante; remitir al/a la cliente a servicios de bienestar infantil; hablar y ofrecer exámenes de detección de cáncer de cuello uterino; hablar sobre el cáncer de mama; ofrecer servicios de consejería para hombres y adolescentes; hablar sobre seguridad y apoyo a la mujer; ofrecer atención posaborto, 
según sea necesario; hablar sobre la transmisión y prevención de ITS/VIH y zika evaluación de riesgos; hablar sobre protección doble y salud positiva y ofrecerle al/a la cliente consejería y pruebas de VIH. El proveedor le ofrece una prueba de VIH al/a la cliente, según los protocolos nacionales, y lo/a alienta a divulgar su estado de ITS/VIH a su(s) pareja(s), lo cual incluye hacer saber al/a la cliente los riesgos y beneficios de la divulgación. Una vez que se completa la sesión de consejería, el proveedor le da al/a la cliente instrucciones de seguimiento sobre el método anticonceptivo elegido, el folleto del método y un folleto sobre preservativos. El proveedor y el/la cliente también acuerdan una fecha para una visita de seguimiento.

\section{¿QUÉ INCLUYE ESTE PAQUETE DE HERRAMIENTAS?}

Las ayudas de trabajo y las guías de la ECB+ están diseñadas para programas de salud reproductiva centrados en reforzar la calidad de la consejería de planificación familiar y en responder a las necesidades de servicios y consejería adicionales de los clientes. Para complementar las herramientas ya existentes de los proveedores y facilitar la prestación de servicios de planificación familiar integrales, la segunda edición incorporó ayudas de trabajo adicionales y la Rueda con los criterios médicos de elegibilidad para el uso de anticonceptivos de la Organización Mundial de la Salud, además de agregar orientación adicional sobre otros servicios integrados. A continuación, encontrará una lista de los componentes del paquete de herramientas:

1. Guía del usuario de la ECB+ sobre cómo implementar la ECB+. Explica cómo usar las ayudas de trabajo; puede distribuirse durante la capacitación de la ECB + o usarse para autoaprendizaje con las ayudas de trabajo de la $\mathrm{ECB}+$.

2. Ayudas de trabajo de la $\mathrm{ECB}+$, incluidas las siguientes:

- El Algoritmo de la ECB+ que resume los 19 pasos recomendados para implementar la $\mathrm{ECB}+$ durante la consulta de planificación familiar. Estos pasos se organizan según cuatro etapas de consulta: evaluación de necesidades previas a la elección, elección del método, acciones posteriores a la elección y detección sistemática para otros servicios. Durante cada etapa de consulta, se guía al proveedor sobre cómo usar las ayudas de trabajo de la $\mathrm{ECB}+$ paso a paso. De acuerdo con la respuesta del/de la cliente sobre los puntos analizados, el algoritmo indica qué acciones realizar. Se puede encontrar el algoritmo de la ECB + en las páginas 7 y 8 , y también por separado en otras ayudas de trabajo del paquete de herramientas.

- Tarjetas de consejería que el proveedor usa durante la sesión de consejería. Hay 34 tarjetas de consejería. La primera tarjeta presenta seis preguntas que el proveedor de servicios formula para descartar un embarazo de la cliente (adoptadas de aquellas desarrolladas por Stanback et al. 1999). Hay 18 tarjetas específicas de métodos que presentan información sobre cada método de planificación familiar. Cada tarjeta de método tiene en el frente una ilustración del método anticonceptivo. En el reverso se presenta una lista de las características clave del método y se describe su uso, indicaciones, factores de riesgo y nivel de efectividad. Estas tarjetas se usan para descartar aquellos métodos que no son apropiados para las intenciones reproductivas del/de la cliente y para acotar la elección y llegar a una decisión final. En las quince (15) tarjetas de consejería se proporciona información adicional sobre la consejería y los servicios que puede necesitar un/a cliente de planificación familiar. Las tarjetas son las siguientes: Períodos saludables para el embarazo y el espaciamiento entre embarazos; promoción de un período posparto saludable para la madre; atención posaborto; promoción de la salud del recién nacido y del lactante; prevención y transmisión de ITS/VIH; prevención y transmisión del virus del Zika; evaluación de riesgo de ITS/VIH; prevención, dignidad y salud positiva; protección doble; consejería y pruebas de VIH; pruebas de detección de cáncer de cuello uterino; consejería para adolescentes; seguridad y apoyo a la mujer, servicios para hombres; e información y concienciación sobre el cáncer de mama. Estas tarjetas se usan durante la cuarta etapa de la consulta: detección sistemática para otros servicios.

- Folletos de métodos sobre cada uno de los 18 métodos anticonceptivos. Están diseñados para ayudar al/a la cliente a entender mejor el método elegido. El proveedor le da al/a la cliente un folleto del método seleccionado y un folleto con información sobre preservativos para que se lleve a su casa. Los proveedores deben alentar a los clientes analfabetos, o con un bajo nivel de alfabetización, a que se lleven el folleto a su casa para que su pareja o amigo cercano pueda repasarlo con ellos otra vez.

\footnotetext{
${ }^{3}$ y cualquier otra enfermedad infecciosa de emergencia que pueda transmitirse por vía sexual
} 
- La Rueda con los criterios médicos de elegibilidad (CME) para el uso de anticonceptivos de la OMS (2015) es una ayuda de trabajo para los proveedores sobre las cuatro categorías de elegibilidad para el uso de anticonceptivos en relación con las afecciones médicas descritas en el documento Criterios médicos de elegibilidad para el uso de anticonceptivos, quinta edición publicado por el Departamento de Salud Reproductiva de la Organización Mundial de la Salud. Esta herramienta guía a los proveedores a través de las afecciones médicas y los medicamentos que pueden tener contraindicaciones con el uso de algún método anticonceptivo en particular. La OMS probó la ayuda de trabajo en tres países y encontró que resultó ser muy útil para los proveedores que la usaron.

3. Guía del instructor de la ECB+ que los supervisores y otros pueden usar para capacitar a los proveedores en el uso de la ECB + . La guía incluye ejercicios y actividades para aumentar la comprensión y el uso apropiado del paquete de herramientas ECB + por parte de los participantes.

Las ayudas de trabajo de la ECB+, la Guia del instructor de la ECB+ y la Guía del usuario de la ECB+ incorporan los últimos estándares internacionales de planificación familiar e ITS/VIH y orientación que siguen las recomendaciones de la Organización Mundial de la Salud (OMS), incluidos los siguientes: Criterios médicos de elegibilidad para el uso de anticonceptivos (OMS, 2015), Planificación familiar: un manual mundial para proveedores (OMS/Departamento de Salud Reproductiva e Investigaciones Conexas y JHU/CCP, actualización del proyecto INFO 2011), Tecnología anticonceptiva (Hatcher et al. 2011), Infecciones de transmisión sexual y otras infecciones del tracto reproductivo: Una guía para la práctica básica (OMS, 2005) y Guías para el tratamiento de las infecciones de transmisión sexual (OMS, 2003).

Estas ayudas de trabajo se pueden revisar según las guías y los protocolos nacionales o regionales. Las copias digitales de los materiales de la ECB+ están disponibles para que las ayudas de trabajo y las guías de instrucciones puedan imprimirse o adaptarse con facilidad para satisfacer las necesidades de cada comunidad.

\section{¿CÓMO DEBE USARSE ESTE PAQUETE DE HERRAMIENTAS?}

1. Lea esta Guía del usuario de la ECB + por completo para obtener información sobre cómo implementar la Estrategia de Consejería Balanceada Plus.

2. Consulte el algoritmo de la ECB + para recordar los 19 pasos utilizados para implementar la $\mathrm{ECB}+$. Es útil tener una copia disponible en el escritorio del proveedor o en una pared del área de consulta para que el proveedor pueda consultarla fácilmente.

3. Use las tarjetas de consejería de la ECB+ y la Rueda con los CME para ayudar al/a la cliente a elegir un método que se adapte a sus intenciones reproductivas. Si la cliente es mujer, use la primera tarjeta de consejería para descartar que esté embarazada. Si no lo está, use las tarjetas de método para ayudar al/a la cliente a elegir el método anticonceptivo que mejor se adapte a sus intenciones reproductivas, descartando aquellos métodos que no sean apropiados. Durante la consejería, haga hincapié en la protección doble.

4. Una vez que el/la cliente haya elegido un método anticonceptivo, use el folleto del método de la $\mathrm{ECB}+$ correspondiente para analizar las contraindicaciones. Si no hay ninguna, repase el resto del folleto con el/la cliente para reforzar la información sobre el método elegido y responder preguntas. Esto ayuda a que el/la cliente entienda mejor el método. Entréguele el folleto al/a la cliente. Puede mencionarlo en su casa o usarlo para hablar con su pareja.

5. Durante la elección del método anticonceptivo, y después de elegirlo, use las tarjetas de consejería para determinar los servicios de salud adicionales que el/la cliente de planificación familiar pueda necesitar. Estos servicios adicionales incluyen consejería sobre lo siguiente: atención posparto para la madre y el recién nacido; exámenes detección de cáncer de cuello uterino y de cáncer de mama; necesidades del adolescente; seguridad y apoyo a la mujer; atención posaborto; servicios para hombres; prevención y transmisión de ITS / VIH; prevención y transmisión del virus del Zika; realizar una evaluación de riesgos; definir protección doble y hablar sobre VIH y ofrecer consejería y pruebas de detección.

6. Para los instructores, use la Guía del instructor de la ECB+ para que el personal de atención de salud se familiarice con esta perspectiva de consejería y para capacitarlos en un uso efectivo de la ECB+. Los ejercicios de la Guía del instructor se pueden enseñar todos juntos en un taller, o bien pueden usarse por separado durante las reuniones de personal o en la capacitación en el lugar de trabajo durante visitas de supervisión.

7. Las cuatro ayudas de trabajo de la ECB+, la Guía del usuario de la ECB+ y la Guía del instructor de la ECB + también están disponibles en formato electrónico en el sitio web del Population 
Council, en http://www.popcouncil.org/research/the-balanced-counseling-strategy-plus-atoolkit-for-family-planning-service. Adapte estos materiales para el uso en su región o país, según sea necesario.

\section{¿POR QUÉ ES IMPORTANTE CAPACITAR A LOS PROVEEDORES DE SERVICIOS SOBRE LA ECB+?}

\section{Cumplimiento deficiente por parte de los proveedores}

Cuando la ECB original se desarrolló en Perú, se les brindó a los proveedores de atención de salud una capacitación inicial de dos días (16 horas) y un curso de actualización de un día seis meses después. Una evaluación del uso de la ECB reveló que hubo mejoras significativas en la calidad de atención, así como en el conocimiento de los clientes sobre ciertos métodos, cuando los proveedores usaron las ayudas de trabajo. Solo el 37 por ciento de los proveedores capacitados sobre el uso del modelo de la ECB y las ayudas de trabajo realmente los usaron para aconsejar clientes. Esto se atribuyó a la corta duración de la capacitación y a deficiencias en el componente de implementación del modelo de la ECB (León et al. 2003b; León et al. 2001). Además, los beneficios para los clientes fueron menores cuando los proveedores recibieron menos de tres días de capacitación.

\section{Cumplimiento mejorado de manera significativa por parte de los proveedores}

Cuando la ECB se adaptó para Guatemala, se hizo un gran hincapié en el refuerzo del aprendizaje a través de la supervisión. La capacitación de ocho horas incluyó por lo menos tres horas de juego de roles, seguida de supervisión y recapacitación. Ocho semanas después de la capacitación inicial, se controló a cada proveedor mientras aconsejaba clientes dos veces por semana, como mínimo. Se observó al proveedor durante la consejería y se le hicieron comentarios tan pronto como se fue el/la cliente. Se observaron entre tres y cuatro sesiones de consejería durante cada visita a un proveedor. Una evaluación de la ECB en Guatemala demostró que, como resultado de esta estrategia de capacitación con mayor respaldo, el 70 por ciento de los proveedores de servicio capacitados usaban las ayudas de trabajo en las interacciones diarias con los clientes. Por lo tanto, los investigadores encontraron una calidad mejorada de atención en los proveedores que usaron el modelo de la ECB (León et al. 2003a; León et al. 2003c).

\section{¿QUIÉN DEBERÍA USAR LA GUÍA DEL INSTRUCTOR DE LA ECB+?}

Las parteras, los supervisores, los administradores de programas o cualquier persona responsable de capacitar a los proveedores de atención de salud pueden usar esta Guía del instructor de la ECB+. $\mathrm{El}$ instructor debe estar familiarizado con el uso de la Guía del instructor de la ECB+ y con las ayudas de trabajo de la ECB+.

\section{¿CÓMO DEBERÍA IMPLEMENTARSE LA CAPACITACIÓN DE LA ECB+?}

$\mathrm{La} \mathrm{ECB}+$ puede usarse como se indica en este manual, o bien se puede presentar en una capacitación más amplia sobre planificación familiar. Por ejemplo, en Kenia, se ofreció la capacitación de la ECB+ como parte de una sesión de capacitación más extensa para proveedores de planificación familiar (enfermeros recibidos, enfermeros matriculados y enfermeros inscriptos). A toda capacitación de la ECB+ le debe seguir un curso de actualización periódico o una capacitación en el lugar de trabajo durante visitas de supervisión.

La Guía del usuario de la ECB+ está diseñada para reforzar la capacitación y funcionar como un recordatorio de los pasos necesarios para implementar el modelo de la ECB+ para los clientes de consejería sobre planificación familiar. Para una implementación óptima de la ECB+ en los servicios de planificación familiar, los proveedores deben recibir la capacitación completa y el curso de actualización posterior.

Los ejercicios de la Guía del instructor de la ECB+ se pueden enseñar todos juntos en un taller, pueden usarse por separado durante las reuniones de personal, en una capacitación en el lugar de trabajo durante visitas de supervisión, o bien pueden incorporarse en un programa de capacitación más extenso. Se alienta a los instructores a adaptar cualquiera de los ejercicios de este módulo o a agregar otros ejercicios que ayuden a permitir que los proveedores usen la $\mathrm{ECB}+$ de forma efectiva durante las consultas sobre planificación familiar. Asegúrese de asignar tiempo de práctica suficiente. No se puede subestimar la importancia de la repetición para dominar cualquier nueva metodología o habilidad. El éxito de la ECB+ radica en la habilidad del proveedor para usar las ayudas de trabajo de la ECB+. Por lo tanto, la práctica debe ser una prioridad durante cualquier capacitación o acontecimiento de supervisión. 


\section{Algoritmo para el uso de la Estrategia de Consejería Balanceada Plus}

\section{ETAPA PREVIA A LA ELECCIÓN}

(1) Establezca y mantenga una relación cordial y cálida.

2 Informe al/a la cliente (y a su pareja, si se encuentra presente) que durante la consulta tendrá la oportunidad de abordar tanto sus necesidades de salud como sus necesidades de planificación familiar.

(3) Pregúntele al/a la cliente sobre el tamaño actual de su familia y sobre sus prácticas anticonceptivas actuales. Asesore al/a la cliente sobre períodos saludables para el embarazo y para el espaciamiento entre embarazos usando una tarjeta de consejería.

a) Si el/la cliente actualmente usa un método de planificación familiar o de retraso del embarazo, pregúntele si ambos miembros de la pareja están satisfechos con el método y si les interesa continuar con él, o bien si desean cambiar de método.

b) Si la pareja se encuentra presente, use la tarjeta Apoyo y servicios para hombres.

4 Descarte la posibilidad de embarazo usando la tarjeta Lista de verificación para asegurarse de manera razonable de que una mujer no está embarazada.

Muestre todas las tarjetas de método. Pregúntele al/a la cliente si desea un método en particular. Formule todas las preguntas que se detallan a continuación. Aparte las tarjetas de método según las respuestas del/de la cliente.

a) ¿Desea tener hijos en un futuro?

Si la respuesta es "Sí, aparte la tarjeta Vasectomía y la tarjeta Ligadura de trompas. Explique por qué. Si la respuesta es "No", conserve todas las tarjetas y continúe.

b) ¿Ha dado a luz en las últimas 48 horas?

Si la respuesta es "Sí", a parte la tarjeta Inyectables combinados y la tarjeta Anticonceptivos orales combinados (Píldora). Explique por qué.

Si la respuesta es "No", continúe con la siguiente pregunta.

c) ¿Está amamantando a un lactante de menos de 6 meses?

Si la respuesta es "Sín, aparte la tarjeta Inyectables combinados y la tarjeta Anticonceptivos orales combinados (Píldora). Explique por qué.

Si la respuesta es "No" o si ha vuelto a tener la menstruación, aparte la tarjeta Método de la amenorrea de la lactancia (MELA). Explique por qué.

d) ¿Respalda su pareja su decisión sobre planificación familiar?

Si la respuesta es "Sí, continúe con la siguiente pregunta.

Si la respuesta es "No", aparte las siguientes tarjetas: Preservativo femenino, Preservativo masculino, Método de Días Fijos@), Método de Dos Días@ y Retirada. Explique por qué.

e) ¿Sufre alguna afección médica? ¿Toma medicamentos?

Si la respuesta es "Sí, pregunte qué afecciones padece o qué medicamentos toma. Consulte la Rueda con los criterios médicos de elegibilidad para el uso de anticonceptivos de la OMS o las directrices nacionales actuales y aparte las tarjetas de todos los métodos contraindicados. Explique por qué.

Si la respuesta es "No", conserve todas las tarjetas y continúe.

f) ¿Existen métodos que no desee usar o que no haya tolerado en el pasado?

Si la respuesta es "Sín, aparte las tarjetas de los métodos que la cliente no desee.

Si la respuesta es "No", conserve el resto de las tarjetas.

\section{ETAPA DE ELECCIÓN DEL MÉTODO}

(7) Repase brevemente los métodos que no haya apartado e indique su efectividad.

a) Disponga las tarjetas restantes por orden de efectividad (consulte el reverso de cada tarjeta).

b) En orden de efectividad (de mayor a menor), repase brevemente los atributos en cada tarjeta de método.

(8) Pídale al/a la cliente que elija el método que encuentre más conveniente.

a) Si la cliente es adolescente, use la tarjeta de consejería para informarle que puede obtener cualquier método.

(9) Mediante el folleto específico del método, compruebe que la cliente no presente ninguna afección por la cual no se recomiende el método.

a) Repase la sección "Método no recomendado si..." del folleto.

b) Si el método no es recomendable, pídale al/a la cliente que seleccione otro método de las tarjetas restantes. Repita el proceso desde el paso 8. 


\section{ETAPA POSTERIOR A LA ELECCIÓN}

(10) Analice el método elegido con el/la cliente, con el folleto específico del método como herramienta de consejería. Determine el entendimiento del/de la cliente y refuerce la información clave.

(11) Asegúrese de que el/la cliente haya tomado una decisión definitiva. Dele el método elegido, un método de respaldo o derívelo, según el método seleccionado.

(12) Aliente al/a la cliente a involucrar a su(s) pareja(s) en las decisiones sobre prácticas anticonceptivas, ya sea mediante una charla o una visita a la clínica.

\section{ETAPA DE DETECCIÓN SISTEMÁTICA PARA OTROS SERVICIOS}

(13) Mediante la información obtenida con anterioridad, determine la necesidad de la cliente de recibir servicios de atención posparto, de control de salud para recién nacidos, lactantes o niños, o de posaborto.

a) Si la cliente informó haber dado a luz recientemente, repase con ella la tarjeta Promoción de un período posparto saludable y la tarjeta Promoción de la salud del recién nacido y del lactante. Proporcione los servicios necesarios o haga una derivación, según corresponda.

b) Para clientes con niños de menos de 5 años, pregunte si los niños han recibido los servicios de control de salud correspondientes. Proporcione los servicios de vacunación o control del crecimiento necesarios o haga una derivación, según corresponda.

c) Si la cliente informó un aborto reciente, repase con ella la tarjeta Atención posaborto. Proporcione los servicios de atención posaborto necesarios o haga una derivación, según corresponda.

(14)

Pregúntele a la cliente cuándo fue su último examen de detección de cáncer de cuello uterino (IVAA/IVSL o Papanicolaou) o de cáncer de mama.

a) Si su último examen de detección de cáncer de cuello uterino fue hace más de 3 años ( ${ }^{\star}$ o, en caso de ser VIH positivo, en los últimos 6 a 12 meses) o si no sabe, pregúntele si le gustaría hacerse uno ese mismo día. Repase la tarjeta Examen de detección de cáncer de cuello uterino. Proporcione los servicios necesarios o haga una derivación.

b) Si el último examen de detección de cáncer de cuello uterino de la cliente fue hace menos de 3 años, continúe con la siguiente pregunta.

c) Repase con la cliente la tarjeta de consejería Información y concienciación sobre el cáncer de mama.

(15) Analice con el/la cliente las tarjetas de consejería Prevención y transmisión de ITS/VIH y Protección doble. Ofrézcale preservativos e instrucciones sobre el uso correcto y constante.

a) En las regiones con virus del Zika activo, analice con el/la cliente las tarjetas de consejería Prevención y transmisión del virus del Zika.

(16) Lleve a cabo una evaluación del riesgo de ITS y VIH usando la tarjeta de consejería. Si se identifican los síntomas, trate al/a la cliente de manera sindrómica.

(17) Pregúntele al/a la cliente si conoce su estado de VIH.

a) Si el/la cliente sabe que tiene $\mathrm{VIH}$,

- Repase con el/la cliente la tarjeta de consejería Prevención, dignidad y salud positiva.

- Derive al/a la cliente a un centro de tratamiento y atención de bienestar.

b) Si el/la cliente sabe que es VIH negativo,

- analice un plazo de repetición de la prueba.

c) Si el/la cliente desconoce su estado,

- háblele sobre consejería y pruebas de VIH (HCT) usando la tarjeta de consejería.

- ofrézcale o hágale una prueba, según los protocolos nacionales.

- Asesore al/a la cliente sobre los resultados de la prueba. Si el/la cliente tiene VIH, repase con él/ella la tarjeta de consejería Prevención, dignidad y salud positiva, y derívelo/a a un centro de tratamiento y atención de bienestar.

d) Asesore a la cliente usando la tarjeta Seguridad y apoyo a la mujer.

- Si la cliente presenta signos graves que indiquen que puede ser víctima de violencia infligida por la pareja, derívela a servicios especializados.

(18) Proporcione instrucciones de seguimiento, un folleto sobre preservativos y un folleto sobre el método elegido. Fije una fecha para la próxima visita.

(19) Agradézcale por su visita. Complete la sesión de consejería. 


\section{Consejos para los instructores}

1. Lea esta Guía del instructor de la ECB+ por completo para prepararse para el taller. Marque las páginas que deben consultar los participantes durante la capacitación.

2. Siga los pasos detallados sobre cómo realizar la capacitación que se proporcionan en esta guía. Tenga en cuenta que hay más de 3 horas de juegos de roles y ejercicios de práctica. Es importante respetar los tiempos sugeridos para garantizar tiempo de práctica suficiente. Adapte los ejercicios a sus circunstancias locales, si lo desea.

3. Practique usar las ayudas de trabajo de la ECB+ para aconsejar a los clientes sobre planificación familiar y sobre otros servicios relacionados. Familiarizarse con las ayudas de trabajo incrementará su capacidad como instructor de la ECB+.

4. Antes de la capacitación, realice las copias necesarias de la Guía del usuario de la ECB+ y de las ayudas de trabajo de la ECB+ para entregárselas a los participantes. (Nota: Si está disponible, entregue a los participantes la copia original a color de Estrategia de Consejería Balanceada Plus: Un paquete de herramientas para proveedores de servicios de planificación familiar que trabajan en entornos con alta prevalencia de ITS / VIH, la cual cuenta con la Guía del usuario de la ECB+, las ayudas de trabajo y la Guía del instructor de la ECB+).

5. Asegúrese de tener suficientes folletos de métodos de la ECB+ para que los proveedores los usen en su práctica luego de la capacitación.

6. La Estrategia de Consejería Balanceada Plus: Un paquete de herramientas para proveedores de servicios de planificación familiar que trabajan en entornos con alta prevalencia de ITS / VIH también está disponible en formato electrónico en el sitio web del Population Council, en http://www.popcouncil.org/ research/the-balanced-counseling-strategy-plus-a-toolkit-for-family-planning-service. Úsela para imprimir más material, como por ejemplo, los folletos de la ECB+ o la Guía del usuario de la ECB+. En caso de que no pueda imprimir estos materiales, puede fotocopiarlos.

7. Durante la capacitación, asegúrese de tener en cuenta las siguientes técnicas de facilitación:

- Formule preguntas frecuentemente. Es importante responder en el momento cualquier pregunta sobre cómo se usan las ayudas de trabajo de la ECB+.

- Use preguntas abiertas que empiecen con «cómo», «qué», «cuándo» y «por qué» para iniciar un análisis o para obtener comentarios.

- Responda las preguntas difíciles de la siguiente forma:

- Reconozca el esfuerzo del participante, sin importar el tipo de pregunta. Una buena opción es responder «Es una muy buena pregunta», independientemente de qué tan difícil o inapropiada sea.

- Invite al grupo a responder la pregunta del participante. Esta estrategia también involucra al grupo en el proceso de aprendizaje.

- Mitigue la posible vergüenza de las preguntas incorrectas o inapropiadas esperando al descanso para responderlas. Por ejemplo, puede decir: «Es una muy buena pregunta. ¿Por qué no hablamos al respecto durante el descanso?»

- Posponga hasta el descanso las discusiones prolongadas que lo alejan del tema.

- Use sus habilidades de observación para saber qué tan bien los participantes comprenden y reciben la capacitación. A medida que observa cómo se recibe la capacitación, ajuste la facilitación para satisfacer las necesidades de aprendizaje de los participantes (consulte la tabla en la página siguiente).

8. Recuerde: Las técnicas de capacitación efectivas mantienen a los participantes involucrados en el proceso de aprendizaje y ayudan a los instructores a evaluar cómo se recibe la capacitación y a ajustar el proceso, según sea necesario. Consulte la tabla en la página siguiente para obtener orientación. 


\begin{tabular}{|c|c|}
\hline $\begin{array}{l}\text { Si los participantes } \\
\text { parecen estar... }\end{array}$ & Haga lo siguiente... \\
\hline ABURRIDOS & $\begin{array}{l}\text { - Acelere el ritmo de la capacitación } \\
\text { - Tome un descanso } \\
\text { - Deje de hablar e invite a la participación mediante preguntas o haciendo } \\
\text { que los participantes practiquen } \\
\text { - Cambie su estilo de capacitación: use diferentes técnicas, como apagar } \\
\text { la presentación de PowerPoint y solo hablar } \\
\text { - Realice una práctica espontánea o trabajo en grupos pequeños }\end{array}$ \\
\hline CONFUNDIDOS & $\begin{array}{l}\text { - Haga preguntas para aclarar la comprensión de los participantes } \\
\text { sobre el tema } \\
\text { - Dé ejemplos o haga una demostración } \\
\text { - Haga que otros en el grupo expliquen el tema } \\
\text { - Haga que los participantes practiquen Ayúdelos a practicar, si es necesario }\end{array}$ \\
\hline DURMIÉNDOSE & $\begin{array}{l}\text { - Asegúrese de que la temperatura en el salón no sea demasiado alta } \\
\text { y de que haya ventilación } \\
\text { - Asegúrese de que haya suficiente luz } \\
\text { - Use varios métodos de capacitación y ayudas visuales } \\
\text { - Realice ejercicios rompehielos espontáneos } \\
\text { - Tome un descanso }\end{array}$ \\
\hline $\begin{array}{l}\text { DISTRAÍDOS } \\
\text { Hablan, escriben, miran } \\
\text { sus relojes, mueven } \\
\text { papeles }\end{array}$ & $\begin{array}{l}\text { - Deje de hablar y haga preguntas } \\
\text { - Camine entre los participantes } \\
\text { - Haga que los participantes practiquen } \\
\text { - Pídales a otros en el grupo que expliquen el tema } \\
\text { - Acelere el ritmo } \\
\text { - Cambie su técnica de capacitación }\end{array}$ \\
\hline ATENTOS & - Continúe así \\
\hline
\end{tabular}




\section{Ejemplo de cronograma: Capacitación de la ECB+}

\begin{tabular}{|c|c|c|}
\hline 8:00 a. m. - - & 8:40 a. m. & Bienvenida y ejercicio del teléfono \\
\hline 8:40 a. m. - - & 9:30 a. m. & Antecedentes de la Estrategia de Consejería Balanceada Plus \\
\hline 9:30 a. m. - - & 11:00 a. m. & Etapa previa a la elección \\
\hline 11:00 a. m. - & 11:15 a. m. & Descanso \\
\hline 11:15 a. m. - & $12: 00$ p. m. & Etapa de elección del método \\
\hline 12:00 p. m. - & $12: 45$ p. m. & Etapa posterior a la elección \\
\hline 12:45 p. m. - & $2: 00$ p. m. & Almuerzo \\
\hline 2:00 p. m. - & 4:15 p. m. & Etapa de detección sistemática para otros servicios \\
\hline 4:15 p. m. & $4: 45$ p. m. & Juego de roles $n .^{\circ} 1$ \\
\hline 4:45 p. m. & 5:00 p. m. & Descanso \\
\hline 5:00 p. m. & $5: 30$ p. m. & Juego de roles $n .^{\circ} 2$ \\
\hline 5:30 p. m. - & $5: 45$ p. m. & Pasos siguientes y cierre \\
\hline
\end{tabular}




\section{П Capacitación para proveedores de planificación ᄃ familiar sobre la ECB+}

\section{Introducción}

Tiempo total: 90 minutos

Al final de esta sesión, los participantes:

- Se conocerán entre sí

- Podrán describir por qué y cómo se desarrolló la ECB+

\section{BIENVENIDA}

Tiempo: 20 minutos

\section{Materiales y preparativos}

- Tenga disponible un rotafolio u hojas grandes de papel y marcadores.

- Anote en una hoja del rotafolio el objetivo del taller con anticipación.

\section{Instrucciones}

1. Use el siguiente ejercicio para ayudar a los participantes a conocerse entre sí. Use otro rompehielos, si lo desea.

a. Divida a los participantes en parejas.

b. Pida a cada participante que le cuente a su pareja algo interesante acerca de sí mismo/a que sus colegas no sepan.

c. Conceda unos minutos para que el primer participante de la pareja cuente su historia.

d. Después de cinco minutos, pida que cambien de rol y que la otra persona cuente a su pareja algo sobre sí mismo/a.

e. Conceda unos minutos para que el segundo participante de la pareja cuente su historia.

f. Una vez que el grupo haya terminado (no permita que hablen mucho tiempo), pida a cada participante que: (1) presente a su pareja diciendo su nombre y que (2) cuente una cosa interesante sobre él/ella.

g. Usted puede iniciar presentándose y contando al grupo algo interesante sobre usted.

2. Repase el objetivo de la capacitación:

3. Logística: repase dónde están los baños, avise si habrá refrescos, dónde se tendrá el almuerzo y cualquier otro tema de este tipo.

\section{OBJETIVO}

Al finalizar la capacitación, los participantes podrán usar las ayudas de trabajo de la ECB+ para aconsejar a un/a cliente sobre planificación familiar y sobre consejería y pruebas de VIH (HCT).

4. Reglas de convivencia: pídales a los participantes que sugieran cualquier regla de convivencia que piensen que el grupo debería cumplir. Escriba las reglas de convivencia en el rotafolio. (Nota: Si los participantes no la mencionan, incluya una regla sobre el uso de teléfonos celulares.)

5. Inicie la sesión con el ejercicio del teléfono que se encuentra a continuación. Es un ejercicio divertido y participativo para presentar la necesidad de la ECB+. Además, involucra a los participantes desde el inicio de la capacitación. 


\section{EJERCICIO DEL TELÉFONO}

Tiempo: 20 minutos

\section{Materiales y preparativos}

- Tenga disponible un rotafolio u hojas grandes de papel y marcadores.

- Tenga 4 o 5 hojas de papel en blanco a mano.

- Haga una filmina o una presentación en PowerPoint de la diapositiva n. ${ }^{\circ} 1$ (se encuentra en la página 14). Si no cuenta con una computadora o un proyector, dibuje la gráfica de la diapositiva n. ${ }^{\circ}$ en el papel del rotafolio.

\section{Instrucciones}

1. Pida a todos que se pongan de pie y formen un semicírculo. (Trate de encontrar un espacio en el salón que quede libre de mesas y sillas).

2. Dele a la primera persona en el semicírculo una hoja en blanco y una lapicera o un marcador. Después, entregue los mismos elementos a cada 4ta o 5ta persona y, también, a la última persona en el semicírculo.

3. Explique que usted va a leer algo a la primera persona en el semicírculo.

4. Explique que esta persona repetirá lo que escuchó a la siguiente persona en la línea. Siguiendo la secuencia, la siguiente persona repetirá lo que escuchó a la siguiente persona, y así, hasta que la información llegue a la última persona en la línea.

5. Deben tenerse en cuenta las siguientes dos reglas:

1. Deben susurrar la información a su compañero para que los demás no oigan.

2. Deben decir la información una sola vez; no se puede repetir.

6. Pida a los participantes con la hoja en blanco que escriban exactamente lo que escuchan. Estas son las reglas:

1. No pueden pedirle a la persona que les dio la información que repita nada.

2. Nadie debe ver lo que escriben.

7. Recuerde a los participantes que, cuando sea su turno, pueden hablar lento pero no pueden repetir la información.

8. Sea consciente de que los participantes pueden empezar a reírse. Sonría y aliéntelos a que permanezcan lo más callados que puedan para que sus compañeros puedan escuchar la frase.

9. Lea en voz baja la siguiente información a la primera persona en el semicírculo. Hable despacio y claro. Tenga cuidado de que la persona no pueda ver lo que está leyendo.

\section{LEA ESTO}

Las personas recuerdan el 25 por ciento de lo que escuchan; el 45 por ciento de lo que escuchan y ven; y el 70 por ciento o más de lo que ven, escuchan y experimentan por sí mismas.

10. Dígale a la primera persona que repita lo que escuchó a la siguiente persona, y que continúen así a lo largo de toda la línea.

11. Recuerde a los participantes con la hoja en blanco que escriban exactamente lo que escuchan.

12. Aliente a los participantes a que permanezcan lo más callados que puedan para que la persona que reciba la información pueda escuchar lo que le dicen.

13. Espere hasta que la última persona en el semicírculo haya escuchado la frase y la haya escrito en su hoja.

14. Lea en voz alta exactamente lo que usted (el instructor) le leyó a la primera persona.

15. Pida a la primera persona en el semicírculo con la hoja de papel que lea lo que escribió.

16. Continúe por el semicírculo y pida al resto de los participantes con una hoja de papel, incluida la última persona, que lean lo que escribieron.

17. Se espera que el mensaje haya sido bastante distorsionado para cuando le toque leer a la última persona lo que escribió.

18. Después de que los participantes se hayan calmado, pídales que se sienten. 


\section{Instrucciones para procesar el ejercicio}

1. Pregunte por qué se distorsionó el mensaje.

2. Pregunte cómo se podría haber evitado esta distorsión. ¿Cómo se podría haber mejorado para que más personas pudieran recordarlo?

3. Escriba las respuestas de los participantes en el rotafolio. Si no se menciona, sugiera lo siguiente:

- El mensaje podría haber sido más corto.

- El mensaje podría haber contado con ayudas visuales.

- La persona podría haber recibido material impreso de lectura para ayudarla a recordar el mensaje.

4. Pregunte si los participantes podrían recordar el mismo mensaje dentro de una semana (Espere que la respuesta sea «no»).

\section{DIAPOSITIVA N. ${ }^{\circ}$ 1: TASAS DE RETENCIÓN DESPUÉS DE 60 DÍAS}

$100 \%$

$90 \%$

$80 \%$

$70 \%$

$60 \%$

$50 \%$

$40 \%$

$30 \%$

$25 \%$

$20 \%$

$10 \%$

$0 \%$

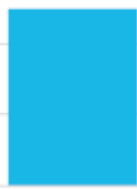

$45 \%$

Escuchar

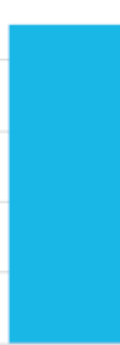

Escuchar y ver

\section{$70 \%$}

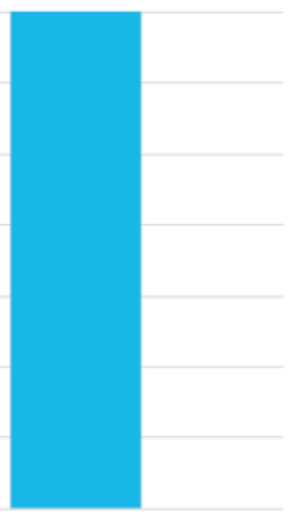

Escuchar, ver y experimentar

5. Muestre la diapositiva n. ${ }^{\circ} 1$ de las tasas de retención y, luego, formule las siguientes preguntas:

- ¿Qué hubiera pasado si yo (usted, el instructor) les hubiera dado el mensaje usando la diapositiva?

- Si les hubiera dado una copia de la diapositiva para que se la llevaran a casa, ¿recordarían el mensaje dentro de una semana?

6. Explique que el objetivo de este ejercicio es que los participantes:

- reflexionen sobre lo difícil que es recordar algo que uno solo escucha;

- se den cuenta de que menos información mejora el aprendizaje;

- comprendan la necesidad de reforzar la información verbal con materiales escritos.

7. Haga hincapié en que, por lo general, se le da demasiada información a los clientes a la hora de elegir un método anticonceptivo.

8. Pregunte cómo la imposibilidad de recordar información podría afectar al/a la cliente y su uso de un método anticonceptivo. Escriba las respuestas en el rotafolio.

9. Explique que si ellos, los participantes, no pudieron recordar el mensaje sencillo del ejercicio que acaban de realizar, ¿cómo se puede esperar que los clientes de planificación familiar recuerden toda la información que reciben?

10. Explique que ahora hablará sobre la relación entre los objetivos del ejercicio del teléfono y el motivo del desarrollo de la ECB+. 


\section{ANTECEDENTES DE LA ESTRATEGIA DE CONSEJERÍA BALANCEADA PLUS}

Tiempo: 50 minutos

\section{Materiales y preparativos}

- Tenga disponible un rotafolio u hojas grandes de papel y marcadores.

- Anote en una hoja del rotafolio el objetivo del taller con anticipación.

- Tenga copias del paquete de herramientas de la ECB+ para todos los participantes. Las necesitarán durante las sesiones de práctica, y para llevarlas a sus casas y usarlas en la clínica. (Nota: Si el paquete de herramientas completo no está disponible, asegúrese de que al menos haya copias suficientes de la Guía del usuario de la ECB+ y de las ayudas de trabajo de la ECB+).

- Si aún no lo ha hecho, repase la Guía del usuario de la ECB+ antes de la capacitación, y tenga una copia del paquete de herramientas de la $\mathrm{ECB}+$ para usar durante el taller.

- Tenga disponible un rotafolio u hojas grandes de papel y marcadores.

- Prepare un rotafolio o una presentación en PowerPoint con un resumen de los tres descubrimientos clave mencionados en el punto n. ${ }^{\circ} 1$ de «Instrucciones para la explicación de la Estrategia de Consejería Balanceada: El comienzo» (página 15).

- Prepare un rotafolio o una presentación en PowerPoint con la definición de una ayuda de trabajo, la cual se encuentra en la casilla «Aclaración» del punto n. ${ }^{\circ} 4$ de «Instrucciones para la explicación de la Estrategia de Consejería Balanceada: El comienzo» (página 16).

- Prepare un rotafolio o una presentación en PowerPoint con los estudios de investigación práctica mencionados en el punto n. ${ }^{\circ} 7$ de «Instrucciones para la explicación de la Estrategia de Consejería Balanceada Plus» (página 16).

- Prepare un rotafolio con la lista de consideraciones a tener en cuenta cuando se realiza una sesión de consejería a un/a cliente con conciencia y respeto, las cuales están mencionadas en «Instrucciones para la explicación de la tercera edición de la Estrategia de Consejería Balanceada Plus» (página 17).

\section{Instrucciones para la explicación de la Estrategia de Consejería Balanceada: El comienzo}

1. Explique que a fines de la década de 1990, el programa FRONTERAS trabajó en colaboración con los ministerios de salud de distintos países latinoamericanos para desarrollar una estrategia práctica, interactiva y amigable con los clientes con la cual mejorar la consejería dentro de las consultas sobre planificación familiar. Esto fue en respuesta a un estudio para evaluar el cumplimiento de los proveedores con las nuevas directrices nacionales sobre atención de planificación familiar. Hubo tres hallazgos principales: (Nota: Cuando analice los hallazgos, muestre el rotafolio o la presentación en PowerPoint que preparó con anterioridad).

- Los proveedores no analizaban los deseos de los clientes.

- Por lo general, formulaban preguntas médicas, como la fecha de la última menstruación de la cliente.

- No hacían preguntas básicas sobre las intenciones reproductivas de la cliente, como por ejemplo, si deseaba más hijos o si su pareja cooperaba con el uso de métodos anticonceptivos.

- La información obtenida de la cliente, como la presión arterial, a menudo tenía un uso práctico limitado en el proceso de selección de un método.

\section{- A menudo, los proveedores daban demasiada información.}

- Daban demasiada información detallada sobre la mayoría de los métodos anticonceptivos disponibles en las clínicas dependientes del Ministerio de Salud, independientemente de que el método sirviera para satisfacer las necesidades de la cliente.

- Esto sobrecargaba a los clientes con más información de la que podían recordar y usar.

- La información sobre el método anticonceptivo elegido era escasa.

- Se pasaba la mayor parte del tiempo de consejería describiendo las numerosas opciones de métodos. Se ignoraba la información importante para el proveedor y el/la cliente, como por ejemplo, los efectos secundarios, las contraindicaciones y los signos de advertencia relacionados con el método elegido.

- Por estos motivos, los clientes entrevistados sabían muy poco sobre el método que habían elegido luego de la consulta. 
2. Explique que como resultado de estos hallazgos, el Population Council y el Ministerio de Salud del Perú desarrollaron y probaron una estrategia de consejería interactiva y amigable con los clientes que buscaba simplificar la toma de decisiones y responder de una manera más apropiada a las necesidades de los clientes y a sus intenciones reproductivas.

3. Explique que esta nueva estrategia de planificación familiar se llamó Estrategia de Consejería Balanceada o ECB. Las ayudas de trabajo de uso sencillo son un componente clave de la ECB.

4. Esclarezca qué es una ayuda de trabajo. (Nota: Haga referencia al contenido del rotafolio que preparó con anterioridad).

\section{ACLARACIÓN}

Una ayuda de trabajo es un lugar para guardar información, que no es la memoria a largo plazo, y al cual se accede en tiempo real en el trabajo.

Características de una ayuda de trabajo:

- Más confiable que la memoria

- Describe el comportamiento deseado en el trabajo

- Reduce el ensayo y error y reduce la cantidad de memoria necesaria para realizar tareas en el trabajo

\section{Instrucciones para la explicación de la Estrategia de Consejería Balanceada Plus}

1. Mencione que, por lo general, las tareas actuales de los servicios de planificación familiar para evitar las ITS y el VIH se han limitado a la educación de reducción de riesgos, de ITS, a la educación para alentar el uso de preservativos y a proporcionar opciones de planificación familiar a los clientes infectados para evitar embarazos no deseados.

2. Mencione que en muchos países africanos, por lo general, las tareas de consejería y pruebas de VIH (HCT) se limitan a casos de atención prenatal y solo en algunos centros aislados.

3. Explique que el gran porcentaje de mujeres sexualmente activas que usan un método de planificación familiar implica una oportunidad para que los proveedores integren información sobre otros servicios.

4. Señale que en respuesta a la necesidad de incorporar consejería, exámenes de detección y servicios para las ITS, incluido el VIH, a las consultas sobre planificación familiar de rutina en entornos caracterizados por una alta prevalencia de estas infecciones, la ECB original se revisó para incorporar consejería de prevención de VIH, evaluaciones de riesgo y consejería y pruebas de VIH (HCT).

5. Mencione que el programa FRONTERAS desarrolló y probó la ECB + mediante estudios de investigación práctica en Kenia (del 2005 al 2007) y en Sudáfrica (del 2004 al 2006).

Ambos países tienen tasas altas de ITS, incluido el VIH, y sus tasas de prevalencia de métodos anticonceptivos son relativamente altas para la región.

6. Explique que los ministerios de salud de ambos países deseaban desarrollar herramientas prácticas para mejorar la calidad de los servicios y la cantidad de clientes que recibían servicios integrados.

7. Señale los hallazgos clave sobre el uso de la ECB + de los estudios de investigación práctica realizados en Kenia y Sudáfrica. (Nota: Muestre una diapositiva o un rotafolio de estos hallazgos cuando los analice).

- La integración de la consejería sobre prevención de ITS/VIH y la evaluación de riesgos con la oferta de HCT durante las consultas de planificación familiar es posible y aceptable para los clientes y proveedores.

- La calidad de la atención tanto para la planificación familiar como para la consejería de ITS/VIH mejoró significativamente con el uso de las herramientas de la ECB+.

- El servicio de HCT mejoró considerablemente. En Kenia, se ofreció el servicio de HCT a más del 40 por ciento de los clientes, y alrededor de la mitad decidió realizarse una prueba, ya sea en el lugar o mediante una derivación. En Sudáfrica, la cantidad de personas a las que se les ofreció una prueba aumentó a un 29 por ciento. Además, se observó un aumento general en el distrito, en el cual se duplicó la cantidad de individuos que se realizaron una prueba.

- El uso de las herramientas de la ECB+ facilitó una mayor evaluación de riesgo para las ITS y el VIH. Asimismo, las decisiones sobre la elección de un método anticonceptivo se realizaron con un mejor entendimiento de su relación con la prevención de infecciones. 
- A pesar de la preocupación de que al incorporar estos servicios pueda haber un impacto negativo en los servicios de planificación familiar, la mejora en la calidad de la consejería y la falta de evidencias de una disminución en el uso demostraron que esta preocupación era infundada.

\section{Instrucciones para la explicación de la tercera edición de la Estrategia de Consejería Balanceada Plus}

1. Explique que desde la publicación del paquete de herramientas de la ECB+ en 2008, distintas organizaciones y gobiernos lo han usado. Con base en sus experiencias, algunos socios modificaron la herramienta, agregaron preguntas o reformularon el paquete de herramientas para que se adapte a su contexto local o a un tema específico en el cual se centraba su programa. Otros incorporaron el paquete de herramientas a actividades y sistemas de capacitación más grandes, incluidos muchos gobiernos y ministerios de salud que adoptaron este paquete como una herramienta a disposición de los proveedores que prestaban el servicio de planificación familiar. En 2011, se desarrolló una segunda edición actualizada de la $\mathrm{ECB}+$ para incorporar algunas de las experiencias y necesidades de estos socios y también para incorporar las actualizaciones de los Criterios Médicos de Elegibilidad (CME) de 2010 de la OMS.

2. Indique que las experiencias con el uso de la segunda edición del paquete de herramientas de la $\mathrm{ECB}+$ en diversos entornos y contextos, junto con la recolección de comentarios y experiencias de otras organizaciones, las nuevas tecnologías de anticonceptivos y las actualizaciones adicionales de los CME de la OMS en 2015, dejaron en claro que sería conveniente realizar otra revisión y actualización al paquete de herramientas. Esta actualización respondió a numerosos desarrollos que ocurrieron desde su última publicación:

- Los socios y colegas que implementaron la herramienta mencionaron la necesidad de integrar servicios adicionales al algoritmo y a los componentes asociados del paquete de herramientas de la Estrategia de Consejería Balanceada Plus. También, hay un gran interés en integrar la planificación familiar a otros servicios que los clientes necesitan, además de los que ya están incluidos en la ECB+. Estos temas incluyen los siguientes: información sobre cáncer de mama, atención posaborto, seguridad y apoyo a la mujer y consejería específica para hombres y adolescentes.

- En 2015, la Organización Mundial de la Salud publicó la quinta edición de los Criterios médicos de elegibilidad para el uso de anticonceptivos, en la cual se actualizó la guía en materia de seguridad y eficacia de algunos métodos.

- Se desarrollaron y aprobaron dos nuevas tecnologías anticonceptivas para uso en servicios de planificación familiar y se incluyeron en los CME de 2015 de la OMS: el diafragma Caya ${ }^{\circledR} /$ Silcs y el anillo vaginal de progesterona.

3. Mencione que las dos ediciones anteriores se probaron en Kenia y ahora son parte de las directrices nacionales de planificación familiar.

\section{Instrucciones para la explicación de la Consejería con conciencia y respeto}

1. Explique a los participantes que aconsejar a los clientes de planificación familiar sobre otros problemas de salud implica hacer preguntas que pueden ser incomodas y distintas a las que se hacen habitualmente durante una sesión de planificación familiar.

2. Explique que puede ser difícil comenzar una conversación sobre estos problemas con un/a cliente porque va a tener que hacerle preguntas muy personales.

3. Explique que comenzar una consulta con preguntas sobre la salud general de una mujer puede allanar el camino para realizar preguntas más sensibles sobre prácticas sexuales y VIH.

4. Repase la siguiente lista de preguntas que los participantes pueden usar cuando hablan con un/a cliente, y revíselas con ellos. (Nota: Prepare estas preguntas con anterioridad en el rotafolio. Modifique las preguntas, según crea necesario).

- ¿Habló alguna vez con su pareja sobre cuándo desean tener hijos y cuántos desean tener?

- ¿Habló alguna vez con su pareja sobre planificación familiar?

- ¿Habló alguna vez con su pareja sobre su vida sexual en general?

- ¿Tiene otras parejas sexuales?

- ¿Cuántas parejas sexuales ha tenido en el pasado?

- ¿Usa preservativos? 
- ¿Se ha realizado alguna vez un examen de detección de cáncer de cuello uterino?

- ¿Usó alguna vez algún tipo de anticonceptivo? ¿Cuáles? ¿Con qué frecuencia? ¿Cómo se siente su pareja al respecto?

- ¿Habló alguna vez con su pareja sobre ITS o VIH?

- ¿Tuvo alguna vez una ITS?

- ¿Se realizó alguna vez una prueba de VIH?

- ¿Se realizó su pareja alguna vez una prueba de VIH?

- ¿Qué probabilidad hay de que pueda tener una ITS o VIH? ¿Qué probabilidad hay de que su pareja pueda tener una ITS o VIH?

- ¿Cree que en la actualidad su pareja puede tener una ITS? ¿Usted tiene algún síntoma que le preocupe?

- ¿Alguien alguna vez le exigió de forma violenta tener relaciones sexuales con usted?

- ¿Alguien la forzó alguna vez a tener relaciones sexuales?

- ¿Alguna vez se sintió deprimida luego de tener un bebé?

- ¿Habló alguna vez con su pareja sobre tener relaciones sexuales después del embarazo?

5. Pida a los participantes que se dividan en parejas y que se hagan algunas de las preguntas entre sí. Pídales que estén atentos a qué preguntas los hacen sentir incómodos al hacerlas $\mathrm{o}$ al responderlas.

6. Recuerde a los participantes que hablar sobre estos temas puede ser una experiencia incómoda, incluso para los profesionales de la salud.

7. Señale que para que los clientes reciban servicios de salud integrales, es necesario mantener estas conversaciones y sentirse seguros al entablarlas.

8. Mencione que para reducir el estigma sobre estos problemas, debemos comenzar a hablar libremente sobre relaciones sexuales y sobre la salud en general de mujeres y hombres.

\section{Instrucciones para la explicación del paquete de herramientas de la Estrategia de Consejería Balanceada Plus}

1. Pida a los participantes que abran su copia de la Estrategia de Consejería Balanceada Plus: Un paquete de herramientas para proveedores de servicios de planificación familiar que trabajan en entornos con alta prevalencia de ITS/VIH. Deles alrededor de un minuto para que abran el paquete y vean el contenido.

2. Repase los contenidos del paquete de herramientas. Si el paquete de herramientas completo no está disponible, repase las ayudas de trabajo de la ECB+ y la Guía del usuario de la $E C B+y$, luego, describa lo siguiente:

- Guía del usuario de la ECB+ sobre cómo implementar la ECB+. Es una explicación detallada del algoritmo de 19 pasos de la ECB+.

- El algoritmo de la ECB+ que resume los 19 pasos recomendados para implementar la ECB+ durante la consulta de planificación familiar. Estos pasos se organizan según cuatro etapas de consulta: evaluación de necesidades previas a la elección, elección del método, acciones posteriores a la elección y detección sistemática de otras necesidades de servicios. Durante cada etapa de consulta, se guía al proveedor sobre cómo usar las ayudas de trabajo de la ECB+ paso a paso. De acuerdo con la respuesta del/de la cliente sobre los puntos analizados, el algoritmo indica qué acciones realizar.

- Tarjetas de consejería que el proveedor usa durante la sesión de consejería. Hay 34 tarjetas de consejería. La primera tarjeta presenta seis preguntas que el proveedor de servicios formula para descartar que la cliente esté embarazada (adoptadas de aquellas desarrolladas por Stanback et al. 1999). Hay 18 tarjetas específicas de métodos que presentan información sobre cada método de planificación familiar. Cada tarjeta de método tiene en el frente una ilustración del método anticonceptivo. En el reverso se presenta una lista de las características clave del método y se describe su efectividad. Estas tarjetas se usan para descartar aquellos métodos que no son apropiados para las 
intenciones reproductivas del/de la cliente y para acotar la elección y llegar a una decisión final. En las quince tarjetas de consejería, se proporciona información adicional sobre la consejería y los servicios que puede necesitar un/a cliente de planificación familiar. Estos servicios adicionales incluyen consejería sobre lo siguiente: períodos saludables para el embarazo y para el espaciamiento entre embarazos; período posparto saludable para la madre y el recién nacido; exámenes de detección de cáncer de cuello uterino y de cáncer de mama; consejería para adolescentes; seguridad y apoyo a la mujer; servicios para hombres; atención posaborto; prevención y transmisión de ITS/VIH; prevención y transmisión del virus del Zika; evaluación de riesgos; protección doble; salud positiva, dignidad y prevención, y consejería y pruebas de VIH.

- Folletos de métodos sobre cada uno de los 18 métodos anticonceptivos. Están diseñados para ayudar al/a la cliente a entender mejor el método elegido. El proveedor le da al/a la cliente un folleto del método seleccionado y un folleto con información sobre preservativos para que se lleve a su casa. Los proveedores deben alentar a los clientes analfabetos, o con un bajo nivel de alfabetización, a que se lleven el folleto a su casa para que su pareja o amigo cercano pueda repasarlo con ellos otra vez.

- La Rueda con los criterios médicos de elegibilidad para el uso de anticonceptivos de la OMS (2015) es una ayuda de trabajo para los proveedores sobre las cuatro categorías de elegibilidad para el uso de anticonceptivos en relación con las condiciones médicas descritas en el documento Criterios médicos de elegibilidad para el uso de anticonceptivos, quinta edición, publicado por el Departamento de Salud Reproductiva de la Organización Mundial de la Salud. La ayuda de trabajo es una herramienta interactiva para identificar métodos contraindicados para afecciones médicas específicas. La herramienta se probó en tres países y se encontró que fue muy útil para los proveedores que la usaron.

3. Señale que las ayudas de trabajo de la ECB + y la Guía del usuario de la ECB+ incorporan los últimos estándares internacionales y orientación que sigue las recomendaciones de la OMS (2015).

4. Explique a los participantes que deben consultar la Guía del usuario de la ECB+ cuando necesitan obtener más información sobre cómo usar la ECB+. La Guía del usuario de la ECB+ es mucho más completa que el algoritmo de la ECB+.

5. Antes de continuar, asegúrese de que no haya preguntas.

6. Explique que los participantes ahora aprenderán cómo implementar la ECB+ usando las ayudas de trabajo de la ECB+. 


\section{Etapa previa a la elección}

Tiempo total: 90 minutos

Al final de esta sesión, los participantes:

- podrán aconsejar a un/a cliente de planificación familiar sobre la etapa previa a la elección de la ECB+.

\section{ACLARACIÓN DE VALORES}

Tiempo: 20 minutos

\section{Materiales y preparativos}

- Tenga disponible un rotafolio u hojas grandes de papel y marcadores.

- Tenga preparada una lista con declaraciones de valores para leerles en voz alta a los participantes. Puede agregar o quitar declaraciones de la lista que se encuentra en el punto n. ${ }^{\circ} 5$.

\section{Instrucciones}

1. Explique que nuestros valores son una parte fundamental de nuestras vidas y que tienen un efecto en cómo nos comportamos tanto personal como profesionalmente.

2. Señale que es importante prestar atención a nuestros valores en lo que respecta a temas de salud y salud sexual y que también es importante evitar hacer juicios de valor que afecten nuestro trabajo profesional.

3. Mencione que leerá algunas declaraciones y, luego de cada una, votarán si están de acuerdo o no. Luego se analizarán las declaraciones de forma grupal.

4. Señale que no hay respuestas «correctas» $\mathrm{O}$ «incorrectas» con respecto a los valores.

5. Lea las declaraciones de a una y haga que el grupo vote.

- Es aceptable que una persona tenga más de una pareja sexual a la vez.

- Es más aceptable que los hombres tengan varias parejas sexuales, a que las mujeres tengan varias parejas sexuales.

- Las personas que no usan preservativos son las únicas culpables si contraen VIH.

- Los proveedores de atención de salud tienen el derecho a saber el estado de VIH de sus pacientes.

- Una mujer que sabe que está infectada con VIH no debería tener un bebé.

- Se debería alentar la práctica de sexo oral para reducir el riesgo de contraer VIH.

- Los niños deberían aprender sobre VIH tan pronto como sea posible.

- Se debería disuadir a las adolescentes de usar la planificación familiar.

- Educar a los padres sobre el uso de preservativos ayudará a proteger a los adolescentes del VIH.

- La mayor parte de las mujeres sin educación son incapaces de tomar sus propias decisiones sobre su vida sexual y reproductiva.

6. Una vez que haya analizado las declaraciones mencionadas arriba y cómo pueden afectar el comportamiento de los participantes con los clientes, fomente un análisis sobre cómo respetar los valores de otros a pesar de los propios. (Nota: Escriba las respuestas en el rotafolio).

7. Señale que los proveedores deben ser conscientes de sus propias creencias y deben evitar imponérselas a sus clientes.

\section{PASOS DEL 1 AL 6}

Tiempo: 45 minutos

\section{Materiales y preparativos}

- Tenga disponible un rotafolio u hojas grandes de papel y marcadores.

- Asegúrese de que todos los participantes tengan una copia de la Guía del usuario de la ECB+ y de las tarjetas de consejería. 


\section{Instrucciones}

PASO 1. ESTABLEZCA Y MANTENGA UNA RELACIÓN CORDIAL Y CÁLIDA.

1. Pida a los participantes que abran la Guía del usuario de la ECB+ y que se dirijan al paso 1 . Repase las siguientes acciones que ayudan a lograr el paso 1:

- Establezca una actitud formal, pero amigable.

- Llame al/a la cliente por su nombre.

- Demuestre interés en lo que el/la cliente le cuenta.

- Establezca contacto visual con el/la cliente.

- Escuche y responda sus preguntas.

- Demuestre apoyo y comprensión sin juzgar.

- Formule preguntas para alentar la participación en la charla.

2. Pregunte a los participantes si hay otras acciones que sean útiles para establecer una relación cálida y cordial. (Nota: Escriba las respuestas en el rotafolio).

PASO 2. INFORME AL/A LA CLIENTE (Y A SU PAREJA, SI SE ENCUENTRA PRESENTE) QUE DURANTE LA CONSULTA TENDRÁ LA OPORTUNIDAD DE ABORDAR TANTO SUS NECESIDADES DE SALUD COMO SUS NECESIDADES DE PLANIFICACIÓN FAMILIAR.

1. Explique que los clientes de planificación familiar pueden tener dudas sobre otros problemas de salud o necesitar otros servicios de salud. Estas dudas y servicios pueden tratarse durante la misma consulta y se incluyen en la etapa de detección sistemática para otros servicios.

2. Pida a los participantes que piensen en otros servicios que estén disponibles en el centro donde se implementará la ECB + . Pregunte sobre aquellos servicios que un/a cliente pueda necesitar y que están disponibles mediante una derivación.

3. Diga a los participantes que le informen a cada cliente sobre estos servicios y que tomen nota de cualquier servicio específico que el paciente solicite para que pueda abordarlo luego de repasar el algoritmo de la ECB+.

4. Explique que el objetivo principal de la ECB+ es guiar a los proveedores a través del proceso de consejería sobre planificación familiar y facilitar la selección de un método de planificación familiar apropiado. Es por eso que este tema se abordará primero.

PASO 3. PREGÚNTELE AL/A LA CLIENTE SOBRE EL TAMAÑO ACTUAL DE SU FAMILIA, SOBRE SU DESEO DE TENER MÁS HIJOS Y SOBRE SUS PRÁCTICAS ANTICONCEPTIVAS ACTUALES. ASESORE AL/A LA CLIENTE SOBRE PERÍODOS SALUDABLES PARA EL EMBARAZO Y PARA EL ESPACIAMIENTO ENTRE EMBARAZOS USANDO UNA TARJETA DE CONSEJERÍA.

1. Explique que todas las parejas e individuos tienen derecho a decidir libre y responsablemente la cantidad de hijos y el espaciamiento entre hijos, así como a tener acceso a información y educación sobre planificación familiar.

2. Explique que los datos muestran tasas más altas de enfermedad o mortalidad maternal, infantil y prenatal cuando un embarazo ocurre en menos de dos años o en más de cinco años luego de un nacimiento vivo.

3. Explique que los datos muestran un efecto negativo similar en la salud de la madre y del bebé cuando un embarazo ocurre menos de seis meses después de un aborto provocado o espontáneo.

4. Explique que los resultados de los estudios muestran claramente que las mujeres jóvenes que quedan embarazadas antes de los 18 años se enfrentan, al igual que sus hijos, a consecuencias negativas tanto en lo social como en lo relacionado con la salud. Las mujeres jóvenes de entre 15 y 19 años tienen el doble de probabilidades de morir por complicaciones relacionadas con el embarazo que una mujer de 20 años o más, y las mujeres menores a 15 años tienen cinco veces más probabilidades de morir.

5. Pida a los participantes que formulen las siguientes preguntas a sus clientes:

- ¿Cuántos hijos tiene?

- ¿Cuántos hijos desea tener? ¿Cuántos hijos desea tener su pareja?

- ¿Usa actualmente algún método anticonceptivo o está retrasando un embarazo?

- Si la respuesta es sí, ¿qué método usa? ¿Está satisfecha con su método actual o le gustaría cambiarlo? 
6. Repase con los participantes los puntos de consejería que se encuentran en la tarjeta Períodos saludables para el embarazo y para el espaciamiento entre embarazos. Lea los siguientes puntos en voz alta con los participantes:

- Para las mujeres que desean tener más hijos después de un nacimiento vivo, aconseje lo siguiente:

- Por la salud de la madre y del bebé, espere al menos 2 años (24 meses), pero no más de 5 años antes de tratar de quedar embarazada otra vez.

- El uso de un método de planificación familiar elegido por la mujer permite planificar un embarazo saludable.

- Para las mujeres que deciden tener un hijo después de un aborto espontáneo o un aborto provocado, aconseje lo siguiente:

- Por la salud de la madre y del bebé, espere al menos 6 meses antes de tratar de quedar embarazada otra vez.

- El uso de un método de planificación familiar elegido por la mujer permite planificar un embarazo saludable.

- Para adolescentes, aconseje lo siguiente:

- Por la salud de la madre y del bebé, espere al menos hasta tener 18 años antes de tratar de quedar embarazada.

- Si es sexualmente activa, el uso de un método de planificación familiar elegido por la mujer permite evitar embarazos no deseados.

7. Si la pareja de la cliente se encuentra presente, use la tarjeta Apoyo y servicios para hombres.

8. Pregunte a los participantes si tienen alguna duda.

PASO 4. DESCARTE UN EMBARAZO USANDO LA TARJETA LISTA DE VERIFICACIÓN DE EMBARAZO, LA CUAL CUENTA CON 6 PREGUNTAS.

1. Explique que es importante descartar la posibilidad de que la cliente esté embarazada antes de continuar con la consulta de planificación familiar. El embarazo es una contraindicación para la mayoría de los métodos, excepto los métodos de barrera, como los preservativos.

2. Pida a los participantes que saquen sus tarjetas de consejería de la ECB+ y que busquen la tarjeta Lista de verificación de embarazo para descartar embarazos.

3. Repase las 6 preguntas de la tarjeta:

- ¿Tuvo un bebé hace menos de 6 meses? Si la respuesta es «Sí», ¿ realiza una lactancia completa o casi completa? ¿No ha tenido su menstruación desde el parto?

- ¿Se abstuvo de tener relaciones sexuales sin protección (sin un método de planificación familiar) desde su última menstruación o parto?

- ¿Ha dado a luz en las últimas 4 semanas?

- ¿Su menstruación comenzó en los últimos 7 días (o en los últimos 12 si planea usar un dispositivo intrauterino [DIU])?

- ¿Tuvo un aborto espontáneo o un aborto provocado en los últimos 7 días?

- ¿Usa un método anticonceptivo confiable de forma sistemática y correcta?

4. Indique a los participantes que se dirijan a la primera tabla de la página siguiente, la cual también aparece en la Guía del usuario de la ECB+, y repase qué acciones tomar según cómo la cliente responda cada una de las 6 preguntas. 
Responde "Sín a cualquiera de las preguntas y no tiene señales ni síntomas de embarazo

*Una vez que la cliente haya respondido "Sín a una de las preguntas, no es necesario que continúe con el resto.

Responde "No" a todas las preguntas
1. Un embarazo es poco probable.

2. Diríjase al paso 5.

1. No se puede descartar un embarazo.

2. De ser posible dele a la cliente una prueba de embarazo o derívela a una clínica prenatal.

3. Bríndele un método de respaldo, como preservativos, para que use hasta que tenga su menstruación.

4. Bríndele de manera anticipada el método preferido (siempre que sea posible) para que lo use el primer día de su periodo O BIEN pídale que regrese en ese momento para recibir el método que eligió.

5. Diríjase al paso 13.

PASO 5. MUESTRE TODAS LAS TARJETAS DE MÉTODO. PREGÚNTELE AL/A LA CLIENTE SI DESEA UN MÉTODO EN PARTICULAR.

1. Muestre todas las tarjetas de método como lo indica la figura 1 (consulte el Apéndice) de la Guía del usuario de la ECB+.

2. Explique que antes de acotar las opciones de métodos de un/a cliente, el proveedor le debe preguntar si ya tiene un método en mente.

3. Indique a los participantes que se dirijan a la tabla a continuación en la Guía del usuario de la $E C B+$, y repase qué hacer cuando la cliente responda a la pregunta «¿Tiene algún método en particular en mente?»

Si el/la cliente...
Responde "No"
Responde "Sí"
Le da información incompleta sobre
el método que eligió
0
no conoce otras alternativas que pueden
ser más convenientes

Haǵa lo siguiente...

Diríjase al paso 6.

1. Pregúntele qué método desea.

2. Pregúntele qué sabe acerca del método.

3. Si la información es correcta, diríjase al paso 9.

1. Corrija la información incorrecta.

2. Diríjase al paso 6 para ayudar al/a la cliente a elegir un método, si es necesario.

\section{PASO 6. FORMULE TODAS LAS PREGUNTAS QUE SE DETALLAN A CONTINUACIÓN. APARTE LAS TARJETAS DE MÉTODO SEGÚN LAS RESPUESTAS DE LA CLIENTE.}

1. Señale que este es un paso central para el modelo de la ECB+. Pida a los participantes que se dirijan al paso 6 de la Guía del usuario de la ECB+.

2. Explique que en el paso $\mathbf{6}$ hay seis preguntas clave. Estas preguntas ayudan al proveedor a identificar las intenciones reproductivas del/de la cliente. También ayudan al/a la cliente a elegir el mejor método de planificación familiar para sus necesidades.

3. Mencione que los participantes pueden comenzar el proceso diciéndole al/a la cliente algo como «Ahora analizaremos sus necesidades anticonceptivas. Reduciremos la cantidad de métodos que puedan ser apropiados para usted. Luego, analizaremos las características principales de cada método. Esto nos ayudará a encontrar el método indicado para satisfacer sus necesidades». 
4. Cuando explique este paso, demuestre cómo hacer las preguntas y cómo apartar las tarjetas de consejería con un participante. Seleccione a un participante del grupo (o hágalo con otro instructor) y dele el siguiente texto:

\section{SITUACIÓN HIPOTÉTICA}

Usted es una mujer de 28 años con tres hijos. Ha dado a luz hace de 5 meses. Está amamantando a su bebé y tiene antecedentes de fibroides uterinos. Está cansada y no quiere tener hijos por un tiempo. Su esposo no coopera con la planificación familiar. No quiere que nada interfiera con el hecho de tener relaciones sexuales cuando él lo desea. Usted ha usado espermicidas en el pasado. La ineficacia del método dio lugar a su tercer embarazo. Está interesada en un método que pueda usar sin que su esposo lo note.

5. Pida a los participantes que se dirijan a la tabla debajo del paso $\mathbf{6}$ de la Guía del usuario de la ECB+ para que sigan la lectura.

6. Comience con la siguiente pregunta: «¿Desea tener hijos en un futuro?»

7. Demuestre cómo mantener o descartar las tarjetas de método según las instrucciones en la tabla que se encuentra a continuación.

\begin{tabular}{|l|l|}
\hline Si el/la cliente... & Haga lo siguiente... \\
\hline Responde "Sí" & $\begin{array}{l}\text { 1. Aparte las tarjetas Vasectomía y Ligadura de trompas. } \\
\text { 2. Explíquele que la esterilización es permanente y no es adecuada para } \\
\text { alguien que puede querer otro hijo. }\end{array}$ \\
\hline Responde "No" & Conserve todas las tarjetas y continúe. \\
\hline
\end{tabular}

8. Formule la siguiente pregunta: «¿Ha dado a luz en las últimas 48 horas?»

9. Demuestre cómo mantener o descartar las tarjetas de método según las instrucciones en la tabla que se encuentra a continuación.

\begin{tabular}{|l|l|}
\hline Si la cliente... & \begin{tabular}{l} 
Haga lo siguiente... \\
\hline Responde "Sí"
\end{tabular} \\
$\begin{array}{l}\text { 1. Aparte las tarjetas Anticonceptivos orales combinados (Píldora), } \\
\text { Inyectable mensual, Implantes y Ligadura de trompas. }\end{array}$ \\
$\begin{array}{l}\text { 2. Explique que los métodos hormonales combinados y la ligadura } \\
\text { de trompas no son seguros para el uso inmediatamente después } \\
\text { del parto. }\end{array}$ \\
\hline Responde "No" & Conserve todas las tarjetas y continúe. \\
\hline
\end{tabular}

10. Formule la pregunta siguiente: «¿Está amamantando a un lactante de menos de 6 meses?»

11. Demuestre cómo mantener o descartar las tarjetas de consejería según las instrucciones en la tabla que se encuentra a continuación.

\begin{tabular}{|l|l|}
\hline Si la cliente... & Haga lo siguiente... \\
\hline Responde "Sí» & $\begin{array}{l}\text { 1. Aparte las tarjetas Anticonceptivos inyectables combinados (AIC) } \\
\text { y Anticonceptivos orales combinados (Píldora). } \\
\text { 2. Explique que las hormonas en estos métodos afectan la lactancia. }\end{array}$ \\
\hline 1. Aparte las tarjetas Método de la amenorrea de la lactancia (MELA) \\
Responde "No" & 2. Exillo vaginal de progesterona (AVP). \\
& no amamanten o que vuelvan a tener su menstruación.
\end{tabular}

12. Asegúrese de que no haya preguntas pendientes hasta el momento.

13. Formule la siguiente pregunta: «¿Respalda su pareja su decisión sobre planificación familiar?»

14. Demuestre cómo mantener o descartar las tarjetas de consejería según las instrucciones en la siguiente tabla. 


\section{Si el/la cliente...}

Responde "Sí»"

Responde "No"

\section{Haga lo siguiente...}

Continúe con la pregunta siguiente.

1. Aparte las tarjetas Preservativo femenino, Preservativo masculino, Método de Días Fijos ${ }^{\circledR}$, Método de Dos Días ${ }^{\circledR}$ y Retirada.

2. Explíquele que estos métodos requieren la cooperación de su pareja.

15. Explique a los participantes que deben invitar al/a la cliente a que lleve a su pareja a la sesión de consejería para hablar sobre planificación familiar con un proveedor.

16. Señale que los preservativos masculinos y femeninos son importantes para la protección contra las ITS, incluido el VIH y el virus del Zika, y que también se requiere la cooperación de la pareja.

17. Formule la siguiente pregunta: «¿Sufre alguna afección médica? ¿Toma medicamentos?»

18. Demuestre el uso de la Rueda con los criterios médicos de elegibilidad para el uso de anticonceptivos de la OMS para determinar los métodos anticonceptivos que están contraindicados para una afección que tenga la cliente o para un medicamento que esté tomando. Siga las instrucciones en la tabla que se encuentra a continuación.

\begin{tabular}{|l|l|}
\hline Si el/la cliente... & Haga lo siguiente... \\
\hline Responde "Sí" & $\begin{array}{l}\text { 1. Pregúntele qué afecciones médicas padece o qué medicamentos toma. } \\
\text { 2. Consulte la Rueda con los criterios médicos de elegibilidad para el uso } \\
\text { de anticonceptivos de la OMS (incluida) o las directrices nacionales } \\
\text { actuales para identificar los métodos contraindicados. }\end{array}$ \\
$\begin{array}{l}\text { 3. Aparte todas las tarjetas con métodos contraindicados. } \\
\text { 4. Explíquele al/a la cliente por qué aparta las tarjetas de método, según } \\
\text { la información proporcionada en las directrices. }\end{array}$ \\
\hline Responde "No" & Continúe con la pregunta siguiente.
\end{tabular}

19. Lea en voz alta la siguiente nota sobre la Rueda con los criterios médicos de elegibilidad para el uso de anticonceptivos de la OMS:

- La Rueda con los criterios médicos de elegibilidad (CME) para el uso de anticonceptivos de la OMS es una ayuda de trabajo para los proveedores basada en las cuatro categorías de elegibilidad para el uso de anticonceptivos en relación con las afecciones médicas descritas en el documento «Criterios médicos de elegibilidad para el uso de anticonceptivos», quinta edición, publicado por el Departamento de Salud Reproductiva de la Organización Mundial de la Salud. Esta herramienta guía a los proveedores a través de las afecciones médicas y los medicamentos que pueden tener contraindicaciones con el uso de algún método anticonceptivo en particular. La OMS probó la ayuda de trabajo en tres países y encontró que resultó ser muy útil para los proveedores que la usaron.

20. Pregunte a los participantes si tienen dudas sobre los Criterios Médicos de Elegibilidad para el uso de anticonceptivos de la OMS, sobre la Rueda con los CME para el uso de anticonceptivos de la OMS o sobre las directrices nacionales relacionadas con las contraindicaciones.

21. Formule la última pregunta: «¿Existen métodos que no desee usar o que no haya tolerado en el pasado?»

22. Demuestre cómo mantener o descartar las tarjetas de consejería según las instrucciones en la tabla que se encuentra a continuación.

\section{Si el/la cliente...}

\section{Responde "Sín}

Responde "No"

El/la cliente eliminó un método debido a rumores o información falsa.

\section{Haga lo siguiente...}

1. Pregúntele qué métodos usó y cuál fue su experiencia con cada uno.

2. Aparte las tarjetas de los métodos que el/la cliente no desee.

Conserve el resto de las tarjetas.

1. Proporciónele la información correcta.

2. No aparte la tarjeta para ese método. 


\section{PRÁCTICA}

Tiempo: 25 minutos

\section{Instrucciones}

1. Haga que los participantes realicen un juego de roles breve para practicar la etapa previa a la elección de la ECB + usando los pasos del 1 al 6.

a. Pida a los participantes que elijan una pareja, preferentemente la persona sentada a su lado.

b. Haga que una de las personas en la pareja actúe como el «proveedor de servicios» y que la otra actúe como el/la «cliente».

c. Pídale a la persona que actúa como proveedor que use las tarjetas de consejería para llevar a cabo la etapa previa a la elección de la ECB+.

d. Pídale a la persona que actúa como «cliente» que piense en un/a cliente de planificación familiar al que haya aconsejado recientemente y que actúe como él/ella cuando su pareja le formule las preguntas previas a la elección.

e. Pídale a la persona que actúa como «cliente» que piense en un método anticonceptivo que planea usar y si tendrá o no una afección por la cual ese método no se recomendaría.

f. Si el/la «cliente» decide tener contraindicaciones para el primer método elegido, asegúrese de tener otro método en mente para permitirle al proveedor de servicios descubrir cuál es.

g. Dígale a la persona que actúa como proveedor que luego del paso $\mathbf{6}$ debe quedarse con las tarjetas de método restantes que no se hayan apartado durante el juego de roles. (Nota: Cuando los participantes realicen el juego de roles, camine por el salón para observarlos y, si es necesario, corríjalos delicadamente).

h. Recuérdele al «proveedon» que use habilidades de buena consejería.

i. Asigne alrededor de 15 minutos para este juego de roles.

j. Luego de 15 minutos, pida a los participantes que cambien de roles. Asigne alrededor de 15 minutos para el segundo juego de roles.

k. Asegúrese de pedirle a la persona que actúa como proveedor que debe quedarse con las tarjetas de método restantes que no se hayan apartado durante el juego de roles.

2. Pregunte si los participantes tienen alguna otra consulta. Responda todas las preguntas y todos los comentarios antes de continuar.

3. Recuerde a los participantes que la ECB + se desarrolló como respuesta al hallazgo de que los proveedores les daban a los clientes demasiada información sobre todos los métodos. Lo hacían sin importar si el método era relevante para satisfacer las necesidades o las intenciones reproductivas del/de la cliente.

4. Mencione que las tarjetas de método restantes del juegos de roles son un ejemplo de cómo identificar los métodos anticonceptivos más apropiados para las necesidades e intenciones del/de la cliente.

5. Explique que esto ayuda a reducir la cantidad de información que se les da a los clientes. También ayuda a mejorar la memoria y la retención de la información. Recuérdeles a los participantes el ejercicio del juego del teléfono. 


\section{Etapa de elección del método}

Tiempo total: 45 minutos

Al final de esta sesión, los participantes:

- podrán aconsejar a un/a cliente de planificación familiar sobre la etapa de elección del método de la $\mathrm{ECB}+$.

\section{PASOS DEL 7 AL 9}

Tiempo: 30 minutos

\section{Materiales y preparativos}

- Asegúrese de que los participantes tengan los folletos de método de la ECB+.

\section{Instrucciones}

1. Pida a los participantes que miren el reverso de las tarjetas de método que no se apartaron durante el juego de roles.

2. Repase la sección sobre la efectividad del método y señale lo siguiente:

- La descripción escrita de la efectividad del método.

- El porcentaje en el lado izquierdo de la tarjeta, el cual también representa la efectividad.

3. Explique que la efectividad del método se mide en función del número de embarazos entre 100 mujeres durante el primer año de uso del método.

4. Señale que a mayor porcentaje, más efectivo es el método. Un porcentaje más alto significa que por año ocurren menos embarazos cada 100 mujeres que usan ese método.

5. Señale la información de efectividad del método en las tarjetas Ligadura de trompas y Método de Dos Días como ejemplo. Pida a los participantes que se dirijan a la figura 3 en la Guía del usuario de la ECB+.

FIGURA 3. EJEMPLO DE TARJETAS DE MÉTODO QUE MUESTRAN LA EFECTIVIDAD PARA PREVENIR UN EMBBARAZO

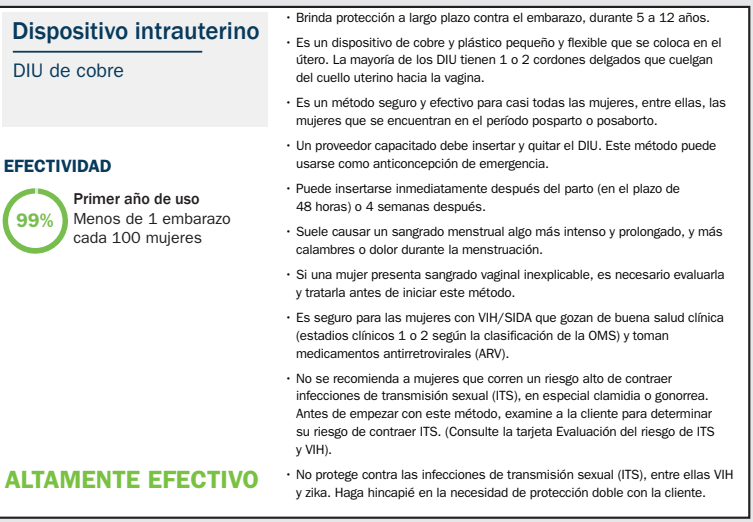

Método de Dos Días ${ }^{\circledR} \quad$ - Método óptimo para mujeres con secreciones saludables

Las secreciones saludables no tienen mal olor ni causan

La cliente controla sus secreciones del cuello del útero al menos dos veces al día. Si nota secreciones de cualquier a ese control, probablemente pueda quedar embarazada (días fértiles).

EFECTIVIDAD

Uso habitual

- Durante los días en que la cliente puede quedar embarazada, debe abstenerse de tener relaciones sexuales sin protección o puede usar preservativos u otro método de

No protege contra las infecciones de transmisión sexual
(ITS), entre ellas VIH y zika.

Requiere la cooperación de la pareja. 


\section{PASO 7. REPASE BREVEMENTE LOS MÉTODOS QUE NO SE HAYAN APARTADO E INDIQUE}

SU EFECTIVIDAD.

1. Señale las características del método, las cuales se encuentran a la derecha de la información sobre la efectividad.

2. Pida a los participantes que ordenen las tarjetas de método restantes por orden de efectividad. Las tarjetas se deben ordenar de más efectiva (mayor porcentaje) a menos efectiva (menor porcentaje).

3. Demuestre cómo ordenar las tarjetas con el mayor porcentaje de efectividad primero y los porcentajes más bajos al final.

4. Explique que, luego de comenzar con la tarjeta con el mayor porcentaje (más efectiva), el proveedor repasa las características de las tarjetas de método restantes con el/la cliente.

5. Explique que, de esta manera, el proveedor solo proporciona información sobre los métodos de planificación familiar que son relevantes para las necesidades e intenciones reproductivas $\mathrm{del} / \mathrm{de}$ la cliente.

6. Señale que al comenzar por la tarjeta con el mayor porcentaje el proveedor analiza el método más efectivo primero.

7. Haga hincapié en que los preservativos (masculinos o femeninos) son el único método que ofrece protección doble: protección contra el embarazo y contra las ITS, incluido el VIH y el virus del Zika. Haga hincapié en lo siguiente:

- Los preservativos masculinos y femeninos reducen significativamente el riesgo de contraer una ITS, incluido el VIH y el virus del Zika, cuando se usan de forma sistemática y correcta en cada acto sexual.

- Cuando se usan de forma correcta y sistemática, el uso de preservativos previene del 80 al 95 por ciento de la transmisión del VIH que hubiera ocurrido sin su uso.

- Los preservativos reducen el riesgo de contraer muchas ITS cuando se usan de forma sistemática y correcta:

- Proporcionan mejor protección contra la propagación de ITS por secreciones, como el VIH, el zika, la gonorrea y la clamidia.

- Protegen, asimismo, contra la propagación de ITS por contacto directo, como el herpes y el virus del papiloma humano.

\section{PASO 8. PÍdALE AL/A LA CLIENTE QUE ELIJA EL MÉTODO QUE ENCUENTRE MÁS CONVENIENTE.}

1. Explique que si la cliente es adolescente, el proveedor debe usar la tarjeta Consejería para adolescentes, para informarle que puede obtener cualquier método.

2. Mencione que, en este punto, el proveedor pregunta si el/la cliente tiene alguna consulta, duda o comentario sobre los métodos analizados.

3. Explique que luego de responder las preguntas, el proveedor le pide al/a la cliente que elija un método de las tarjetas que se analizaron.

4. Haga hincapié en que, una vez que se elige el método, el proveedor no debe quitar las tarjetas de método de la mesa. Es posible que el/la cliente las necesite si tiene afecciones por las cuales no se recomienda el método o por si cambia de opinión.

5. Mencione que si no prefiere ninguno de los métodos analizados o si no se puede decidir, debe darle un método para que use hasta que se decida y dirigirse al paso 13.

6. Señale la importancia de no dejar que un/a cliente se vaya con las manos vacías. Los preservativos pueden proporcionar doble protección hasta que el/la cliente seleccione otro método.

7. Pregunte si los participantes tienen alguna duda o algún comentario. Asegúrese de responder todas las preguntas antes de continuar al paso 9.

PASO 9. CON EL FOLLETO ESPECÍFICO DEL MÉTODO, COMPRUEBE QUE EL/LA CLIENTE NO PRESENTE NINGUNA AFECCIÓN POR LA CUAL NO SE RECOMIENDE EL MÉTODO.

1. Explíqueles que las contraindicaciones de un método ya se repasaron en el paso 6, y que este paso está diseñado para confirmar que el/la cliente no padezca de ninguna afección que represente una contraindicación.

2. Explíqueles que el proveedor selecciona el folleto para el método que el/la cliente eligió. Tomemos como ejemplo el método denominado píldora. 
3. Señale que el proveedor debe repasar la sección «Método no recomendado si...» del folleto. La píldora no se recomienda si la cliente:

- está amamantando a un lactante de menos de 6 meses;

- se encuentra dentro de los 21 días de haber dado a luz (sin importar el estado de lactancia);

- fuma cigarrillos y tiene más de 35 años;

- tiene presión arterial alta, 140/90 o más;

- padece de determinadas enfermedades cardíacas o vasculares graves poco frecuentes (la situación debe analizarse con el proveedor de atención de salud);

- sufre de enfermedad hepática grave;

- presenta coágulos sanguíneos, trombosis venosa profunda o embolia pulmonar, o se encuentra en tratamiento anticoagulante (la situación debe analizarse con el proveedor de atención de salud);

- sufre de lupus;

- sufre de una enfermedad de la vesícula biliar, incluso si se la trata médicamente (la situación debe analizarse con el proveedor de atención de salud);

- tiene cáncer de mama o tuvo antecedentes de esa enfermedad;

- sufre de migraña (dolores de cabeza intensos que no cesan al tomar paracetamol) y tiene 35 años o más;

- presenta aura de migraña (la visualización ocasional de un punto brillante que crece en un ojo);

- toma medicamentos anticonvulsivos o rifampicina (para la tuberculosis u otras infecciones); $y$

- es VIH positivo y consume inhibidores de la proteasa reforzados con ritonavir como parte de la terapia antirretroviral de gran actividad (TARGA).

4. Explique que si el/la cliente sufre de una afección por la cual no se recomienda el método elegido, no es necesario dar más información, de la disponible en el folleto, y que el/la cliente necesitará seleccionar otro método.

5. Indique a los participantes que se dirijan a la tabla que se encuentra a continuación y en la Guía del usuario de la ECB+, y repase cómo el proveedor decide si proporciona el método o si vuelve al paso anterior.

\begin{tabular}{|l|l|}
\hline Si el/la cliente... & Haga lo siguiente... \\
\hline No tiene afecciones & Diríjase al paso 10. \\
\hline Tiene alguna afección & $\begin{array}{l}\text { 1. Explique que es necesario que elija otro método. } \\
\text { 2. Vuelva al paso } 7 .\end{array}$ \\
\hline $\begin{array}{l}\text { Tiene alguna afección y llegó hasta este } \\
\text { paso desde el paso } 5 \text { (ya tenía un método } \\
\text { en mente). }\end{array}$ & $\begin{array}{l}\text { 1. Explique que es necesario que elija otro método. } \\
\text { 2. Vuelva al paso } 6 .\end{array}$ \\
\hline
\end{tabular}

\section{PRÁCTICA}

\section{Tiempo: 15 minutos}

1. Pida a los participantes que giren hacia su pareja y que le expliquen los pasos del $\mathbf{7}$ al $\mathbf{9 .}$ No necesitan realizar un juego de roles; solo deben explicar el proceso.

2. Luego de 7 u 8 minutos, pídales que cambien de roles y que el oyente explique los pasos del 7 al 9. 


\section{Etapa posterior a la elección}

Tiempo total: 45 minutos

Al final de esta sesión, los participantes:

- podrán aconsejar a un/a cliente de planificación familiar sobre la etapa posterior a la elección de la $\mathrm{ECB}+$.

PASOS DEL 10 AL 12

Tiempo: 20 minutos

\section{Materiales y preparativos}

- Ninguno.

\section{Instrucciones}

PASO 10. ANALICE EL MÉTODO ELEGIDO CON EL/LA CLIENTE, USANDO EL FOLLETO DEL MÉTODO COMO HERRAMIENTA DE CONSEJERÍA. DETERMINE EL ENTENDIMIENTO DEL/DE LA CLIENTE Y REFUERCE LA INFORMACIÓN CLAVE.

1. Explique que, en este punto, el/la cliente ya seleccionó un método y está listo para escuchar más información sobre este.

2. Explique que esto es importante para ayudar a que el/la cliente comprenda mejor el método que eligió. La comprensión es clave para un uso efectivo del método y para mantener la salud $\mathrm{del} / \mathrm{de}$ la cliente.

3. Mencione algunas formas en las que los participantes puedan comenzar la conversación, por ejemplo, «Señora o señor \{nombre\}, este folleto es para que se lo lleve a casa. Antes de irse, me gustaría que repasáramos la información».

4. Use el folleto de método de la ECB+ sobre la píldora para demostrar cómo un proveedor repasa la siguiente información presente en el folleto de método con un/a cliente:

- Información general (esta es la misma información que se encuentra en la tarjeta de consejería de la $\mathrm{ECB}+$ )

- Cómo funciona el método

- Información importante (sobre el método)

- Método no recomendado si

- Efectos secundarios

- Beneficios para la salud (si corresponde)

- Cómo se usa

- Seguimiento (si corresponde)

- Regrese al centro de salud si

5. Explique que luego de que el proveedor analiza la información en el folleto de método, se lo entrega al/a la cliente. Lo alienta a que repase el folleto de nuevo en su casa y cuando necesite recordar algo sobre el método.

6. Mencione que un proveedor puede comprobar la comprensión que tiene un/a cliente sobre el método al pedirle que responda a las siguientes preguntas con sus propias palabras. $\mathrm{El} /$ la cliente puede consultar el folleto.

- ¿Cómo se usa el método que eligió?

- ¿Qué efectos secundarios puede experimentar con el método?

- ¿Puede el método protegerlo contra ITS, incluido el VIH y el virus del Zika?

- ¿Cuáles son los signos que indican que debe volver al centro de atención de salud?

7. El proveedor debe asegurarle al/a la cliente que no es un problema olvidar algunos detalles del método. Asegúrese de que el/la cliente pueda encontrar la información en el folleto.

8. Recuerde preguntarle si tiene alguna duda. Refuerce la información básica sobre el método elegido, según sea necesario. 
¿Qué ocurre si hay métodos que no están disponibles?

1. Pregunte a los participantes qué harían si métodos como el DIU, la ligadura de trompas o la vasectomía no estuvieran disponibles en el centro de atención de salud.

2. Si los participantes no lo mencionan, repase lo siguiente:

- Hable con el/la cliente sobre estos métodos de todos modos (si cubren las intenciones reproductivas del/de la cliente).

- Entréguele al/a la cliente el folleto sobre el método elegido.

- Derive al/a la cliente a un centro o instalación comercial donde pueda obtener el método.

- Proporciónele al/a la cliente un método alternativo y apropiado hasta que pueda obtener el método elegido.

3. Vuelva a señalar la importancia de nunca dejar que un/a cliente se vaya con las manos vacías. Esta puede ser su primera y última consulta. Es importante responder a las necesidades del/ de la cliente, incluso cuando usted no tenga el método disponible.

4. Repase qué hacer si un/a cliente selecciona un método que no está disponible temporalmente (fuera de stock).

- Entréguele al/a la cliente un folleto sobre el método elegido.

- Derive al/a la cliente a otro centro o instalación comercial donde pueda obtener el método.

- Proporciónele al/a la cliente un método de respaldo hasta que pueda obtener el método elegido.

- Pídale al/a la cliente que vuelva al centro cuando el método esté disponible.

5. Pregunte si tiene consultas o comentarios.

PASO 11. ASEGÚRESE DE QUE EL/LA CLIENTE HAYA TOMADO UNA DECISIÓN DEFINITIVA. DELE EL MÉTODO ELEGIDO, UN MÉTODO DE RESPALDO O DERÍVELO, SEGÚN EL MÉTODO SELECCIONADO.

1. Explique que los proveedores le deben preguntar al/a la cliente si su elección es definitiva. Asegúrese de que el/la cliente esté satisfecho/a con el método.

2. Indique a los participantes que se dirijan a la tabla a continuación, la cual también se encuentra disponible en la Guia del usuario de la $E C B+$, y repase qué hacer según las respuestas del/de la cliente.

\section{Si el/la cliente..}

Está satisfecho con el método elegido

No está satisfecho con el método elegido y desea considerar otras opciones

\section{Haga lo siguiente..}

1. Entréguele el método y el folleto.

2. Si elige DIU, implante, ligadura de trompas o vasectomía, y no están disponibles en el lugar, derívelo de ser necesario.

3. Si el/la cliente no puede usar el método elegido inmediatamente, proporciónele un método de respaldo (por ejemplo, preservativos). Entréguele el folleto de la ECB+ sobre preservativos.

4. Sugiera que se abstenga de tener relaciones sexuales hasta que obtenga el método elegido.

1. Asegúrele que está bien cambiar de opinión. El/la cliente tiene derecho a tomar una decisión informada.

2. Vuelva al paso 7.

3. Haga hincapié en la importancia de no dejar que el/la cliente se vaya con las manos vacías. Si un método no está disponible, asegúrese de que el/la cliente tenga un método de respaldo, el folleto de la ECB+ sobre preservativos y derívelo/a.

PASO 12. ALIENTE AL/A LA CLIENTE A INVOLUCRAR A SU(S) PAREJA(S) EN LAS DECISIONES SOBRE PRÁCTICAS ANTICONCEPTIVAS, YA SEA MEDIANTE UNA CHARLA O MEDIANTE UNA VISITA A LA CLÍNICA.

1. Pregunte a los participantes las formas en las que un/a cliente puede involucrar a su pareja en las decisiones sobre prácticas anticonceptivas.

2. Si los participantes no lo mencionan, repase lo siguiente:

- Su pareja puede recordarle la hora en la que debe tomar el método, si es que toma el método regularmente, y las fechas de seguimiento. 
- Puede negociar el uso de preservativos para prevenir ITS, incluido el VIH y el virus del Zika.

- Puede charlar sobre sus planes de tener hijos, sin importar su estado de VIH.

- Puede explicarle a su pareja que la prevención de la transmisión de madre a hijo (PTMH) durante el embarazo puede reducir la transmisión de VIH y de zika a los lactantes.

- Su pareja puede ayudarlo si necesita servicios de bienestar o de VIH (terapia antirretroviral $[\mathrm{ARV}]$ y sitios de bienestar).

3. Aliente a los participantes a adaptar esta lista según lo que funcione para ellos y sus clientes.

\section{PRÁCTICA}

Tiempo: 25 minutos

1. Pida a los participantes que se junten con la misma pareja.

2. Haga que una de las personas en la pareja actúe como el «proveedor de servicios» y que la otra actúe como el/la «cliente».

3. Explique que el proveedor ayudará al/a la cliente a seleccionar un método siguiendo los pasos del 7 al 12, con la ayuda de las tarjetas y los folletos de método.

4. Explique que la persona que actúa de «proveedor de servicios» puede consultar los pasos del 7 al 12 en el algoritmo de la ECB+ como apoyo. Recuérdeles usar habilidades de buena consejería. (Nota: Cuando los participantes realicen el juego de roles, camine por el salón para observarlos y, si es necesario, corríjalos delicadamente).

5. Asigne alrededor de 10 minutos para este juego de roles. Luego, pídales a las parejas que intercambien roles y que repitan el proceso.

6. Asigne alrededor de 10 minutos para el segundo juego de roles.

7. Luego del segundo juego de roles, pregunte si los participantes tienen alguna duda o algún comentario. Responda todas las preguntas y todos los comentarios antes de continuar. 


\section{Etapa de detección sistemática para otros servicios}

\section{Tiempo total: 135 minutos}

$\mathrm{Al}$ final de esta sesión, los participantes podrán realizar lo siguiente:

- Identificar la necesidad del/de la cliente de obtener consejería o servicios de posparto, para recién nacidos, para lactantes, de salud infantil o de atención posaborto.

- Aconsejar a los clientes sobre servicios apropiados y necesarios.

- Identificar la necesidad de un examen de detección de cáncer de cuello uterino o de cáncer de mama. Proporcionar los servicios necesarios o hacer una derivación.

- Identificar el nivel de riesgo de VIH asociado con distintas conductas.

- Proporcionar consejería y pruebas de VIH.

- Aconsejar a los clientes, cuando sea apropiado, sobre prevención del VIH, reducción de riesgos, protección doble y sobre salud positiva, dignidad y prevención.

- Aconsejar a los clientes, cuando sea apropiado, sobre prevención del zika, reducción de riesgos y protección doble.

- Aconsejar a los clientes sobre seguridad y apoyo a la mujer.

- Identificar la necesidad de consejería de servicios para adolescentes.

- Proporcionar consejería para servicios para hombres.

- Aconsejar a los clientes sobre servicios apropiados y necesarios, o bien derivarlos.

\section{EJERCICIO DE ATENCIÓN POSNATAL ${ }^{2}$}

\section{Tiempo: 25 minutos}

\section{Materiales y preparativos}

- Imprima cada uno de los siguientes títulos en tarjetas (o en pedazos de papel), uno por tarjeta y en letras grandes: Primera visita (de 24 a 48 horas); Segunda visita (de 3 a 7 días); Tercera visita (de 4 a 6 semanas); Cuarta visita (de 4 a 6 meses).

- Pegue los carteles en la parte alta de una pared y deje lugar para que los participantes se reúnan alrededor.

- Disponga de cuatro marcadores para entregar.

\section{Instrucciones}

1. Informe a los participantes que realizarán una actividad orientada a los servicios relacionados con la atención posnatal.

2. Defina «atención posnatal dirigida» a los participantes y explique la lógica de los servicios de atención posnatal.

3. Consulte las directrices nacionales para obtener la información detallada y los servicios que se incluyen en la atención posnatal y para hacer hincapié en el tema entre el grupo de proveedores que se está capacitando.

\section{NOTA}

El período posnatal es el que empieza inmediatamente después de dar a luz y se extiende hasta, aproximadamente, seis semanas después del nacimiento. Período posparto y puerperio son otros términos usados para describir el mismo período. La atención posnatal dirigida es un conjunto de servicios de atención posnatal proporcionados a la madre y al bebé en cuatro visitas como mínimo, durante los primeros seis meses. El programa recomendado es el siguiente:

- Dentro de las 48 horas

- Entre los 3 y 7 días

- Entre las 4 y 6 semanas

- Entre los 4 y 6 meses

La atención posnatal satisface las necesidades de la madre y el bebé, reduce el riesgo de morbilidad y mortalidad, y promueve la salud y el bienestar.

\footnotetext{
${ }^{2}$ Este ejercicio se adaptó del plan de estudio titulado: Community Based Maternal and Newborn Care (Atención a la madre y al recién nacido basada en la comunidad) (Ministerio de Salud Pública y Sanidad y Ministerio de Servicios Médicos, Kenia, 2008).
} 
4. Haga que los participantes cuenten, de a uno a la vez, 1, 2, 3 y 4 . Todos los participantes que contaron 1 formarán un grupo, y los que contaron 2, 3 y 4 harán lo mismo para formar cuatro grupos separados. Cada grupo se parará en frente del cuadro impreso que le corresponda a su número. Entréguele un marcador a cada grupo.

5. Pida a los participantes que se tomen 5 minutos para proponer ideas sobre los servicios para madres y bebés que deberían incluirse en el número de visita que le corresponde a su grupo.

6. Pídale a un participante de cada grupo que divida el cuadro impreso en dos partes iguales. Con el marcador, escriba «Madre» de un lado y «Bebé» del otro.

7. Según las ideas propuestas por el grupo, haga que cada grupo escriba los servicios para la madre y para el bebé del lado correspondiente.

8. Una vez que los cuatro grupos hayan finalizado, pídale a cada grupo que revise lo que escribieron los demás.

9. Para comenzar con el análisis y los comentarios, pídale a cada grupo que indique si se enumeraron servicios con los que no están de acuerdo, que no entiendan o en los que encuentran algún problema.

10. Analice los servicios anotados para cada visita. Para obtener la lista completa de los elementos y períodos clave de la atención posnatal para la madre y el bebé, consulte las directrices nacionales para servicios de atención posnatal o las directrices de la OMS sobre atención posparto y posnatal.

11. Una vez que los participantes hayan repasado los elementos y períodos clave para los servicios de atención posnatal, analice brevemente los principales signos de peligro durante el período posnatal.

12. Explique que los signos de peligro son afecciones sobre las que el proveedor debe aconsejar a la mujer y a su familia en cada visita. Si la madre o el bebé dan indicios de estos signos de peligro, los proveedores deben recomendarle a la mujer que vaya al centro de salud de inmediato, ya sea durante el día o durante la noche.

13. Lea la siguiente lista con los participantes:

14. Pregunte a los participantes si tienen alguna duda sobre los signos de peligro mencionados anteriormente. Responda cualquier pregunta antes de continuar.

\begin{tabular}{l|l}
\hline Madre & Bebé \\
\hline - Sangrado vaginal & - Dificultad para respirar \\
- Ataques & - Convulsiones (ataques) \\
- Respiración rápida o dificultosa & - Fiebre \\
- Fiebre y estado demasiado débil para salir de la & - Frío \\
$\quad$ cama & - Sangrado \\
- Dolor abdominal intenso & - Deja de alimentarse \\
- Dolores de cabeza intensos con visión borrosa & - Diarrea y vómitos
\end{tabular}

\section{EJERCICIO DE EVALUACIÓN DEL RIESGO DE VIH}

Tiempo: 20 minutos

\section{Materiales y preparativos}

- Imprima cada uno de los siguientes títulos en tarjetas (o en pedazos de papel), uno por tarjeta y en letras grandes: Riesgo alto, Riesgo medio, Riesgo bajo y Sin riesgo.

- Pegue los carteles (Riesgo alto, Riesgo medio, Riesgo bajo y Sin riesgo) en la pared.

- Con letras claras y grandes imprima por separado cada una de las siguientes conductas sexuales (u otras conductas que correspondan a su área o a la población de clientes) en tarjetas, notas adhesivas o pedazos de papel:

- Abstinencia

- Masturbación

- Sexo vaginal sin preservativo

- Sexo vaginal con preservativo 
- Abrazar a una persona con VIH

- Besar

- Sexo seco sin preservativo

- Masaje

- Realizar sexo oral a un hombre sin preservativo

- Realizar sexo oral a un hombre con preservativo

- Realizar sexo oral a una mujer sin una barrera de protección bucal

- Realizar sexo oral a una mujer con una barrera de protección bucal

- Madre infectada con VIH que amamanta a su bebé

- Sexo anal sin preservativo

- Sexo anal con preservativo

\section{Instrucciones}

1. Informe a los participantes que realizarán una actividad orientada a las conductas que implican un riesgo de contraer VIH.

2. Coloque las tarjetas de conducta sexual boca abajo en un pila. Pídales a los participantes que tomen una tarjeta y que la coloquen en la pared bajo la categoría de riesgo de transmisión de VIH correspondiente (Riesgo alto, Riesgo medio, Riesgo bajo o Sin riesgo). (Nota: Entregue a los participantes cinta adhesiva para pegar la tarjeta en la pared debajo del cartel correspondiente).

3. Una vez que todas las tarjetas estén en la pared, pida a los participantes que revisen dónde se colocaron las tarjetas. Luego, pídales que indiquen si:

- están en desacuerdo con la ubicación de alguna de las tarjetas;

- no comprenden dónde ubicar alguna de las tarjetas;

- tuvieron alguna dificultad para ubicar alguna de las tarjetas.

4. Comience por preguntarles a los participantes por qué creen que la tarjeta se ubicó en una determinada categoría. Analice la ubicación de las tarjetas seleccionadas, en particular aquellas que no sean claras en lo que respecta al riesgo o aquellas que estén claramente mal ubicadas. Controle las respuestas correctas en la página siguiente si no está seguro sobre a cuál categoría pertenece una determinada conducta.

5. Pida a los participantes que observen las conductas en las categorías Riesgo bajo y Sin riesgo. Pida al grupo que identifique otras conductas que podrían pertenecer a estas categorías. Señale que algunas conductas sexuales placenteras implican un riesgo bajo o ningún riesgo.

6. Finalice haciendo hincapié en que los riesgos dependen del contexto de la conducta y de otros factores como los siguientes:

- Sexo (masculino o femenino)

- Estado de VIH de la pareja

- Participación de la pareja como «dadon» o «receptor» de la conducta sexual

- Dificultad para saber el estado de VIH de la pareja

7. Recuerde a los participantes que deben ser conscientes de sus valores cuando hablan sobre ITS/VIH para no imponer sus propios valores sobre los de otras personas.

\section{Respuestas correctas}

\section{SIN RIESGO}

- Abstinencia

- Masturbación

- Abrazar a una persona con VIH

- Besar

- Masaje

\section{RIESGO BAJO}

- Sexo vaginal con preservativo

- Realizar sexo oral a un hombre con preservativo

- Realizar sexo oral a una mujer con una barrera de protección bucal 


\section{RIESGO MEDIO}

- Realizar sexo oral a un hombre sin preservativo

- Realizar sexo oral a una mujer sin una barrera de protección bucal

- Madre infectada con VIH que amamanta a su bebé y que toma medicamentos antirretrovirales (ARV)

- Sexo anal con preservativo

\section{RIESGO ALTO}

- Sexo vaginal sin preservativo

- Sexo anal sin preservativo

- Sexo seco sin preservativo

- Madre infectada con VIH que amamanta a su bebé y que NO toma medicamentos antirretrovirales (ARV)

\section{PASOS DEL 13 AL 19}

Tiempo: 90 minutos

\section{Materiales y preparativos \\ - Ninguno.}

\section{Instrucciones}

PASO 13. MEDIANTE LA INFORMACIÓN OBTENIDA CON ANTERIORIDAD, DETERMINE LA NECESIDAD DE LA CLIENTE PARA OBTENER SERVICIOS DE ATENCIÓN NATAL, DE CONTROL DE SALUD PARA RECIÉN NACIDOS, LACTANTES O NIÑOS.

1. Explique que este paso implica la integración de los servicios de atención postnatal, de control de salud para recién nacidos, lactantes y niños en las sesiones de planificación familiar.

2. Consulte el paso $\mathbf{1 3}$ del algoritmo con los participantes.

3. Indique a los participantes que consideren la información que les brindó la cliente con anterioridad durante la sesión de consejería, incluidas sus respuestas a las preguntas del paso 3 y el paso 4, para determinar la necesidad que tiene la cliente de obtener estos servicios.

4. Indique a los participantes que si la información no se ha mencionado todavía, debe hacerle las siguientes dos preguntas a la cliente de planificación familiar:

- ¿Ha dado a luz recientemente?

- ¿Tiene hijos menores de 5 años?

\section{Si la cliente...}

Dio a luz recientemente

Tiene hijos menores de 5 años

\section{Haga lo siguiente...}

1. Repase con la cliente la tarjeta de consejería Promoción de un período posparto saludable para la madre.

2. Repase con la cliente la tarjeta de consejería Salud del recién nacido y del lactante.

1. Pregúntele si los llevó a los servicios de bienestar infantil.

2. Pregúntele si los hijos recibieron todas sus vacunas.

3. Pregúntele si le controlaron la altura y el peso de los hijos.

4. Derívela a los servicios de bienestar infantil si es necesario.

5. Indique a los participantes que se dirijan a la Guía del usuario de la ECB+ y a la tabla a continuación para repasar qué hacer según las respuestas de la cliente.

6. Consulte la tarjeta de consejería Promoción de un período posparto saludable. Repase los siguientes puntos que los proveedores pueden usar para analizar la salud posparto con la cliente si dio a luz recientemente:

- Asegúrese de que la madre tenga ayuda durante los primeros días después del nacimiento; aliente el descanso y el tiempo de sueño.

- Recomiende una dieta nutritiva para la madre que incluya mucho líquido y micronutrientes (entre ellos, vitamina A y hierro). 
- Analice el sangrado posparto normal y la secreción de loquios (secreción vaginal posparto). Aconseje sobre los signos de peligro materno, como el sangrado o las secreciones vaginales con mal olor.

- Analice la necesidad de que se realicen cuatro visitas de atención posnatal: cuando hayan transcurrido de 24 a 48 horas, 3 a 7 días, 4 a 7 semanas y de 4 a 6 meses.

- Aconseje sobre el mantenimiento de la higiene personal, incluso del perineo y las mamas.

- Aconseje sobre el regreso a la actividad sexual, que debe darse cuando la madre se sienta lista y, por lo general, cuando se dejen de secretar los loquios. Informe que puede volver a quedar embarazada incluso antes de que regrese su período menstrual si no usa un método anticonceptivo.

- Aconseje sobre la depresión posparto, que puede conllevar lo siguiente: llanto fácil; cansancio, agitación o irritabilidad; falta de motivación; dificultad para dormir y rechazo al bebé.

7. Explíquele a los proveedores que si no pueden aconsejar sobre servicios de posparto o proporcionarlos, deben derivar a la cliente a un centro apropiado en el cual pueda recibir estos servicios.

8. Consulte la tarjeta de consejería Promoción de la salud del recién nacido y del lactante y brinde la consejería y los servicios indicados. Repase los siguientes puntos que los proveedores pueden usar para analizar la salud de un recién nacido o lactante con la cliente si dio a luz recientemente:

- Hable sobre el lavado cuidadoso de las manos para prevenir infecciones antes de estar en contacto con el bebé y después de cambiarle los pañales.

- Aconseje a la madre sobre los signos de peligro de los recién nacidos y sobre cuándo buscar atención inmediata. Los signos de peligro incluyen los siguientes: dificultad en la alimentación o la respiración; temperatura demasiado alta o baja e irritabilidad por largos períodos.

- Analice la importancia de realizar una buena ventilación de los ambientes y de mantener al bebé tibio.

- Aliente a las madres a amamantar exclusivamente por 6 meses. No es necesario nada más, ni siquiera agua. Incorpore alimentos complementarios a los 6 meses y continúe amamantando.

- Para los lactantes expuestos al VIH:

- Aconseje a la madre para que le dé al lactante medicamentos antirretrovirales (ARV) diariamente mientras amamante y que continúe haciéndolo una semana después de dejar de amamantar (alrededor de un año), y aconséjele que continúe con los ARV según los protocolos nacionales.

- Recomiende que a las 6 semanas se le realice una prueba de detección de VIH al lactante expuesto y que comience a recibir profilaxis con cotrimoxazol (CTX).

- Ponga a la madre y al lactante en contacto con una clínica de VIH.

- Use las directrices nacionales e internacionales para explicar el programa de inmunización, e incluya una recomendación para vitamina A a los 6 meses.

- Hable sobre la necesidad de asistir a una clínica de bienestar infantil (incluidas las actividades clave como el control de crecimiento).

9. Explíquele a los proveedores que si no pueden aconsejar sobre servicios para lactantes o recién nacidos, o proporcionarlos, deben derivar a la cliente a un centro apropiado en el cual pueda recibir estos servicios y consejería.

10. Explique a los participantes los tipos de servicios que se incluyen en los servicios de bienestar infantil y la importancia de recibir atención y controles oportunos durante los primeros cinco años de vida del niño. Léales la siguiente lista de los servicios que pueden incluirse en los servicios de bienestar infantil:

- Vacunación

- Control del crecimiento

- Apoyo de alimentación para lactantes

- Provisión de vitamina A a los 6 meses

- Servicios para niños enfermos (incluida la Atención integrada a las enfermedades prevalentes de la infancia, AIEPI) 
11. Explíqueles a los proveedores que, si la cliente tiene un hijo menor de 5 años, deben preguntarle si visitó los servicios de bienestar infantil, y deben proporcionar estos servicios o derivar a la cliente si es necesario.

12. Si la cliente informó un aborto reciente, repase con ella la tarjeta Atención posaborto. Proporcione los servicios de atención posaborto necesarios o haga una derivación, según corresponda.

13. Pregunte a los participantes si tienen alguna duda sobre los servicios de atención de posparto, bienestar infantil o posaborto.

PASO 14. PREGÚNTELE A LA CLIENTE CUÁNDO FUE SU ÚLTIMO EXAMEN DE DETECCIÓN DE CÁNCER DE CUELLO UTERINO (IVAA/IVSL O PAPANICOLAOU) O DE CÁNCER DE MAMA.

1. Haciendo referencia a la información en el Manual del usuario, explique a los participantes que el cáncer de cuello uterino:

- se produce debido al crecimiento descontrolado y sin tratamiento de células anormales en el cuello uterino;

- se origina por una infección de transmisión sexual, el virus del papiloma humano (VPH);

- tarda entre 10 y 20 años en desarrollarse, por lo que hay un largo período de oportunidad para detectar y tratar los cambios y crecimientos antes de que causen cáncer.

2. Haciendo referencia a la información en Manual del usuario, explique a los participantes que el examen de detección del cáncer de cuello uterino:

- ayuda a detectar cualquier cambio y crecimiento precanceroso antes de que se convierta en cáncer;

- es simple, rápido y, por lo general, no provoca dolor.

3. Indíqueles a los proveedores que luego de informar a la cliente sobre el cáncer de cuello uterino, deben preguntarle cuándo se realizó el último examen de detección.

4. Indique a los participantes que se dirijan a la Guía del usuario de la ECB+ y a la tabla a continuación para repasar qué hacer según las respuestas de la cliente.

\section{Si la cliente...}

Se realizó el último examen de detección hace más de 3 años

0

No sabe cuándo fue su último examen de detección

Se realizó el último examen de detección hace menos de 3 años

\section{Haga lo siguiente...}

Proporcione un examen de detección IVAA/IVSL o un Papanicolaou.

0

Cuando el examen esté disponible, derive el examen de detección IVAA/IVSL o el Papanicolaou a un centro apropiado.

Informe a la cliente sobre cuándo realizarse el próximo examen de detección.

5. Pregunte a los participantes si tienen alguna duda sobre los exámenes de detección de cáncer de cuello uterino.

6. Repase con la cliente la tarjeta de consejería Información y concienciación sobre el cáncer de mama.

7. Pregunte a los participantes si tienen alguna duda relacionada con la información y concientización sobre el cáncer de mama.

PASO 15. ANALICE CON EL/LA CLIENTE LA TARJETA DE CONSEJERÍA PREVENCIÓN Y TRANSMISIÓN DE ITS/VIH Y LA TARJETA PROTECCIÓN DOBLE. OFRÉZCALE PRESERVATIVOS Y DELE INDICACIONES SOBRE EL USO CORRECTO Y SISTEMÁTICO. ${ }^{3}$

1. Explique que esta es la primera parte de la integración de la consejería y pruebas de VIH/ITS a las sesiones de planificación familiar.

2. Consulte la tarjeta de consejería Prevención y transmisión de ITS/VIH. Repase los siguientes puntos que los proveedores pueden usar para analizar las ITS y el VIH con el/la cliente:

- Una persona puede infectarse con una ITS, incluido el VIH y el virus del Zika, a través de actividades sexuales inseguras y sin protección.

- Las ITS son comunes y el zika es común en algunas zonas.

- Una persona que vive con una ITS (incluido el VIH) puede verse saludable y no tener síntomas ni ser consciente de que está infectada.

Para las regiones con virus del Zika activo o para viajeros en esas regiones, también use la tarjeta de consejería sobre el zika. 
- Los síntomas frecuentes de una ITS incluyen secreción vaginal y del pene, irritación en el área genital, ardor al orinar en el caso de los hombres y dolor en la parte abdominal baja en el caso de las mujeres.

- Algunas ITS pueden tratarse. Para evitar una reinfección, se debe tratar a ambos miembros de la pareja.

- El riesgo de infección puede reducirse usando un preservativo, limitando el número de parejas sexuales y retrasando las relaciones sexuales (adolescentes).

- El VIH es una infección de transmisión sexual (ITS). El VIH se transmite mediante el intercambio de fluidos corporales, como semen, sangre y leche materna, y durante el parto.

- Conocer su estado de VIH lo protege a usted, a su pareja y a su familia.

- Aunque el VIH no tiene cura, su identificación y tratamiento tempranos pueden permitir que una persona lleve una vida larga y productiva, y evitar que la pareja se infecte.

- La circuncisión masculina reduce el riesgo de infección heterosexual de VIH en hombres en, aproximadamente, un $60 \%$, y debe ser un elemento de un paquete de prevención de VIH integral.

- La transmisión materna del VIH al niño puede reducirse de manera sustancial al identificar a las mujeres que tienen VIH y proporcionarles tratamiento o medicamentos ARV profilácticos durante el embarazo.

3. Indique a los participantes que luego de analizar la prevención y transmisión de VIH, deben preguntarle al/a la cliente si tiene alguna duda.

4. Explique a los participantes que la protección doble previene de forma simultánea las ITS y el embarazo.

5. Consulte la tarjeta de consejería Protección doble. Repase los siguientes puntos que los proveedores pueden usar para analizar la protección doble con el/la cliente:

- La protección doble es el uso de preservativos de manera sistemática y correcta junto con otro método de planificación familiar. Esto proporciona protección adicional contra embarazos en caso de que el preservativo falle.

- Use preservativos masculinos o femeninos de manera correcta y sistemática en cada acto sexual. Este método protege contra las ITS y evita el embarazo.

- Solo tenga intimidad sexual segura, durante la cual se evite que el semen y los fluidos vaginales entren en contacto con los genitales u otras áreas vulnerables de la pareja, como la boca y el ano.

- Retrase o evite la actividad sexual, especialmente con parejas cuyo estado de ITS/VIH se desconoce.

6. Indíqueles a los proveedores que le pregunten al/a la cliente si tiene alguna duda.

7. Indíqueles a los proveedores que les ofrezcan preservativos a los clientes, si están disponibles. Si no lo están, los proveedores deben informar a los clientes dónde conseguirlos.

8. Señale que los proveedores también deben mostrarle al/a la cliente cómo usar un preservativo de forma correcta.

9. Demuestre cómo usar un preservativo en frente de la clase. Si los participantes se sienten cómodos con los preservativos, haga que uno de ellos demuestre cómo usarlo.

\section{PASO 16A: LLEVE A CABO UNA EVALUACIÓN DEL RIESGO DE ITS Y VIH USANDO LA TARJETA DE} CONSEJERÍA. SI SE IDENTIFICAN LOS SÍNTOMAS, TRATE AL/A LA CLIENTE DE MANERA SINDRÓMICA.

1. Explique que, en esta etapa, el proveedor debe explorar qué sabe el/la cliente sobre ITS, VIH y SIDA para corregir cualquier información incorrecta, completar lo que el/la cliente ya sabe y responder preguntas.

2. Pida a los participantes que consulten la tarjeta de consejería Evaluación del riesgo de ITS y VIH de la ECB+. Esta tarjeta presenta los puntos a continuación, los cuales el proveedor analiza con los clientes para ayudarlos a percibir su riesgo de ITS/VIH:

- Estado de VIH y estado de VIH de su(s) pareja(s). Si la pareja es positivo, pregunte si toma medicamentos antirretrovirales (ARV).

- Número de parejas sexuales, tanto las actuales como las anteriores.

- Conocimiento sobre las prácticas sexuales y las parejas anteriores de su pareja.

- Conocimiento del estado de circuncisión de la pareja hombre.

- Uso actual y anterior de preservativos (incluida su percepción de la actitud de la pareja) y si es consciente de que los preservativos protegen contra ITS/VIH y evitan los embarazos. 
- Tipo de sexo o actividades y conductas sexuales (por ejemplo, monogamia mutua, si la pareja tiene otras parejas sexuales, sexo oral, sexo anal, sexo seco o uso de detergentes o espermicidas).

- Situación en el hogar (por ejemplo, en lo referido a violencia de pareja y apoyo social).

- Uso de los servicios de prevención de la transmisión de madre a hijo (PTMH) durante el embarazo, el parto y la lactancia.

3. Pregúnteles a los participantes si tienen alguna duda sobre la evaluación de riesgo de ITS y VIH o sobre los puntos antes mencionados.

4. Explique que en este punto, el proveedor tiene la oportunidad de corregir información incorrecta, completar lo que el/la cliente ya sabe y responder preguntas sobre ITS y VIH.

5. Mencione que una vez que el proveedor tiene un panorama más claro de los riesgos sexuales y del contexto social del/de la cliente, puede ayudarlo a diseñar un plan para reducir el riesgo usando cualquiera de las siguientes estrategias:

- Reducción del número de parejas sexuales.

- Uso de preservativos (masculinos o femeninos) de manera correcta y sistemática en cada acto sexual. Los preservativos son el único método que protege contra ITS, incluido el VIH.

- Poner preservativos a disposición de su pareja y fomentar el uso correcto y sistemático.

- Evitar el uso de instrumentos sucios y que puedan cortar la piel, o agujas.

- Detección y tratamiento inmediatos de cualquier ITS o infección de cuello uterino.

- Ejecución de cualquier procedimiento que involucre el tracto genital en un ambiente aséptico.

- Aplicación del método de protección doble.

- Conocimiento del estado de VIH.

6. Infórmeles a los proveedores que tienen la responsabilidad de ayudar a los clientes a reducir su riesgo de contraer VIH e ITS.

7. Indique a los participantes que, si el/la cliente tiene una ITS, deben tratarlo/a de manera sindrómica según las directrices nacionales, o bien derivarlo/a para que se realice exámenes de detección, si están disponibles.

8. Indique a los participantes que consulten las directrices para ITS o a las directrices nacionales para el manejo de ITS.

PASO 16B. PARA LAS REGIONES CON VIRUS DEL ZIKA ACTIVO O PARA VIAJEROS EN ESAS REGIONES, REALICE UNA EVALUACIÓN DE RIESGO DE ZIKA USANDO LA TARJETA DE CONSEJERÍA.

\section{PASO 17. PREGÚNTELE AL/A LA CLIENTE SI CONOCE SU ESTADO DE VIH.}

1. Indique a los participantes que pregunten delicadamente si el/la cliente conoce su estado de VIH.

2. Infórmele al/a la cliente que no divulgará su estado sin su consentimiento.

3. Repase con los participantes la siguiente tabla del Manual del usuario, y siga las instrucciones sobre consejería y pruebas de VIH apropiadas según los conocimientos del/de la cliente sobre el estado de VIH y de la prueba de detección de este.

\begin{tabular}{|l|l|}
\hline Si el/la cliente... & Haga lo siguiente... \\
\hline Sabe su estado de VIH y tiene VIH & $\begin{array}{c}\text { 1. repase con el/la cliente la tarjeta de consejería } \\
\text { Prevención, dignidad y salud positiva. }\end{array}$ \\
$\begin{array}{l}\text { 2. Pregúntele cuándo fue la última vez que asistió } \\
\text { a un centro de salud para su visita de control. } \\
\text { 3. Derive al/a la cliente a un centro de tratamiento } \\
\text { y atención de bienestar, si es necesario. }\end{array}$ \\
\hline Sabe su estado de VIH y es negativo & Establezca un plazo para volver a realizar la prueba.
\end{tabular}

Si el/la cliente conoce su estado de VIH y si tiene VIH:

- Repase con los participantes los puntos de consejería que se encuentran en la tarjeta de consejería Prevención, dignidad y salud positiva. Lea los siguientes puntos en voz alta a los participantes:

- Las personas que viven con VIH siempre deben usar un preservativo de forma correcta y sistemática con sus parejas sexuales. 
- Si una mujer con VIH desea quedar embarazada, el riesgo de contagiarle VIH al recién nacido puede reducirse significativamente al tomar medicamentos antirretrovirales (ARV) y mediante un parto seguro. Es importante recibir atención en una clínica de atención prenatal y un centro de tratamiento de VIH.

- Las personas que viven con VIH necesitan chequeos de salud regulares para determinar si necesitan medicamentos ARV, para evaluar el tratamiento con los ARV y para descartar otras infecciones o enfermedades.

- Si un/a cliente toma algún ARV, debe asistir a las visitas de seguimiento en la clínica, según la recomendación del proveedor. Cuando el/la cliente comienza a tomar medicamentos ARV, las visitas pueden ser más frecuentes.

- El/la cliente debe hacer lo mejor posible por respetar el régimen de medicación prescrito y no debe compartir sus medicamentos.

- Las parejas también deben realizarse lo exámenes de detección. El/la cliente puede traer a su pareja para recibir consejería y hablar, si es de ayuda.

- Si actualmente toma medicamentos para la tuberculosis, debe realizar el seguimiento correspondiente con el proveedor.

- La salud positiva se logra al cuidar de uno mismo y al estar alerta a las inquietudes de salud que requieren de atención, entre las que pueden incluirse temas de salud física y mental, así como de apoyo social.

- Indique a los participantes que deben apoyar a los clientes y alentarlos a que divulguen su estado de VIH a sus parejas. Explique a los participantes que revelar su estado tiene sus beneficios. Lea los beneficios a continuación en voz alta y explique que revelar el estado de VIH ayudará al/a la cliente a lo siguiente:

- Obtener apoyo de su cónyuge, familia y de algún centro de salud.

- Planear mejor y tomar decisiones apropiadas sobre la atención y el apoyo del VIH y sobre asuntos familiares.

- Obtener acceso temprano a medicamentos y ayuda para mantenerse saludable.

- Salvar la vida de una pareja VIH negativo y la de un niño que aún no ha nacido al no infectarlos.

- Negociar mejor el uso de preservativos con su pareja para evitar que se infecte.

- Evitar la exposición a infecciones repetidas que comprometerán su salud.

- Lea los siguientes riesgos de revelar el estado de VIH y explique que también pueden existir riesgos relacionados con la divulgación del estado de VIH:

- Estigmatización y discriminación por parte de la familia, de amigos y de la comunidad.

- Maltrato del cónyuge.

- Divorcio del cónyuge.

- Informe a los participantes que deben mostrar sensibilidad y ser receptivos con todas las preocupaciones y preguntas que el/la cliente pueda tener.

- Explíqueles que deben estar preparados para ofrecer recursos, si están disponibles, a las personas con VIH que enfrentan maltratos o situaciones familiares difíciles debido a su estado.

- Señale que, como proveedores, deben poder informar al/a la cliente sobre la importancia de mantenerse saludable, responder sus preguntas y derivarlo/a a un centro apropiado para que obtenga atención integral.

- Indique a los participantes que se informen sobre los centros de salud y bienestar de VIH y sobre los servicios disponibles. Explique que deben derivar a los clientes a los servicios apropiados cuando sea necesario.

Si el/la cliente conoce su estado de VIH y es negativo:

- Indique a los participantes que analicen volver a realizar la prueba de detección si el/la cliente sabe que su estado de VIH es negativo. El proveedor debe considerar la evaluación de riesgo y las conductas sexuales del/de la cliente para decidir la frecuencia más apropiada para realizar las pruebas de VIH.

- Explique a los participantes que el proceso de volver a realizarse las pruebas de detección de VIH, independientemente de las recomendaciones internacionales para volver a realizarlas, incluida la frecuencia de la prueba, varía según la conducta de riesgo y las prácticas sexuales $\mathrm{del} /$ de la cliente. 
- Indíqueles a los proveedores que consulten los protocolos y directrices nacionales para determinar el período apropiado y las recomendaciones para volver a realizar la prueba de VIH.

- Explique que los proveedores deben hacer hincapié en la prevención, la detección temprana y el tratamiento rápido de las ITS, incluido el VIH, como pilares provechosos para los clientes, sus familias y para la comunidad en general.

Si el/la cliente desconoce su estado de VIH:

- Mencione que el proveedor debe usar la tarjeta Consejería y pruebas de VIH (HCT) para guiar el análisis sobre las pruebas de detección de VIH. A continuación, encontrará los puntos clave que los proveedores deben cubrir con el/la cliente:

- Saber su estado de VIH puede ayudarlo a tomar decisiones sobre cómo a protegerse usted mismo y a su(s) pareja(s) sexual(es).

- Las pruebas de detección permiten que las personas que viven con VIH reciban tratamiento para que puedan vivir una vida plena. La prueba incluye la extracción de una muestra de sangre pequeña. La prueba es gratuita y se encuentra disponible en clínicas, hospitales y centros de consejería y pruebas de VIH.

- Los resultados de las pruebas se mantienen en estricta confidencialidad.

- Cuando una persona se infecta con VIH, pueden pasar 3 meses o más hasta que la prueba detecte la infección. Esto se denomina «período ventana» y es la razón por la que es tan importante repetir la prueba.

- Un resultado positivo significa que la persona se encuentra infectada con VIH y puede transmitirle el virus a otros.

- Un resultado negativo puede significar que la persona no se encuentra infectada o que se encuentra en el «período ventana». Se debe realizar otra prueba dentro de los 3 meses. $\mathrm{Si}$ la segunda prueba también es negativa, la persona no tiene VIH, pero aún puede infectarse con el virus.

- El VIH es una infección de transmisión sexual (ITS). Es importante pedirle a su(s) pareja(s) sexual(es) que también se haga(n) una prueba.

- Indique que los proveedores deben hacer hincapié en la prevención, la detección temprana y el tratamiento rápido de las ITS, incluido el VIH, como pilares provechosos para los clientes, sus familias y para la comunidad en general.

- Explique a los participantes que, por lo general, las pruebas de VIH son un acontecimiento aterrador para los individuos. Muchas personas que saben que deben hacerse una prueba no la hacen por miedo o por otros motivos.

- Señale que como proveedores, deben ser capaces de responder a los miedos, excusas y argumentos que los clientes plantean como motivos por los que no se harán una prueba de detección o por los que no pueden hacerla.

- Consulte el Manual del usuario y analice brevemente las políticas de la OMS sobre los servicios de consejería y pruebas de VIH iniciadas por el proveedor (PITC, provider-initiated HIV testing and counseling).

- Indique a los proveedores que ofrezcan o inicien una prueba de detección de VIH en la clínica de planificación familiar, según los protocolos nacionales. Si no se prestan los servicios de pruebas de detección, explíqueles a los proveedores que deben derivar al/a la cliente a servicios de HCT de especialidad.

- Explique que los participantes deben estar preparados para aconsejar al/a la cliente sobre los resultados de la prueba de detección de VIH.

- Señale que si el resultado de la prueba del/de la cliente es positivo, los participantes deben repasar la tarjeta Prevención, dignidad y salud positiva con el/la cliente y derivarlo/a a un centro de atención de bienestar y tratamiento para que reciba los servicios necesarios relacionados con el VIH.

Asesore a la cliente usando la tarjeta Seguridad y apoyo a la mujer.

- Si la cliente presenta signos graves que indiquen que puede ser víctima de violencia infligida por la pareja, derívela a servicios especializados.

PASO 18. PROPORCIONE INSTRUCCIONES DE SEGUIMIENTO, UN FOLLETO SOBRE PRESERVATIVOS Y UN FOLLETO SOBRE EL MÉTODO ELEGIDO. FIJE UNA FECHA PARA LA PRÓXIMA VISITA.

1. Recuerde a los participantes que el proveedor debe resumir los puntos clave mencionados durante la consulta.

2. Explique que el proveedor debe proporcionarle al/a la cliente instrucciones de seguimiento para el método elegido, junto con el folleto de método correspondiente. 
3. Mencione que el proveedor también debe entregarle al/a la cliente un folleto sobre preservativos y reiterar el hecho de que solo los preservativos proporcionan protección doble contra las ITS y para evitar los embarazos no deseados.

4. Mencione que los proveedores pueden necesitar darle al/a la cliente una cita de seguimiento, según el método que se brindó.

5. Repase algunos de los motivos por los cuales un/a cliente debe volver a la clínica, por ejemplo:

- Comprobar cómo el/la cliente usa el método.

- Proporcionar un nuevo suministro del método.

- Proporcionar la información y el apoyo necesarios para que el/la cliente continúe el uso correcto y sistemático del método, o para seleccionar otro método.

- Traer a la pareja para consejería adicional sobre planificación familiar o ITS/VIH.

- Realizarse una prueba de VIH.

6. Explique que es importante alentar al/a la cliente a que vuelva al centro de atención de salud cada vez que tenga una duda o si desea de cambiar de método.

\section{PASO 19: AGRADÉZCALE POR SU VISITA. COMPLETE LA SESIÓN DE CONSEJERÍA.}

1. Mencione que el proveedor debe ser cálido y cordial cuando finaliza una sesión. Esta actitud alentará al/a la cliente a sentirse bienvenido/a a volver.

2. Recuerde a los participantes que el/la cliente tiene el derecho a cambiar sus objetivos en materia de reproducción y a dejar de usar el método de planificación familiar si lo desea.

\section{SESIONES DE PRÁCTICA DE JUEGO DE ROLES}

\section{Tiempo total: 90 minutos}

Al final de esta sesión, los participantes podrán realizar lo siguiente:

- Aconsejar a los clientes con las ayudas de trabajo de la ECB+.

\section{Materiales y preparativos}

- Divida a la mitad la cantidad de participantes que se esperan para el taller. Esa es la cantidad de textos de juegos de roles que necesitará.

- Haga copias suficientes de los textos (los cuales se encuentran al final de este ejercicio) para todos los participantes que las necesitarán. Está bien si varios participantes tienen el mismo rol de cliente. (Nota: Hay dos juegos de roles. Puede usar los mismos textos, pero asegúrese de que los participantes reciban un texto diferente para el segundo juego de roles).

- Puede inventar sus propios textos y roles, si lo desea.

- Recorte por las líneas para que pueda darle a cada participante que tenga el rol de cliente un texto para usar.

- Note que el método ideal para cada rol está escrito entre paréntesis al final de cada texto.

JUEGO DE ROLES N. ${ }^{\circ} 1$

\section{Tiempo: 30 minutos}

\section{Instrucciones para el juego de roles $\mathrm{n} .^{\circ} 1$}

1. Pida a los participantes que se pongan de pie. Haga que cuenten de la siguiente manera: «1», «2», «1», «2» y así sucesivamente.

2. Explique que los «1» tendrán el rol de «proveedores de planificación familiar» y los «2» el de «clientes de planificación familiar».

3. Pídales a todos los «2» que levanten las manos.

4. Pídales a los «1» que encuentren a un participante con el cual trabajar.

5. Una vez que los participantes encuentran pareja, entregue un texto a cada participante que tenga el rol de «cliente».

\section{Realización del juego de roles $n .^{\circ} 1$}

1. Pida a los participantes que busquen un lugar en el salón en el que puedan realizar la sesión de consejería. (Nota: Aún no deje que tomen asiento). 
2. Pida a los participantes que comiencen con el juego de roles de pie para que puedan saludar al/a la cliente. Luego del saludo, pueden sentarse y comenzar la sesión de consejería.

3. Asigne alrededor de 30 minutos para el juego de roles.

4. Luego de 25 minutos, dígales a los participantes que tienen 5 minutos para finalizar la sesión de consejería. (Nota: Durante el juego de roles, camine por el salón y observe el desempeño de los participantes. Tome nota de cualquier cosa que observe que no se haga bien y recopile esa información para cuando evalúe el juego de roles).

\section{Evaluación del juego de roles}

1. Cuando se acabe el tiempo, pregúnteles a los participantes que tengan el rol de proveedores cómo fue atravesar todo el proceso de la ECB + con el uso del algoritmo y de las ayudas de trabajo.

2. Pregúnteles si tienen dudas o comentarios sobre el uso del algoritmo de la ECB+, las tarjetas de consejería, la rueda con los CME de la OMS o sobre los folletos de método para aconsejar a su cliente.

3. Responda todas las preguntas y los comentarios antes de continuar. (Nota: Es importante que se familiarice con el uso de las ayudas de trabajo de la ECB+ para aconsejar a los clientes de planificación familiar. Esta experiencia lo ayudará a responder mejor a las respuestas y comentarios de los participantes).

4. Formule las siguientes preguntas a los participantes con el rol de clientes:

- ¿Cómo fue que lo aconsejaran con el enfoque de la ECB+?

- ¿Algo lo confundió? Si la respuesta es «sí», ¿qué fue?

- ¿Tiene algún consejo para los participantes que desempeñaron el rol de proveedores? (Nota: Escriba los consejos de los participantes en el rotafolio o en la hoja).

5. Ofrezca cualquier refuerzo positivo o comentario según sus observaciones durante el juego de roles.

\section{JUEGO DE ROLES N. ${ }^{\circ} 2$}

Tiempo: 30 minutos

\section{Instrucciones para el juego de roles $\mathrm{n} .^{\circ} 2$}

1. Dígales a los participantes que invertirán los roles. La persona que tiene el rol de cliente ahora será el proveedor, y el proveedor será el/la cliente.

2. Entregue a cada cliente un texto con un rol. (Consulte los textos para el juego de roles n. ${ }^{\circ} 2$ al final de esta sección).

\section{Realización del juego de roles}

1. Pida a los participantes que comiencen el juego de roles con un saludo, tal como hicieron en el anterior.

2. Asigne alrededor de 30 minutos para el segundo juego de roles.

3. Durante el juego de roles, camine por el salón y observe el desempeño de los participantes. Tome nota de cualquier cosa que observe que no se haga bien y recopile esa información para cuando evalúe el juego de roles.

\section{Evaluación del juego de roles}

1. Cuando se acabe el tiempo, pregúnteles a los participantes que tengan el rol de proveedores cómo fue usar el algoritmo y las ayudas de trabajo de la ECB+.

2. Pregúnteles si tienen dudas o comentarios sobre cómo usar el algoritmo de la ECB+, las tarjetas de consejería, la rueda con los CME de la OMS o sobre los folletos de método para aconsejar a su cliente. Responda todas las preguntas antes de continuar.

3. Formule las siguientes preguntas a los participantes con el rol de clientes:

- ¿Cómo fue que lo aconsejaran con el enfoque de la ECB+?

- ¿Algo lo confundió? Si la respuesta es «sí», ¿qué fue?

- ¿Tiene algún consejo para los participantes que desempeñaron el rol de proveedores? (Nota: Escriba los consejos de los participantes en el rotafolio o en la hoja).

4. Mencione sus comentarios según las observaciones que hizo durante el juego de roles.

5. Responda todas las preguntas y los comentarios antes de continuar con el próximo paso. 


\section{Sesiones de práctica de juego de roles: texto para los participantes con rol de cliente}

Es una mujer casada de 23 años con dos hijos pequeños. Quiere esperar 2 o 3 años antes de volver a quedar embarazada. A su esposo no le interesa la planificación familiar. Usted nunca antes usó métodos anticonceptivos modernos. Su último hijo tiene 5 meses y lo está amamantando. Está muy preocupada sobre el uso del DIU y lo rechazará si se lo ofrecen. No está segura de su estado de VIH, pero cree que su esposo tuvo muchas parejas antes de casarse. Nunca se realizó un examen de detección de cáncer de cuello uterino.

(Anticonceptivos inyectables combinados [AIC])

Es una mujer de 26 años que dio a luz hace una semana. La alimentación del lactante es mixta porque trabaja durante el día y no tiene suficiente leche materna para extraer. Anteriormente usó un inyectable cada 3 meses, pero ahora quiere cambiar de método ya que está cansada de la inyección. Toma medicamentos para la hipertensión y su presión arterial está controlada.

(Anticonceptivos orales de progestina como agente único, minipildora)

Es una mujer casada de 40 años a quien el resultado de la prueba de VIH le dio positivo hace un mes. Su conteo de células CD4 es $<200$ y tiene presión arterial alta sin controlar. El médico ha comenzado a suministrarle medicamentos ARV. Le gustaría seguir con el uso de un inyectable cada 3 meses, el cual nunca le dio problemas desde que lo comenzó a usar en su adolescencia.

(Inyectables de progestina como agente único)

Es una joven de 18 años. Tuvo su primera menstruación hace 10 días. Es sexualmente activa y tiene un novio. Quiere evitar un embarazo y desea usar la píldora porque escuchó que previene embarazos. Ni usted ni su novio quieren usar preservativos. Más adelante en la consulta revela que tuvo relaciones sexuales sin protección hace dos días. Tiene una leve secreción vaginal.

(Píldoras anticonceptivas de emergencia [PAE] y la pildora)

Tiene 25 años y múltiples parejas sexuales. De a poco, cuenta que es una trabajadora sexual que intenta ganar el dinero suficiente para mantener a sus dos hijos. Sus parejas (pagas) no quieren usar preservativos. Ha escuchado sobre las enfermedades de transmisión sexual y tiene miedo de contagiarse alguna. Tampoco puede permitirse quedar embarazada de nuevo.

(Preservativo femenino)

Es un muchacho adolescente que asistió a la clínica con una ITS, pero no con VIH. Le preocupa volver a contraer una ITS. Ha tenido muchas novias. Su novia actual quiere quedar embarazada para demostrarle que lo ama, pero usted no está muy entusiasmado con la idea. Si el «proveedor» le ofrece preservativos, acéptelos. Antes de irse, pregúntele al proveedor cómo puede su novia evitar un embarazo.

(Preservativo masculino, y el proveedor debe alentarlo a que su novia haga una visita). 
Es una mujer casada de 30 años que no quiere tener más hijos. Ya tiene cuatro (el último tiene 3 meses) y está cansada y harta de estar embarazada. Su pareja quiere tener más hijos. A su marido le gusta tener relaciones sexuales de forma frecuente y no le gusta usar preservativos. Le asustan las inyecciones. Ha tenido convulsiones leves en el pasado y, a veces, toma medicamentos para evitarlas. Si le ofrecen la minipíldora, explique que tiene miedo de olvidar tomarla todos los días. Su marido viaja ocasionalmente y no está segura si le es fiel.

(DIU)

Es una mujer de 20 años con un hijo de 4 meses al que amamanta. Su esposo trabaja en una granja en condiciones de trabajador emigrante; además está ausente 22 días al mes. Usted nunca usó la planificación familiar, pero desea controlar su fertilidad. Está por empezar su menstruación. Es lunes y su esposo vuelve a casa este fin de semana. No quiere usar preservativos y no apoya la planificación familiar. Si le ofrecen el DIU, explique que no puede permitirse ir al hospital, que se encuentra a 100 millas (160 km, aprox.).

(Anticonceptivos orales de progestina como agente único, minipildora)

Es una mujer casada de 35 años con 3 hijos. Su hijo menor tiene 6 semanas. No está lista para tener otro hijo. Su esposo no coopera con la planificación familiar. Vive a una distancia considerable del centro de salud. Escuchó comentarios negativos sobre el DIU y lo rechazará si se lo ofrecen. Si le ofrecen implantes, explique que su marido se daría cuenta y se enojaría. Tuvo una aventura extramatrimonial hace varios años.

(Inyectables de progestina como agente único: el acetato de medroxiprogesterona de depósito (DMPA) solo requiere que la clienta vuelva cada 3 meses)

Es una joven soltera de 18 años. Tiene un novio y no quiere quedar embarazada. Usted y su novio van a la escuela. Está por empezar su menstruación. Si le ofrecen un DIU o Norplant, explique que no quiere un objeto extraño en su cuerpo. Si le ofrecen inyectables, grite y diga que odia las agujas. Si le ofrecen la minipíldora, explique que ya vino antes a la clínica para obtenerla, pero nunca hay stock disponible. No tiene ninguna afección que evite que tome la píldora. Además, hay una farmacia en su comunidad que vende la píldora más conocida en el mercado. Tuvo muchos novios en el pasado.

(Anticonceptivos orales combinados)

Tiene 29 años y ha estado alimentando a su hijo con lactancia total y usando el MELA como anticonceptivo. Está comenzando a darle comida a su hijo. Quiere asegurarse de que el MELA todavía es efectivo. Eligió el MELA porque quiere amamantar a su bebé y porque es muy religiosa. Ni usted ni su esposo creen en los métodos anticonceptivos modernos. Su esposo la apoya en querer un período de espaciamiento entre hijos. Si le ofrecen el Método de Dos Días, explique que no quiere tocar sus genitales. Tanto usted como su esposo son monógamos y creen en la fidelidad.

(Método de Días Fijos) 
Es una mujer de 22 años con un hijo de 1 año. Tiene un matrimonio estable y su esposo apoya la planificación familiar. A usted no le gustan los métodos anticonceptivos modernos. A veces, él usa un preservativo, pero no de forma sistemática porque le reduce la sensación. No quiere lidiar con los efectos secundarios de los métodos hormonales. Es religiosa y no quiere un método moderno. Si el proveedor le ofrece un método de conciencia de la fertilidad, como el Método de Días Fijos o el Método de Dos Días, aparente estar interesada. Luego, cuente que sus ciclos menstruales son muy irregulares.

(Preservativo femenino)

Tiene 39 años y 6 hijos. Está cansada y no quiere tener más hijos. Su esposo coopera con la planificación familiar, pero no usará un preservativo. Ya probó métodos hormonales, pero no le gustan los efectos secundarios. Además, a veces olvidaba tomar la píldora, lo cual provocó su quinto embarazo. Le asusta el DIU y escuchó que las mujeres pueden quedar embarazadas con ese método. Vive lejos del hospital, pero puede llegar si lo planea con anticipación. A pesar de que no le gustan los efectos secundarios de la píldora, consideraría un inyectable mensual hasta que le realicen una ligadura de trompas en el hospital. Sospecha que su esposo no le es fiel.

(Anticonceptivos inyectables combinados [AIC] hasta que la cliente pueda realizarse la ligadura de trompas en el hospital)

Es un hombre de 38 años que acompaña a la clínica a su esposa ya que ella quiere la planificación familiar. No puede permitirse tener más hijos, ya que ahora tiene 5. Su esposa usó muchos métodos, pero aún así tuvo 5 embarazos. Ambos piensan que tienen suficientes hijos. Si le ofrecen la ligadura de trompas, mencione que se acaban de enterar que su esposa está embarazada. Al final de la consulta, revele que es VIH positivo. Confiese que estuvo con muchas mujeres en el pasado.

(Vasectomía) 


\section{Pasos siguientes y cierre}

Tiempo total: 15 minutos

Al final de este ejercicio, los participantes:

- Tendrán un plan para incorporar la ECB+ a su trabajo de consejería en el centro de atención de salud.

\section{Materiales y preparativos}

- Tenga disponible un rotafolio u hojas grandes de papel y marcadores.

- Si se les otorgarán certificados a los participantes, encárguese de que los hagan, los firmen y de que estén listos para distribuir al final del taller.

\section{Instrucciones}

1. Pregunte a los participantes si les gustó usar la $\mathrm{ECB}+\mathrm{y}$ las ayudas de trabajo.

2. Recuerde a los participantes que el algoritmo de 19 pasos de la ECB + es un resumen de la Guía del usuario de la ECB+ y que es más fácil de consultar en el trabajo.

3. Aliente a los participantes a repasar las secciones de la Guía del usuario de la ECB+ para que recuerden exactamente cómo realizar cada uno de los 19 pasos.

4. Pregunte a los participantes qué pasos tomarán para implementar el modelo de la ECB+ en su trabajo. En otras palabras, ¿qué harán diferente cuando vuelvan a la clínica?

5. Escriba sus respuestas en el rotafolio o en la hoja.

6. Pregúnteles a los participantes qué pueden hacer para promover el uso de la ECB+ en sus centros de atención de salud. (Nota: Escriba las respuestas en el rotafolio o en la hoja).

7. Antes de cerrar el taller, asegúrese de que no haya dudas ni comentarios pendientes.

8. Recuerde a los participantes que el paquete de herramientas de la ECB+ también está disponible en formato electrónico. Las ayudas de trabajo (algoritmo, tarjetas de consejería y folletos de método) se pueden adaptar o revisar fácilmente para apoyar los protocolos nacionales o regionales. En la Guía del usuario de la ECB+, se proporcionan las directrices para adaptar estas ayudas de trabajo.

9. Agradezca a todos por su participación.

10. Realice cualquier actividad de cierre y entregue los certificados, si están disponibles. 


\section{凸包 Apéndice}

FIGURA 1. TARJETAS DE MÉTODO DE LA ECB+

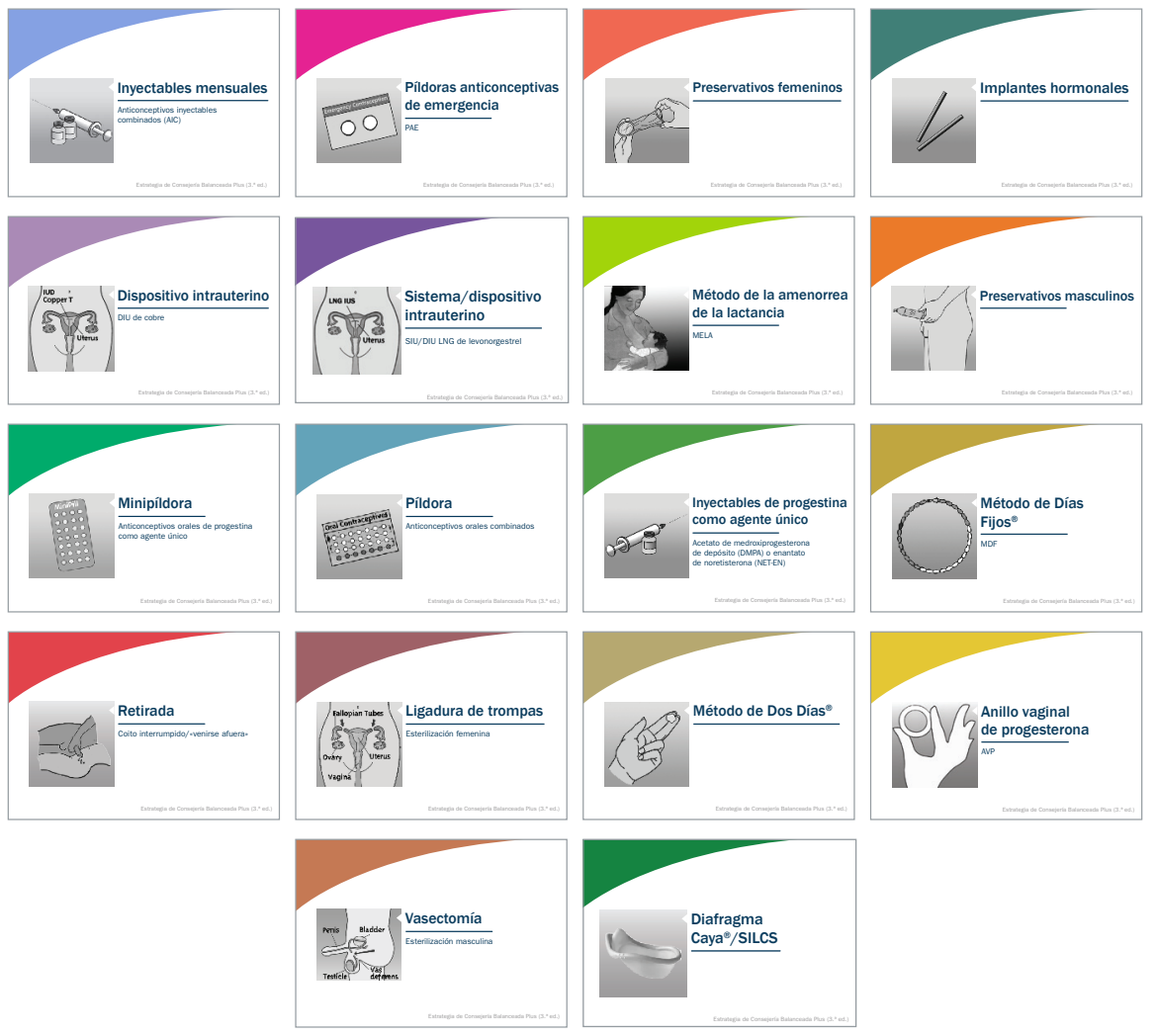

FIGURA 2. TARJETAS DE MÉTODO ORGANIZADAS SEGÚN SU EFECTIVIDAD

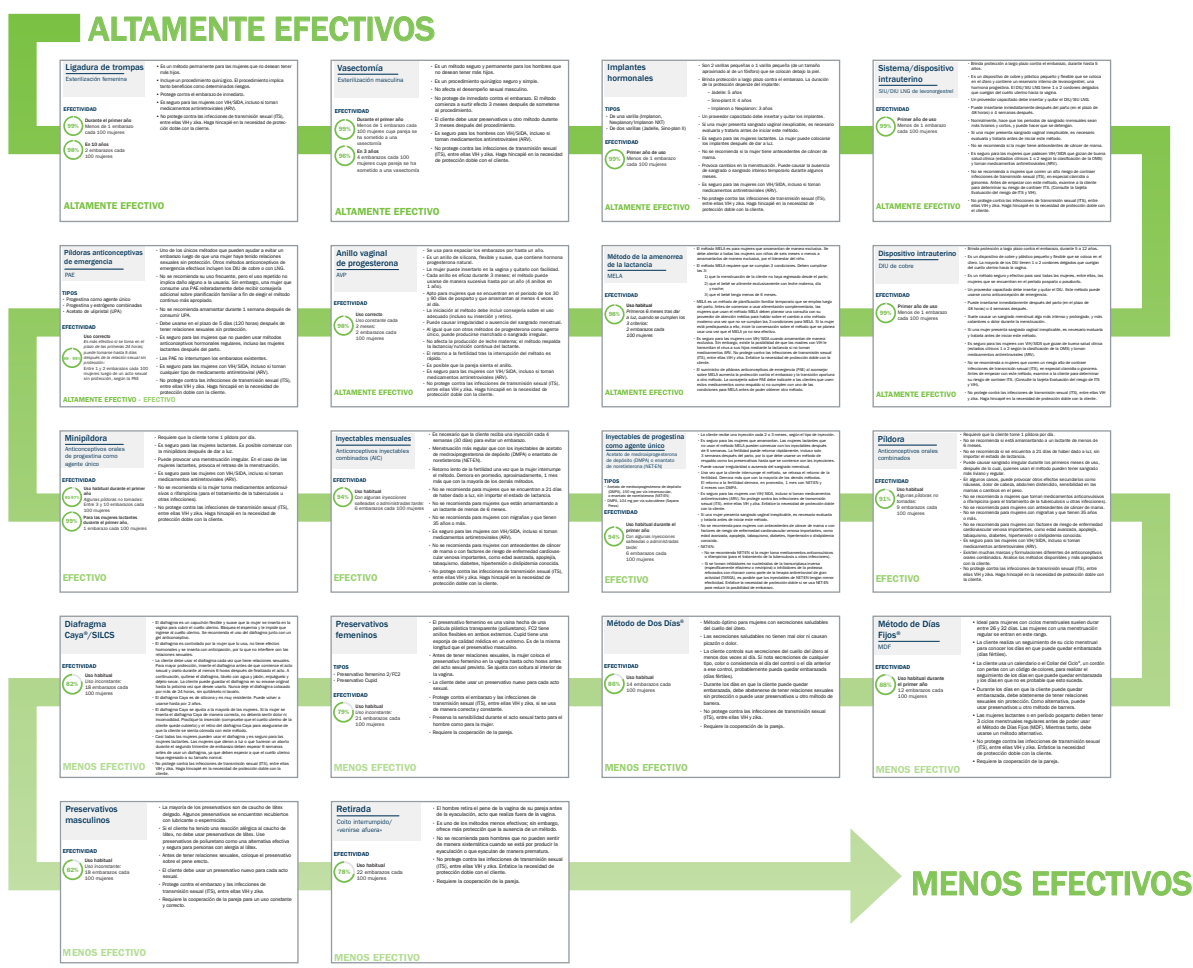




\section{几 Para obtener referencias adi- ¿ cionales}

\section{FRONTERAS}

Artículo de revista especializada: Liambila, W., Askew, I., Mwangi, J., Ayisi, R., Kibaru, J., \& Mullick, S. (2009). Feasibility and effectiveness of integrating provider-initiated testing and counseling within family planning services in Kenya [Viabilidad y efectividad en la integración de consejería y pruebas iniciadas por el proveedor a los servicios de planificación familiar en Kenia]. AIDS (Londres, Inglaterra), 23 Suppl 1, S115-21.

Informe: Feasibility, Acceptability, Effect and Cost of Integrating Counseling and Testing for HIV within Family Planning Counseling and Testing for HIV within Family Planning Services in Kenya [Viabilidad, aceptabilidad, efecto y costo de la integración de consejería y pruebas de VIH a la consejería sobre planificación familiar y a las pruebas de detección de VIH dentro de los servicios de planificación familiar en Kenia] http://pdf.usaid.gov/pdf docs/Pnadn569.pdf (en inglés)

Video: Using the Balanced Counseling Strategy Plus in South Africa [Uso de la Estrategia de Consejería Balanceada Plus en Sudáfrica] http://www.popcouncil.org/research/using-bcs-insouth-africa (en inglés).

\section{PROGRAMA INTEGRA INITIATIVE}

Artículo de revista especializada: Ndwiga, C., Abuya, T., Mutemwa, R., Kimani, J. K., Colombini, M., Mayhew, S., ... Warren, C. E. (2014). Exploring experiences in peer mentoring as a strategy for capacity building in sexual reproductive health and HIV service integration in Kenya [Exploración de experiencias de tutoría como estrategia para construir capacidades en la integración de servicios de salud reproductiva sexual y VIH en Kenia]. BMC Health Services Research, 14, 98.

Resumen de políticas: http:/ /www.integrainitiative.org/wp/wp-content/uploads/2015/09/ Integra-Steps02-peer-mentoring.pdf (en inglés)

Sitio en Internet: http://www.integrainitiative.org/projects/integrainitiative/overview-andobjectives/ (en inglés) 


\section{Referencias}

Askew, Ian. 2007. «Achieving synergies in prevention through linking sexual and reproductive Health and HIV services» [Logrando sinergias en prevención a través de la combinación de la salud reproductiva y sexual, y los servicios de VIH], en Donta, Balaiah et al. (eds.), Proceedings of the International Conference on Actions to Strengthen Linkages between Sexual and Reproductive Health and HIV/AIDS. Mumbai: Sociedad India para el Estudio de la Reproducción y la Fertilidad y la Organización Mundial de la Salud.

Agencia Central de Estadística (CBS, Central Bureau of Statistics) [Kenia], Ministerio de Salud (MDS) [Kenia] y ORC Macro. 2004. Encuesta Demográfica y de Salud en Kenia 2003. Calverton, Maryland: CBS, MDS y ORC Macro.

Engenderhealth y Planned Parenthood Association de Sudáfrica. 2001. Plan de estudios titulado: Men As Partners: A Program for Supplementing the Training of Life Skills Educators, 2nd Edition. [Hombres como parejas: Un programa para complementar la capacitación de educadores de habilidades para la vida, 2da edición] Nueva York: Engenderhealth y Planned Parenthood de Sudáfrica. 2002.

Hatcher, R.A. et al. 2011. Contraceptive Technology [Tecnología Anticonceptiva]. Edición 20a revisada. Nueva York: Ardent Media.

León, Federico R. 1999. «Peru: Providers’ compliance with quality of care norms [Perú: Cumplimiento de los proveedores con las normas de calidad de atención]», Informe final de FRONTERAS. Washington, DC: Population Council.

León, Federico R. et al. 2001. «Length of counseling sessions and the amount of relevant information exchanged: A study in Peruvian clinics [Duración de las sesiones de consejería y cantidad de información relevante proporcionada: Un estudio en clínicas peruanas]», International Family Planning Perspectives 27(1):28-33, 46.

León, Federico R. et al. 2003a. «Effects of IGSS’s job aids-assisted balanced counseling algorithms on quality of care and client outcomes (Guatemala) [Efectos de las ayudas de trabajo de los algoritmos de consejería balanceada en la calidad de atención y en los resultados con los clientes del IGSS] (Guatemala)», Informe final de FRONTERAS. Washington, DC: Population Council.

León, Federico R. et al. 2003b. «Enhancing quality for clients: Balanced Counseling Strategy [Mejorando la calidad para los clientes: Estrategia de Consejería Balanceada]», Documento de Programas n. ${ }^{\circ} 3$. Washington, DC: Population Council.

León, Federico R. et al. 2003c. «Testing balanced counseling to improve provider-client interaction in Guatemala's MOH clinics [Prueba de la consejería balanceada para mejorar la interacción clienteproveedor en las clínicas del MSPAS de Guatemala]», Informe Final de FRONTERAS. Washington, DC: Population Council.

León, Federico R. et al. 2004. «One-year client impacts of quality of care improvements achieved in Peru [Impactos en la calidad de atención a clientes logrados en un año en Perú]», Informe Final de FRONTERAS. Washington, DC: Population Council.

León, Federico, Ricardo Vernon, Antonieta Martin y Linda Bruce. 2008.

Estrategia de Consejería Balanceada: Un paquete de herramientas para proveedores de servicios de planificación familiar. Washington, DC: Population Council.

Liambila, Wilson et al. 2008. «Feasibility, effectiveness and cost of models of integrating counseling and testing for HIV within family planning services in Kenya [Viabilidad, efectividad y costos de los modelos para la integración de la consejería y pruebas de VIH a los servicios de planificación familiar en Kenia]», Informe Final de FRONTERAS. Washington, DC: Population Council.

Mullick, Saiqa, Mantshi Menziwa, Doctor Khoza y Edwin Maroga. 2008. «Feasibility, effectiveness and cost of models of integrating counseling and testing for HIV within family planning services in North West Province, South Africa [Viabilidad, efectividad y costos de los modelos para la integración de la consejería y pruebas de VIH a los servicios de planificación familiar en la provincia noroeste, Sudáfrica]», Informe Final de FRONTERAS. Washington, DC: Population Council. 
Stanback J. et al. 1999. «Checklist for ruling out pregnancy among family planning clients in primary care [Lista de verificación para descartar el embarazo en las clientes de planificación familiar en atención primaria de salud]», Lancet 354(9178):566.

Organización Mundial de la Salud. 2003. Guías para el tratamiento de las infecciones de transmisión sexual. Ginebra: OMS.

—. 2004. Criterios médicos de elegibilidad para el uso de anticonceptivos, 3. ${ }^{a}$ edición. Ginebra: OMS.

—. 2005. Infecciones de transmisión y otras infecciones del tracto reproductivo: Una guía para la práctica básica. Ginebra: OMS.

— . 2015. Criterios médicos de elegibilidad para el uso de anticonceptivos. 5ta edición. Ginebra: OMS.

— . 2010. WHO Technical Consultation on Postpartum and Postnatal Care [Consulta técnica sobre atención posparto y posnatal de la OMS]. Ginebra: OMS.

—. 2016. Prevención de la transmisión sexual del virus de Zika: Orientaciones provisionales. OMS/ ZIKV /MOC/16. 1 Rev. 3

Organización Mundial de la Salud, Departamento de Salud Reproductiva e Investigación (OMS/ISR) y Johns Hopkins, Facultad de Salud Pública Bloomberg/Centro de Programas de Comunicación (CPC) Proyecto INFO. 2011. Planificación Familiar: Un manual mundial para proveedores. Baltimore y Ginebra: JHU/CPC y OMS.

Organización Mundial de la Salud y Programa Conjunto de las Naciones Unidas sobre VIH/SIDA (ONUSIDA) Guía sobre los servicios de consejería y pruebas de VIH iniciadas por el proveedor en centros de salud. Ginebra: OMS. 
迎 Notas: 


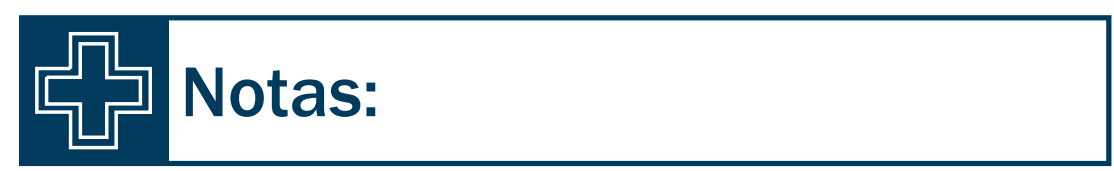


迎 Notas: 
El Population Council aborda problemas críticos relacionados con la salud y el desarrollo, que van desde frenar la propagación del VIH hasta mejorar la salud reproductiva y garantizar que los jóvenes tengan una vida plena y productiva. A través de investigaciones en biomedicina, ciencias sociales y salud pública en 50 países, trabajamos con nuestros socios para entregar soluciones que se traducen en políticas, programas y tecnologías más efectivos que mejoren vidas alrededor del mundo. Establecido en 1952, y con sede central en Nueva York, Project Council es una organización no gubernamental sin fines de lucro regida por un consejo administrativo internacional.

Para obtener información adicional, comuníquese con:

Population Council

4301 Connecticut Ave., NW, Suite 280

Washington, DC 20008 USA

Teléfono: (202) 237-9400

Fax: (202) 237-8410

Correo electrónico: publications@popcouncil.org

www.popcouncil.org 


\section{Algoritmo para el uso de la Estrategia de Consejería Balanceada Plus TERCERA EDICIÓN, 2015}

\section{ETAPA PREVIA A LA ELECCIÓN}

(1) Establezca y mantenga una relación cordial y cálida.

(2) Informe a la cliente (y a su pareja, si se encuentra presente) que durante la consulta tendrá la oportunidad de abordar tanto sus necesidades de salud como sus necesidades de planificación familiar.

(3) Pregúntele a la cliente sobre el tamaño actual de su familia y sobre sus prácticas anticonceptivas actuales. Asesore a la cliente sobre períodos saludables para el embarazo y el espaciamiento entre embarazos usando una tarjeta de consejería.

a) Si la cliente actualmente usa un método de planificación familiar o posponiendo el embarazo, pregúntele si ambos miembros de la pareja están satisfechos con

el método y si les interesa continuar con él, o bien si desean cambiar de método.

b) Si la pareja se encuentra presente, use la tarjeta de apoyo y servicios para hombres.

(4) Descarte la posibilidad de embarazo usando la tarjeta Lista de verificación para asegurarse de manera razonable de que una mujer no está embarazada.

(5) Muestre todas las tarjetas de métodos. Pregúntele al/a la cliente si desea un método en particular.

6) Formule todas las preguntas que se detallan a continuación. Aparte las tarjetas de método según las respuestas del/de la cliente.

a) ¿Desea tener hijos en un futuro?

Si la respuesta es "Sin", aparte la tarjeta Vasectomía y la tarjeta Ligadura de trompas. Explique por qué.

Si la respuesta es "No", conserve todas las tarjetas y continúe.

b) ¿Ha dado a luz en las últimas 48 horas?

Si la respuesta es "Sín, aparte la tarjeta Inyectables combinados y la tarjeta Anticonceptivos orales combinados (Píldora). Explique por qué. Si la respuesta es "No", continúe con la siguiente pregunta.

c) ¿Está amamantando a un lactante de menos de 6 meses?

Si la respuesta es "Sin, aparte la tarjeta Inyectables combinados y la tarjeta Anticonceptivos orales combinados (Píldora). Explique por qué.

Si la respuesta es "No" o si ha vuelto a tener la menstruación, aparte la tarjeta Método de la amenorrea de la lactancia (MELA). Explique por qué.

d) ¿Respalda su pareja su decisión sobre planificación familiar?

Si la respuesta es "Sí", continúe con la siguiente pregunta.

Si la respuesta es "No", aparte las siguientes tarjetas: Preservativo femenino, Preservativo masculino, Método de Días Fijos@, Método de Dos Días@ y Retirada. Explique por qué.

e) ¿Sufre alguna afección médica? ¿Toma medicamentos?

Si la respuesta es "Sí, pregunte qué afecciones padece o qué medicamentos toma. Consulte la Rueda con los criterios médicos de elegibilidad para el uso de anticonceptivos de la OMS o las directrices nacionales actuales y aparte las tarjetas de todos los métodos contraindicados. Explique por qué. Si la respuesta es "No", conserve todas las tarjetas y continúe.

f) ¿Existen métodos que no desee usar o que no haya tolerado en el pasado?

Si la respuesta es "Sin, aparte las tarjetas de los métodos que el/la cliente no desee.

Si la respuesta es "No", conserve el resto de las tarjetas.

\section{ETAPA DE ELECCIÓN DEL MÉTODO}

(7) Repase brevemente los métodos que no haya apartado e indique su efectividad.

a) Disponga las tarjetas restantes por orden de efectividad (consulte el reverso de cada tarjeta).

b) En orden de efectividad (de mayor a menor), repase brevemente los atributos en cada tarjeta de método.

(8) Pídale al/a la cliente que elija el método que ella o su pareja encuentre más conveniente.

a) Si el/la cliente es adolescente, use la tarjeta de consejería para informarle que puede obtener cualquier método.

(9) Mediante el folleto específico del método, compruebe que el/la cliente no presente ninguna afección por la cual no se recomiende el método.

a) Repase la sección "Método no recomendado si..." del folleto.
b) Si el método no es recomendable, pídale al/a la cliente que seleccione otro método de las tarjetas restantes. Repita el proceso desde el paso 8.

\section{ETAPA POSTERIOR A LA ELECCIÓN}

10) Analice el método elegido con el/la cliente, con el folleto específico del método como herramienta de consejería. Determine el entendimiento del/ de la cliente, y refuerce la información clave.

11) Asegúrese de que el/la cliente haya tomado una decisión definitiva. Dele el método elegido, un método de respaldo o derívelo/a, según el método seleccionado.

(12) Aliente al/a la cliente a involucrar a su pareja en las decisiones sobre prácticas anticonceptivas, ya sea mediante una charla o una visita a la clínica.

\section{ETAPA DE DETECCIÓN SISTEMÁTICA PARA OTROS SERVICIOS}

13) Mediante la información obtenida con anterioridad, determine la necesidad de la cliente de recibir servicios de atención posparto, de control de salud para recién nacidos, lactantes o niños, o de posaborto.

a) Si la cliente informó haber dado a luz recientemente, repase con ella la tarjeta Promoción de un período posparto saludable y la tarjeta Promoción de la salud del recién

nacido y del lactante. Proporcione los servicios necesarios o haga una derivación, según corresponda.

b) Para clientes con niños de menos de 5 años, pregunte si los niños han recibido los servicios de control de salud correspondientes. Proporcione los servicios

de vacunación o control del crecimiento necesarios o haga una derivación, según corresponda.

c) Si la cliente informó un aborto reciente, repase con ella la tarjeta Atención posaborto. Proporcione los servicios de atención posaborto necesarios o haga una derivación, según corresponda.

14. Pregúntele a la cliente cuándo fue su último examen de detección de cáncer de cuello uterino (IVAA/IVSL o Papanicolaou) o de cáncer de mama.

a) Si su último examen de detección de cáncer de cuello uterino fue hace más de 3 años (o, en caso de ser VIH positivo, en los últimos 6 a 12 meses) o si no sabe,

pregúntele si le gustaría hacerse uno ese mismo día. Repase la tarjeta Examen de detección de cáncer de cuello uterino. Proporcione los servicios necesarios

o haga una derivación.

b) Si el último examen de detección de cáncer de cuello uterino de la cliente fue hace menos de 3 años, continúe con la siguiente pregunta.

c) Repase con la cliente la tarjeta de consejería Información y concienciación sobre el cáncer de mama.

15) Analice con el/la cliente las tarjetas de consejería Prevención y transmisión de ITS/VIH y Protección doble. Ofrézcale preservativos e instrucciones sobre el uso correcto y constante.

a) En las regiones con virus del Zika activo, analice con el/la cliente las tarjetas de consejería Prevención y transmisión del virus del Zika.

(16) Lleve a cabo una evaluación del riesgo de ITS y VIH usando la tarjeta de consejería. Si se identifican los síntomas, trate al/a la cliente de manera sindrómica.

(17) Pregúntele al/a la cliente si conoce su estado de VIH.

a) $\mathrm{Si}$ el/la cliente sabe que tiene $\mathrm{VIH}$,

- repase con el/la cliente la tarjeta de consejería Prevención, dignidad y salud positiva.

- Derive al/a la cliente a un centro de tratamiento y atención de bienestar.

b) Si el/la cliente sabe que es VIH negativo,

- analice un plazo de repetición de la prueba.

c) Si el/la cliente desconoce su estado

- Hable sobre los servicios de consejería y pruebas de VIH (HCT, HIV Counseling and Testing) usando la tarjeta de consejería.

- Ofrézcale o hágale una prueba, según los protocolos nacionales.

- Asesore al/a la cliente sobre los resultados de la prueba. Si el/la cliente tiene VIH, repase con el/ella la tarjeta de consejería Prevención, dignidad y salud positiva, y derívelo/a a un centro de tratamiento y atención de bienestar.

d) Aconseje a la cliente usando la tarjeta Seguridad y apoyo a la mujer.

- Si la cliente presenta signos graves que indiquen que puede ser víctima de violencia infligida por la pareja, derívela a servicios especializados.

(18) Proporcione instrucciones de seguimiento, un folleto sobre preservativos y un folleto sobre el método escogido. Fije una fecha para la próxima visita.

19 Agradézcale por su visita. Complete la sesión de consejería.

Adaptado por K4Health con el permiso de Population Council y el apoyo de los ciudadanos estadounidenses a través de la Agencia de los Estados Unidos para el Desarrollo Internacional (USAID, por sus siglas en inglés). El contenido de este material adaptado es responsabilidad exclusiva de la fuente original, y no refleja los puntos de vista de la USAID ni del Gobierno de los Estados Unidos. 


\section{Inyectables men- suales}

Anticonceptivos inyectables combinados (AIC) 


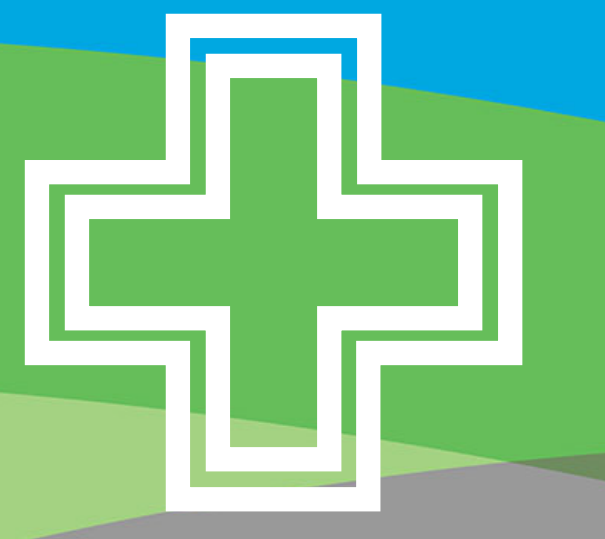

Estrategia de Consejería Balanceada Plus Un paquete de herramientas para proveedores de servicios de planificación familiar que trabajan en entornos con alta prevalencia de ITS $/ V I H$

\section{TARJETAS DE CONSEJERÍA}

Tercera edición, 2015 


\section{Inyectables mensuales}

\section{Anticonceptivos de emergencia}

Preservativos femeninos

I Implantes hormonales

Dispositivo intrauterino de cobre (DIU)

Sistema intrauterino de levonorgestrel

$\square$ Método de la amenorrea de la lactancia

(15 Preservativos masculinos

回 Minipildora

$\square$ Pildora

Inyectables de progestina como agente único

\section{पص Retirada}

Ligadura de trompas

\section{$\square$ Método de Dos Días}

صasectomía

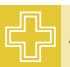

Anillo vaginal de progesterona

늠 Diafragma Caya $\%$ Silcs

П Períodos saludables para el embarazo y el

$\square$ espaciamiento entre embarazos

$\square$ Promoción de un período posparto saludable $\square$ para la madre

Atención posaborto

5

Promoción de la salud del recién nacido y del lactante

Prevención y transmisión de ITS y VIH
Evaluación del riesgo de ITS y VIH

Prevención, dignidad y salud positiva

几

5 Protección doble

$\square$ Consejería y pruebas de VIH

प다

$\sqrt{\square}$

Examen de detección de cáncer de cuello uterino

几

Consejería para adolescentes

\section{$\square$ Seguridad y apoyo a la mujer}

$\sqrt{1}$

Servicios para hombres

ᄂ

I Información y concienciación sobre el cáncer

de mama 


\section{Clasificaciones de efectividad}

LOS MÉTODOS SE DEFINEN PARA SU USO HABITUAL DE LA SIGUIENTE MANERA:

ALTAMENTE

EFECTIVO

EFECTIVO

MENOS

EFECTIVO
< 5 embarazos cada 100 mujeres en el período designado

Entre 5 y 10 embarazos cada 100 mujeres en el período designado

> 10 embarazos cada 100 mujeres en el período designado 
ALTAMENTE EFECTIVO < 5 embarazos cada 100 mujeres en el período designado

Dispositivo intrauterino de cobre (DIU)

Sistema intrauterino
de levonorgestrel

\section{洱 Píldora}

Inyectables mensuales
П Inyectables de progestina como agente único

Ђ马 Minipíldora

\section{鸟 Diafragma Caya ${ }^{\circledR} /$ Silcs}

Preservativos femeninos

־ Preservativos masculinos
Método de Días Fijos ${ }^{\circledR}$

Método de Dos Días

Retirada

MENOS EFECTIVO > 10 embarazos cada 100 mujeres en el período designado 


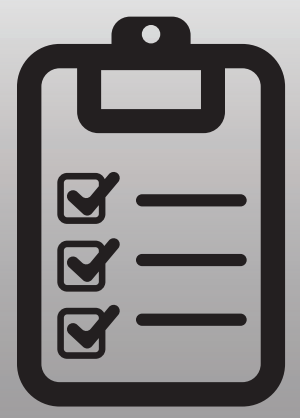

Lista de verificación para asegurarse de manera razonable de que una mujer no está embarazada 
Lista de verificación para asegurarse de manera

razonable de que una

mujer no está embarazada
El objetivo del servicio de planificación familiar (PF) es brindarle a la cliente su método preferido el mismo día de la visita. Es preferible brindarle un método anticonceptivo a que se vaya y se embarace. Los riesgos asociados con ofrecerle un método anticonceptivo a una mujer que puede estar embarazada y no saberlo son bajos.

\section{FORMULE ESTAS 6 PREGUNTAS:}

1. ¿Tuvo un bebé hace menos de 6 meses? Si la respuesta es "Sí", ¿amamanta al bebé? ¿Ha tenido su menstruación desde el parto?

2. ¿Se abstuvo de tener relaciones sexuales sin protección (sin un método de PF) desde su último sangrado menstrual o parto?

3. ¿Ha dado a luz en las últimas 4 semanas?

4. ¿Su menstruación comenzó en los últimos 7 días (o en los últimos 12 si planea usar un DIU de cobre)?

5. ¿Tuvo un aborto espontáneo o un aborto provocado en los últimos 7 días?

6. ¿Usa un método anticonceptivo confiable de forma sistemática y correcta?
Si la respuesta a cualquiera de estas preguntas es "sí" y la cliente no tiene signos 0 síntomas de embarazo:

* Una vez que la cliente ha respondido que sí a una de las preguntas, no es necesario seguir haciéndole el resto de las preguntas.

1. El embarazo es poco probable.

2. Continúe con el paso 5.
Si responde "no" a todas las preguntas:

1. No se puede descartar un embarazo.

2. De ser posible dele a la cliente una prueba de embarazo o derívela a una clínica prenatal.

3. Bríndele un método de respaldo, como preservativos, para que use hasta que tenga su menstruación.

4. Bríndele de manera anticipada el método que prefiera (siempre que sea posible) para que lo use el primer día de su periodo O BIEN

pídale que regrese en ese momento para recibir su método que eligió.

5. Diríjase al paso 13. 


\section{Inyectables mensuales}

Anticonceptivos inyectables

combinados (AIC) 


\section{Inyectables mensuales}

Anticonceptivos inyectables combinados (AIC)

\section{EFECTIVIDAD}

Uso habitual

94\% Con algunas inyecciones salteadas o administradas tarde: 6 embarazos cada 100 mujeres
- Es necesario que la cliente reciba una inyección cada 4 semanas (30 días) para evitar un embarazo.

- Menstruación más regular que con los inyectables de acetato de medroxiprogesterona de depósito (DMPA) o enantato de noretisterona (NET-EN).

- Retorno lento de la fertilidad una vez que la mujer interrumpe el método. Demora en promedio, aproximadamente, 1 mes más que con la mayoría de los demás métodos.

- No se recomienda para mujeres que se encuentran a 21 días de haber dado a luz, sin importar el estado de lactancia.

- No se recomienda para mujeres que están amamantando a un lactante de menos de 6 meses.

- No se recomienda para mujeres con migrañas y que tienen 35 años o más.

- Es seguro para las mujeres con VIH/SIDA, incluso si toman medicamentos antirretrovirales (ARV).

- No se recomienda para mujeres con antecedentes de cáncer de mama o con factores de riesgo de enfermedad cardiovascular venosa importantes, como edad avanzada, apoplejía, tabaquismo, diabetes, hipertensión o dislipidemia conocida.

- No protege contra las infecciones de transmisión sexual (ITS), entre ellas VIH y zika. Haga hincapié en la necesidad de protección doble con la cliente. 


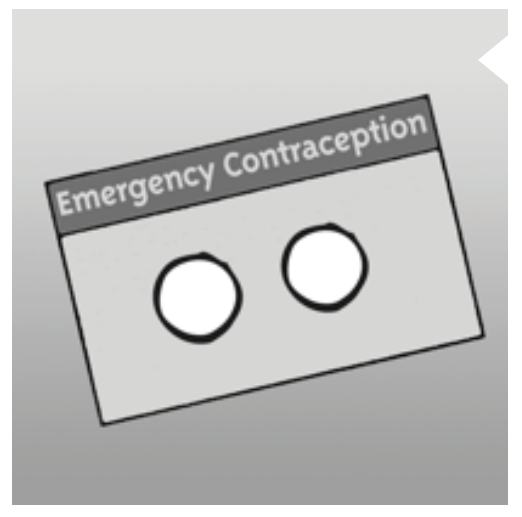

Píldoras anticonceptivas de emergencia

PAE 


\section{Píldoras anticonceptivas de emergencia}

\section{PAE}

\section{TIPOS}

- Progestina como agente único

- Progestina y estrógeno combinadas

- Acetato de ulipristal (UPA)

\section{EFECTIVIDAD}

Uso correcto

Es más efectivo si se toma en el plazo de las primeras 24 horas; puede tomarse hasta 5 días después de la relación sexual sin protección:

Entre 1 y 2 embarazos cada 100 mujeres luego de un acto sexual sin protección, según la $\mathrm{PAE}$
- Uno de los únicos métodos que pueden ayudar a evitar un embarazo luego de que una mujer haya tenido relaciones sexuales sin protección. Otros métodos anticonceptivos de emergencia efectivos incluyen los DIU de cobre o con LNG.

- No se recomienda su uso frecuente, pero el uso repetido no implica daño alguno a la usuaria. Sin embargo, una mujer que consume una PAE reiteradamente debe recibir consejería adicional sobre planificación familiar a fin de elegir el método continuo más apropiado.

- No se recomienda amamantar durante 1 semana después de consumir UPA.

- Debe usarse en el plazo de 5 días (120 horas) después de tener relaciones sexuales sin protección.

- Es seguro para las mujeres que no pueden usar métodos anticonceptivos hormonales regulares, incluso las mujeres lactantes después del parto.

- Las PAE no interrumpen los embarazos existentes.

- Es seguro para las mujeres con VIH/SIDA, incluso si toman cualquier tipo de medicamento antirretroviral (ARV).

- No protege contra las infecciones de transmisión sexual (ITS), entre ellas VIH y zika. Haga hincapié en la necesidad de protección doble con la cliente. 


\section{Preservativos femeninos}

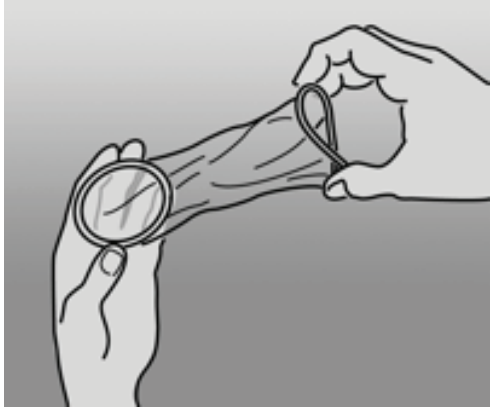




\section{Preservativos femeninos}

\section{TIPOS}

- Preservativo femenino 2/FC2

- Preservativo Cupid

\section{EFECTIVIDAD}

Uso habitual

79\% Uso inconstante:

21 embarazos cada

100 mujeres
- El preservativo femenino es una vaina hecha de una película plástica transparente (poliuretano). FC2 tiene anillos flexibles en ambos extremos. Cupid tiene una esponja de calidad médica en un extremo. Es de la misma longitud que el preservativo masculino.

- Antes de tener relaciones sexuales, la mujer coloca el preservativo femenino en la vagina hasta ocho horas antes del acto sexual previsto. Se ajusta con soltura al interior de la vagina.

- La cliente debe usar un preservativo nuevo para cada acto sexual.

- Protege contra el embarazo y las infecciones de transmisión sexual (ITS), entre ellas VIH y zika, si se usa de manera correcta y constante.

- Preserva la sensibilidad durante el acto sexual tanto para el hombre como para la mujer.

- Requiere la cooperación de la pareja. 


\section{Implantes hormonales}




\section{Implantes \\ hormonales}

\section{TIPOS}

- De una varilla (Implanon, Nexplanon/Implanon NXT)

- De dos varillas (Jadelle, Sino-plan II)

\section{EFECTIVIDAD}

Primer año de uso

Menos de 1 embarazo

cada 100 mujeres
- Son 2 varillas pequeñas o 1 varilla pequeña (de un tamaño aproximado al de un fósforo) que se colocan debajo la piel.

- Brinda protección a largo plazo contra el embarazo. La duración de la protección depende del implante:

- Jadelle: 5 años

- Sino-plant II: 4 años

- Implanon o Nexplanon: 3 años

- Un proveedor capacitado debe insertar y quitar los implantes.

- Si una mujer presenta sangrado vaginal inexplicable, es necesario evaluarla y tratarla antes de iniciar este método.

- Es seguro para las mujeres lactantes. La mujer puede colocarse los implantes después de dar a luz.

- No se recomienda si la mujer tiene antecedentes de cáncer de mama.

- Provoca cambios en la menstruación. Puede causar la ausencia de sangrado o sangrado intenso temporario durante algunos meses.

- Es seguro para las mujeres con VIH/SIDA, incluso si toman medicamentos antirretrovirales (ARV).

- No protege contra las infecciones de transmisión sexual (ITS), entre ellas VIH y zika. Haga hincapié en la necesidad de protección doble con la cliente. 


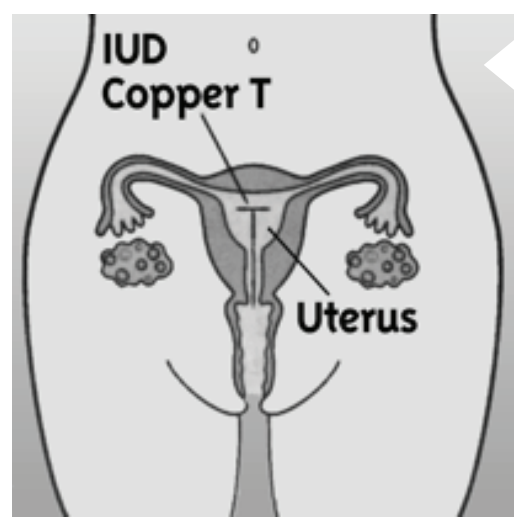

\section{Dispositivo intrauterino}

DIU de cobre 


\section{Dispositivo intrauterino}

\section{DIU de cobre}

\section{EFECTIVIDAD}

\section{Primer año de uso}

Menos de 1 embarazo

cada 100 mujeres
- Brinda protección a largo plazo contra el embarazo, durante 5 a 12 años.

- Es un dispositivo de cobre y plástico pequeño y flexible que se coloca en el útero. La mayoría de los DIU tienen 1 o 2 cordones delgados que cuelgan del cuello uterino hacia la vagina.

- Es un método seguro y efectivo para casi todas las mujeres, entre ellas, las mujeres que se encuentran en el período posparto o posaborto.

- Un proveedor capacitado debe insertar y quitar el DIU. Este método puede usarse como anticoncepción de emergencia.

- Puede insertarse inmediatamente después del parto (en el plazo de 48 horas) o 4 semanas después.

- Suele causar un sangrado menstrual algo más intenso y prolongado, y más calambres o dolor durante la menstruación.

- Si una mujer presenta sangrado vaginal inexplicable, es necesario evaluarla y tratarla antes de iniciar este método.

- Es seguro para las mujeres con VIH/SIDA que gozan de buena salud clínica (estadios clínicos 1 o 2 según la clasificación de la OMS) y toman medicamentos antirretrovirales (ARV).

- No se recomienda a mujeres que corren un riesgo alto de contraer infecciones de transmisión sexual (ITS), en especial clamidia o gonorrea. Antes de empezar con este método, examine a la cliente para determinar su riesgo de contraer ITS. (Consulte la tarjeta Evaluación del riesgo de ITS y VIH).

- No protege contra las infecciones de transmisión sexual (ITS), entre ellas VIH y zika. Haga hincapié en la necesidad de protección doble con la cliente. 


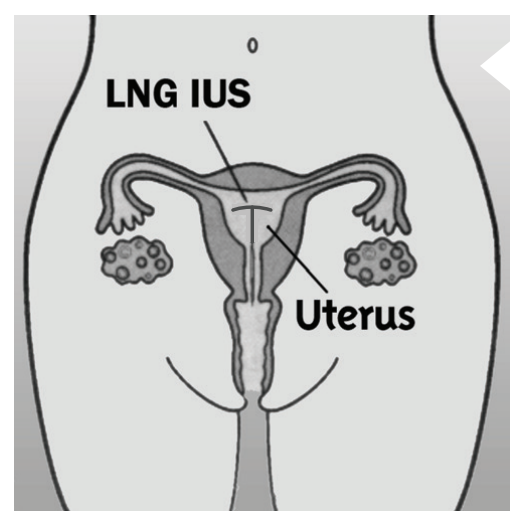

Sistema/dispositivo intrauterino

SIU/DIU LNG de levonorgestrel 


\section{Sistema/dispositivo intrauterino}

SIU/DIU LNG de levonorgestrel

\section{EFECTIVIDAD}

Primer año de uso

Menos de 1 embarazo

cada 100 mujeres
- Brinda protección a largo plazo contra el embarazo, durante hasta 5 años.

- Es un dispositivo de cobre y plástico pequeño y flexible que se coloca en el útero y contiene un reservorio interno de levonorgestrel, una hormona progestina. EI DIU/SIU LNG tiene 1 o 2 cordones delgados que cuelgan del cuello uterino hacia la vagina.

- Un proveedor capacitado debe insertar y quitar el DIU/SIU LNG.

- Puede insertarse inmediatamente después del parto (en el plazo de 48 horas) o 4 semanas después.

- Normalmente, hace que los periodos de sangrado mensuales sean más livianos y cortos, y puede hacer que se detengan.

- Si una mujer presenta sangrado vaginal inexplicable, es necesario evaluarla y tratarla antes de iniciar este método.

- No se recomienda si la mujer tiene antecedentes de cáncer de mama.

- Es seguro para las mujeres que padecen VIH/SIDA que gozan de buena salud clínica (estadios clínicos 1 o 2 según la clasificación de la OMS) y toman medicamentos antirretrovirales (ARV).

- No se recomienda a mujeres que corren un alto riesgo de contraer infecciones de transmisión sexual (ITS), en especial clamidia o gonorrea. Antes de empezar con este método, examine a la cliente para determinar su riesgo de contraer ITS. (Consulte la tarjeta Evaluación del riesgo de ITS y VIH).

- No protege contra las infecciones de transmisión sexual (ITS), entre ellas VIH y zika. Haga hincapié en la necesidad de protección doble con el cliente. 


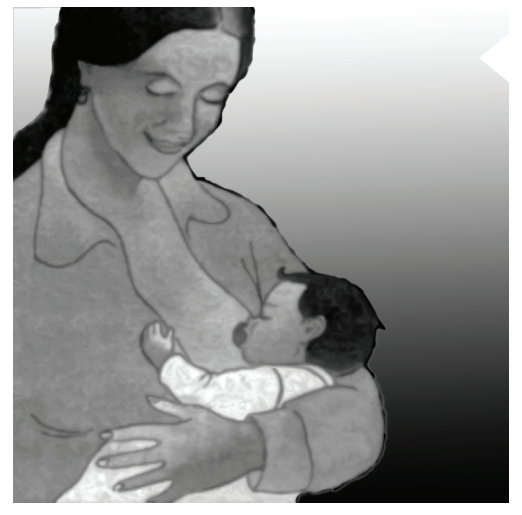

\section{Método de la amenorrea de la lactancia}

MELA 


\section{Método de la amenorrea de la lactancia}

\section{MELA}

\section{EFECTIVIDAD}

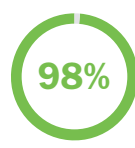

\section{Uso habitual}

Primeros 6 meses tras dar a luz, cuando se cumplen los 3 criterios:

2 embarazos cada 100 mujeres
- El método MELA es para mujeres que amamantan de manera exclusiva. Se debe alentar a todas las mujeres con niños de seis meses o menos a amamantarlos de manera exclusiva, por el bienestar del niño.

- El método MELA requiere que se cumplan 3 condiciones. Deben cumplirse las 3:

1) que la menstruación de la cliente no haya regresado desde el parto;

2) que el bebé se alimente exclusivamente con leche materna, día y noche;

3) que el bebé tenga menos de 6 meses.

- MELA es un método de planificación familiar temporario que se emplea luego del parto. Antes de comenzar a usar alimentación complementaria, las mujeres que usan el método MELA deben planear una consulta con su proveedor de atención médica para hablar sobre el cambio a otro método moderno una vez que no se cumplan las 3 condiciones para MELA. Si la mujer está predispuesta a ello, inicie la conversación sobre el método que se planea usar una vez que el MELA ya no sea efectivo.

- Es seguro para las mujeres con VIH/SIDA cuando amamantan de manera exclusiva. Sin embargo, existe la posibilidad de que las madres con $\mathrm{VIH}$ le transmitan el virus a sus hijos mediante la lactancia si no toman medicamentos ARV. No protege contra las infecciones de transmisión sexual (ITS), entre ellas VIH y zika. Enfatice la necesidad de protección doble con la cliente.

- El suministro de píldoras anticonceptivas de emergencia (PAE) al aconsejar sobre MELA aumenta la protección contra el embarazo y la transición oportuna a otro método. La consejería sobre PAE debe indicarle a las clientes que usen estos medicamentos como respaldo si no cumplen con uno de las condiciones para MELA antes de poder obtener otro método. 


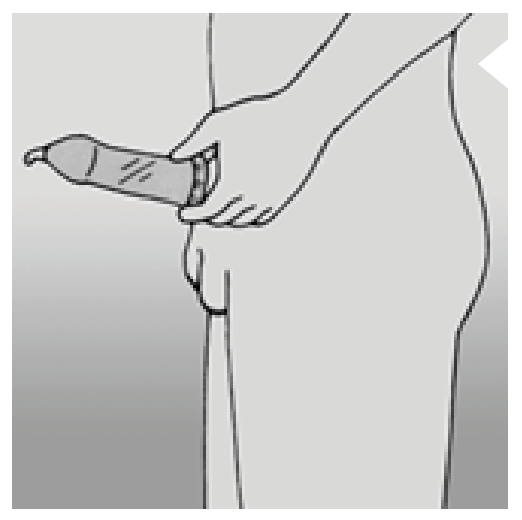

\section{Preservativos masculinos}




\section{Preservativos masculinos}

\section{EFECTIVIDAD}

Uso habitual

Uso inconstante:

18 embarazos cada

100 mujeres
- La mayoría de los preservativos son de caucho de látex delgado. Algunos preservativos se encuentran recubiertos con lubricante o espermicida.

- Si el cliente ha tenido una reacción alérgica al caucho de látex, no debe usar preservativos de látex. Use preservativos de poliuretano como una alternativa efectiva y segura para personas con alergia al látex.

- Antes de tener relaciones sexuales, coloque el preservativo sobre el pene erecto.

- El cliente debe usar un preservativo nuevo para cada acto sexual.

- Protege contra el embarazo y las infecciones de transmisión sexual (ITS), entre ellas VIH y zika.

- Requiere la cooperación de la pareja para un uso constante y correcto. 


\section{Minipíldora}

Anticonceptivos orales de progestina como agente único 


\section{Minipíldora}

\section{Anticonceptivos orales}

de progestina como agente único

\section{EFECTIVIDAD}

Uso habitual durante el primer año

Algunas píldoras no tomadas: Entre 3 y 10 embarazos cada 100 mujeres

Para las mujeres lactantes durante el primer año, 1 embarazo cada 100 mujeres
- Requiere que la cliente tome 1 píldora por día.

- Es seguro para las mujeres lactantes. Es posible comenzar con la minipíldora después de dar a luz.

- Puede provocar una menstruación irregular. En el caso de las mujeres lactantes, provoca el retraso de la menstruación.

- Es seguro para las mujeres con VIH/SIDA, incluso si toman medicamentos antirretrovirales (ARV).

- No se recomienda si la mujer toma medicamentos anticonvulsivos o rifampicina (para el tratamiento de la tuberculosis u otras infecciones).

- No protege contra las infecciones de transmisión sexual (ITS), entre ellas VIH y zika. Haga hincapié en la necesidad de protección doble con la cliente. 


\section{Píldora}

Oral contraceptives

O-0.0-0.0-0.0-07]

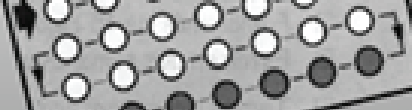

\section{Anticonceptivos orales combinados}




\section{Píldora}

Anticonceptivos orales combinados

\section{EFECTIVIDAD}

$91 \%$

Uso habitual

Algunas píldoras no

tomadas:

9 embarazos cada 100 mujeres
- Requiere que la cliente tome 1 píldora por día.

- No se recomienda si está amamantando a un lactante de menos de 6 meses.

- No se recomienda si se encuentra a 21 días de haber dado a luz, sin importar el estado de lactancia.

- Puede causar sangrado irregular durante los primeros meses de uso, después de lo cual, quienes usan el método pueden tener sangrado más liviano y regular.

- En algunos casos, puede provocar otros efectos secundarios como náuseas, dolor de cabeza, abdomen distendido, sensibilidad en las mamas o cambios en el peso.

- No se recomienda a mujeres que toman medicamentos anticonvulsivos o rifampicina (para el tratamiento de la tuberculosis u otras infecciones).

- No se recomienda para mujeres con antecedentes de cáncer de mama.

- No se recomienda para mujeres con migrañas y que tienen 35 años o más.

- No se recomienda para mujeres con factores de riesgo de enfermedad cardiovascular venosa importantes, como edad avanzada, apoplejía, tabaquismo, diabetes, hipertensión o dislipidemia conocida.

- Es seguro para las mujeres con VIH/SIDA, incluso si toman medicamentos antirretrovirales (ARV).

- Existen muchas marcas y formulaciones diferentes de anticonceptivos orales combinados. Analice los métodos disponibles y más apropiados con la cliente.

- No protege contra las infecciones de transmisión sexual (ITS), entre ellas VIH y zika. Haga hincapié en la necesidad de protección doble con la cliente. 


\section{Inyectables de progestina como agente único}

Acetato de medroxiprogesterona de depósito (DMPA) o enantato de noretisterona (NET-EN) 


\section{Inyectables de progestina como agente único}

Acetato de medroxiprogesterona de depósito (DMPA) o enantato de noretisterona (NET-EN)

\section{TIPOS}

- Acetato de medroxiprogesterona de depósito (DMPA), 150 mg por vía intramuscular, o enantato de noretisterona (NET-EN)

- DMPA, 104 mg por vía subcutánea (Sayana Press)

\section{EFECTIVIDAD}

Uso habitual durante el primer año

Con algunas inyecciones salteadas o administradas tarde:

6 embarazos cada 100 mujeres
- La cliente recibe una inyección cada 2 o 3 meses, según el tipo de inyección.

- Es seguro para las mujeres que amamantan. Las mujeres lactantes que no usan el método MELA pueden comenzar con los inyectables después de 6 semanas. La fertilidad puede retornar rápidamente, incluso solo 3 semanas después del parto, por lo que debe usarse un método de respaldo como los preservativos hasta que se comience con las inyecciones.

- Puede causar irregularidad o ausencia del sangrado menstrual.

- Una vez que la cliente interrumpe el método, se retrasa el retorno de la fertilidad. Demora más que con la mayoría de los demás métodos.

El retorno a la fertilidad demora, en promedio, 1 mes con NET-EN y 4 meses con DMPA.

- Es seguro para las mujeres con VIH/SIDA, incluso si toman medicamentos antirretrovirales (ARV). No protege contra las infecciones de transmisión sexual (ITS), entre ellas VIH y zika. Enfatice la necesidad de protección doble con la cliente.

- Si una mujer presenta sangrado vaginal inexplicable, es necesario evaluarla y tratarla antes de iniciar este método.

- No se recomienda para mujeres con antecedentes de cáncer de mama o con factores de riesgo de enfermedad cardiovascular venosa importantes, como edad avanzada, apoplejía, tabaquismo, diabetes, hipertensión o dislipidemia conocida.

- NET-EN:

- No se recomienda NET-EN si la mujer toma medicamentos anticonvulsivos o rifampicina (para el tratamiento de la tuberculosis u otras infecciones).

- Si se toman inhibidores no nucleósidos de la transcriptasa inversa (específicamente efavirenz o neviripina) o inhibidores de la proteasa reforzados con ritonavir como parte de la terapia antirretroviral de gran actividad (TARGA), es posible que los inyectables de NET-EN tengan menor efectividad. Enfatice la necesidad de protección doble si se usa NET-EN para reducir la posibilidad de embarazo. 


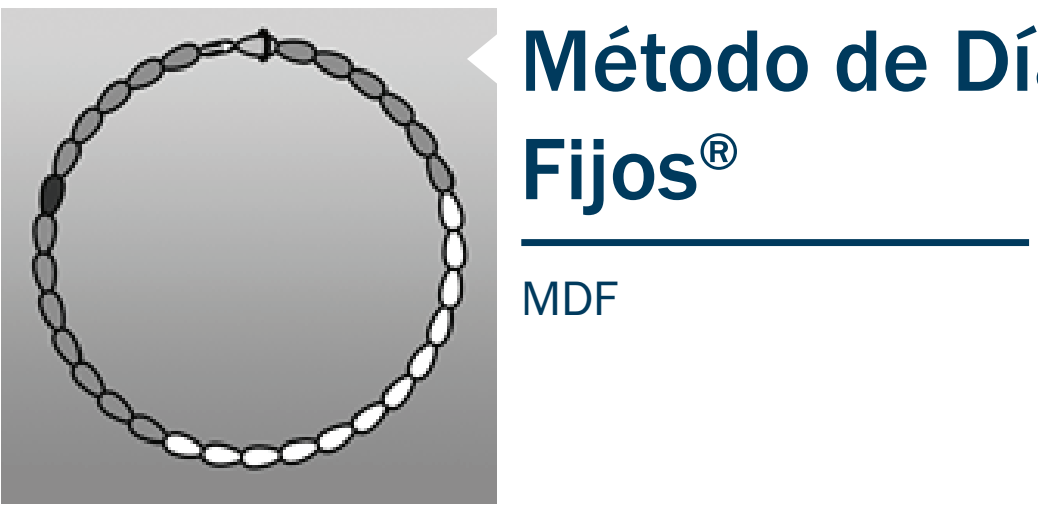




\section{Método de Días}

\section{Fijos $^{\circledR}$}

\section{MDF}

\section{EFECTIVIDAD}

Uso habitual durante el

$88 \%$ primer año

12 embarazos cada

100 mujeres
- Ideal para mujeres con ciclos menstruales suelen durar entre 26 y 32 días. Las mujeres con una menstruación regular se entran en este rango.

- La cliente realiza un seguimiento de su ciclo menstrual para conocer los días en que puede quedar embarazada (días fértiles).

- La cliente usa un calendario o el Collar del Ciclo®, un cordón con perlas con un código de colores, para realizar el seguimiento de los días en que puede quedar embarazada y los días en que no es probable que esto suceda.

- Durante los días en que la cliente puede quedar embarazada, debe abstenerse de tener relaciones sexuales sin protección. Como alternativa, puede usar preservativos u otro método de barrera.

- Las mujeres lactantes o en período posparto deben tener 3 ciclos menstruales regulares antes de poder usar el Método de Días Fijos (MDF). Mientras tanto, debe usarse un método alternativo.

- No protege contra las infecciones de transmisión sexual (ITS), entre ellas VIH y zika. Enfatice la necesidad de protección doble con la cliente.

- Requiere la cooperación de la pareja. 


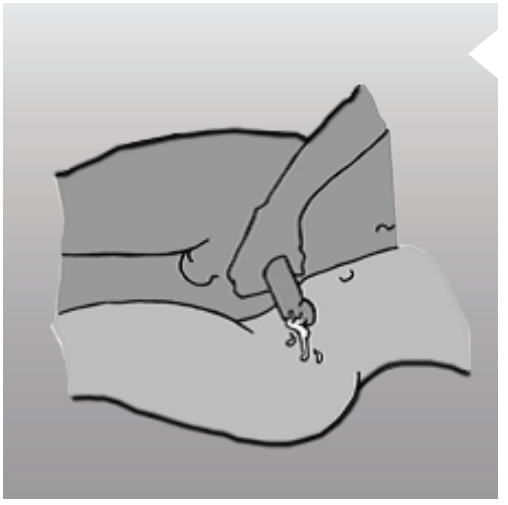

\section{Retirada}

Coito interrumpido/ "venirse afuera" 


\section{Retirada}

Coito interrumpido/ "venirse afuera"

\section{EFECTIVIDAD}

\section{Uso habitual}

$78 \% 22$ embarazos cada

100 mujeres
- El hombre retira el pene de la vagina de su pareja antes de la eyaculación, acto que realiza fuera de la vagina.

- Es uno de los métodos menos efectivos; sin embargo, ofrece más protección que la ausencia de un método.

- No se recomienda para hombres que no pueden sentir de manera sistemática cuando se está por producir la eyaculación o que eyaculan de manera prematura.

- No protege contra las infecciones de transmisión sexual (ITS), entre ellas VIH y zika. Enfatice la necesidad de protección doble con el cliente.

- Requiere la cooperación de la pareja. 


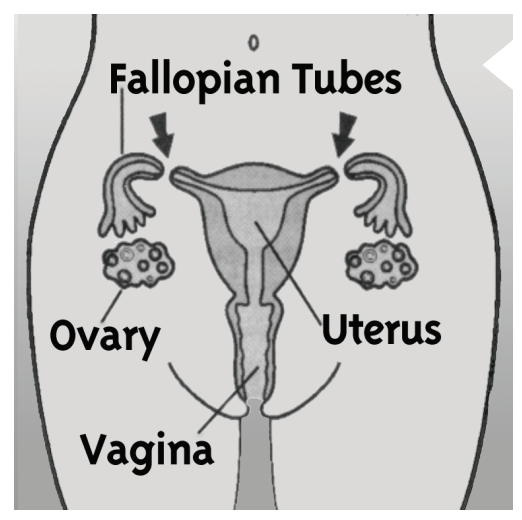

\section{Ligadura de trompas}

Esterilización femenina 


\section{Ligadura de trompas}

Esterilización femenina

\section{EFECTIVIDAD}

Durante el primer año

99\% Menos de 1 embarazo cada 100 mujeres

En 10 años

2 embarazos cada

100 mujeres
- Es un método permanente para las mujeres que no desean tener más hijos.

- Incluye un procedimiento quirúrgico. El procedimiento implica tanto beneficios como determinados riesgos.

- Protege contra el embarazo de inmediato.

- Es seguro para las mujeres con VIH/SIDA, incluso si toman medicamentos antirretrovirales (ARV).

- No protege contra las infecciones de transmisión sexual (ITS), entre ellas VIH y zika. Haga hincapié en la necesidad de protección doble con la cliente. 


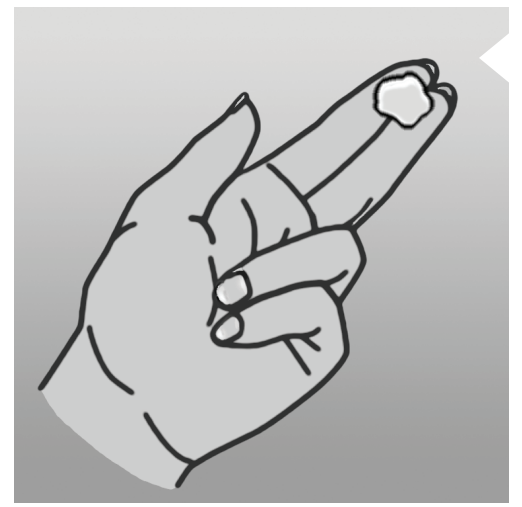

\section{Método de Dos Días ${ }^{\circledR}$}




\section{Método de Dos Días ${ }^{\circledR}$}

\section{EFECTIVIDAD}

Uso habitual

14 embarazos cada

100 mujeres
- Método óptimo para mujeres con secreciones saludables del cuello del útero.

- Las secreciones saludables no tienen mal olor ni causan picazón o dolor.

- La cliente controla sus secreciones del cuello del útero al menos dos veces al día. Si nota secreciones de cualquier tipo, color o consistencia el día del control o el día anterior a ese control, probablemente pueda quedar embarazada (días fértiles).

- Durante los días en que la cliente puede quedar embarazada, debe abstenerse de tener relaciones sexuales sin protección o puede usar preservativos u otro método de barrera.

- No protege contra las infecciones de transmisión sexual (ITS), entre ellas VIH y zika.

- Requiere la cooperación de la pareja. 


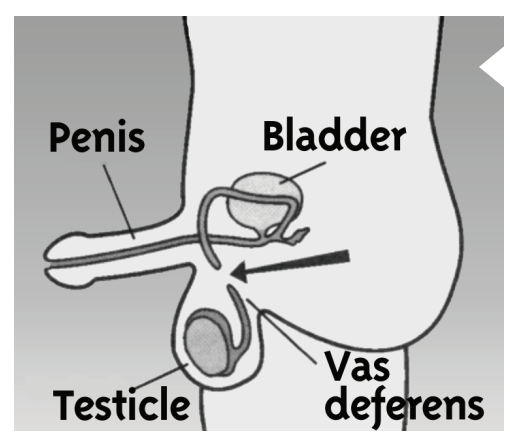

Vasectomía

Esterilización masculina 


\section{Vasectomía}

Esterilización masculina

\section{EFECTIVIDAD}

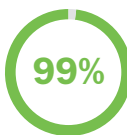

Durante el primer año

Menos de 1 embarazo cada 100 mujeres cuya pareja se ha sometido a una vasectomía

\section{En 3 años}

4 embarazos cada 100 mujeres cuya pareja se ha sometido a una vasectomía
- Es un método seguro y permanente para los hombres que no desean tener más hijos.

- Es un procedimiento quirúrgico seguro y simple.

- No afecta el desempeño sexual masculino.

- No protege de inmediato contra el embarazo. El método comienza a surtir efecto 3 meses después de someterse al procedimiento.

- El cliente debe usar preservativos u otro método durante 3 meses después del procedimiento.

- Es seguro para los hombres con VIH/SIDA, incluso si toman medicamentos antirretrovirales (ARV).

- No protege contra las infecciones de transmisión sexual (ITS), entre ellas VIH y zika. Haga hincapié en la necesidad de protección doble con el cliente. 


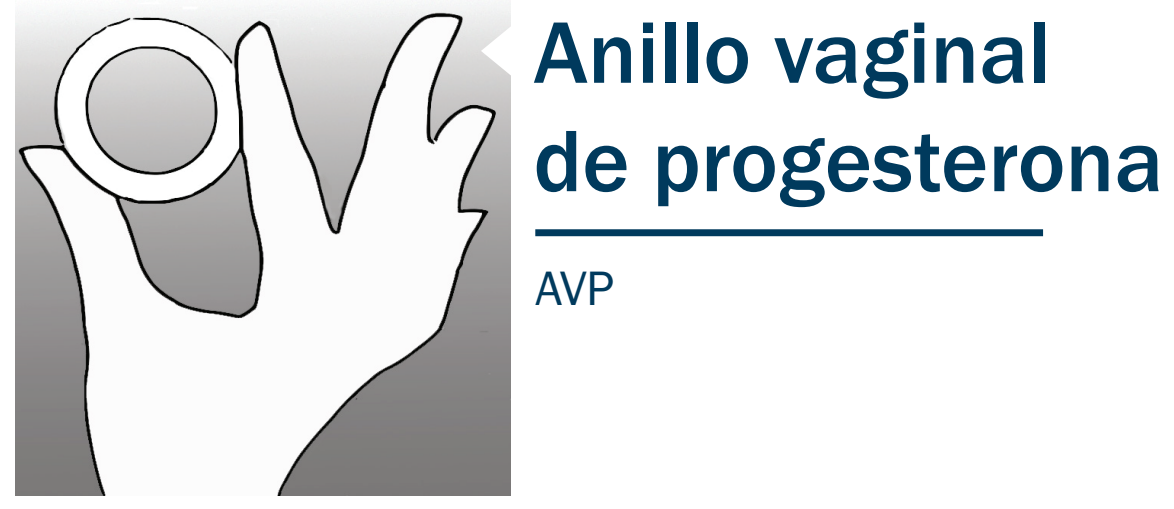

Estrategia de Consejería Balanceada Plus (3. ${ }^{a}$ ed.) 


\section{Anillo vaginal de progesterona}

AVP

\section{EFECTIVIDAD}

\section{Uso correcto}

Uso constante cada

98\% 3 meses:

2 embarazos cada 100 mujeres
- Se usa para espaciar los embarazos por hasta un año.

- Es un anillo de silicona, flexible y suave, que contiene hormona progesterona natural.

- La mujer puede insertarlo en la vagina y quitarlo con facilidad.

- Cada anillo es eficaz durante 3 meses; el método puede usarse de manera sucesiva hasta por un año (4 anillos en 1 año).

- Apto para mujeres que se encuentran en el periodo de los 30 y 90 días de posparto y que amamantan al menos 4 veces al día.

- La iniciación al método debe incluir consejería sobre el uso adecuado (incluso su inserción y retiro).

- Puede causar irregularidad o ausencia del sangrado menstrual.

- Al igual que con otros métodos de progesterona como agente único, puede producirse manchado o sangrado irregular.

- No afecta la producción de leche materna; el método respalda la lactancia/nutrición continua del lactante.

- El retorno a la fertilidad tras la interrupción del método es rápido.

- Es posible que la pareja sienta el anillo.

- Es seguro para las mujeres con VIH/SIDA, incluso si toman medicamentos antirretrovirales (ARV).

- No protege contra las infecciones de transmisión sexual (ITS), entre ellas VIH y zika. Haga hincapié en la necesidad de protección doble con la cliente. 


\section{Diafragma Caya ${ }^{\circledR} /$ SILCS}




\section{Diafragma Caya ${ }^{\circledR} /$ SILCS}

\section{EFECTIVIDAD}

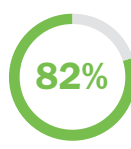

Uso habitual

Uso inconstante:

18 embarazos cada

100 mujeres
- El diafragma es un capuchón flexible y suave que la mujer se inserta en la vagina para cubrir el cuello uterino. Bloquea el esperma y le impide que ingrese al cuello uterino. Se recomienda el uso del diafragma junto con un gel anticonceptivo.

- El diafragma es controlado por la mujer que lo usa, no tiene efectos hormonales y se inserta con anticipación, por lo que no interfiere con las relaciones sexuales.

- La cliente debe usar el diafragma cada vez que tiene relaciones sexuales. Para mayor protección, inserte el diafragma antes de que comience el acto sexual y úselo durante al menos 6 horas después de finalizado el acto. A continuación, quítese el diafragma, lávelo con agua y jabón, enjuáguelo y déjelo secar. La cliente puede guardar el diafragma en su envase original hasta la próxima vez que desee usarlo. Nunca deje el diafragma colocado por más de 24 horas, sin quitárselo ni lavarlo.

- El diafragma Caya es de silicona y es muy resistente. Puede volver a usarse hasta por 2 años.

- El diafragma Caya se ajusta a la mayoría de las mujeres. Si la mujer se inserta el diafragma Caya de manera correcta, no debería sentir dolor ni incomodidad. Practique la inserción (compruebe que el cuello uterino de la cliente quede cubierto) y el retiro del diafragma Caya para asegurarse de que la cliente se sienta cómoda con este método.

- Casi todas las mujeres pueden usar el diafragma y es seguro para las mujeres lactantes. Las mujeres que dieron a luz o que tuvieron un aborto durante el segundo trimestre de embarazo deben esperar 6 semanas antes de usar un diafragma, ya que deben esperar a que el cuello uterino haya regresado a su tamaño normal.

- No protege contra las infecciones de transmisión sexual (ITS), entre ellas VIH y zika. Haga hincapié en la necesidad de protección doble con la cliente. 


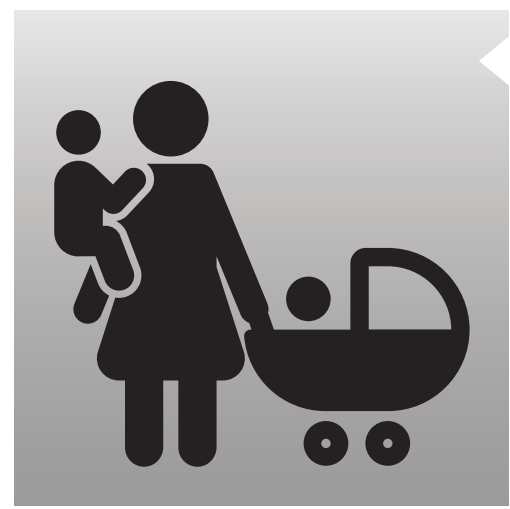

\section{Períodos saludables para el embarazo y el espaciamiento entre embarazos}


Períodos saludables

para el embarazo y el

espaciamiento entre

embarazos

\section{Aconseje sobre períodos \\ saludables para el embarazo y el espaciamiento entre embarazos}

- Para aquellas mujeres que desean tener más hijos después de un nacimiento vivo, aconseje lo siguiente:

- Por razones de salud de la madre y del bebé, espere al menos 2 años (24 meses) antes de tratar de volver a quedar embarazada.

- El uso de un método de planificación familiar de su elección permite que la mujer planee un embarazo saludable y brinda mejores resultados en términos de salud, para ella, para el recién nacido y para otros niños que pueda tener.

- Para aquellas mujeres que deciden tener un hijo luego de un aborto espontáneo o un aborto provocado, aconseje lo siguiente:

- Por razones de salud de la madre y del bebé, espere al menos 6 meses antes de tratar de volver a quedar embarazada.

- El uso de un método de planificación familiar de su elección permite que la mujer planee un embarazo saludable.

- Para aquellas mujeres adolescentes, aconseje lo siguiente:

- Por razones de salud de la madre y del bebé, espere hasta tener 18 años antes de tratar de quedar embarazada. A madres adolescentes, aconséjeles que esperen hasta tener 18 años antes del siguiente embarazo.

- De ser sexualmente activa, la adopción y el inicio tempranos de un método de planificación familiar de su elección le permiten a la mujer joven evitar embarazos no buscados y preservar su salud.

- Para aquellas mujeres de más de 35 años, o con 5 o más embarazos a término, todo embarazo adicional implica mayor riesgo tanto para la madre como para el bebé. 


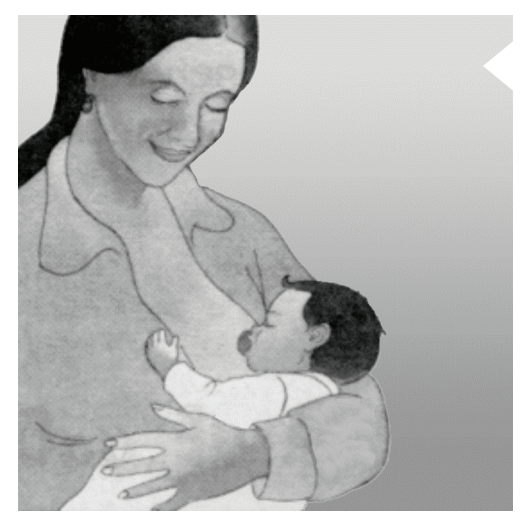

\section{Promoción de un período posparto saludable para la madre}




\section{Promoción de un}

\section{período posparto}

saludable para la

\section{madre}

- Asegúrese de que la madre tenga apoyo durante los primeros días después del nacimiento; aliéntela a que descanse y duerma.

- Recomiende una dieta nutritiva para la madre, que incluya mucho líquido y micronutrientes (entre ellos, vitamina A y hierro).

- Analice el sangrado posparto normal y la secreción de loquios. Aconseje sobre los signos de peligro materno, como el sangrado intenso 0 secreciones vaginales con mal olor y fiebre, dolor de cabeza fuerte 0 convulsiones.
- Analice la necesidad de que se realicen cuatro visitas de atención posnatal: a las 24-48 horas, a los 3-7 días, a las 4-6 semanas y a los 4-6 meses.

- Si la mujer planea comenzar a usar alimentación complementaria antes de los 6 meses posparto, analice la transición a un método de planificación familiar (PF) antes del inicio de ese tipo de alimentación.

- Aconseje sobre el mantenimiento de la higiene personal, incluso del perineo y las mamas.

- Aconseje sobre el regreso a la actividad sexual, que debe darse cuando la madre se sienta lista y, por lo general, cuando se dejen de secretar los loquios. Una vez que eso sucede, puede volver a quedar embarazada, incluso antes de que vuelva a tener su periodo. El embarazo puede producirse incluso si aún se amamanta parcialmente, y es más probable que se produzca con lactantes de mayor edad.

- Aliéntela a que use un método de PF. La mayoría de los métodos son seguros para las madres lactantes. Considere suministrar anticonceptivos de emergencia con instrucciones de uso si la madre deja de amamantar de manera exclusiva o si vuelve a tener su periodo y tiene relaciones sexuales antes de comenzar con otro método de planificación familia.

- Aconseje sobre la depresión posparto, que puede conllevar lo siguiente: Ilanto fácil; cansancio, agitación o irritabilidad; falta de motivación; dificultad para dormir y rechazo al bebé. 


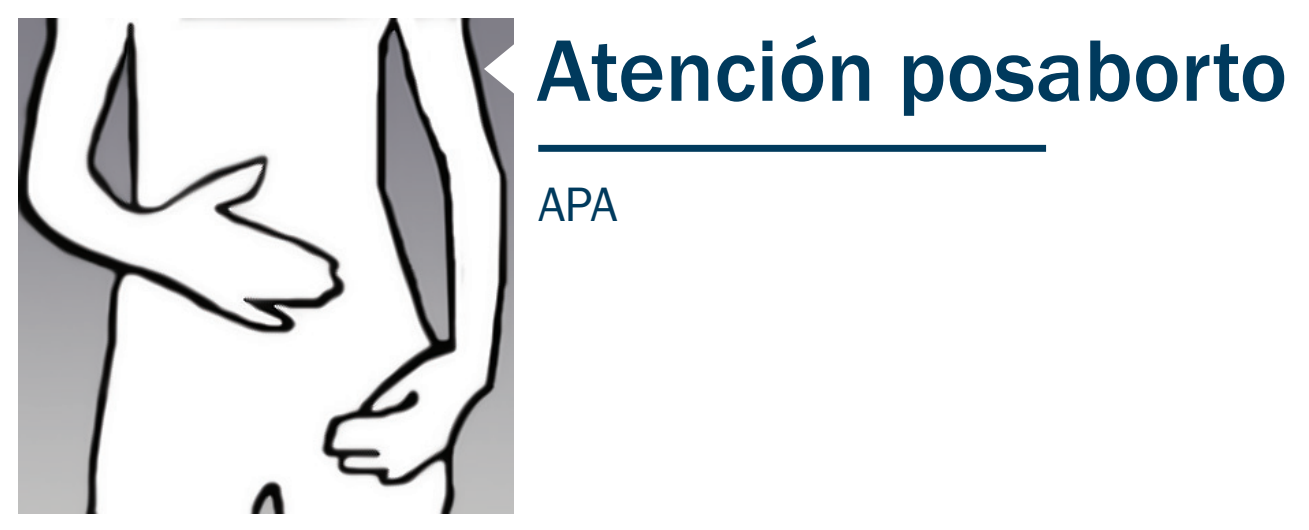

Estrategia de Consejería Balanceada Plus (3. ${ }^{a}$ ed.) 


\section{Atención posaborto}

\section{APA}

- Informe a la cliente que, tras un aborto espontáneo durante el primer trimestre, el retorno a la fertilidad es rápido, en el plazo de 2 semanas a partir del acontecimiento.

- Para mejor salud de la madre y el niño, las parejas deben esperar 6 meses antes de tratar de que la mujer quede embarazada.

- Aconseje sobre el regreso a la actividad sexual, que debe darse cuando la mujer se sienta lista (a menos que tenga antecedentes de infección o trauma; en ese caso, espere a que la afección se trate y se resuelva).

- Informe que puede quedar embarazada incluso antes de volver a tener su periodo. Aliéntela a que use un método de planificación familiar (PF).
- La mayoría de los métodos anticonceptivos pueden ser usados por una mujer que recibe atención posaborto (APA), con la excepción de la ligadura de trompas y un DIU en caso de infección o traumatismo en el cuello uterino o la vagina.

- Después de cualquier evacuación uterina, hable con la mujer y ayúdela a elegir un método anticonceptivo de su preferencia. Si este no se encuentra disponible o la mujer no se decide, entréguele preservativos o anticonceptivos de emergencia y ofrézcale derivarla al centro de salud más cercano si no se decide antes de recibir el alta.

- Informe a la mujer sobre las ventajas de los preservativos como método de protección doble.

- A toda mujer tratada con misoprostol puede ofrecérsele de inmediato cualquier método anticonceptivo, excepto un dispositivo intrauterino (DIU). Si la mujer prefiere un DIU, pídale que regrese cuando la evacuación uterina sea completa y cuando los resultados de las pruebas garanticen que no tiene infecciones.

- Analice el sangrado normal posaborto. Oriente sobre los signos de peligro materno, como el sangrado intenso o secreciones vaginales con mal olor.

- Asegúrese de que la mujer tenga apoyo durante los primeros días. Aliente a la mujer a que descanse y duerma.

- Si se trata de una paciente con antecedentes de violación y abuso sexual, derívela a otros servicios de atención y apoyo.

- Reconozca que atravesar el proceso de la atención posaborto (APA) puede ser emocionalmente traumático e infórmele los servicios psicosociales disponibles; ofrézcale la oportunidad de expresar sus sentimientos en cuanto al proceso. 


\section{Promoción de la salud del recién nacido y del lactante}




\section{Promoción de la salud del recién nacido y del lactante}

- Hable sobre el lavado cuidadoso de las manos para prevenir infecciones antes de estar en contacto con el bebé y luego de cambiarle los pañales.

- No ponga nada en el cordón del bebé y no humedezca el área del cordón hasta que este se seque y se caiga, aproximadamente, 2 semanas después del nacimiento.

- Oriente a la madre sobre los signos de peligro de los recién nacidos y sobre cuándo buscar atención inmediata. Los signos de peligro incluyen los siguientes: dificultad en la alimentación o la respiración; temperatura demasiado alta o baja e irritabilidad por largos períodos.

- Analice la importancia de realizar una buena ventilación de los ambientes y de mantener al bebé tibio.
- Aliente a las madres a amamantar exclusivamente por 6 meses. No es necesario nada más, ni siquiera agua. Incorpore alimentos complementarios a los 6 meses y continúe amamantando. La lactancia exclusiva durante los primeros 6 meses y la ausencia del periodo menstrual durante ese plazo se denomina Método de la amenorrea de la lactancia (MELA) (consulte la tarjeta Método de amenorrea de la lactancia).

- En caso de lactantes expuestos a VIH:

-Aconseje a la madre a que le administre al niño medicamentos antirretrovirales (ARV) a diario mientras lo amamanta y que continúe durante 1 semana una vez que se interrumpa la lactancia (alrededor de 1 año), o que la madre continúe con su tratamiento de ARV según los protocolos nacionales.

-Recomiende que a las 6 semanas se le realice un examen de detección de $\mathrm{VIH}$ al lactante expuesto y que comience a recibir profilaxis con cotrimoxazol (CTX).

-Ponga a la madre y al lactante en contacto con una clínica de $\mathrm{VIH}$.

- Use las directrices nacionales e internacionales para explicar el programa de inmunización, y recomiende suplementos de vitamina A a los 6 meses.

- Hable sobre la necesidad de asistir a una clínica de bienestar infantil (incluidas las actividades clave como el control de crecimiento). 


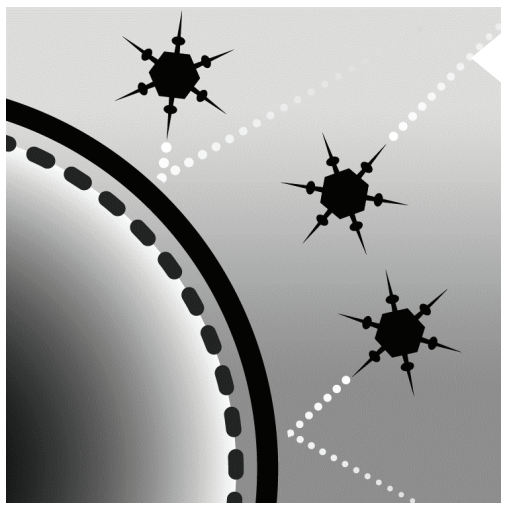

Prevención y transmisión de ITS y VIH 


\section{Prevención}

\section{y transmisión de ITS/VIH}

Analice lo siguiente en cuanto a todas las infecciones de transmisión sexual (ITS), incluso VIH:

- Una persona puede infectarse con ITS, incluido el VIH, a través de actividades sexuales inseguras y sin protección.

- Las ITS son comunes.

- Una persona que vive con ITS (incluido el VIH) puede verse saludable y no tener síntomas ni ser consciente de que está infectada.

- Los síntomas frecuentes de una ITS incluyen secreción vaginal y del pene, irritación en el área genital, ardor al orinar en el caso de los hombres y dolor en la parte abdominal baja en el caso de las mujeres.
- Algunas ITS pueden tratarse. Para evitar una nueva infección, ambos miembros de la pareja deben tratarse y abstenerse de tener relaciones sexuales sin protección hasta que ambos hayan finalizado el tratamiento.

- El riesgo de infección puede reducirse mediante el uso de preservativos, limitando la cantidad de parejas sexuales y retrasando las relaciones sexuales.

Analice los siguientes hechos, específicos del VIH:

- El VIH es una infección de transmisión sexual. El VIH se transmite mediante el intercambio de fluidos corporales, como semen, sangre y leche materna, y durante el parto.

- Conocer el estado de VIH del cliente lo protege a él, a su pareja y a su familia. A los clientes se les puede ofrecer que se hagan una prueba el día de la fecha, si esa opción se encuentra disponible, o una derivación a una institución que haga esas pruebas.

- Aunque el VIH no tiene cura, su identificación y tratamiento tempranos pueden permitir que una persona lleve una vida larga y productiva, y evitar que la pareja se infecte.

- La circuncisión masculina reduce de manera significativa el riesgo de infección por VIH en las parejas heterosexuales.

- La transmisión materna de VIH al niño puede reducirse de manera sustancial al identificar a las mujeres que viven con VIH y brindarles tratamiento o medicamentos ARV profilácticos durante el embarazo y la lactancia, si la mujer opta por amamantar. 


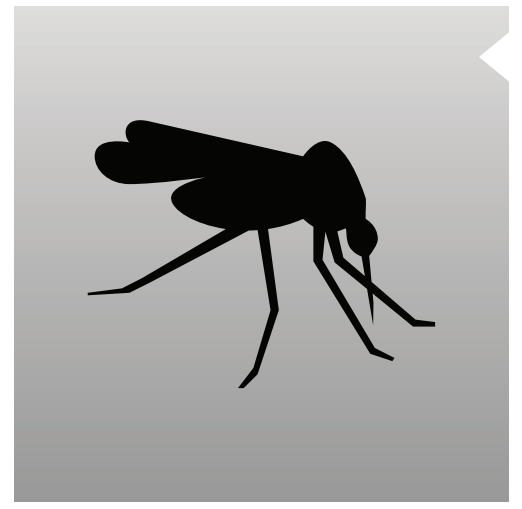

\section{Prevención y transmisión del virus del Zika}




\section{Prevención}

\section{y transmisión del}

\section{virus del Zika}

\section{En regiones SIN transmisión activa del virus} del Zika:

- Los hombres y las mujeres que regresan de zonas con transmisión activa del zika deben usar preservativo o abstenerse de tener relaciones sexuales durante, por lo menos, 6 meses después de su regreso, a fin de prevenir la transmisión del virus mediante la actividad sexual.

- Las parejas sexuales de mujeres embarazadas que regresan de zonas con transmisión activa del zika deben usar preservativo o abstenerse de tener relaciones sexuales durante el resto del embarazo.

- Se recomienda que las parejas o las mujeres que planeen un embarazo y que regresen de zonas con transmisión activa del zika esperen al menos 6 meses antes de intentar concebir.

\section{Analice los siguientes datos sobre la transmisión del virus del Zika:}

- El zika se propaga principalmente mediante la picadura de un mosquito de la especie Aedes infectado; SIN EMBARGO, una persona también puede infectarse con zika si tiene relaciones sexuales sin protección o inseguras.

- El zika se transmite mediante el intercambio de fluidos corporales, como semen, sangre y leche materna.

- La infección por virus del Zika puede transmitirse de una mujer embarazada a su bebé y provocarle microcefalia (cerebro pequeño) y otros defectos graves en el sistema nervioso.

- Una persona infectada con el virus del Zika puede no presentar síntomas, verse sana y no saber que se encuentra infectada por el virus. Puede transmitir el virus antes de que aparezcan los síntomas, mientras duren los síntomas y después de que los síntomas desaparezcan. Los síntomas incluyen fiebre, erupción, dolor en las articulaciones o conjuntivitis (ojos rojos). El virus del Zika también puede causar complicaciones neurológicas.

- El riesgo de infección por el virus del Zika puede reducirse mediante el uso sistemático y correcto de preservativos, limitando la cantidad de parejas sexuales, retrasando las relaciones sexuales y absteniéndose de tener relaciones sexuales.

- Las mujeres que han tenido relaciones sexuales sin protección y no deseen quedar embarazadas debido a una posible infección por zika deben tener acceso a anticonceptivos de emergencia y consejería.

- Las mujeres embarazadas y aquellas que podrían quedar embarazadas y sus parejas deben usar preservativos o abstenerse de tener relaciones sexuales.

- Un análisis de sangre o de orina puede confirmar una infección por zika.

- No existen vacunas ni medicamentos para prevenir el zika. 


\section{Evaluación del riesgo de ITS y VIH}

\section{Analice los siguientes temas para evaluar los riesgos del/de la cliente de contraer ITS y VIH:}

- Pregúntele al/a la cliente sobre el uso pasado y actual de preservativos (incluso la percepción de la actitud de la pareja al respecto) y pregúntele si sabe que los preservativos protegen contra las ITS/VIH y el embarazo.

- Pregúntele al/a la cliente si conoce su estado de VIH y el de sus parejas. Si un miembro de la pareja es positivo, pregunte si toma medicamentos antirretrovirales (ARV).
- Analice los riesgos asociados con parejas múltiples o simultáneas. Esto incluye un mayor riesgo de contraer infecciones de transmisión sexual (ITS) y VIH.

- Pregúntele al/a la cliente si sabe si su pareja masculina está circuncidado. Explique que la circuncisión masculina reduce el riesgo de transmisión de ITS o VIH a la pareja del hombre.

- Analice con los clientes los tipos de relaciones sexuales o actividades y conductas sexuales que pueden aumentar el riesgo de contraer una ITS o VIH (por ejemplo, si un miembro de la pareja tiene varios compañeros sexuales, el sexo oral, el sexo anal, el sexo seco, el uso de detergentes o espermicidas).

- Analice si el/la cliente conoce los antecedentes sexuales de su pareja, incluso parejas múltiples o simultáneas. Si el/la cliente o su pareja tienen antecedentes de parejas múltiples o simultáneas, sugiérale asistir a consejería de parejas o el asesoramiento y pruebas voluntarias (VCT, voluntary testing and counseling) para determinar su estado de $\mathrm{VIH}$.

- Pregúntele al/a la cliente sobre la situación en su hogar (por ejemplo, en lo referido a violencia de pareja y apoyo social). Si menciona violencia, consulte la tarjeta Seguridad y apoyo a la mujer.

- Pregunte si la mujer ha usado programas de prevención de la transmisión del VIH de madre a hijo (PTMH) durante el embarazo. Analice los beneficios de los servicios de prevención de la transmisión de madre a hijo (PTMH) para prevenir la transmisión del VIH durante el embarazo. 


\section{Evaluación del riesgo de ITS y VIH}




\section{Prevención, dignidad y salud positiva}




\section{Prevención, dignidad y salud positiva}

Brinde apoyo y consejería sobre temas relacionados con la divulgación del estado de VIH. Asegúrese de que el cliente sepa que divulgar su estado es su decisión y que el proveedor no compartirá dicho estado sin su consentimiento.
Analice lo siguiente con el cliente:

- Quienes padecen VIH deben someterse a chequeos regulares para determinar si necesitan medicamentos antirretrovirales (ARV), establecer su evolución con los ARV y descartar otras infecciones o enfermedades. Al comenzar con medicamentos ARV, las visitas pueden ser frecuentes.

- Quienes consumen ARV deben hacer lo posible por tomar los medicamentos según lo prescripto y no compartirlos.

- Las parejas también deben hacerse la prueba. El cliente puede traer a su pareja para recibir consejos y hablar.

- Si actualmente toma medicamentos para la tuberculosis, debe hacer seguimiento con el proveedor de atención médica.

- Si una mujer con VIH desea quedar embarazada:

- El riesgo de contagiarle VIH al recién nacido puede reducirse mucho al tomar medicamentos ARV y tener un parto seguro. Es importante recibir atención en una clínica de cuidado prenatal y un centro de tratamiento del $\mathrm{VIH}$.

- Si una mujer en una relación serodiscordante (un miembro de la pareja tiene VIH y el otro no) intenta quedar embarazada:

- El riesgo de transmisión de VIH puede reducirse al tener relaciones sexuales sin protección (es decir, sin preservativos) solamente durante el periodo fértil de la mujer. El miembro seropositivo de la pareja debe continuar consumiendo ARV para reducir la cantidad de virus en su cuerpo.

- La salud positiva se logra al cuidar de uno mismo y estar alerta a las inquietudes de salud que requieren de atención, entre las que pueden incluirse temas de salud física y mental, así como también de apoyo social. 


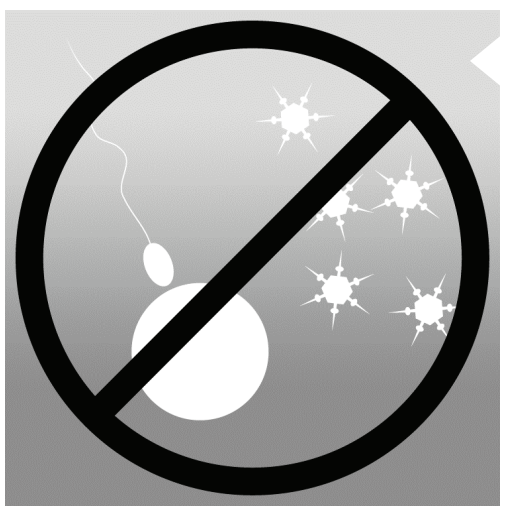

Protección doble 


\section{Protección doble}

\section{Analice lo siguiente con el/la cliente:}

- La protección doble es el uso de preservativos de manera sistemática y correcta junto con otro método de planificación familiar. Esto brinda protección adicional para evitar el embarazo en caso de que el preservativo falle.

- Use un preservativo masculino o femenino de forma sistemática y correcta en todas las relaciones sexuales. Este método protege contra las infecciones de transmisión sexual (ITS) y el embarazo.

- Solo tenga intimidad sexual segura, durante la cual se evite que el semen y los fluidos vaginales entren en contacto con los genitales u otras áreas vulnerables de la pareja, como la boca y el ano.

- Retrase o evite la actividad sexual, especialmente con parejas cuyo estado de ITS/VIH se desconoce.

- Retrase o evite la actividad sexual si la pareja se ha visto expuesta al virus del Zika. 


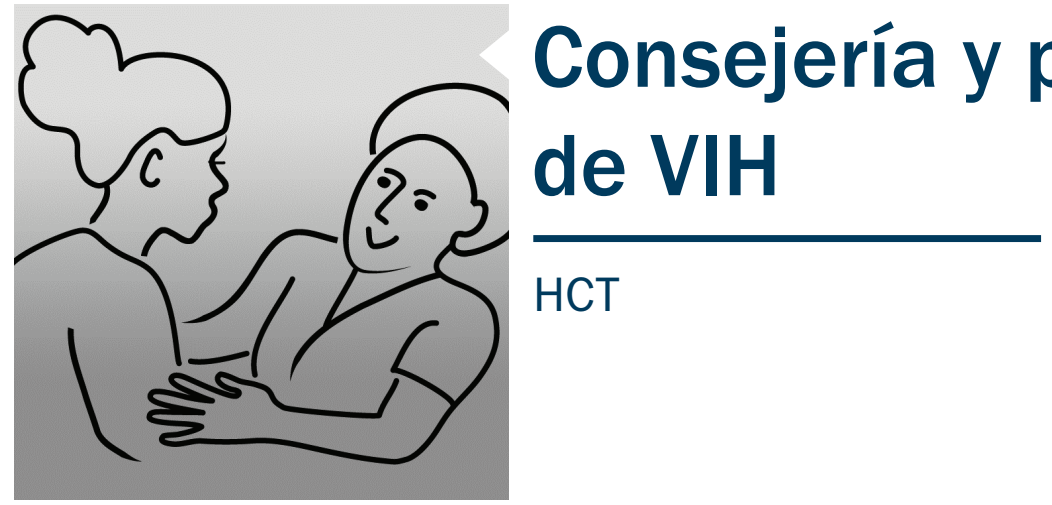




\section{Consejería y pruebas Analice lo siguiente con el/la cliente:}

\section{de VIH}

- Conocer el estado de VIH del/de la cliente puede ayudarle a tomar decisiones sobre cómo protegerse a sí mismo y a sus parejas sexuales.

- Las pruebas permiten que quienes tienen VIH reciban tratamiento y puedan llevar una vida plena. La prueba incluye la extracción de una muestra de sangre pequeña. La prueba es gratuita y se encuentra disponible en clínicas, hospitales y centros de consejería y pruebas de VIH.

- Los resultados de las pruebas se mantienen en estricta confidencialidad.

- Cuando una persona se infecta con VIH, pueden pasar 3 meses o más hasta que la prueba detecte la infección. Esto se denomina "período ventana" y es la razón por la que es tan importante repetir la prueba.

- Un resultado positivo significa que la persona se encuentra infectada con VIH y puede transmitirle el virus a otros.

- Un resultado negativo puede significar que la persona no se encuentra infectada o que se encuentra en el "período ventana". Debe realizarse otra prueba en el plazo de 3 meses. Si la segunda prueba también es negativa, la persona no tiene $\mathrm{VIH}$, pero aún puede infectarse con el virus.

- EI VIH es una infección de transmisión sexual (ITS). Es importante pedirle a las parejas sexuales que también se hagan una prueba. 


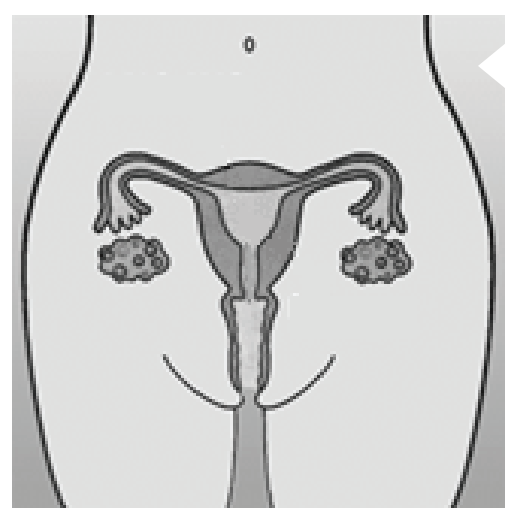

Examen de detección de cáncer de cuello uterino 


\section{Examen de detección de cáncer de cuello uterino}

Si la cliente tiene entre 30 y 49 años o es VIH positivo (de cualquier edad), pregúntele si alguna vez le han hecho exámenes de detección de cáncer de cuello uterino.
- El cáncer de cuello uterino es un cáncer frecuente en el aparato reproductivo. Puede prevenirse, se detecta fácilmente y se cura si se trata en los primeros estadios.

- El cáncer de cuello uterino es provocado por la infección con un virus denominado VPH.

- La mayoría de las infecciones desaparecen, pero las más persistentes pueden conducir a un cáncer de cuello uterino.

- Describa la manera en que se presenta este tipo de cáncer:

- El cáncer de cuello uterino es indoloro y avanza de manera lenta.

- Surge en la abertura del útero.

- En un estadio avanzado, la mujer puede presentar olor inusual o anormal en la vagina, relaciones sexuales dolorosas, sangrado tras el acto sexual y dolor en la espalda y la parte baja del abdomen.

- La detección se lleva a cabo mediante una prueba rápida, simple y, generalmente, indolora realizada por un proveedor capacitado (prueba de VPH, IVAA o Papanicolaou).

- El examen de detección de cáncer de cuello uterino debe realizarse cada 3 a 5 años (según las directrices nacionales). Las mujeres con VIH deben hacerse la prueba cada 3 años. Si la prueba es positiva, se recomienda un tratamiento. El tratamiento temprano incluye el congelamiento de llagas precancerosas (crioterapia) y puede realizarse como procedimiento ambulatorio.

- Las clientes con llagas cancerosas avanzadas se derivan para recibir tratamiento especial. 


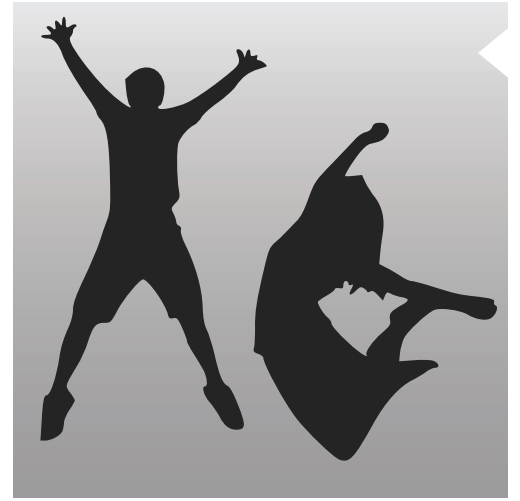

\section{Consejería para adolescentes}




\section{Consejería para adolescentes}

Si el/la cliente es menor de 18 años, analice las necesidades de salud adolescente.

- La adolescencia es un período de transición marcado por cambios físicos, psicológicos y sociales importantes.

- Los adolescentes tienen necesidades de salud reproductiva únicas que pueden abordarse mediante los servicios de salud, entre ellos consejería.

- Pregúntele a los clientes sobre los recursos en sus comunidades:

- ¿Cuentan con personas positivas y comprensivas a quienes recurrir en busca de consejo y apoyo? Entre ellas se pueden incluir parejas, padres, docentes y líderes de la comunidad.
- Todos los métodos anticonceptivos modernos son, generalmente, seguros para los adolescentes.

- Con adolescentes casados, analice el tamaño de familia deseado (consulte la tarjeta HTSP).

- Con adolescentes solteros, describa la importancia de retrasar el matrimonio y el embarazo:

- Por razones de salud de la madre y del bebé, espere hasta tener 18 años antes de tratar de quedar embarazada.

- Deben evitarse el matrimonio y el embarazo tempranos para permitir el desarrollo físico y mental completo de las jóvenes.

- Para evitar embarazos no deseados, es importante que las jóvenes usen un método anticonceptivo moderno de manera constante.

- Describa otros temas de salud que enfrentan los adolescentes:

- Las adolescentes sexualmente activas corren riesgo de contraer infecciones de transmisión sexual (ITS), incluso VIH y zika. El uso de preservativos además de otro método de planificación familiar puede brindar protección adicional contra las ITS y el VIH (consulte Prevención y transmisión de ITS/VIH).

- Las jóvenes tienen necesidades nutricionales importantes para garantizar un desarrollo saludable.

- Analice los servicios orientados a la juventud, entre ellos clubes deportivos y sociales, clubes de madres jóvenes, grupos religiosos o grupos comunitarios. Derive al/a la cliente a los servicios, según necesidad. 


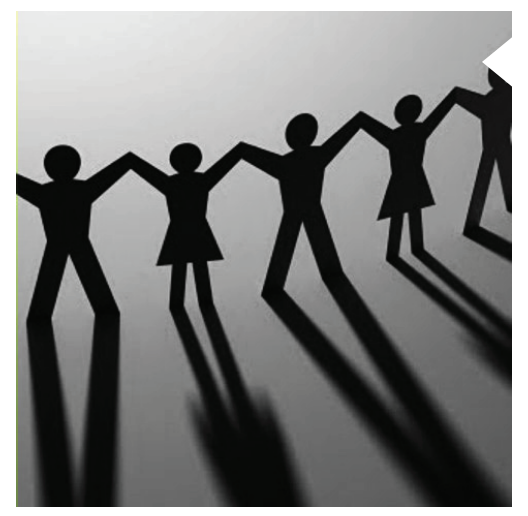

Seguridad y apoyo a la mujer 


\section{Seguridad y apoyo a la mujer}

Tómese el tiempo necesario para evaluar el riesgo de sufrir violencia infligida por la pareja que corre la mujer y los riesgos potenciales que el uso de planificación familiar (PF) implican para la mujer.

Comience brindándole a la cliente información sobre violencia infligida por la pareja:

- Deseamos garantizar que las mujeres y sus familias se desarrollen en un entorno comprensivo y seguro. Esto incluye garantizar que las mujeres sientan que, tanto ellas como sus hijos, se encuentran seguros en su hogar. Compartimos la siguiente información con todos nuestros clientes y formulamos algunas preguntas confidenciales.

- Una de cada tres mujeres en todo el mundo han sufrido violencia infligida por la pareja o violencia sexual infligida por otras personas distintas de la pareja en algún momento de su vida.
- Todo tipo de violencia infligida por la pareja implica el daño a una persona que puede derivar en otros riesgos de salud, no solo para la mujer sino también para sus hijos. Esto incluye mayor riesgo de lo siguiente: enfermedades crónicas, depresión, suicidio, sistema inmunitario deprimido, bajo peso al nacer, abuso infantil y violencia intergeneracional.

Formule las siguientes preguntas para determinar si existe violencia infligida por la pareja (VIP):

- ¿Se encuentra en una relación con una persona que la amenaza, asusta o insulta, o trata mal?

- ¿Alguien la fuerza a participar de actividades sexuales indeseadas o que la hacen sentir incómoda?

Si la cliente menciona que tiene miedo a ser víctima o que ha sufrido violencia por parte de su pareja, O BIEN si la cliente presenta indicios que indiquen que puede ser víctima de violencia infligida por la pareja (incluso dolor agudo o crónico de origen desconocido, problemas ginecológicos o sexuales frecuentes, o depresión y ansiedad), haga lo siguiente:

- Sea comprensivo y legitime su experiencia.

- Evalúe si la cliente vive en situación de riesgo; en caso afirmativo, y si usted se encuentra debidamente capacitado, desarrolle un plan de seguridad o derívela a otro recurso que pueda brindar asistencia de inmediato.

- Evalúe si la cliente se encuentra en crisis, p. ej., si presenta angustia extrema; en caso afirmativo, bríndele el respaldo emocional necesario o derívela de inmediato a un recurso que pueda brindarle asistencia de inmediato.

- Aconseje a la cliente sobre los servicios de derivación disponibles en la comunidad. Entre estos servicios pueden incluirse los siguientes: centros para mujeres, refugios o lugares seguros, consejería psicológica, programas de consejería para parejas, y servicios médicos y legales. Bríndele a la cliente apoyo y derívela a los servicios que elija. 


\section{Servicios para}

hombres y apoyo

a sus parejas 


\section{Servicios para}

\section{hombres y apoyo}

\section{a sus parejas}

Analice la responsabilidad de los hombres en la toma de decisiones reproductivas y sexuales

- Los hombres también pueden usar métodos anticonceptivos.

- Los hombres deben asumir una actitud activa en cuanto a la paternidad. Los hombres pueden decidir de manera conjunta con sus parejas:

- La cantidad de hijos que desean tener.

- Cuándo y cómo usar los métodos de planificación familiar.

- Dónde buscar servicios de planificación familiar, servicios de maternidad y servicios de salud infantil.

- También son compañeros en la prevención y el tratamiento de las infecciones de transmisión sexual (ITS), entre ellas VIH y zika.

- Los hombres deben usar preservativos durante todo el embarazo si viven en una zona de transmisión activa del zika.
Si el hombre se encuentra presente durante una consulta por servicios de planificación familiar y de VIH:

- Felicite al hombre por su presencia e infórmele los servicios disponibles para hombres, explíquele los beneficios de la planificación familiar y el espaciamiento entre embarazos.

- La planificación familiar permite que los clientes planeen la cantidad de hijos que desean tener y el momento en que desean tenerlos. Esperar 24 meses entre los nacimientos de los hijos mejora la salud de la madre, la salud de todos los hijos y los recursos disponibles para sostener a la familia.

- Describa los servicios disponibles para hombres, además de la planificación familiar, como detección y tratamiento de ITS, detección y consejería sobre el VIH, detección de la hipertensión, consejería sobre obesidad y consejería sobre tabaquismo.

- Si la clínica brinda alguno de los servicios anteriormente mencionados, entre ellos los métodos anticonceptivos para hombres, ofrézcalos o derive al hombre dentro de las instalaciones. Si estos servicios no se encuentran disponibles, informe al hombre sobre lugares donde sí se encuentran disponibles y ofrezca derivarlo a tales centros. 


\section{Información}

y concienciación sobre

el cáncer de mama

Estrategia de Consejería Balanceada Plus ( $3 .^{a}$ ed.) 


\section{Información}

y concienciación sobre

\section{el cáncer de mama}

Analice lo siguiente con la cliente:

- El cáncer de mama es un tumor maligno que se desarrolla a partir de las células de la mama.

- El cáncer de mama es la segunda causa principal de muerte y el segundo tipo de cáncer más frecuente. Si se detecta de manera temprana, puede curarse.

- Todas las mujeres y los hombres se encuentran en riesgo.

\section{Pruebas y detección temprana del cáncer de} mama

- La detección del cáncer de mama incluye el autoexamen de mamas (AEM), el examen clínico de mamas y el diagnóstico por imágenes de las mamas (mamografía o ecografía).

Nota: No todos los tipos de cáncer de mama son palpables; en consecuencia, se recomienda el examen clínico y el diagnóstico por imágenes de las mamas en combinación con el AEM para tener las mayores posibilidades de detectar de manera temprana cualquier tipo de cáncer de mama.
Sobre el autoexamen de mamas:

- Explique que el autoexamen de mamas (AEM) es fácil de realizar. Puede realizarse en cualquier momento, mientras está recostada, toma una ducha o se baña.

- El AEM es simple e importante; permite la detección temprana de bultos en las mamas y que las clientes busquen atención médica de manera voluntaria para recibir tratamiento.

- El tratamiento temprano aumenta las posibilidades de una cura total. Los exámenes mensuales y correctos ayudan a detectar de manera temprana los cambios en las mamas.

Las mujeres deben realizarse un AEM al menos una vez por mes en el mismo momento del ciclo menstrual, ya que la forma y la sensibilidad de las mamas cambia según las diferentes etapas del ciclo. El mejor momento es inmediatamente después de la menstruación (el periodo). Si la mujer toma una píldora anticonceptiva, el mejor día es el primer día del nuevo blíster de píldoras. En el caso de mujeres que consumen Depo Provera, Norplant, que han llegado a la menopausia o cuyos ciclos menstruales no son regulares, el AEM debe hacerse el primer día de cada mes calendario. Los hombres también deben autoexaminarse de manera regular, idealmente el primer día de cada mes calendario.

\section{Aparición del cáncer de mama:}

- Mayoría de los casos: un bulto indoloro en la mama

- Otros síntomas: retracción del pezón, cambios en la piel tales como oscurecimiento y aparición de hoyuelos (aspecto similar al de la cáscara de una naranja), y secreciones del pezón que parecen ser sanguinolentas.

- Apariciones tardías: ulceración, agrandamiento de los ganglios linfáticos en la axila y el cuello. El dolor suele ser un síntoma tardío.

- Si nota alguno de los signos/síntomas anteriores, infórmelo a su proveedor de atención médica más cercano. 


\section{Estrategia de Consejería Balanceada Plus}

\section{Tercera edición}

El paquete de herramientas Estrategia de Consejería Balanceada Plus (ECB+), desarrollada y probada en Kenia y Sudáfrica, proporciona la información y los materiales que los proveedores de atención médica necesitan para brindar consejería de planificación familiar completa y de calidad a clientes que viven en áreas con altas tasas de infecciones de transmisión sexual (ITS) y virus de la inmunodeficiencia humana $(\mathrm{VIH})$. La ECB+ se adaptó de la Estrategia de Consejería Balanceada (León 1999; León et al. 2003a, b, c; León et al. 2008). La primera y la segunda edición de los paquetes de herramientas de la Estrategia de Consejería Balanceada y de la Estrategia de Consejería Balanceada Plus son productos del programa FRONTERAS del Population Council, con apoyo de la Agencia de los Estados Unidos para el Desarrollo Internacional (United States Agency for International Development, USAID), acuerdo cooperativo HRN-A-00-98-00012-00.

En la tercera edición de la ECB+, se incluye contenido actualizado de acuerdo con los últimos Criterios médicos de elegibilidad de la OMS (2015). Se incorpora la evidencia más actualizada sobre indicaciones clínicas para la provisión de métodos de planificación familiar, incluso métodos nuevos, y se incluyen cuatro tarjetas de consejería nuevas que abordan los temas Consejería para adolescentes, Servicios para hombres, Atención posaborto, y Seguridad y apoyo a la mujer. Estas tarjetas actualizadas incluyen instrucciones para guiar a los proveedores en la consejería adicional y los servicios que puedan necesitar los clientes de la planificación familiar. El Evidence Project y el Integra Project del Population Council financiaron el desarrollo de la tercera edición de las tarjetas de consejería de la ECB+.
Nota: Estas tarjetas forman parte de un paquete de publicaciones titulado Estrategia de Consejería Balanceada Plus: un paquete de herramientas para proveedores de servicios de planificación familiar que trabajan en entornos con alta prevalencia de ITS/VIH.

El paquete de herramientas ECB+ presenta los siguientes documentos:

- Algoritmo

- Tarjetas de consejería

- Folletos de métodos

- Guía del Usuario

- Guía del Instructor

- Rueda con los criterios médicos de elegibilidad para el uso de anticonceptivos de la OMS

Deseamos agradecer a las siguientes personas por brindar su experiencia y contribuciones invalorables a esta edición de la ECB+: Megan Christofield, Heather Clark, Mychelle Farmer, Kamlesh Giri, Joanne Gleason, Mark Hathaway, Anushka Kalyanpur, Maggie Kilbourne-Brook, Karen Kirk, Ricky Lu, Ruth Merkatz, Charity Ndwiga, Anne Pfitzer, Saumya Ramarao, Naomi Rijo, Elizabeth Rochette, Jill Schwartz, Leigh Stefanik, John Townsend, Chi-Chi Undie, Katie Unthank, Anneka Van Scoyoc, Charlotte Warren, Ellen Weiss, Kelsey Wright. Para obtener el paquete completo, visite http://www.popcouncil.org/bcsplus

El proyecto Knowledge for Health II (K4Health [Conocimiento para la salud]) (AID-OAA-A-13-00068) adaptó este contenido con el permiso de Population Council y con el apoyo de los ciudadanos estadounidenses a través de la Agencia de los Estados Unidos para el Desarrollo Internacional (USAID, por sus siglas en inglés). El contenido de este material adaptado es responsabilidad exclusiva de la fuente original, y no refleja los puntos de vista de la USAID ni del Gobierno de los Estados Unidos. El material original se encuentra aquí: http://www.popcouncil.org/ research/the-balanced-counseling-strategy-plus-a-toolkit-for-family-planning-service

POPULATION COUNCIL

Ideas. Evidence. Impact. 


\section{Inyectables mensuales}

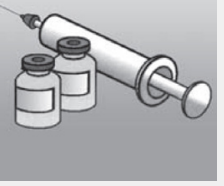

Anticonceptivos inyectables combinados (AIC)

\section{EFECTIVIDAD}

94\% Con algunas inyecciones salteadas o administradas tarde:

6 embarazos cada 100 mujeres

\section{INFORMACIÓN GENERAL}

- Es necesario que se administre una inyección cada 4 semanas (30 días) para evitar un embarazo.

- Menstruación más regular que con los inyectables de acetato de medroxiprogesterona de depósito (DMPA) o enantato de noretisterona (NET-EN).

- Regreso de la fertilidad diferido una vez que la mujer interrumpe el método. Demora, en promedio, aproximadamente 1 mes más que con la mayoría de los demás métodos.

- Es seguro para las mujeres con VIH/SIDA, incluso si toman medicamentos antirretrovirales (ARV).

- No protege contra las infecciones de transmisión sexual (ITS), entre ellas VIH y zika.

\section{CÓMO FUNCIONA EL MÉTODO}

- La inyección contiene dos hormonas, progestina y estrógeno.

- Estas hormonas evitan que los ovarios liberen óvulos (ovulación). También engrosan la mucosa cervicouterina. Esto impide que el esperma se encuentre con un óvulo.

- Se recibe una inyección cada 4 semanas (30 días).

\section{INFORMACIÓN IMPORTANTE}

- Este método no implica una participación continua de la paciente.

- Es privado. A simple vista, es imposible identificar cuando alguien está usando un inyectable.

- No interfiere con las relaciones sexuales.

- El regreso de la fertilidad demora aproximadamente 1 mes más que con la mayoría de los demás métodos.

- Use preservativos (femeninos o masculinos) si siente que corre riesgo de contraer una ITS o VIH (protección doble). 


\section{MÉTODO NO RECOMENDADO SI...}

- se encuentra a 21 días de haber dado a luz (sin importar el estado de lactancia).

- amamanta a un lactante de menos de 6 meses.

- fuma cigarrillos y tiene más de 35 años.

- tiene presión arterial alta, 140/90 o más.

- presenta una combinación de factores de riesgo cardiovascular como diabetes, hipertensión, edad avanzada o fuma. La situación debe analizarse con el proveedor de atención de salud.

- sufre de enfermedad hepática grave.

- tiene cáncer de mama o presenta factores de riesgo de enfermedad cardíaca: edad avanzada, apoplejía, tabaquismo, presión arterial alta o niveles altos de colesterol.

- sufre de migraña (dolores de cabeza intensos que no cesan al tomar paracetamol) y tiene 35 años o más.

- presenta aura de migraña (la visualización ocasional de un punto brillante que crece en un ojo) a cualquier edad.

- existen antecedentes de coágulos sanguíneos, denominados trombosis, o cirugía mayor con inmovilización prolongada.

- sufre de lupus.

- es VIH positivo y consume inhibidores de la proteasa reforzados con ritonavir como parte de la terapia antirretroviral de gran actividad (TARGA).

\section{EFECTOS SECUNDARIOS}

- Los efectos secundarios frecuentes incluyen lo siguiente:

- menstruación más liviana y menos días de sangrado

- menstruación irregular

- menstruación prolongada o poco frecuente

- ausencia de la menstruación

- Los cambios en la menstruación son normales. Estos cambios suelen disminuir o detenerse en el plazo de 3 meses desde el inicio de las inyecciones.

- Una vez que se interrumpe la administración de las inyecciones, los cambios menstruales no se detienen sino hasta que pasa el efecto de la inyección (2-3 meses o más).

- Algunas mujeres pueden aumentar de peso, sufrir dolores de cabeza, mareos o sensibilidad en las mamas.

- No se trata de signos de enfermedad.

- No todas las mujeres sufren estos efectos secundarios. 


\section{CÓMO SE USA}

- Un proveedor le administrará la inyección.

- Se regresa cada 4 semanas (30 días) para recibir otra inyección.

- Incluso si es tarde, regrese. Quizás aún sea posible administrar la inyección.

- Si se cambia a otra marca de inyectable, obtenga instrucciones sobre el modo de uso del producto nuevo.

\section{SEGUIMIENTO}

- Regrese cada 4 semanas (30 días) para recibir la siguiente inyección.

- Intente asistir de manera puntual. Puede recibir la inyección hasta 7 días antes o 7 días después de lo indicado. Sin importar cuán tarde sea, regrese para recibir la siguiente inyección.

- Si demora más de 7 días en recibir la inyección, absténgase de tener relaciones sexuales o use preservativos hasta que pueda recibirla.

\section{REGRESE AL CENTRO DE SALUD SI...}

- tiene consultas o problemas.

- necesita otra inyección.

- comienza a sufrir cualquier problema de salud.

- se retrasó en recibir la inyección, tuvo relaciones sexuales en los últimos 5 días y desea evitar un embarazo. Puede tomar píldoras anticonceptivas de emergencia (PAE).

- piensa que puede estar embarazada. 


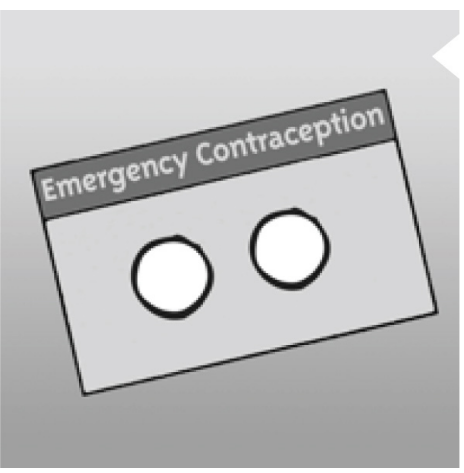

\section{Píldoras}

\section{anticonceptivas \\ de emergencia \\ PAE}




\section{0 de emergencia \\ PAE}

Píldoras anticonceptivas

\section{EFECTIVIDAD}

$98-99 \%$

Uso correcto

Es más efectivo si se toma en el plazo de las primeras 24 horas;

puede tomarse hasta 5 días después de la relación sexual sin

protección:

1-2 embarazos cada 100 mujeres después de un acto sexual sin protección, según la PAE

\section{INFORMACIÓN GENERAL}

- Uno de los únicos métodos que pueden ayudar a evitar un embarazo luego de que una mujer haya tenido relaciones sexuales sin protección.

- No se recomienda su uso frecuente. Una mujer que consume PAE repetidamente debe recibir asesoramiento adicional sobre planificación familiar a fin de elegir el método continuo más apropiado.

- Debe usarse en el plazo de 5 días (120 horas) después de tener relaciones sexuales sin protección.

- Es seguro para las mujeres que no pueden usar métodos anticonceptivos hormonales regulares, incluso las mujeres lactantes después del parto.

- No se recomienda amamantar durante 1 semana después de consumir acetato de ulipristal (UPA, ulipristal acetate)

- Las PAE no interrumpen los embarazos existentes.

- Es seguro para las mujeres con VIH/SIDA, incluso si toman medicamentos antirretrovirales (ARV).

- No protege contra las infecciones de transmisión sexual (ITS), entre ellas VIH y zika.

\section{CÓMO FUNCIONA EL MÉTODO}

- Las PAE contienen las mismas hormonas que las píldoras anticonceptivas orales de progestina como agente único o combinadas, pero en dosis mayores.

- Estas hormonas evitan que los ovarios liberen óvulos (ovulación). 


\section{INFORMACIÓN IMPORTANTE}

- Todas las mujeres pueden tomar una PAE de manera segura y efectiva, incluso quienes no pueden usar alguno de los métodos anticonceptivos hormonales continuos.

- Se puede usar una PAE para cualquier acto sexual sin protección, incluso un acto forzado (violación).

- También es posible usarlas en caso de errores o fallas en el uso de anticonceptivos, por ejemplo:

- El preservativo se rompió, se deslizó o no se usó de la manera correcta.

- No se tomaron 3 o más píldoras anticonceptivas combinadas.

- Se comenzó un nuevo ciclo de píldoras 3 días tarde o más.

- Han pasado más de 7 días o 2 semanas de la fecha indicada para una nueva dosis de un anticonceptivo inyectable (según el tipo de inyección).

- El dispositivo intrauterino (DIU) se ha salido de lugar.

- Se usó el Método de Dos Días o el Método de Días Fijos de forma incorrecta. Por ejemplo, la mujer no se abstuvo de tener relaciones sexuales o no usó preservativos durante los días en que podía quedar embarazada.

- Las PAE reducen la necesidad de realizarse un aborto.

- Los productos especializados de PAE, los anticonceptivos orales combinados (la píldora) o los anticonceptivos orales de progestina como agente único (la minipíldora) pueden usarse como una PAE.

- Tenga un método de PAE a mano en caso de una emergencia (relaciones sexuales sin protección).

- No deben usarse como reemplazo de un método anticonceptivo continuo.

- Es posible quedar embarazada inmediatamente después de ingerir una PA si se tienen relaciones sexuales sin protección (incluso 1 día después de tomar una PAE).

- Use otro método anticonceptivo de inmediato para continuar protegiéndose y, así, evitar un embarazo.

- Si siente que corre riesgo de contraer una ITS, incluso VIH o zika, use preservativos (femeninos o masculinos).

\section{MÉTODO NO RECOMENDADO SI...}

- Se toman medicamentos anticonvulsivos o rifampicina.

\section{EFECTOS SECUNDARIOS}

- Es posible que se experimente sangrado vaginal leve 1-2 días después de tomar una PAE.

- Es posible que se sientan náuseas, dolor abdominal, fatiga, dolor de cabeza, sensibilidad en los senos, mareos o vómitos durante la semana posterior a la ingesta de la PAE.

- Es posible que el período menstrual se adelante o se atrase en relación con lo esperado. 


\section{CÓMO SE USA}

- Tome las PAE en cuanto sea posible, en el plazo de 5 días (120 horas) después de la relación sexual sin protección. Cuanto antes se tomen, mejor. La eficacia de las PAE disminuye con el tiempo.

- Tome las píldoras según las instrucciones de su proveedor.

Importante: La dosificación varía según la marca. El proveedor proporcionará la información posológica según la marca o el tipo de píldora.

- Si se vomita en el plazo de 2 horas desde la ingesta de las PAE, debe tomarse otra dosis. Si se vomita 2 horas después de tomar las PAE, no es necesario tomar otra dosis.

- Inicie otro método anticonceptivo de inmediato. Las PAE no son tan efectivas como un método anticonceptivo continuo.

- Lleve un paquete de PAE (o píldoras anticonceptivas orales, con instrucciones sobre cómo usarlas como PAE) a su hogar para usarlas cuando las necesite.

\section{REGRESE AL CENTRO DE SALUD SI...}

- Tiene consultas o problemas.

- piensa que podría estar embarazada. 


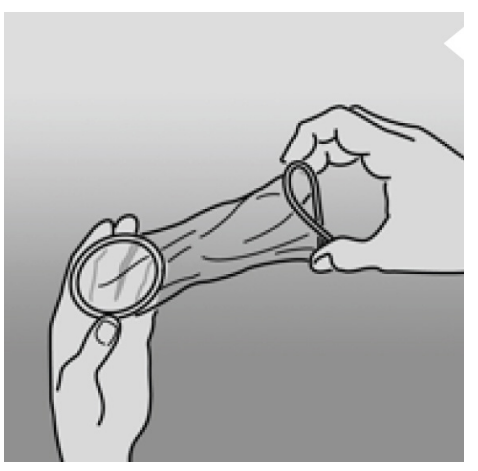

\section{Preservativos} femeninos 


\section{Preservativos femeninos}

\section{TIPOS}

- Preservativo femenino 2/FC2

- Cupid

\section{EFECTIVIDAD}

\section{$79 \%$ Uso inconstante: \\ 21 embarazos cada 100 mujeres}

\section{INFORMACIÓN GENERAL}

- El preservativo femenino es una vaina de látex transparente con anillos flexibles en ambos extremos. Es de la misma longitud que el preservativo masculino.

- Antes de tener relaciones sexuales, colóquese el preservativo en la vagina. Se ajusta con soltura al interior de la vagina.

- Debe usar un preservativo nuevo para cada acto sexual.

- Protege contra el embarazo y las infecciones de transmisión sexual (ITS), entre ellas VIH y zika.

- Preserva la sensibilidad durante el acto sexual tanto para el hombre como para la mujer.

- Requiere la cooperación de la pareja.

\section{CÓMO FUNCIONA EL MÉTODO}

- Antes de tener relaciones sexuales, colóquese el preservativo en la vagina.

- El preservativo forma una barrera que mantiene el esperma fuera de la vagina durante la relación sexual. Esto evita el embarazo.

- El preservativo cubre el cuello uterino dentro de la vagina. El cuello uterino es un espacio cerrado, por lo que el preservativo femenino no puede desaparecer dentro del cuerpo.

- También protege contra la transmisión de ITS, entre ellas VIH. 


\section{INFORMACIÓN IMPORTANTE}

- Puede usarse como un método temporario o de respaldo.

- Puede usarse sin consultar a un proveedor de atención médica.

- Su uso puede ser iniciado por la mujer.

- No debe usarse si la pareja está usando un preservativo masculino. La fricción entre ambos preservativos puede hacer que uno o ambos se rompan.

- Puede ser relativamente caro y difícil de encontrar.

- Requiere que la mujer se toque los genitales.

- Es posible que el preservativo emita un sonido durante el acto sexual; el uso de lubricante puede ayudar a solucionar este problema.

- Puede usarse durante el embarazo para proteger a la madre y al feto de ITS.

\section{CÓMO SE USA}

1. Use un preservativo femenino nuevo para cada acto sexual.

2. Controle el envoltorio del preservativo. Si se encuentra rasgado o dañado, no lo use. Evite usar un preservativo con posterioridad a su fecha de vencimiento. Hágalo solamente si no se encuentran disponibles preservativos más nuevos.

3. Insértelo hasta 8 horas antes de la relación sexual. Para mayor protección, inserte el preservativo antes de que el pene entre en contacto con la vagina.

4. Frote los lados del preservativo femenino uno contra el otro para que el lubricante se disperse uniformemente y, luego, insértelo:

- Sostenga el preservativo con el extremo abierto más grande hacia abajo.

- Elija una posición para su inserción que le sea cómoda. Puede agacharse, levantar una pierna, sentarse o recostarse.

- Sujete el anillo interno del extremo cerrado. Apriételo de modo que se vuelva largo y estrecho.

- Encuentre el orificio de la vagina y separe los labios mayores (labia). Con la otra mano, empuje con suavidad el anillo interno hacia el interior de la vagina, tanto como sea posible.

- Inserte un dedo dentro del preservativo para empujarlo hasta el lugar correcto. Procure que entre 2 a $3 \mathrm{~cm}$ de preservativo y el anillo exterior permanezcan fuera de la vagina.

5. Cuando esté lista para el acto sexual, guí el pene hacia el preservativo. Asegúrese de que el preservativo no se deslice hacia afuera. Si el pene sale del preservativo, interrumpa el acto sexual. Ayude a guiarlo nuevamente dentro del preservativo.

6. Si el anillo exterior ingresa a la vagina o si el preservativo se sale de la vagina durante el acto sexual, vuelva a colocar el preservativo en su lugar.

7. Después del acto sexual, quítese el preservativo antes de pararse para evitar la salida de semen. Para retirar el preservativo femenino, tome el anillo exterior, gírelo para sellar el fluido en su interior y tire de él con suavidad para sacarlo de la vagina.

8. Coloque el preservativo en un pañuelo descartable o en el envase vacío. Tírelo a la basura o la letrina. No lo tire al sanitario. Eso podría causar problemas de plomería. 


\section{EFECTOS SECUNDARIOS}

Ninguno.

\section{REGRESE AL CENTRO DE SALUD SI...}

- Tiene consultas o problemas.

- Tuvo relaciones sexuales sin protección en los últimos 5 días y desea evitar un embarazo. Puede tomar píldoras anticonceptivas de emergencia (PAE).

Importante: Si no usó un preservativo para el acto sexual, trate de usar uno la próxima vez. Cometer un error una o dos veces no significa que sea demasiado tarde para usar preservativos en el futuro. 


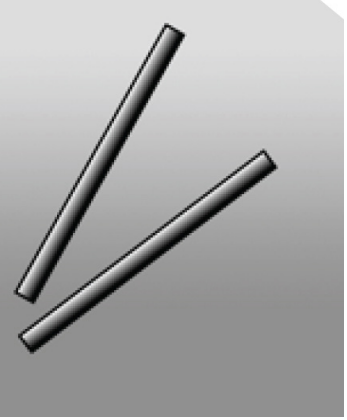

Implantes hormonales 


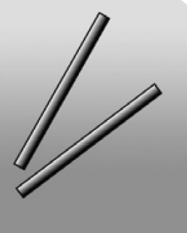

\section{Implantes hormonales}

\section{TIPOS}

- De una varilla (Implanon, Nexplanon/Implanon NXT)

- De dos varillas (Jadelle, Sino-plan II)

\section{EFECTIVIDAD}

Menos de 1 embarazo cada 100 mujeres

\section{INFORMACIÓN GENERAL}

- Son cápsulas o varillas pequeñas (de un tamaño aproximado al de un fósforo) que se colocan debajo de la piel.

- Brindan protección a largo plazo contra el embarazo, durante 3 a 5 años. La duración de la protección depende del implante.

- Un proveedor capacitado debe insertar y quitar los implantes.

- Es seguro para las mujeres lactantes. Es posible colocarse los implantes después de dar a luz.

- Suele provocar cambios en la menstruación. Puede causar la ausencia de sangrado o sangrado intenso temporario durante algunos meses.

- Es seguro para las mujeres con VIH/SIDA, incluso si toman medicamentos antirretrovirales (ARV).

- No protege contra las infecciones de transmisión sexual (ITS), entre ellas VIH y zika.

\section{CÓMO FUNCIONA EL MÉTODO}

- Un proveedor capacitado inserta los implantes debajo de la piel, generalmente en la cara interna de la parte superior del brazo.

- Los implantes liberan una hormona (progestina) lentamente. La progestina es responsable de hacer que la mucosa del cuello uterino sea más gruesa. Esto impide que el esperma se encuentre con un óvulo.

- Esta hormona también evita que los ovarios liberen óvulos (ovulación). 


\section{INFORMACIÓN IMPORTANTE}

- Es uno de los métodos más efectivos y duraderos.

- Debe insertarlo y quitarlo un proveedor capacitado.

- Puede ayudar a reducir la anemia.

- No interfiere con las relaciones sexuales.

- Es posible que sea difícil de obtenerse en determinadas localidades.

- Use preservativos (femeninos o masculinos) para protegerse de las ITS, incluso VIH o zika.

\section{MÉTODO NO RECOMENDADO SI...}

- Sufre de sangrado vaginal inesperado.

- Tiene cáncer de mama o tuvo antecedentes de esa enfermedad en los últimos 5 años.

- Toma medicamentos anticonvulsivos o rifampicina (ya que puede reducir la efectividad del anticonceptivo).

- Presenta coágulos sanguíneos.

- Sufre de lupus.

- Existen antecedentes de enfermedad hepática grave.

\section{EFECTOS SECUNDARIOS}

- Durante los primeros meses, los efectos secundarios frecuentes incluyen lo siguiente:

- Menstruación más liviana y menos días de sangrado

- Menstruación irregular que dura más de 8 días

- Menstruación poco frecuente o ausencia de sangrado (amenorrea)

- Después de un año, los efectos secundarios frecuentes incluyen lo siguiente:

- Menstruación más liviana y menos días de sangrado

- Menstruación irregular o sangrado poco frecuente

- Implanon causa una menstruación prolongada menos irregular que Jadelle. Sin embargo, es más probable que Implanon cause menstruación poco frecuente o ausencia total de sangrado.

- Puede causar dolor de cabeza, dolor abdominal, sensibilidad en los senos u otros efectos secundarios.

- Estos efectos son comunes y no deben considerarse signos de enfermedad. 


\section{CÓMO SE USA}

- Un proveedor capacitado administra un anestésico en el brazo para evitar el dolor. Luego inserta los implantes debajo de la piel.

- El procedimiento demora solo unos pocos minutos. La paciente permanece completamente despierta durante el procedimiento. Es posible sentir un tirón, presión o dolor leve mientras el proveedor inserta los implantes.

- Tras el procedimiento, obtenga de su proveedor la siguiente información:

- tipo de implante

- fecha de inserción

- mes y año en que los implantes deben quitarse o reemplazarse

\section{SEGUIMIENTO}

- Mantenga el área de la inserción seca durante 4 días.

- El brazo quizás duela durante algunos días. También es posible que el lugar de la inserción se hinche o presente moretones.

- Eso es normal. Desaparecerá sin tratamiento alguno.

\section{REGRESE AL CENTRO DE SALUD SI...}

- Hay inflamación, pus o enrojecimiento en el lugar de la inserción, que empeora o no desaparece.

- Se ve que el implante se está saliendo.

- Tiene consultas o problemas.

- Es momento de reemplazar los implantes.

- Desea quitarse los implantes.

- Se ha aumentado mucho de peso. Es posible que los implantes no la protejan de un embarazo si pesa más de 70 kilogramos.

- Comienza a sufrir cualquier problema de salud.

- Piensa que puede estar embarazada. 


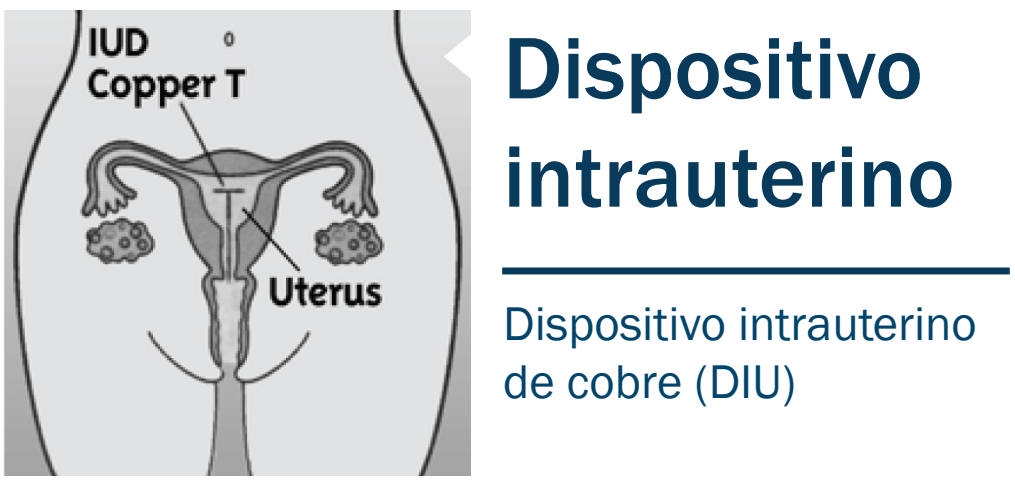




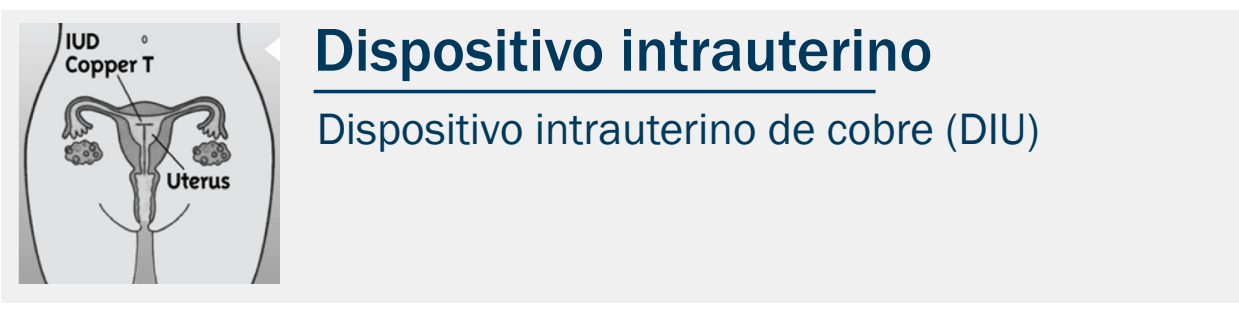

\section{EFECTIVIDAD}

Primer año de uso

Menos de 1 embarazo cada 100 mujeres

\section{INFORMACIÓN GENERAL}

- Brinda protección a largo plazo contra el embarazo, durante 5 a 12 años.

- Es un dispositivo de cobre y plástico, pequeño y flexible que se coloca en el útero. La mayoría de los DIU tienen 1 o 2 cordones delgados que cuelgan del cuello uterino hacia la vagina.

- Es un método seguro y efectivo para casi todas las mujeres. Entre ellas se incluyen las mujeres que se encuentran en el período posparto o posaborto.

- Un proveedor capacitado debe insertar y quitar el DIU.

- Puede insertarse inmediatamente después del parto (en el plazo de 48 horas) o 4 semanas después.

- Suele causar una menstruación más intensa y prolongada, y más calambres o dolor durante la menstruación.

- Es seguro para las mujeres con VIH o con SIDA que gozan de buena salud clínica y toman medicamentos antirretrovirales (ARV).

- No se recomienda para mujeres que corren un riesgo alto de tener infecciones de transmisión sexual (ITS).

- No protege contra las infecciones de transmisión sexual (ITS), entre ellas VIH y zika.

\section{CÓMO FUNCIONA EL MÉTODO}

- Un proveedor capacitado inserta el DIU en el útero, donde permanece el dispositivo.

- El dispositivo de cobre y plástico evita que el esperma se encuentre con el óvulo. 


\section{INFORMACIÓN IMPORTANTE}

- Uno de los métodos más efectivos y duraderos.

- Debe insertarlo y quitarlo un proveedor capacitado.

- Una vez que el DIU se quita, el retorno a la fertilidad es inmediato.

- No interfiere con las relaciones sexuales.

- No requiere que haga nada una vez que se haya insertado el DIU.

- Puede usarse como un anticonceptivo de emergencia si se inserta en el plazo de cinco días después de tener relaciones sexuales sin protección o cinco días después del tiempo de ovulación estimado.

- Si siente que corre riesgo de contraer una ITS, incluso VIH o zika, use preservativos (femeninos o masculinos).

\section{MÉTOdO NO RECOMENDADO SI...}

- Está embarazada o piensa que podría estarlo.

- Sufre de sangrado vaginal inusual. Busque asistencia adicional de un proveedor de atención médica.

- Sufre de gonorrea o clamidia.

- Tiene VIH y no está bien desde el punto de vista clínico.

- Corre un riesgo alto de tener una ITS.

\section{EFECTOS SECUNDARIOS}

- Sangrado o manchado luego de la inserción. Esto puede continuar entre 3 y 6 meses.

- Calambres y dolor durante algunos días luego de la inserción.

- Cambios en los patrones de sangrado. Entre ellos se incluye una menstruación intensa y prolongada, sangrado irregular o más calambres y dolor durante la menstruación. Esto es normal, especialmente entre los primeros 3 y 6 meses luego de la inserción.

- No se trata de signos de enfermedad.

- Los efectos secundarios suelen disminuir después de los primeros meses.

\section{BENEFICIOS PARA LA SALUD}

- Puede ayudar a prevenir el cáncer de útero. 


\section{CÓMO SE USA}

- Hágase un examen pélvico para descartar la presencia de infecciones en los genitales.

- Tome ibuprofeno, paracetamol u otro analgésico 30 minutos antes de la inserción, a fin de reducir los calambres y el dolor.

- Un proveedor capacitado inserta el DIU en un lugar donde cuenta con los suministros y el equipo necesarios.

- El proveedor inserta el DIU en el útero a través la vagina y el cuello uterino. Corta los cordones del DIU y deja, aproximadamente, $3 \mathrm{~cm}$ fuera del cuello uterino.

- Es posible que sienta incomodidad o calambres durante el procedimiento. Eso es normal.

- Tras el procedimiento, obtenga de su proveedor la siguiente información:

- Tipo de DIU que se le colocó

- Fecha de inserción

- Fecha en que el DIU debe quitarse o reemplazarse

\section{REGRESE AL CENTRO DE SALUD SI...}

- Tiene consultas o problemas.

- Experimenta alguno de los siguientes síntomas, especialmente durante los primeros 20 días luego de la inserción:

- Dolor grave o en aumento en el bajo vientre

- Dolor durante las relaciones sexuales

- Secreciones vaginales inusuales

- Fiebre, escalofríos, náuseas o vómitos

- El proveedor programó una visita entre 3 y 6 semanas después de la inserción del DIU.

- Piensa que es posible que el DIU se haya salido de lugar (no se sienten los cordones o se siente el plástico duro del DIU que se ha salido parcialmente del útero).

- No ha tenido el período menstrual o piensa que es posible que esté embarazada.

- Desea quitarse el DIU por alguna razón. 


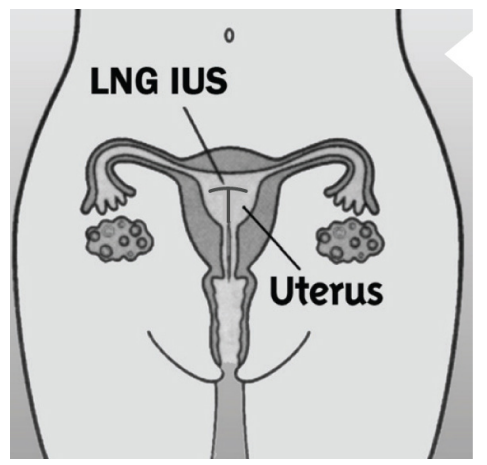

Sistema/

dispositivo

intrauterino

DIU/SIU LNG 


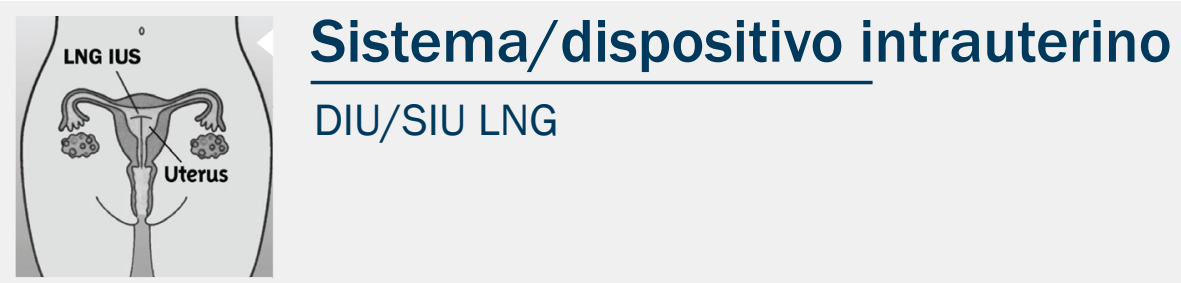

\section{EFECTIVIDAD}

99\% Primer año de uso

Menos de 1 embarazo cada 100 mujeres

\section{INFORMACIÓN GENERAL}

- Brinda protección a largo plazo contra el embarazo, hasta por 5 años.

- Es un dispositivo plástico pequeño y flexible que se coloca en el útero y contiene un reservorio interno de levonorgestrel (LNG), una hormona progestina. EI DIU/SIU LNG tiene 1 o 2 cordones delgados que cuelgan del cuello uterino hacia la vagina.

- Un proveedor capacitado debe insertar y quitar el DIU/SIU LNG.

- Hace que los períodos de menstruación sean más livianos y cortos, y puede hacer que se detengan.

- Es seguro para las mujeres con VIH o con SIDA que gozan de buena salud clínica y toman medicamentos antirretrovirales (ARV).

- No se recomienda para mujeres que corren un riesgo alto de tener infecciones de transmisión sexual (ITS).

- No protege contra las infecciones de transmisión sexual (ITS), entre ellas VIH y zika.

- Puede insertarse inmediatamente después del parto (en el plazo de 48 horas) o 4 semanas después.

\section{CÓMO FUNCIONA EL MÉTODO}

- Un proveedor capacitado inserta el DIU/SIU LNG en el útero, donde permanece el dispositivo.

- El levonorgestrel (LNG) (hormona progesterona) se libera en el útero e inhibe la fertilización del óvulo mediante el engrosamiento de la mucosa cervical, lo cual inhibe el movimiento del esperma y obstaculiza el transporte del óvulo y el esperma. 


\section{INFORMACIÓN IMPORTANTE}

- Uno de los métodos más efectivos y duraderos.

- Debe insertarlo y quitarlo un proveedor capacitado.

- Una vez que se quita el DIU/SIU LNG, el retorno a la fertilidad es inmediato.

- No interfiere con las relaciones sexuales.

- No requiere que haga nada una vez que se haya insertado el DIU/SIU LNG.

- Si siente que corre riesgo de contraer una ITS, incluso VIH, use preservativos (femeninos o masculinos).

\section{MÉTODO NO RECOMENDADO SI...}

- está embarazada o piensa que podría estarlo.

- sufre de sangrado vaginal inusual. Busque asistencia adicional de un proveedor de atención médica.

- sufre de gonorrea o clamidia.

- tiene SIDA y no consume medicamentos ARV, o no está bien desde el punto de vista clínico.

- corre un riesgo alto de tener una ITS.

- existen antecedentes de cáncer de mama.

\section{EFECTOS SECUNDARIOS}

- Sangrado o manchado luego de la inserción. Esto puede continuar entre 3 y 6 meses.

- Calambres y dolor durante algunos días luego de la inserción.

- Cambios en los patrones de sangrado. Entre ellos se incluye una menstruación intensa y prolongada, sangrado irregular o más calambres y dolor durante la menstruación. Esto es normal, especialmente los primeros entre 3 y 6 meses luego de la inserción.

- Síntomas asociados con hormonas, entre ellos dolor de cabeza, sensibilidad en los senos o aumento de peso.

- No se trata de signos de enfermedad.

- Los efectos secundarios suelen disminuir después de los primeros meses.

\section{BENEFICIOS PARA LA SALUD}

- Puede ayudar a prevenir el cáncer de útero.

- El uso del DIU/SIU LNG ofrece muchos beneficios de salud adicionales, entre ellos el tratamiento del sangrado intenso o prolongado, el tratamiento de los trastornos de la menstruación y el endometrio, tales como la endometriosis, adenomiosis o dismenorrea, y como alternativa a la histerectomía. 


\section{CÓMO SE USA}

- Hágase un examen pélvico para descartar la presencia de infecciones en los genitales.

- Tome ibuprofeno, paracetamol u otro analgésico 30 minutos antes de la inserción, a fin de reducir los calambres y el dolor.

- Un proveedor capacitado inserta el DIU/SIU en un lugar donde cuenta con los suministros y el equipo necesarios.

- El proveedor inserta el DIU/SIU en el útero a través la vagina y el cuello uterino. Corta los cordones del DIU/SIU y deja, aproximadamente, $3 \mathrm{~cm}$ fuera del cuello uterino.

- Es posible que sienta incomodidad o calambres durante el procedimiento. Eso es normal.

- Tras el procedimiento, obtenga de su proveedor la siguiente información:

- tipo de DIU/SIU que se le colocó

- fecha de inserción

- fecha en que el DIU/SIU debe quitarse o reemplazarse

\section{REGRESE AL CENTRO DE SALUD SI...}

- tiene consultas o problemas.

- experimenta alguno de los siguientes síntomas, especialmente durante los primeros 20 días luego de la inserción:

- dolor grave o en aumento en el bajo vientre

- dolor durante las relaciones sexuales

- secreciones vaginales inusuales

- fiebre, escalofríos, náuseas o vómitos

- el proveedor programó una visita entre 3 y 6 semanas después de la inserción del DIU/SIU LNG.

- piensa que es posible que el DIU/SIU LNG se haya salido de lugar (no se sienten los cordones o se siente el plástico duro del DIU/SIU que se ha salido parcialmente del útero).

- desea quitarse el DIU/SIU por alguna razón. 


\section{Método de la}

amenorrea de la lactancia

MELA 


\section{$F$ Método de la amenorrea de la lactancia \\ MELA}

\section{EFECTIVIDAD}

\section{Uso habitual}

98\% Primeros 6 meses tras dar a luz, siempre que se cumplan las

3 condiciones: 2 embarazos cada 100 mujeres

\section{INFORMACIÓN GENERAL}

- MELA es el uso de la lactancia total luego de dar a luz para retrasar el retorno a la fertilidad de la mujer.

- MELA requiere 3 condiciones. Deben cumplirse las 3:

1.que la menstruación no haya regresado desde el parto;

2.que el bebé se alimente exclusivamente con leche materna, día y noche;

3.que el bebé tenga menos de 6 meses.

- MELA es un método de planificación familiar temporario que se emplea luego del parto, mientras las mujeres pueden pensar en el método que desean usar una vez que MELA ya no las proteja contra el embarazo.

- Es seguro para las mujeres que tienen VIH/SIDA. Sin embargo, existe la posibilidad de que las madres con VIH le transmitan el virus a sus hijos mediante la lactancia.

- No protege contra las infecciones de transmisión sexual (ITS), entre ellas VIH y zika.

\section{CÓMO FUNCIONA EL MÉTODO}

- La lactancia total detiene la liberación de las hormonas que hacen que la mujer libere óvulos de los ovarios (ovulación). 


\section{INFORMACIÓN IMPORTANTE}

- No interfiere con las relaciones sexuales.

- No se requieren suministros ni tiene ningún costo.

- Su efectividad tras 6 meses posparto es incierta.

- La lactancia completa y exclusiva puede ser poco conveniente o difícil para algunas mujeres.

- Si siente que corre riesgo de contraer una ITS, incluso VIH o zika, use preservativos (femeninos o masculinos).

- Una vez que se comienza a alimentar al bebé con alimentos sólidos o líquidos además de la leche materna, MELA ya no protege contra el embarazo. Comuníquese con un proveedor de atención médica para comenzar a usar otro método anticonceptivo de inmediato.

- Tenga un método de píldoras anticonceptivas de emergencia (PAE) a mano en caso de tener relaciones sexuales sin protección cuando ya no se cumplan las 3 condiciones del método o si no ha visitado un centro de salud.

- Antes de comenzar a usar alimentación complementaria, hable con el proveedor sobre el cambio a otro método moderno.

\section{MÉTODO NO RECOMENDADO SI...}

- Ha dado a luz hace más de 6 meses.

- La menstruación ha regresado.

- Se alimenta al bebé con sólidos o líquidos además de la leche materna.

\section{EFECTOS SECUNDARIOS}

Ninguno.

\section{PARA USO CON PRECAUCIÓN SI SE VIVE CON VIH/SIDA:}

- Las madres que tienen VIH deben hacer lo siguiente:

- Amamantar de manera exclusiva durante 6 meses y continuar amamantando, con alimentos complementarios, por hasta 12 meses.

- Ante la decisión de dejar de amamantar, hacerlo gradualmente en el plazo de un mes. No se recomienda dejar de amamantar de manera abrupta, y se debe contar con una alternativa segura y confiable a la leche materna.

- La administración de medicamentos antirretrovirales (ARV) a las madres que viven con VIH o a los niños expuestos al VIH durante el período de lactancia puede reducir de manera significativa el riesgo de transmisión del virus al amamantar.

- Las madres o los lactantes que han estado recibiendo profilaxis con ARV deben continuarla durante una semana luego de dejar de amamantar por completo. 


\section{BENEFICIOS DE LA LACTANCIA PARA LA SALUD}

- Brinda al bebé el alimento más sano.

- Protege al bebé de la diarrea.

- Reduce el sangrado luego del parto.

- Transfiere la inmunidad de la madre al bebé. Esto ayuda a proteger al bebé de enfermedades tales como las paperas y la neumonía. Estas enfermedades pueden causar la muerte del bebé.

- Ayuda a desarrollar un vínculo estrecho entre la madre y el bebé.

\section{CÓMO SE USA}

- Luego del parto, comience a amamantar en cuanto pueda. La lactancia iniciada en el plazo de una hora después del parto le brindará al bebé todos los beneficios del calostro.

- Amamante al bebé de manera exclusiva durante los primeros seis meses.

- Aliméntelo únicamente con leche materna, día y noche. Se encuentra protegida del embarazo si se cumplen las siguientes 3 condiciones:

1.La menstruación no ha regresado.

2.El bebé es alimentado exclusivamente con leche materna. Debe amamantarlo día y noche.

3.El bebé tiene menos de 6 meses.

- Si alguna de estas condiciones no se cumple, se debe hacer lo siguiente:

- Usar otro método efectivo de planificación familiar que no interfiera con la lactancia.

- Seguir amamantando al bebé. Amamante al bebé incluso si le da otros alimentos sólidos o líquidos.

- Los alimentos complementarios deben incorporarse a los seis meses; sin embargo, la lactancia también debe continuar hasta los 2 años o incluso después. Se debe hablar de la alimentación del lactante con el proveedor de atención de salud.

\section{REGRESE AL CENTRO DE SALUD SI...}

- Tiene consultas o problemas.

- Cualquiera (1) de las 3 condiciones requeridas para el MELA cambia y se necesita otro método.

- Antes de que el bebé cumpla los 6 meses, para poder elegir otro método. 


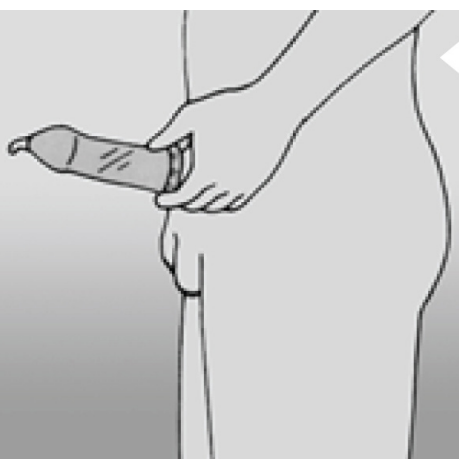

Preservativos masculinos 


\section{Preservativos masculinos}

\section{EFECTIVIDAD}

\section{Uso habitual}

Uso inconstante:

18 embarazos cada 100 mujeres

\section{INFORMACIÓN GENERAL}

- La mayoría de los preservativos son de caucho de látex delgado. Algunos preservativos se encuentran recubiertos con lubricante o espermicida.

- Si ha tenido una reacción alérgica al caucho de látex, no debe usar preservativos de látex.

- Antes de tener relaciones sexuales, coloque el preservativo sobre el pene erecto.

- Debe usar un preservativo nuevo para cada acto sexual.

- Protege contra el embarazo y las infecciones de transmisión sexual (ITS), entre ellas VIH y zika.

- Requiere la cooperación de la pareja para un uso constante y correcto.

\section{CÓMO FUNCIONA EL MÉTODO}

- Antes de tener relaciones sexuales, coloque el preservativo en el pene erecto.

- El preservativo forma una barrera que mantiene el esperma fuera de la vagina durante la relación sexual. Esto evita el embarazo.

\section{INFORMACIÓN IMPORTANTE}

- Puede usarse sin consultar a un proveedor de atención médica.

- Puede usarse como un método temporario o de respaldo.

- Los preservativos, tanto femeninos como masculinos, son el único método que previene la transmisión de ITS y VIH.

- Puede reducir la sensibilidad y hacer que la pareja disfrute menos del acto sexual.

- Debe tomarse el tiempo necesario para colocar el preservativo en el pene erecto antes de que este toque los genitales femeninos.

- Aumenta la participación masculina en la planificación familiar. 


\section{MÉTODO NO RECOMENDADO SI SU PAREJA...}

- Ha tenido una reacción alérgica al caucho de látex. Algunas personas pueden ser alérgicas a solo una marca específica de preservativos. Si no se trata de alergia al látex, cambie de marca.

\section{EFECTOS SECUNDARIOS}

Ninguno.

\section{CÓMO SE USA:}

1. Use un preservativo nuevo para cada acto sexual.

2. Controle el envoltorio del preservativo. Si se encuentra rasgado o dañado, no lo use. Evite usar un preservativo con posterioridad a su fecha de vencimiento. Hágalo solamente si no se encuentran disponibles preservativos más nuevos.

3. Abra el envoltorio con cuidado. No use las uñas, los dientes ni algo que pudiera dañar el preservativo.

4. Antes de cualquier contacto con la vagina, coloque el preservativo en la punta del pene erecto. El lado enrollado debe encontrarse hacia afuera.

5. Desenrolle el preservativo hasta la base del pene erecto. Si el preservativo no se desenrolla, puede estar al revés o dañado, o ser demasiado viejo. Deséchelo. Use un preservativo nuevo. Si el preservativo se ha colocado al revés y no tiene otro disponible, delo vuelta y desenróllelo en el pene.

6. Si lo desea, use agua o un lubricante a base de agua sobre la superficie externa del preservativo. Esto ayuda a prevenir roturas. No use cremas, aceites ni vaselina.

7. Inmediatamente después de la eyaculación, mantenga el borde del preservativo en su lugar. Retire el pene mientras aún se encuentra erecto. Tenga cuidado de que no caiga semen al sacar el pene o quitar el preservativo.

8. Coloque el preservativo en un pañuelo descartable o en el envase vacío. Tírelo a la basura. No lo tire al sanitario. Eso puede causar problemas de plomería.

9. De ser posible, almacene los preservativos en un lugar fresco, seco y oscuro.

Importante: Si no usó un preservativo para el acto sexual, trate de usar uno la próxima vez. Cometer un error una o dos veces no significa que sea demasiado tarde para usar preservativos en el futuro.

\section{REGRESE AL CENTRO DE SALUD SI...}

- Tiene consultas o problemas.

- Tuvo relaciones sexuales sin protección en los últimos 5 días y desea evitar un embarazo. La mujer puede tomar píldoras anticonceptivas de emergencia (PAE). 
POPULATION

COUNCIL

Ideas. Evidence. Impact. 


\section{Minipíldora}

Anticonceptivos orales de progestina como agente único 


\section{Minipíldora}

Anticonceptivos orales de progestina como agente único

\section{EFECTIVIDAD}

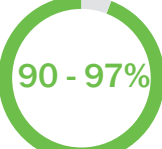

Uso habitual durante el primer año

Con algunas pildoras no tomadas:

Entre 3 y 10 embarazos cada 100 mujeres

Para las mujeres lactantes durante el primer año

1 embarazo cada 100 mujeres

\section{INFORMACIÓN GENERAL}

- Es necesario tomar una 1 píldora por día.

- Es seguro para las mujeres lactantes.

- Es posible comenzar con la minipíldora después de dar a luz.

- Puede provocar menstruación irregular. En el caso de las mujeres lactantes, provoca el retraso de la menstruación.

- Es seguro para las mujeres con VIH/SIDA, incluso si toman medicamentos antirretrovirales (ARV).

- No protege contra las infecciones de transmisión sexual (ITS), entre ellas VIH y zika.

\section{CÓMO FUNCIONA EL MÉTODO}

- Se toma 1 píldora por día. La minipíldora es más efectiva cuando se toma todos los días a la misma hora.

- La minipíldora tiene pequeñas cantidades de progestina. La progestina es responsable de hacer que la mucosa del cuello uterino sea más gruesa. Esto impide que el esperma se encuentre con un óvulo.

- Esta hormona también evita que los ovarios liberen óvulos (ovulación). 


\section{INFORMACIÓN IMPORTANTE}

- Su uso puede interrumpirse en cualquier momento, sin ayuda de un proveedor.

- La mujer controla el método.

- No interfiere con las relaciones sexuales.

- Puede provocar menstruación irregular.

- Es importante recordar tomar una píldora una vez al día, todos los días.

- Todas las píldoras contienen la hormona progestina; ninguna es un placebo ni una píldora de azúcar.

- Si siente que corre riesgo de contraer una ITS, incluso VIH o zika, use preservativos (femeninos o masculinos).

\section{EFECTOS SECUNDARIOS}

- Puede causar menstruación irregular o frecuente los primeros meses o durante todo el tiempo en que consuma la minipíldora.

- Puede causar dolor de cabeza, mareos, sensibilidad en los senos, cambios de humor u otros efectos secundarios posibles.

- En el caso de las mujeres lactantes, la menstruación demora más en regresar después de dar a luz.

- Estos efectos son normales y no deben considerarse indicios de enfermedad.

- No todas las mujeres sufren estos efectos secundarios.

\section{CÓMO SE USA}

- Comience con la primera píldora del blíster, según las instrucciones de su proveedor.

- Tome 1 píldora por día hasta terminar el blíster.

- Tome la píldora todos los días a la misma hora. No saltee ninguna píldora.

- Tenga un nuevo blíster de píldoras a mano antes de finalizar el blíster que está tomando.

- Si adquiere las píldoras en una farmacia, puede usar las instrucciones de este folleto.

- Si se saltea una píldora, siga las pautas detalladas en la página siguiente. 


\begin{tabular}{|c|c|}
\hline Si usted: & Haga lo siguiente: \\
\hline $\begin{array}{l}\text { - Se ha retrasado } \\
3 \text { horas o más en } \\
\text { la ingesta de la } \\
\text { píldora } \\
\text { o } \\
\text { - No tomó una } \\
1 \text { píldora }\end{array}$ & $\begin{array}{l}\text { - Tome la píldora en cuanto sea posible. } \\
\text { - Siga tomando la píldora todos los días a la misma } \\
\text { hora. (Esto significa que es posible que deba tomar } \\
2 \text { píldoras al mismo tiempo o el mismo día). } \\
\text { - Use un método de respaldo (preservativos) o evite } \\
\text { tener relaciones sexuales durante los siguientes } \\
2 \text { días. } \\
\text { - Si tuvo relaciones sexuales sin protección durante } \\
\text { los últimos } 5 \text { días, debe considerar tomar píldoras } \\
\text { anticonceptivas de emergencia (PAE). }\end{array}$ \\
\hline $\begin{array}{l}\text { - Vomita dentro de } \\
2 \text { horas desde que } \\
\text { tomó una píldora. }\end{array}$ & $\begin{array}{l}\text { - Tome otra píldora del blíster en cuanto sea posible. } \\
\text { - Continúe tomando las píldoras de la manera } \\
\text { habitual. }\end{array}$ \\
\hline
\end{tabular}

\section{REGRESE AL CENTRO DE SALUD SI...}

- tiene consultas o problemas.

- necesita más píldoras.

- comienza a sufrir cualquier problema de salud.

- se retrasó en la toma de una píldora o se la salteó, tuvo relaciones sexuales en los últimos 5 días y desea evitar un embarazo. Puede tomar píldoras anticonceptivas de emergencia (PAE).

- piensa que puede estar embarazada. 


\section{Píldora}

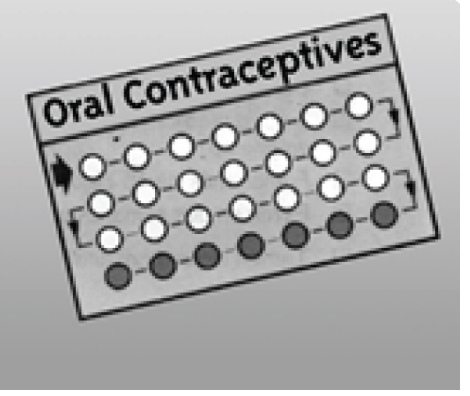

Anticonceptivos orales combinados 


\section{Píldora}

Anticonceptivos orales combinados

\section{EFECTIVIDAD}

Uso habitual durante el primer año

Con algunas pildoras no tomadas:

9 embarazos cada 100 mujeres

\section{INFORMACIÓN GENERAL}

- Es necesario tomar una 1 píldora por día.

- Puede causar sangrado irregular durante los primeros meses de uso.

- Es seguro para las mujeres con VIH/SIDA, incluso si toman medicamentos antirretrovirales (ARV).

- Existen muchas marcas y regímenes diferentes de anticonceptivos orales combinados. Los métodos disponibles y más apropiados deben analizarse con el proveedor de atención de salud.

- No protege contra las infecciones de transmisión sexual (ITS), entre ellas VIH y zika.

\section{CÓMO FUNCIONA EL MÉTODO}

- Se toma 1 píldora por día. La píldora es más efectiva cuando se toma todos los días a la misma hora.

- La píldora contiene pequeñas cantidades de las hormonas estrógeno y progestina.

- Estas hormonas engrosan la mucosa del cuello uterino. Esto impide que el esperma se encuentre con un óvulo.

- También evitan que los ovarios liberen óvulos (ovulación).

\section{INFORMACIÓN IMPORTANTE}

- La mujer controla el método.

- Su uso puede interrumpirse en cualquier momento, sin ayuda de un proveedor.

- No interfiere con las relaciones sexuales.

- Es importante recordar tomar una píldora una vez al día, todos los días.

- Si siente que corre riesgo de contraer una ITS o zika, use preservativos (femeninos o masculinos). 


\section{MÉTOdO NO RECOMENDADO SI...}

- está amamantando a un lactante de menos de 6 meses.

- fuma cigarrillos y tiene más de 35 años.

- presenta riesgo de enfermedad cardíaca, apoplejía, tabaquismo, diabetes, presión arterial alta o niveles altos de colesterol.

- padece de determinadas enfermedades cardíacas o vasculares graves poco frecuentes. La situación debe analizarse con el proveedor de atención de salud.

- presenta coágulos sanguíneos, trombosis venosa profunda o embolia pulmonar, o se encuentra en un tratamiento anticoagulante. La situación debe analizarse con el proveedor de atención de salud.

- sufre de lupus o enfermedad hepática grave o enfermedad de la vesícula biliar, incluso si se la trata médicamente. La situación debe analizarse con el proveedor de atención de salud.

- tiene cáncer de mama o tuvo antecedentes de esa enfermedad.

- presenta aura de migraña.

\section{CÓMO SE USA}

- Comience con la primera píldora del blíster, según las instrucciones de su proveedor.

- Tome 1 píldora por día hasta terminar el blíster.

- Tome la píldora todos los días a la misma hora. No saltee ninguna píldora.

- Tenga un nuevo blíster de píldoras a mano antes de finalizar el blíster que está tomando.

- Si adquiere las píldoras en una farmacia, puede usar las instrucciones de este folleto.

- Si se saltea una píldora, siga las pautas detalladas en la página siguiente.

\section{SI SE SALTEA 10 MÁS PÍLDORAS, SIGA ESTAS PAUTAS}

\begin{tabular}{|c|c|}
\hline Si usted: & Haga lo siguiente: \\
\hline $\begin{array}{l}\text { - Se ha retrasado } \\
3 \text { horas o más en } \\
\text { la ingesta de la } \\
\text { píldora } \\
\text { 0 } \\
\text { - No tomó una } \\
1 \text { píldora }\end{array}$ & $\begin{array}{l}\text { - Tome la píldora en cuanto sea posible. } \\
\text { - Siga tomando la píldora todos los días a la misma } \\
\text { hora. (Esto significa que es posible que deba tomar } \\
2 \text { píldoras al mismo tiempo o el mismo día). } \\
\text { - Use un método de respaldo (preservativos) o evite } \\
\text { tener relaciones sexuales durante los siguientes } \\
2 \text { días. } \\
\text { - Si tuvo relaciones sexuales sin protección durante } \\
\text { los últimos } 5 \text { días, debe considerar tomar píldoras } \\
\text { anticonceptivas de emergencia (PAE). }\end{array}$ \\
\hline $\begin{array}{l}\text { - Vomita dentro de } \\
2 \text { horas desde que } \\
\text { tomó una píldora. }\end{array}$ & $\begin{array}{l}\text { - Tome otra píldora del blíster en cuanto sea posible. } \\
\text { - Continúe tomando las píldoras de la manera } \\
\text { habitual. }\end{array}$ \\
\hline
\end{tabular}




\section{REGRESE AL CENTRO DE SALUD SI...}

- tiene consultas o problemas.

- necesita más píldoras.

- comienza a sufrir cualquier problema de salud.

- se retrasó en la toma de una píldora o se la salteó, tuvo relaciones sexuales en los últimos 5 días y desea evitar un embarazo. Puede tomar píldoras anticonceptivas de emergencia (PAE).

- piensa que puede estar embarazada. 


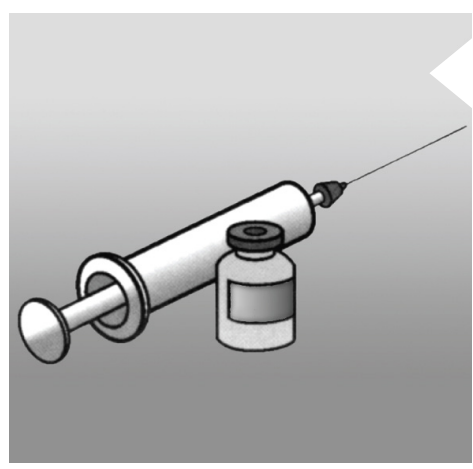

Inyectables de progestina como agente único

Acetato de medroxiprogesterona de depósito (DMPA) o enantato de noretisterona (NET-EN) 


\section{Inyectables de progestina como agente único}

Acetato de medroxiprogesterona de depósito (DMPA) o enantato de noretisterona (NET-EN)

\section{EFECTIVIDAD}

Uso habitual durante el primer año

Con algunas inyecciones salteadas o administradas tarde:

6 embarazos cada 100 mujeres

\section{INFORMACIÓN GENERAL}

- Se administra una inyección cada 2 o 3 meses, según el tipo de inyectable.

- La fertilidad puede regresar hasta 3 semanas después del parto, por lo que se debe usar un método de respaldo como los preservativos hasta que se comience con las inyecciones.

- Es seguro para las mujeres lactantes. Es posible comenzar con el método 6 semanas después de dar a luz.

- Puede causar irregularidad o ausencia de la menstruación.

- Una vez que se interrumpe el método, el retorno a la fertilidad es diferido. La concepción demora más que con otros métodos (1 mes para NET-EN, 4 meses para DMPA, hasta 1 año para Sayana Press ${ }^{\circledR}$ ).

- Es seguro para las mujeres con VIH/SIDA, incluso si toman medicamentos antirretrovirales (ARV).

- No protege contra las infecciones de transmisión sexual (ITS), entre ellas VIH y zika.

\section{CÓMO FUNCIONA EL MÉTODO}

- Los inyectables de progestina como agente único contienen la hormona progestina. La progestina es responsable de hacer que la mucosa del cuello uterino sea más gruesa. Esto impide que el esperma se encuentre con el óvulo.

- Esta hormona también evita que los ovarios liberen óvulos (ovulación).

- DMPA, NET-EN y Sayana Press son diferentes tipos de inyectables.

- Si se usa DMPA, se administra una inyección cada 3 meses (90 días).

- Si se usa NET-EN, se administra una inyección cada 2 meses (60 días).

- Si se usa Sayana Press ${ }^{\circledR}$, se administra una inyección cada 3 meses (90 días). 


\section{INFORMACIÓN IMPORTANTE}

- El método es reversible.

- Puede interrumpirse en cualquier momento, ya sea para cambiar a otro método o para quedar embarazada.

- Es privado. A simple vista, es imposible identificar cuando alguien está usando un inyectable.

- No interfiere con las relaciones sexuales.

- Si siente que corre riesgo de contraer una ITS, incluso VIH o zika, use preservativos (femeninos o masculinos).

\section{MÉTODO NO RECOMENDADO SI...}

- Está amamantando a un lactante de menos de 6 semanas.

- Tiene presión arterial muy alta, superior a 160/100.

- Existen factores de riesgo cardiovasculares importantes, como hipertensión, obesidad, edad avanzada, apoplejía, tabaquismo, diabetes, colesterol alto o ciertas enfermedades cardíacas o vasculares poco frecuentes. La situación debe analizarse con el proveedor de atención de salud.

- Tiene cáncer de mama o antecedentes de esa enfermedad.

- Sufre de sangrado vaginal inexplicable.

- Toma medicamentos anticonvulsivos o rifampicina (NET-EN).

- Sufre de lupus o toma inhibidores de la proteasa reforzados con ritonavir como parte de la terapia antirretroviral de gran actividad (TARGA) (efavirenz o neviripina), ya que pueden causar menor efectividad de NET-EN.

- Existen antecedentes de enfermedad hepática grave.

\section{EFECTOS SECUNDARIOS}

- Al principio, es posible sufrir de sangrado irregular, prolongado o frecuente. Posteriormente, no se experimenta menstruación.

- Los cambios menstruales no se detienen sino hasta que pasa el efecto de la inyección (2-3 meses o más).

- Algunas mujeres aumentan de peso, sufren dolores de cabeza, mareos y otros efectos secundarios. No se trata de signos de enfermedad.

- No todas las mujeres sufren estos efectos secundarios.

\section{BENEFICIOS PARA LA SALUD}

- Ayuda a prevenir el cáncer en el revestimiento del útero. También ayuda a prevenir los fibroides uterinos.

- Puede ayudar a proteger de la enfermedad inflamatoria pélvica (EIP).

- Puede ayudar a prevenir la anemia por deficiencia de hierro.

- Reduce los síntomas de endometriosis (dolor pélvico, sangrado irregular). 


\section{CÓMO SE USA}

- Diríjase a un proveedor para que le administre una inyección.

- Reciba las inyecciones cada 3 meses (DMPA), 2 meses (NET-EN) o autoadminístreselas según las instrucciones cada 3 meses (Sayana Press). Si no se reciben las inyecciones, es posible quedar embarazada en caso de tener relaciones sexuales.

- Incluso si es tarde, regrese. Quizás aún sea posible administrar la inyección.

- Si se cambia a otra marca de inyectable, consulte el presente folleto para obtener información sobre el modo de uso del método.

\section{SEGUIMIENTO}

Para quienes usan DMPA:

- Regrese cada 3 meses o 13 semanas para recibir la siguiente inyección.

- Intente asistir de manera puntual. Puede recibir la inyección hasta 2 semanas antes o 4 semanas después de lo indicado. Sin importar cuán tarde sea, regrese para recibir la siguiente inyección.

- Si demora más de 4 semanas en recibir la inyección, absténgase de tener relaciones sexuales o use preservativos hasta que pueda recibirla.

Para quienes usan NET-EN:

- Regrese cada 2 meses o 9 semanas para recibir la siguiente inyección.

- Intente asistir de manera puntual. Puede recibir la inyección hasta 2 semanas antes o 2 semanas después de lo indicado. Sin importar cuán tarde sea, regrese para recibir la siguiente inyección.

- Si demora más de 2 semanas en recibir la inyección, absténgase de tener relaciones sexuales o use preservativos hasta que la reciba.

Para quienes usan Sayana Press ${ }^{\circledR}$ :

- Regrese para realizarse reevaluaciones periódicas y para recibir inyectores nuevos.

\section{REGRESE AL CENTRO DE SALUD SI...}

- Tiene consultas o problemas.

- Necesita otra inyección.

- Comienza a sufrir cualquier problema de salud.

- Se retrasó en recibir la inyección, tuvo relaciones sexuales en los últimos 5 días y desea evitar un embarazo. Puede tomar píldoras anticonceptivas de emergencia (PAE).

- Piensa que puede estar embarazada. 


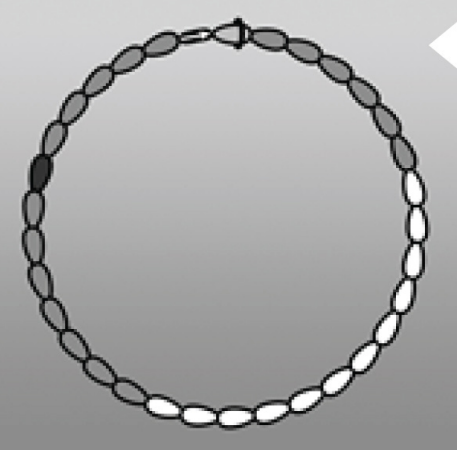

Método de Días

Fijos $^{\circledR}$

MDF 


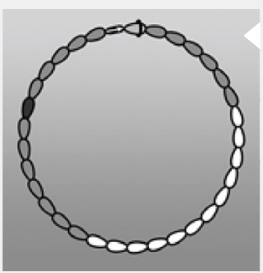

\section{Método de Días Fijos ${ }^{\circledast}$}

MDF

\section{EFECTIVIDAD}

Uso habitual durante el primer año

12 embarazos cada 100 mujeres

\section{INFORMACIÓN GENERAL}

- Ideal para mujeres con ciclos menstruales que suelen durar entre 26 y 32 días. Las mujeres con menstruación regular entran en este rango.

- Se usa un calendario o el Collar del Ciclo®, un collar con perlas con un código de colores, para realizar el seguimiento de los días en que puede quedar embarazada y los días en que no es probable que esto suceda.

- Durante los días en que puede quedar embarazada, debe abstenerse de tener relaciones sexuales o debe usar preservativos u otro método de barrera.

- Las mujeres lactantes o en período posparto deben tener 3 ciclos menstruales regulares antes de poder usar el método MDF. Durante este período, use un método alternativo.

- No protege contra las infecciones de transmisión sexual (ITS), entre ellas VIH y zika.

- Requiere la cooperación de la pareja.

\section{CÓMO FUNCIONA EL MÉTODO}

- Hágase un calendario o use el Collar del Ciclo® para hacer un seguimiento de los días en que puede quedar embarazada. También puede hacer un seguimiento de los días en que no es probable que quede embarazada.

- Los días en que se puede quedar embarazada son los días del 8 al 19 del ciclo menstrual.

- Durante esos días, debe abstenerse de tener relaciones sexuales o debe usar preservativos para evitar quedar embarazada.

\section{EFECTOS SECUNDARIOS}

Ninguno. 


\section{INFORMACIÓN IMPORTANTE}

- Optar por usar el calendario para hacer un seguimiento de los días no implica contar con suministros ni tiene ningún costo.

- Hay 12 días en el mes durante los cuales se puede quedar embarazada. En esos días, debe abstenerse de tener relaciones sexuales o usar un método de barrera. Esto puede ser difícil para algunas parejas.

- Se necesita consejería sobre cómo usar el método de manera correcta.

- Si siente que corre riesgo de contraer una ITS, incluso VIH o zika, use preservativos (femeninos o masculinos).

\section{MÉTODO NO RECOMENDADO SI...}

- no tiene una menstruación regular, es decir, si los ciclos no duran entre 26 y 32 días.

- no puede o no está dispuesta a abstenerse de tener relaciones sexuales o a usar preservativos u otro método de barrera durante los días en que puede quedar embarazada.

- no puede hacer un seguimiento de los días de su ciclo menstrual.

- no ha tenido al menos 3 ciclos menstruales consecutivos desde que se dio a luz.

- no tiene menstruación regular después de haber interrumpido un método hormonal.

\section{BENEFICIOS PARA LA SALUD}

- Es natural, no requiere procedimientos médicos, dispositivos ni hormonas.

- Promueve el involucramiento masculino y la comunicación en la pareja.

- No se producen retrasos en el retorno a la fertilidad.

\section{CÓMO SE USA}

Para usar el método MDF con el Collar del Ciclo®: Cada perla representa un día del ciclo menstrual. La perla de color ROJO marca el primer día de menstruación. Todas las perlas de color MARRÓN marcan los días en que no es probable que quede embarazada. Todas las perlas de color BLANCO marcan los días en que puede quedar embarazada.

1. El primer día de menstruación, mueva el anillo a la perla color ROJO. Además, marque ese día en un calendario. Eso la ayudará a recordar dónde poner

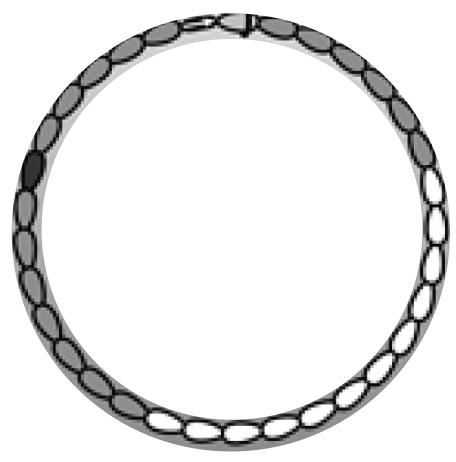
el anillo si un día olvida moverlo.

2. Mueva el anillo a la perla siguiente, día tras día. Siempre mueva el anillo en la dirección de la flecha.

3. Mueva el anillo incluso los días en que tiene su menstruación.

4. Cuando el anillo se encuentre en una perla color MARRÓN, es poco probable que quede embarazada. Puede tener relaciones sexuales sin protección. 
5. Cuando el anillo se encuentre en una perla color BLANCO, puede quedar embarazada. Absténgase de tener relaciones sexuales vaginales o use un preservativo u otro método de barrera.

6. El día en que la menstruación vuelve a comenzar, mueva el anillo a la perla color ROJO para iniciar un nuevo ciclo. Saltee las perlas que queden.

7. Hay una perla color MARRÓN OSCURO. Si la menstruación comienza antes de llegar a la perla color MARRÓN OSCURO, es demasiado pronto. Eso quiere decir que el ciclo menstrual es de menos de 26 días.

8. Si la menstruación no comienza el día después de llegar a la última perla color MARRÓN, es demasiado prolongado. Eso quiere decir que el ciclo menstrual es de más de 32 días.

9. Si más de una vez al año se tiene un ciclo demasiado corto o demasiado largo, debe usarse otro método.

\section{SI USA UN CALENDARIO:}

1. El primer día de menstruación, márquelo en el calendario. Este es el día 1 del ciclo.

2. Los días del 1 al 7 del ciclo menstrual son días en los que es poco probable que quede embarazada. Puede tener relaciones sexuales sin protección.

3. Los días del 8 al 19 del ciclo menstrual son días en los que se puede quedar embarazada si tiene relaciones sexuales sin protección. Absténgase de tener relaciones sexuales vaginales o use un preservativo u otro método de barrera.

4. Desde el día 20 y hasta que la menstruación vuelve a comenzar son días en los que es poco probable que quede embarazada. Puede tener relaciones sexuales sin protección.

5. Para saber si el método funciona para usted, siempre compruebe que el sagrado mensual aparezca cada 26-32 días.

\section{REGRESE AL CENTRO DE SALUD SI...}

- ... tiene consultas o problemas.

- ... tiene dificultades para abstenerse de tener relaciones sexuales o usar preservativos u otro método de barrera durante los días en que puede quedar embarazada. Es posible que desee elegir otro método.

- ... si la menstruación comienza antes de llegar a la perla color MARRÓN OSCURO.

- ... si la menstruación no comienza para el día después de llegar a la última perla color MARRÓN.

- ... si tiene relaciones sexuales un día en el que puede quedar embarazada (los días de las perlas color BLANCO o los días del 8 al 19 del calendario) y desea evitar un embarazo. Puede tomar píldoras anticonceptivas de emergencia (PAE).

- ... piensa que puede estar embarazada. 


\section{Retirada}

Coito interrumpido/"venirse afuera" 


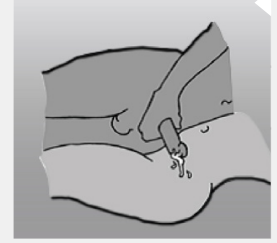

\section{Retirada}

Coito interrumpido/ "venirse afuera"

\section{EFECTIVIDAD}

\section{$78 \%$}

Uso habitual

22 embarazos cada 100 mujeres

\section{INFORMACIÓN GENERAL}

- El hombre retira el pene de la vagina de su pareja antes de la eyaculación, acto que realiza fuera de la vagina.

- Es uno de los métodos menos efectivos; sin embargo, ofrece más protección que la ausencia de un método.

- No se recomienda a hombres que no pueden sentir de manera sistemática cuando se está por producir la eyaculación ni para hombres que eyaculan de manera prematura.

- No protege contra las infecciones de transmisión sexual (ITS), entre ellas VIH y zika.

- Requiere la cooperación de la pareja.

\section{CÓMO FUNCIONA EL MÉTODO}

- resulta difícil mantener el esperma fuera de la vagina de la mujer.

\section{INFORMACIÓN IMPORTANTE}

- La efectividad depende de la voluntad y la capacidad del hombre para usar el método de la retirada en cada acto sexual.

- El líquido preseminal contiene esperma y puede salir durante el acto sexual.

- Las parejas pueden usar la retirada como método de respaldo.

- Puede ser apropiado para las parejas que necesitan un método temporal mientras esperan para comenzar con otro método.

- No requiere suministros ni visitas a una farmacia o clínica. 


\section{MÉTODO NO RECOMENDADO SI...}

- el hombre no puede sentir de manera sistemática cuando se está por producir la eyaculación.

- el hombre eyacula de manera prematura.

- la pareja tiene riesgo alto de contraer infecciones, en cuyo caso se debe usar un preservativo por cada acto sexual. Este método no protege contra las ITS, entre ellas VIH y zika.

\section{EFECTOS SECUNDARIOS}

Ninguno.

\section{BENEFICIOS PARA LA SALUD}

- Promueve el involucramiento masculino y la comunicación en la pareja.

- Una vez que la aplicación de la retirada se interrumpe, no se producen retrasos en el retorno a la fertilidad.

\section{CÓMO SE USA}

- Cuando el hombre siente que está por eyacular, debe retirar el pene de la vagina de la mujer y eyacular fuera de la vagina.

- El hombre debe mantener el semen lejos de los genitales de la mujer.

- Si el hombre ha eyaculado recientemente, antes del acto sexual debe orinar y limpiar la punta del pene para retirar el esperma restante.

- Aprender a aplicar el método de la retirada correctamente puede llevar tiempo. La pareja también puede usar otro método hasta que el hombre sienta que puede usar el método de la retirada de manera correcta en cada acto sexual.

\section{REGRESE AL CENTRO DE SALUD SI...}

- tiene consultas o problemas.

- el hombre tiene dificultades para predecir o controlar el momento de la eyaculación. Es posible que desee elegir otro método.

- el hombre eyaculó dentro de la vagina antes de retirarse. Puede tomar píldoras anticonceptivas de emergencia (PAE).

- se desea un método alternativo o adicional de planificación familiar para mayor protección contra el embarazo. Piensa que puede estar embarazada. 
POPULATION

COUNCIL

Ideas. Evidence. Impact. 


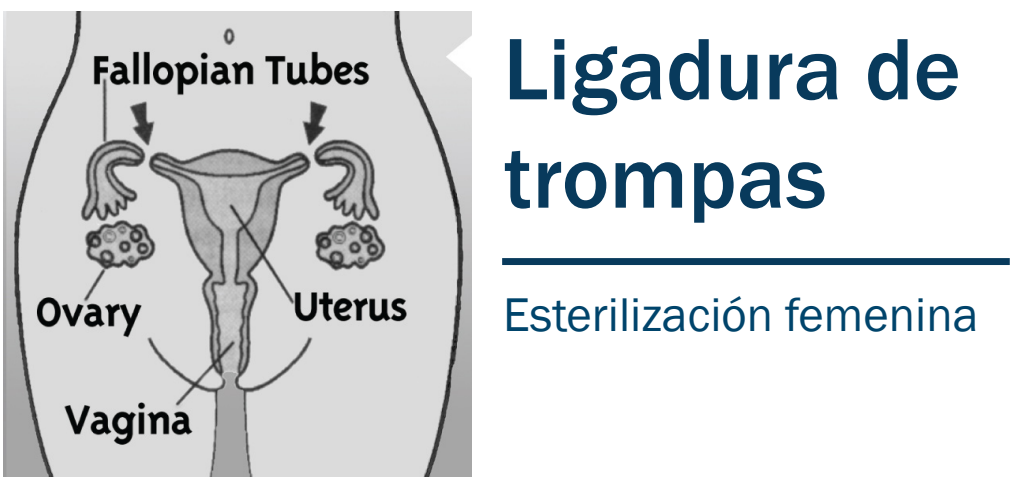




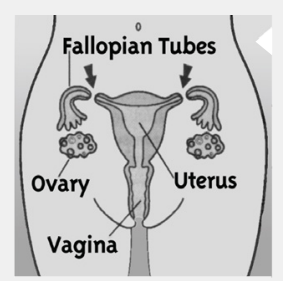

\section{Ligadura de trompas}

Esterilización femenina

\section{EFECTIVIDAD}

$99 \%$

\section{Durante el primer año}

Menos de 1 embarazo cada 100 mujeres

\section{En 10 años}

2 embarazos cada 100 mujeres

\section{INFORMACIÓN GENERAL}

- Es un método permanente para las mujeres que no desean tener más hijos.

- Incluye un procedimiento quirúrgico. El procedimiento implica beneficios y determinados riesgos.

- Protege contra el embarazo de inmediato.

- Es seguro para las mujeres con VIH/SIDA, incluso si toman medicamentos antirretrovirales (ARV).

- No protege contra las infecciones de transmisión sexual (ITS), entre ellas VIH y zika.

\section{CÓMO FUNCIONA EL MÉTODO}

- Un proveedor capacitado hace una pequeña incisión en el abdomen. Luego, ata (o corta) las dos trompas de falopio. Por lo general, las trompas llevan los óvulos desde los ovarios hasta el útero.

- Si las trompas están bloqueadas, los óvulos no pueden transportarse por ellas. No pueden encontrarse con el esperma masculino.

- Se pretende que el método sea permanente.

\section{EFECTOS SECUNDARIOS}

Ninguno. 


\section{INFORMACIÓN IMPORTANTE}

- No es necesario volver a preocuparse por la anticoncepción. El método es muy efectivo.

- Fácil de usar, no es necesario hacer ni recordar nada.

- No afecta el deseo sexual.

- Es posible que se produzcan complicaciones relacionadas con la cirugía y por la anestesia. Sin embargo, estas son poco frecuentes y muy raras.

- En caso de realizar una ligadura de trompas a una mujer con SIDA, es necesario hacer arreglos especiales.

- Si siente que corre riesgo de contraer una ITS, incluso VIH o zika, use preservativos (femeninos o masculinos).

\section{MÉTODO NO RECOMENDADO SI...}

- está embarazada.

- está deprimida.

- padece determinadas afecciones médicas que hacen que sea necesario retrasar el procedimiento.

\section{BENEFICIOS PARA LA SALUD}

- Protege contra el riesgo de embarazo y de la enfermedad inflamatoria pélvica (EIP).

- Puede ayudar a prevenir el cáncer de ovario.

\section{CONSENTIMIENTO INFORMADO}

- Este método requiere un consentimiento informado.

- Antes de prestar su consentimiento informado, debe entender los siguientes puntos:

- También tiene a disposición anticonceptivos temporales.

- La ligadura de trompas es un procedimiento quirúrgico.

- El procedimiento implica determinados riesgos y beneficios (le deben explicar tanto los riesgos como los beneficios de manera tal que pueda comprenderlos).

- De ser exitoso, el procedimiento evitará que vuelva a tener hijos.

- El procedimiento se considera permanente y es probable que no pueda revertirse.

- Puede decidir no someterse al procedimiento en cualquier momento antes de que se realice. No perderá el derecho a otros servicios ni beneficios médicos, de salud u otros.

- Antes del procedimiento, es posible que necesite firmar un formulario de consentimiento. Si no puede leer o escribir, alguien le leerá el formulario y un testigo podrá firmar por usted. 


\section{SEGUIMIENTO}

- Luego del procedimiento, descanse durante 2 días.

- Evite realizar tareas enérgicas y levantar peso durante 1 semana.

- Después del procedimiento, es común experimentar hinchazón y dolor abdominal. Por lo general, estos desaparecen en pocos días.

- En caso de dolor, tome paracetamol o ibuprofeno. No tome aspirina. Este medicamento retrasa la recuperación. No es común que se requiera un analgésico más fuerte.

- Mantenga el área de la incisión seca y limpia durante 1 o 2 días. Evite frotarse la incisión durante 1 semana.

- No tenga relaciones sexuales durante al menos 1 semana. Si el dolor perdura por más de 1 semana, evite tener relaciones sexuales hasta que el dolor desaparezca.

- De ser posible, regrese al centro de salud después de 7 a 14 días. El proveedor de salud revisará el sitio de la incisión. Buscará signos de infección y le quitará los puntos.

\section{REGRESE AL CENTRO DE SALUD SI...}

- tiene consultas o problemas.

- comienza a sufrir cualquier problema de salud.

- piensa que puede estar embarazada. 


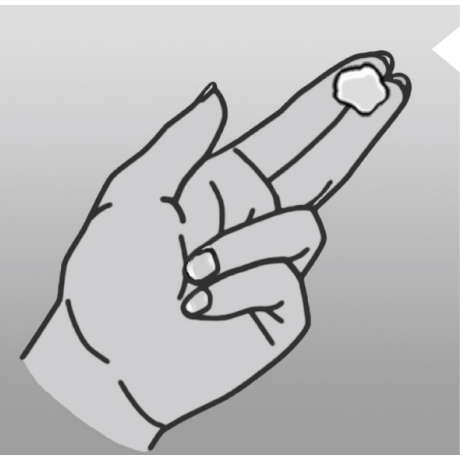

Método de Dos Días ${ }^{\circledR}$ 


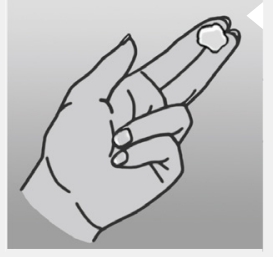

\section{Método de Dos Días ${ }^{\circledR}$}

\section{EFECTIVIDAD}

\section{Uso habitual}

14 embarazos cada 100 mujeres

\section{INFORMACIÓN GENERAL}

- Método óptimo para mujeres con secreciones del cuello uterino saludables.

- Las secreciones saludables no tienen mal olor ni causan picazón o dolor.

- Se debe controlar las secreciones del cuello uterino al menos una vez al día para conocer los días en que puede quedarse embarazada (días fértiles).

- Si nota secreciones de cualquier tipo, color o consistencia el día del control, ese día es fértil y es posible quedar embarazada.

- Durante los días en que puede quedar embarazada, debe abstenerse de tener relaciones sexuales sin protección o puede usar preservativos u otro método de barrera.

- No protege contra las infecciones de transmisión sexual (ITS), entre ellas VIH y zika.

- Requiere la cooperación de la pareja.

\section{CÓMO FUNCIONA EL MÉTODO}

- Controle la presencia de secreciones al menos dos veces al día.

- Según este método, cualquier tipo de secreciones del cuello uterino indica que la mujer es fértil. Las secreciones son cualquier sustancia que se percibe que sale de la vagina, excepto la menstruación.

- Si vio o sintió secreciones hoy o ayer, es posible quedar embarazada hoy.

- Si tuvo secreciones hoy o ayer, hoy debe abstenerse de tener relaciones sexuales o debe usar preservativos u otro método de barrera.

\section{EFECTOS SECUNDARIOS}

Ninguno. 


\section{INFORMACIÓN IMPORTANTE}

- No se requieren suministros ni tiene ningún costo.

- Lo pueden usar mujeres con ciclos de cualquier duración y puede iniciarse en cualquier momento del ciclo.

- Se necesita consejería sobre cómo usar el método de manera correcta.

- Si se tiene una infección vaginal u otra afección que cambie las secreciones del cuello uterino, será difícil usar el Método de Dos Días.

- En los días fértiles, debe abstenerse de tener relaciones sexuales sin protección o usar un método de barrera. Esto puede ser difícil para algunas parejas.

- Si siente que corre riesgo de contraer una ITS, incluso VIH o zika, use preservativos (femeninos o masculinos).

\section{MÉTODO NO RECOMENDADO SI...}

- no puede o no está dispuesta a abstenerse de tener relaciones sexuales o a usar preservativos u otro método de barrera durante los días en que puede quedar embarazada.

- no puede identificar si tiene o no secreciones del cuello uterino.

- tiene una infección que puede afectar las secreciones del cuello uterino.

- no ha tenido al menos 3 ciclos menstruales consecutivos desde que se dio a luz.

- no ha vuelto a tener la menstruación después de haber interrumpido un método hormonal.

\section{BENEFICIOS PARA LA SALUD}

- Es natural, no requiere procedimientos médicos, dispositivos ni hormonas.

- Promueve el involucramiento masculino y la comunicación en la pareja.

- No se producen retrasos en el retorno a la fertilidad.

\section{CÓMO SE USA}

1. Controle si presenta secreciones en cuanto se detenga la menstruación. Controle la presencia de secreciones todos los días. Las secreciones son cualquier sustancia que se percibe que sale de la vagina, excepto la menstruación.

2. Es posible que sienta humedad en el orificio de la vagina o que vea secreciones en los dedos, la ropa interior o en el papel sanitario.

3. Si no notó la presencia de secreciones hoy Y ayer (dos días consecutivos sin secreciones), es poco probable quede embarazada hoy.

4. Si no se está segura de si tiene secreciones, debe abstenerse de tener relaciones sexuales o debe usar preservativos u otro método de barrera.

Nota: El volumen o el aspecto de las secreciones pueden cambiar según el día. CUALQUIER tipo de secreción indica que puede quedarse embarazada. 


\section{REGRESE AL CENTRO DE SALUD SI...}

- tiene dificultades para identificar si tiene o no secreciones del cuello uterino.

- usted o su pareja tienen dificultades para abstenerse de tener relaciones sexuales o usar preservativos durante los días en que puede quedar embarazada. Es posible que desee elegir otro método.

- tiene menos de 5 días con secreciones.

- tiene más de 14 días seguidos con secreciones.

- tuvo relaciones sexuales durante un día fértil y desea evitar un embarazo. Puede tomar píldoras anticonceptivas de emergencia (PAE).

- piensa que puede estar embarazada.

- tiene consultas o problemas. 


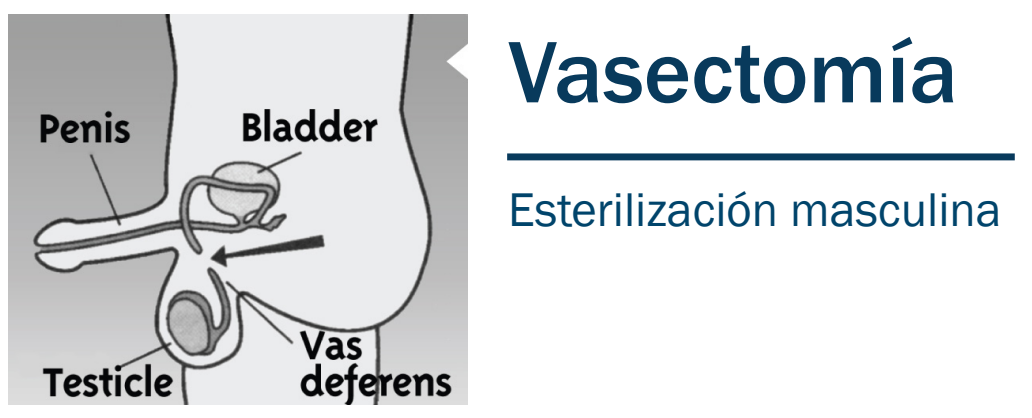




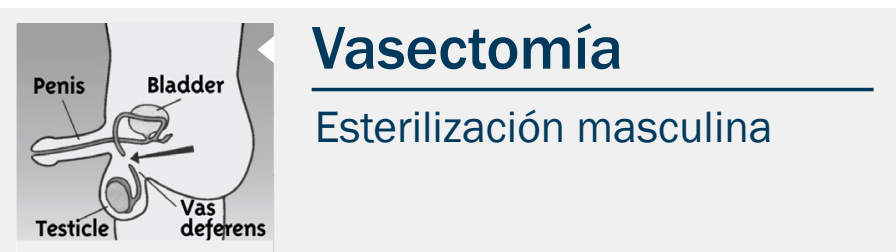

\section{EFECTIVIDAD}

Durante el primer año

99\% Menos de 1 embarazo cada 100 mujeres cuya pareja se ha sometido a una vasectomía

\section{En 3 años}

96\% 4 embarazos cada 100 mujeres cuya pareja se ha sometido a una vasectomía

\section{INFORMACIÓN GENERAL}

- Es un método seguro y permanente para los hombres que no desean tener más hijos.

- Es un procedimiento quirúrgico seguro y simple.

- No afecta el desempeño sexual masculino.

- No protege de inmediato contra el embarazo. El método comienza a surtir efecto 3 meses después de someterse al procedimiento.

- Debe usar preservativos u otro método durante 3 meses después del procedimiento.

- Es seguro para los hombres con VIH/SIDA, incluso si toman medicamentos antirretrovirales (ARV).

- No protege contra las infecciones de transmisión sexual (ITS), entre ellas VIH y zika.

\section{CÓMO FUNCIONA EL MÉTODO}

- Usted se somete a un procedimiento quirúrgico seguro, simple y rápido.

- Un proveedor capacitado hace un corte simple y cierra los tubos que van de los testículos al pene (conducto deferente).

- El cierre de esos tubos mantiene al semen libre de esperma.

- Aún se tienen erecciones y se eyacula semen. Ese semen no contiene esperma, por lo que no se puede embarazar a una mujer. 


\section{INFORMACIÓN IMPORTANTE}

- Es uno de los métodos más efectivos, pero conlleva un bajo riesgo de falla.

- La vasectomía no es completamente efectiva sino hasta 3 meses después del procedimiento. Debe usar preservativos u otro método durante 3 meses.

- Es posible que se produzcan embarazos durante el primer año, por varias razones:

- Durante los primeros 3 meses después del procedimiento, usted no siempre usa un preservativo u otro método durante las relaciones sexuales.

- El proveedor de atención médica comete un error durante el procedimiento.

- Los extremos cortados del conducto deferente vuelven a crecer y se unen.

- Aumenta el disfrute y la frecuencia de las relaciones sexuales porque no es necesario preocuparse por embarazos.

- El procedimiento no implica ningún beneficio ni riesgo de salud en particular.

- En caso de realizar el procedimiento a un hombre con SIDA, es necesario hacer arreglos especiales.

- Si siente que corre riesgo de contraer una ITS, incluso VIH o zika, use preservativos (femeninos o masculinos).

\section{MÉTODO NO RECOMENDADO SI...}

- padece una afección médica que hace que sea necesario retrasar este procedimiento.

\section{CONSENTIMIENTO INFORMADO}

- Este método requiere un consentimiento informado.

- Antes de prestar su consentimiento informado, debe entender los siguientes puntos:

- También tiene a disposición anticonceptivos temporales.

- La vasectomía voluntaria es un procedimiento quirúrgico.

- El procedimiento implica determinados riesgos y beneficios (le deben explicar tanto los riesgos como los beneficios de manera tal que pueda comprenderlos).

- De ser exitoso, el procedimiento evitará que vuelva a tener hijos.

- El procedimiento se considera permanente y es probable que no pueda revertirse.

- Puede decidir no someterse al procedimiento en cualquier momento antes de que se realice. No perderá el derecho a otros servicios ni beneficios médicos, de salud $u$ otros.

- Antes del procedimiento, es posible que necesite firmar un formulario de consentimiento. Si no puede leer, un testigo puede firmar por usted. 


\section{CÓMO SE USA}

- Un proveedor de atención médica capacitado realiza el procedimiento en un lugar donde cuenta con los suministros y el equipo médicos necesarios.

- El proveedor inyecta un anestésico local en el escroto. El paciente permanece despierto durante el procedimiento.

- El proveedor de atención médica realiza el procedimiento.

- Por lo general, puede salir de la clínica en el plazo de una hora.

\section{SEGUIMIENTO}

- Es usual sentir incomodidad en el escroto. Por lo general, dura de 2 a 3 días.

- En caso de dolor, tome paracetamol o ibuprofeno. No tome aspirina. Este medicamento retrasa la recuperación.

- De ser posible, descanse durante 2 días.

- Mantenga el área de la incisión seca y limpia durante 2 o 3 días.

- No tenga relaciones sexuales durante al menos 2 o 3 días.

- Durante los primeros 3 meses después del procedimiento, use un preservativo u otro método de planificación familiar efectivo.

- De ser posible, regrese a la clínica para un análisis del semen. Si no contiene esperma, la vasectomía funciona. Esto es útil, pero no obligatorio.

\section{REGRESE AL CENTRO DE SALUD SI...}

- tiene consultas o problemas.

- comienza a sufrir cualquier problema de salud.

- usted y su pareja tienen relaciones sexuales sin protección en el plazo de 3 meses desde la vasectomía y desea evitar un embarazo. Su pareja puede tomar píldoras anticonceptivas de emergencia (PAE).

- su pareja piensa que puede estar embarazada. 


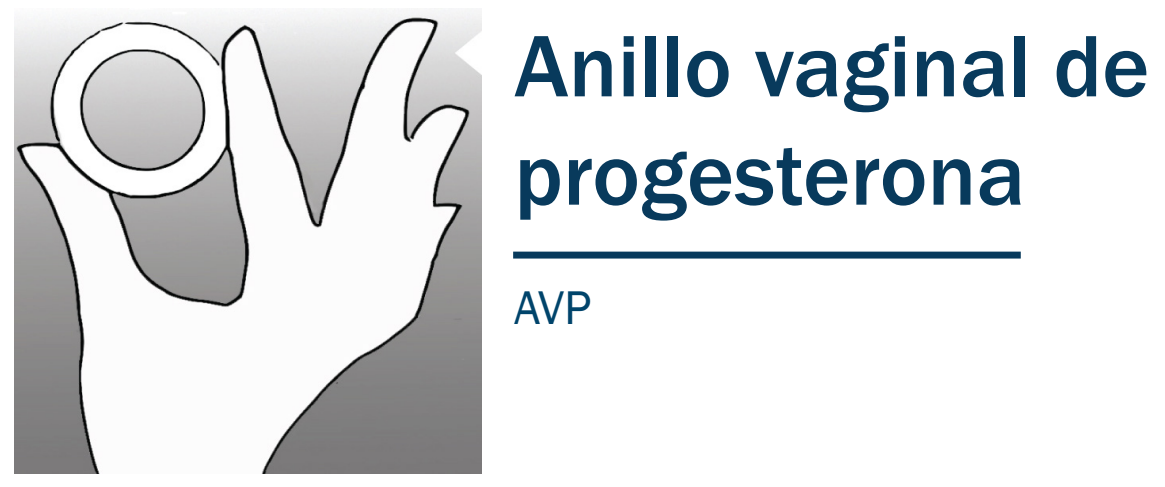




\section{Anillo vaginal de progesterona}

AVP

\section{EFECTIVIDAD}

\section{Uso correcto}

Uso constante cada 3 meses:

2 embarazos cada 100 mujeres

\section{INFORMACIÓN GENERAL}

- Puede ayudar a evitar el embarazo en mujeres que amamantan al menos 4 veces al día durante el primer año posparto.

- Dispositivo flexible y suave con forma de anillo hecho de caucho de silicona; contiene hormona progesterona natural.

- Es posible comenzar con el método a partir de las 4 semanas después de dar a luz.

- Cada anillo puede usarse de manera continua durante 90 días; pueden usarse 4 anillos de manera consecutiva, cambiándolos cada 3 meses, por hasta 12 meses.

- La mujer puede insertárselo y quitárselo ella misma.

- Es seguro para la madre y el bebé.

- No protege contra las infecciones de transmisión sexual (ITS), entre ellas VIH y zika.

\section{CÓMO FUNCIONA EL MÉTODO}

- Libera un nivel constante de la hormona progesterona que se esparce a las paredes de la vagina y, luego, al torrente sanguíneo.

- La progesterona evita el inicio de la ovulación. Refuerza el efecto inhibitorio de la lactancia sobre la supresión de la ovulación.

- Inhibe el crecimiento de los folículos (que contienen un óvulo) y, en consecuencia, evita la ovulación.

- Prolonga el período de amenorrea de la lactancia, lo cual significa que es probable que no se tenga la menstruación.

- La progesterona engrosa la mucosa alrededor del cuello uterino. Esto hace que el esperma no pueda encontrarse con el óvulo con facilidad. 


\section{INFORMACIÓN IMPORTANTE}

- No presenta efectos nocivos sobre la frecuencia de la lactancia, el volumen de leche materna ni el crecimiento del lactante.

- No interfiere con las relaciones sexuales, aunque es posible que la pareja sienta el anillo.

- El método es iniciado por quien lo usa y es reversible.

- La hormona natural progesterona se libera en una dosis baja continua, lo cual provoca menos efectos secundarios.

- Su uso puede interrumpirse en cualquier momento, sin ayuda de un proveedor.

- Quitarse el anillo por un tiempo puede reducir la eficacia.

- El anillo podría decolorarse con el uso.

\section{MÉTODO NO RECOMENDADO SI...}

- no amamanta al menos 4 veces al día.

- tiene una infección del tracto urinario o genital (el método puede iniciarse después del tratamiento), o si ha sufrido enfermedad inflamatoria pélvica o salpingitis desde el parto.

- existen antecedentes de enfermedad uterina (endométrica o cervicouterina) o infecciones del tracto urinario recurrentes.

- tiene sensibilidad a la silicona.

\section{EFECTOS SECUNDARIOS POSIBLES}

- secreciones vaginales

- manchas o sangrado

- sensación de incomodidad en las mamas

- dolor en la parte baja del abdomen

\section{BENEFICIOS PARA LA SALUD}

- La eficacia del método depende de la continuación de la lactancia, la cual beneficia a la madre y al bebé. 


\section{CÓMO SE USA}

- Con las medidas de higiene apropiadas, coloque el anillo con los dedos tan adentro de la vagina como le sea posible, hasta que no lo sienta.

- Si tiene dificultades para insertarlo, trate de hacerlo desde una posición diferente (por ejemplo, con una pierna levantada sobre algún banco o recostada sobre la espalda).

- Si siente que el anillo se desliza, use los dedos para empujarlo y volver a posicionarlo hasta que ya no lo sienta.

- Si el anillo se sale, vuelva a insertarlo en cuanto le sea posible. Asegúrese de que el anillo esté lo suficientemente limpio como para volver a insertarlo. De ser necesario, lávelo con un poco de jabón o agua. No use lavandina ni otros productos de limpieza.

- En caso de estreñimiento, el anillo puede quitarse poco antes de usar el sanitario. Vuelva a insertarlo tomando las medidas de higiene apropiadas.

- Si el anillo sigue saliéndose, es posible que este método no sea apropiado para usted. Es posible que no sea conveniente para mujeres con problemas graves de relajación pélvica.

- Si el anillo se quita por más de 2 horas, vuelva a insertarlo, de ser posible, y comuníquese con su proveedor de atención de salud (use otro método anticonceptivo hasta recibir el asesoramiento apropiado).

- Reemplace el anillo con uno nuevo después de 90 días si se desea seguir evitando un embarazo y se continúa amamantando al menos 4 veces por día.

\section{REGRESE AL CENTRO DE SALUD SI...}

- tiene consultas o problemas.

- piensa que podría estar embarazada.

- la menstruación regresa.

- han pasado más de 12 meses desde que se inició el método.

- interrumpe la lactancia o desea elegir otro método. 


\section{Diafragma Caya $^{\circledR} /$ SILCS}




\section{Diafragma Caya ${ }^{\circledR} /$ SILCS}

\section{EFECTIVIDAD}

Uso habitual

Uso inconstante:

18 embarazos cada 100 mujeres

\section{INFORMACIÓN GENERAL}

- El diafragma es un capuchón flexible y suave que la mujer se inserta en la vagina para cubrir el cuello uterino.

- El diafragma Caya debe usarse en combinación con un gel anticonceptivo.

- Es controlado por la mujer que lo usa, no tiene efectos hormonales y se inserta con anticipación, por lo que no interfiere con las relaciones sexuales.

- Está fabricado de silicona y puede volver a usarse hasta por 2 años.

- Si la mujer se inserta el diafragma de manera correcta, no debería sentir ni dolor ni incomodidad.

- Es seguro para las mujeres lactantes.

- Las mujeres deben esperar 6 semanas luego de dar a luz o tener un aborto durante el segundo trimestre del embarazo antes de usar un diafragma, a fin de hacerlo una vez que el cuello uterino haya regresado a su tamaño normal.

\section{CÓMO FUNCIONA EL MÉTODO}

- El diafragma cubre el cuello uterino. Bloquea el esperma y le impide que ingrese al cuello uterino.

- El diafragma puede volver a usarse. Lávelo con agua y jabón, y déjelo secar.

- Puede guardarlo en su envase original hasta la próxima vez que desee usarlo.

- Nunca deje el diafragma más de 24 horas sin quitárselo ni lavarlo. 


\section{INFORMACIÓN IMPORTANTE}

- Es privado. A simple vista, es imposible identificar cuando alguien lo está usando.

- No interfiere con las relaciones sexuales.

- Se necesita consejería/instrucciones sobre cómo usarlo de manera correcta.

- Su uso puede interrumpirse en cualquier momento, sin ayuda de un proveedor.

- No tiene efectos secundarios hormonales.

- No protege contra las infecciones de transmisión sexual (ITS), entre ellas el VIH.

- Si siente que corre riesgo de contraer una ITS o zika, use preservativos (femeninos o masculinos).

\section{MÉTODO NO RECOMENDADO SI...}

- se ha dado a luz en las últimas 6 semanas.

- se ha tenido un aborto (durante el segundo trimestre del embarazo) en las últimas 6 semanas.

\section{EFECTOS SECUNDARIOS}

Ninguno.

\section{CÓMO SE USA}

- Lávese las manos con agua y jabón.

- Controle que el diafragma no tenga agujeros ni rasgaduras.

- Coloque $4 \mathrm{ml}$ de gel anticonceptivo en el diafragma de silicona.

- Inserte el diafragma en la vagina y cubra el cuello uterino.

- Para mayor protección, inserte el diafragma antes de que comience el acto sexual y úselo durante al menos 6 horas después de finalizado el acto.

- Seis horas después del acto sexual, quite el diafragma. Lávelo con agua y jabón, y déjelo secar.

- Guarde el diafragma Caya en el envase original.

\section{SEGUIMIENTO}

Ninguno.

\section{REGRESE AL CENTRO DE SALUD SI...}

- tiene consultas o problemas.

- comienza a sufrir cualquier problema de salud.

- tuvo relaciones sexuales en los últimos 5 días, no usó ningún método y desea evitar un embarazo. Puede tomar píldoras anticonceptivas de emergencia (PAE).

- piensa que puede estar embarazada. 
El proyecto Knowledge for Health II (K4Health [Conocimiento para la salud]) (AID-OAA-A-13-00068) adaptó este contenido con el permiso de Population Council y con el apoyo de los ciudadanos estadounidenses a través de la Agencia de los Estados Unidos para el Desarrollo Internacional (USAID, por sus siglas en inglés). El contenido de este material adaptado es responsabilidad exclusiva de la fuente original, y no refleja los puntos de vista de la USAID ni del Gobierno de los Estados Unidos. El material original se encuentra aquí: http://www. popcouncil.org/research/the-balancedcounseling-strategy-plus-a-toolkit-for-family-planning-service 